\title{
The influence of guilt presumptive language on investigative interview outcomes
}

Citation for published version (APA):

Adams-Quackenbush, N. M. (2019). The influence of guilt presumptive language on investigative interview outcomes. [Doctoral Thesis, Maastricht University]. Maastricht University. https://doi.org/10.26481/dis.20190618naq

Document status and date:

Published: 01/01/2019

DOI:

10.26481/dis.20190618naq

Document Version:

Publisher's PDF, also known as Version of record

\section{Please check the document version of this publication:}

- A submitted manuscript is the version of the article upon submission and before peer-review. There can be important differences between the submitted version and the official published version of record.

People interested in the research are advised to contact the author for the final version of the publication, or visit the DOI to the publisher's website.

- The final author version and the galley proof are versions of the publication after peer review.

- The final published version features the final layout of the paper including the volume, issue and page numbers.

Link to publication

\footnotetext{
General rights rights.

- You may freely distribute the URL identifying the publication in the public portal. please follow below link for the End User Agreement:

www.umlib.nl/taverne-license

Take down policy

If you believe that this document breaches copyright please contact us at:

repository@maastrichtuniversity.nl

providing details and we will investigate your claim.
}

Copyright and moral rights for the publications made accessible in the public portal are retained by the authors and/or other copyright owners and it is a condition of accessing publications that users recognise and abide by the legal requirements associated with these

- Users may download and print one copy of any publication from the public portal for the purpose of private study or research.

- You may not further distribute the material or use it for any profit-making activity or commercial gain

If the publication is distributed under the terms of Article $25 \mathrm{fa}$ of the Dutch Copyright Act, indicated by the "Taverne" license above, 
The Influence of Guilt Presumptive Language on Investigative Interview Outcomes

Nicole M Adams-Quackenbush 



The Influence of Guilt Presumptive Language on Investigative Interview Outcomes 
Printed by: Gildeprint - The Netherlands 2019 


\title{
The Influence of Guilt Presumptive Language on Investigative Interview Outcomes
}

\author{
Dissertation
}

To obtain the degree of Doctor of Philosophy from University of Portsmouth and the degree of Doctor at Maastricht University, on the authority of the Rector Magnificus Prof. dr. Rianne M. Letschert according to the decision of the Board of Deans to be defended in public

on

Tuesday $18^{\text {th }}$ of June 2019 at 14.00 hours

By

Nicole M Adams-Quackenbush 


\section{PROMOTORS:}

Prof. dr. P. J. van Koppen

Prof. dr. A. Vrij
VU Amsterdam, The Netherlands

University of

Portsmouth, UK

\section{CO-PROMOTOR:}

Dr. R. Horselenberg

Maastricht University, The Netherlands

\section{READING COMMITTEE:}

Prof. mr. dr. Susan van der Aa (Chair)

Prof. mr. dr. Dian V.A. Brouwer

Prof. dr. Henry P. Otgaar

Prof. dr. Gavin Oxburgh

Newcastle University, United Kingdom

dr. mr. Maarten J.J. Kunst Leiden University, The Netherlands

The research presented in this dissertation was supported by a fellowship grant awarded from the Erasmus Mundus Joint Doctorate Program in Legal Psychology (EMJD-LP) awarded to Nicole Adams with Framework Partnership Agreement (FPA) 2013-0036 and Specific Grant Agreement (SGA) 2015-1610. 
This thesis is dedicated to the memory of my father

"When you die you leave two things behind: your kids and your reputation, so make sure they're both good" -Milton Leroy Adams (1951 - 2017)

This thesis is also dedicated to my mother, Colette McNeil, who instilled the value of a strong work ethic and the importance of knowledge in her children. 


\section{CONTENTS}

Chapter 1 General Introduction

\section{Part I: Detecting Confirmation Bias in Investigative} Interviews

Chapter Confirmation Bias in the Investigative Interview

2 with Suspects: A Review of the Literature

Chapter Interview Expectancies: Awareness of Potential

3 Biases Influences behaviour in Interviewees

Chapter Identifying Guilt Presumption through Question

$4 \quad$ Phrasing and Word Abstraction

Chapter Articulating Guilt? The Influence of Guilt

5 Presumption on Interviewer and Interviewee Behaviour

Part II: Exploring Confirmation Bias in Applied Settings

Chapter Where Bias Begins: A Snapshot of Police Officer

6 Beliefs about the Investigative Interview with Suspects

Chapter When Guilt is Presumed: Discursive Indicators of

$7 \quad$ Confirmation Bias and Interviewer Dissonance

During an Interrogation

Chapter Detecting Confirmation Bias in a Suspect's

8

Interrogation: An Evaluation of the Interviews in

a Murder Case

Part III: Implications of this Research for the Police Suspect Interview

Chapter General Discussion: Identifying Confirmation Bias

9 in Police-Suspect Interviews

Chapter The Relevance of Identifying Guilt Presumptive

10 Language in Investigative Interviews:

Valorisation

Appendices

English Summary

Dutch Summary (Samenvatting)

Acknowledgements

Dissemination

Curriculum Vitae 


\section{CHAPTER 1}

\section{General Introduction}




\section{THE IMPLICATIONS OF CONFIRMATION BIAS ON THE INVESTIGATIVE INTERVIEW}

On July $4^{\text {th }}, 1993$ in Breda (The Netherlands), a woman was found brutally murdered in her son's Chinese restaurant. Over the course of the investigation the police received information that prompted them to focus on three men and three women who later became known as 'The Breda Six'. The men maintained their innocence; however, after many hours of questioning and intense pressure from the police, the women confessed to the crime and implicated the men. Although the three women eventually retracted their confessions, it was too late. This was the break the police needed to close the case. The women's confession evidence was used in court as proof of guilt for all six suspects. The women received sentences between 15 and 18 months whilst the men were each sentenced to 10 years in prison (Havinga et al., 2008).

One of the male suspects was intent on proving his innocence and after serving his prison sentence he solicited the help of the Reasonable Doubt Project (Project Gerede Twijfel). ${ }^{1}$ The subsequent re-

1 Gerede Twijfel is a project founded by Professor P. J. van Koppen. At the request of the convicted, their lawyer, or any other person, cases and the evidence are re-evaluated by a team of academics and lawyers. The findings are often published in a report booklet (in Dutch) that may be used in appeals and exoneration trials and are also available to the public (http://www.projectgeredetwijfel.nl). 
evaluation the case found that the women's confessions were inconsistent with evidence found at the scene and contradictory to each other. The project also concluded that the confessions were a product of intense police pressure, coercive interrogation tactics, and a high level of suggestibility in the female suspects. The Reasonable Doubt team were able to provide three plausible alternative scenarios to the murder (Havinga et al., 2008). Eventually the Advocate-General to the Dutch Supreme Court conducted a new forensic investigation of all crime scene evidence. The results of the new investigation found that crucial witness evidence had been omitted from the original trial. In 2012, the Supreme Court decided to reopen the case. In 2013, a new official investigation was conducted, and numerous new witnesses were interviewed.

Despite the collection of new and potentially exonerating evidence, in September 2015 the Dutch Court of Appeals in The Hague upheld the original convictions of the Breda Six. In their reasoning, the judges posited that the confession evidence was admissible and reliable. They also stated that the absence of any incriminating forensic evidence connecting the accused to the scene of the crime, was not proof that the suspects had not been at the scene. Although the Appeals Court upheld the ruling, the suspect's lawyer filed another appeal at the Dutch Supreme Court (Breda Six, 2015). In December 
2017, the Dutch Supreme court made the final ruling that maintained the previous convictions (De Rechtspraak, 2017).

The case of the Breda Six is known in The Netherlands as the "worst miscarriage of justice in Dutch history" (The Amsterdam Herald, 2012). It is a prime example of how biased interviewing of suspects during a criminal investigation can produce questionable confession evidence. That evidence can then lead to miscarriages of justice, or at least the perception of unjust legal decisions. It remains unknown if the Breda Six were guilty of murder, or just simply presumed guilty. What is known through the reanalysis of the case, and resulting new criminal investigation, is that the Dutch police used interrogation techniques that are known to increase the likelihood of false confessions (i.e., guilt presumptive questioning and confession-seeking interview tactics; Kassin \& Gudjonsson, 2004). The police could have treated The Breda Six as potential witnesses to the crime and used the investigative interview to gather valuable information from them. Instead, the police immediately accused the six people and set out to prove their guilt by interviewing them as suspects with the single objective of obtaining a confession. Thus, the interrogative pressure applied to the female suspects in the Breda Six case most likely contributed to the alleged false confessions. 
Once a confession is given, it can be difficult to change the thinking and the theories of those who obtained it, as confessions are the most influential type of evidence in a criminal trial (Davis \& Leo, 2012). The guilt presumption towards the suspects, paired with the subsequent confessions, were then used to influence the views of important judicial players (e.g., judges, juries, prosecutors) and all available evidence was then viewed through a guiltbiased filter (Kassin, Bogart \& Kerner, 2012). In sum, the police believed in the suspect's guilt and sought a confession to prove that guilt, and then that confession was used as evidence of the suspects' guilt. It was tautological reasoning born out of confirmatory thinking.

The focus of this dissertation is to explore the influence of confirmation bias and guilt-presumption on the investigative interview. This is an important topic for interviewing research and practice. Guidelines, frameworks, and training have been introduced to improve the interview process and to assist police officers in gathering information ethically, objectively, and professionally. Despite these efforts, suspects continue to be interrogated to elicit a confession as opposed to being interviewed to seek information about potential involvement in a crime. Whilst it is difficult to detect confirmation bias, examining guilt-presumptive language as a potential indicator of confirmatory thinking may provide the 
insight needed to further develop investigative interviewing practice.

\subsection{CONFIRMATION BIAS UNDER DIFFERENT NAMES AND GUISES}

When a person forms a theory or belief and then seeks out information that supports that belief, whilst ignoring information that discredits it, they have entered a state of irrational thinking called confirmation bias (cf. Gigerenzer, 2008). That type of bias is one of several fallacies common in human cognition (Klayman, 1995; Nickerson, 1998). Confirmation bias (also known as confirmatory thinking or myside bias) is a type of deviation from rational thinking and judgement (Nickerson, 1998). It occurs when a person constructs his or her own reality by favourably evaluating information that confirms preconceptions whilst ignoring or discrediting information that challenges notions or hypotheses (Kunda, 1990; Nickerson, 1998).

There is a natural human tendency to seek out hypothesis confirming information as opposed to disconfirming information (Klayman, 1995; Wason, 1968) because people enjoy being correct about their beliefs (Snyder \& Swann, 1978). However, that tendency becomes problematic when decisions are made based on biased beliefs, and alternative explanations or solutions are not explored. Furthermore, confirmation bias is not a deliberate attempt to be close-minded or prejudicial; however, 
it can pose problems in situations where objectivity and open communication are crucial to success. It is also important to note that confirmation bias does not include explicit or deliberate case building behaviour used to sway an audience or make a point (e.g., arguments by legal counsel or framing used in the media). Confirmation bias generally occurs as an implicit and less conscious way of building a case, or in the evaluation of evidence, so not to cause dissonance with one's beliefs (Nickerson, 1998).

1.1.1 Investigator bias. Confirmation bias has been extensively researched across many disciplines and topics; therefore, it is sometimes discussed under different names as an expression of the context in which it is observed (see Klayman, 1995; Nickerson, 1998). For example, when speaking about confirmation bias in terms of hypotheses or investigative findings (experimental or forensic sciences) it is known as investigator bias. Investigator bias occurs when a scientist unconsciously influences the results of a study toward a specific outcome or interprets the results in a way that confirms his or her hypotheses (e.g., Rosenthal, 1966). In forensic contexts, investigator bias can also occur when law enforcement officers have presumptions about a case, and thus, influences the criminal investigation (e.g., evaluation of evidence, information-gathering, scenario construction) toward confirming their presumptions 
(Edmond, Tangen, Searston, \& Dror, 2015; Rossmo, 2009).

1.1.2 Tunnel vision. Another manifestation of confirmation bias is tunnel vision, which presents as confirmatory thinking that occurs within an attentional bias. Tunnel vision is used to describe the behaviour of an individual who is intently focused on a particular person, thing, or outcome. Within the psycho-legal literature, the meaning of tunnel vision has been expanded to include confirmatory behaviours within that intent focus (Findley, 2012). Tunnel vision and investigator bias overlap in many areas; however, tunnel vision is often used to describe behaviour directed towards a prime suspect (O'Brien, 2007) and only information that seems to incriminate that suspect is gathered. Moreover, any information gathered prior to identifying a prime suspect is also interpreted in a manner that implicates the suspect as the perpetrator of the crime.

Researchers have demonstrated that tunnel vision influences the decision-making process by limiting the amount of information an individual may naturally attempt to gather to make a decision (Rassin, Muris, Booster, \& Kolsloot, 2008), and the type of information sought (Ferrari \& Dovidio, 2001). Tunnel vision is also more likely to occur when the decision is of great importance or consequence, or 
when there is an overload of information that needs to be considered (Rassin, 2007).

\subsubsection{Expectancy effects. Confirmation bias} is also referred to as expectancy within the interpersonal interaction literature (see Burgoon \& Le Poire, 1993; Darley \& Fazio, 1980). The term 'expectancy' is most often used when the biased belief is rooted in preconceived ideas about an individual on a personal level, and is generally based on demographic information (e.g., race, stereotypes, socio-economic status, criminal background, etc.; Darley \& Fazio, 1980; Darley \& Gross, 1983; Miller \& Turnbull, 1986). Thus, expectancies are also prejudicial ideas about how a person will behave, or how an interaction will end, based on beliefs about that person or their group membership. Confirmation bias is exhibited as expectancy when behaviour or information encountered by the Perceiver (person holding the expectancy) during the interaction is evaluated as confirming the presumptions they have about the Target (person the expectancy is about). Any expectancy disconfirming information is ignored or explained away (Darley \& Fazio, 1980).

Expectancy is not often used within the psycholegal literature to describe confirmation bias because of its interpersonal roots. However, a strong argument can be made that expectancy is the best term to describe confirmatory behaviours within investigative interview settings. For example, when 
an interviewer enters an investigative interview with a suspect and has a presumption of guilt, he or she has formed an expectancy regarding culpability. There may also be an expectation that the suspect will deny guilt and engage in deceptive behaviour. The interviewer may also hold an expectation of resistance to the "truth" by the suspect (i.e., selfdeception to avoid responsibility). These expectations not only influence the interviewer's behaviour (e.g., question types, verbal and nonverbal behaviour, interview preparation, and objectivity) but can also influence the suspect's behaviour and the interview outcomes (e.g., cooperation, amount and quality of information, and confession; Kassin, Goldstein, \& Savitsky; Meissner \& Kassin, 2002; Narchet, Meissner, \& Russano, 2011)

\subsection{THE EXPECTANCY CONFIRMATION CYCLE}

Expectancy primarily influences other people through a self-fulfilling prophecy, also known as the expectancy confirmation effect (Madon, Willard, Guyll, \& Scherr, 2011). In a seminal paper on selffulfilling prophecies, Merton (1948) described the phenomenon as "... a false definition of the situation evoking a new behaviour which makes the originally false conception come true" (p. 195). Darley and Fazio (1980) later demonstrated Merton's statement by presenting a six-step model of expectancy confirmation. The researchers posited that expectancy and expectancy confirmation have a 
cyclical relationship where a Perceiver's confirmatory behaviour towards a Target prompts the Target to behave in a way that both confirms and strengthens the Perceiver's preconceptions.

In the Expectancy Confirmation Model (see Figure 1.1), the Perceiver forms an expectancy and exhibits behaviours congruent with that expectancy (steps 1 and 2). The Target then interprets that behaviour and responds (steps 3 and 4). The Perceiver then interprets the Target's behaviour through the filter of their confirmation bias (step 5). Next, the Target interprets his or her own behaviours (step 6) and responds or withdraws. As seen in the model, there is potential for an interaction sequence loop starting at step 2 . Here, the Perceiver can also interpret any response of the Target at step 6 as confirmation of his or her expectancy and either start the process again or leave with their biases and expectancies intact. The Expectancy Confirmation Model demonstrates how expectancy as confirmation bias can elicit the very behaviour that would make the biased and false conception true. Although the model allows for the role of the Perceiver and the Target to be interchangeable, when there is a power imbalance between the Perceiver and the target (such as during an investigative interview), the individual with the most power is generally referred to as the Perceiver. 
Darley and Fazio (1980) also acknowledged how a power imbalance further complicates the interaction for the Target. Perceivers who hold authority over the Target, are less likely to change his or her expectations, which starts an additional sequence of fallacies that linger and possibly worsen as the cycle continues. The power imbalance may also influence the Target to exhibit behaviour congruent with the Perceiver's presumptions as either an undeliberate response to the expectancy, or as a conscious decision of the Target. When the latter occurs, the Target may have decided that it would be more beneficial to his or her situation to conform to the expectancy. Then the Target will begin to exhibit the predicted behaviours as a type of coping mechanism. Consciously conforming to the expected behaviour generally occurs for two reasons: i) the costs of attempting to disconfirm the expectancy require more cognitive resources than the Target has available given the situation (Kaiser \& Miller, 2001), and ii) the Target assumes the outcome will be negative (e.g., cause conflict or retaliation), and is reluctant to attempt to challenge the expectancy (Fazio, Effrein, \& Falender, 1981; Zanna \& Pack, 1975).

An expectancy confirmation cycle that contains a power imbalance where the Perceiver is an authority, and controls the interaction, is especially pertinent for the investigative interview. A custodial 
interview with a suspect contains a clear power imbalance. The suspect is detained, isolated in an interview room, and subjected to questions about a negative event they may or may not have information about. Furthermore, the interview is not a normal mode of communication and is generally perceived as a question and answer session. To that end, a police officer who seeks to confirm a belief guilt about a suspect can easily phrase questions in a manner that implicitly or explicitly sends a message to the suspect about the types of responses the interviewing officer expects to receive. Whilst guilt presumptive questioning may not elicit false confessions in every case, it can subject innocent suspects to needless interrogative pressure and psychological distress (Gudjonsson, 2003). Thus, every effort should be made to ensure investigative interviews are conducted in an objective and information-gathering manner and any guilt judgements are left to the courts.

\subsection{DISRUPTING CONFIRMATORY THINKING}

Disrupting confirmatory thinking is a difficult and multi-step process that starts only when the person holding the bias has acknowledged that his or her presumption could be incorrect. That first step is not an intuitive human behaviour due to belief perseverance (Ross, Lepper, \& Hubbard, 1975) as well as a natural predisposition to avoid cognitive dissonance (Frey, 1982). In fact, belief perseverance 
and dissonance are more likely to strengthen confirmatory thinking as people are more inclined to challenge and question new information that opposes pre-existing beliefs (Ross et al., 1975), particularly if

Step 1

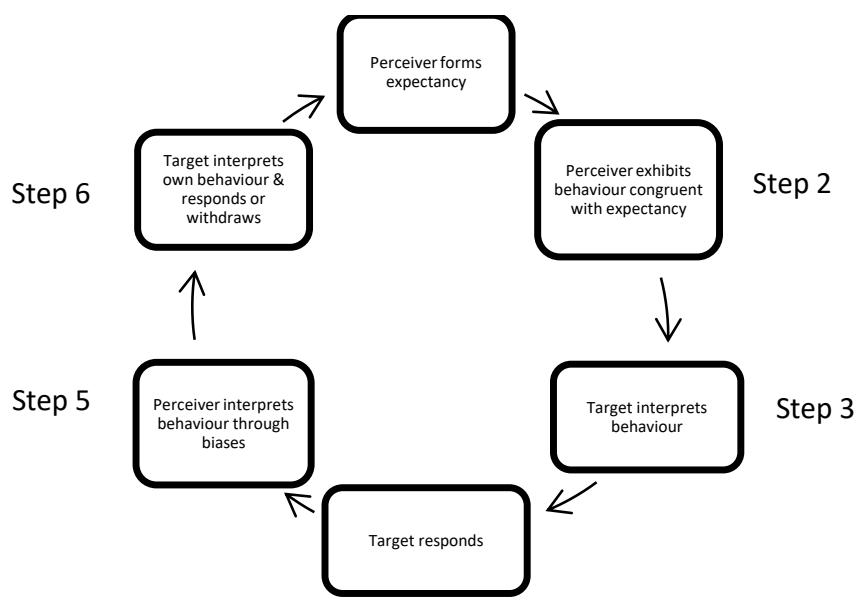

Step 4

Figure 1.1. Author's pictorial interpretation of the expectancy confirmation model proposed by Darley and Fazio (1980). The model demonstrates the cycle of expectancies and confirmation bias in a six-step process.

there is a strong commitment to those beliefs (see Arkes, 1991).

Disrupting confirmatory thinking is further complicated when it involves the cyclical relationship between expectancy and expectancy confirmation 
effects (Darley \& Fazio, 1980). If the Perceiver does manage to discard his biased belief, alternative theories must be: i) identified, ii) accepted or rejected based on an unbiased evaluation of the available information, and iii) applied to the Target's behaviour (Merton, 1948). Moreover, expectancy confirmation effects are difficult to disrupt because they are difficult to identify. Perceivers are unlikely to recognise their bias or to attribute outcomes as being influenced by their behaviour. This occurs because the Perceiver has entered a state of irrational and delusional thinking (Miller \& Turnbull, 1986). Regardless of what is actually occurring during the interaction, the Perceiver will interpret the Target's behaviour as confirming expectations. In the Perceiver's constructed reality, the Target will always be fulfilling the Perceiver's expectancies and this in turn encourages the confirmation bias (Darley \& Fazio, 1980).

Another way to potentially disrupt the expectancy confirmation cycle requires intervention by third-party observers; however, that is also difficult to accomplish for many reasons. As previously discussed, encouraging a Perceiver to modify his or her biased thinking can be a difficult endeavour. An additional difficulty occurs if the Perceiver and third-party observer are members of the same demographic group (e.g., religious, racial, occupational). In that situation, the observer may 
hold the same expectancies and eventually conclude that the Perceiver's theories are correct based on their own biased observations (Brewer \& Nakamura, 1984; Chatman \& Von Hippel, 2001). Researchers have also demonstrated that even when the thirdparty observer is neutral (i.e., does not hold the same beliefs as the Perceiver), they may judge Targets as exhibiting negative or stereotypical behaviour due to the self-fulfilling prophecy (Akehurst \& Vrij, 1999; Narchet et al., 2011). Thus, neutral observers can be influenced by the Target to confirm the Perceiver's belief. Finally, a desire to avoid conflict with the Perceiver could influence a third-party to acquiesce to the biased beliefs (Zanna \& Pack, 1975).

\subsection{CONFIRMATION BIAS AND CRIMINAL INVESTIGATIONS}

Police officers often have the arduous and stressful tasks of collecting information from various sources (e.g., crime scene, witnesses, victims, suspects), then putting those accounts into context of potential evidence collected at the scene, as well as following up on leads to gather and verify more information. When making decisions in high stress/ high cognitive load situations, individuals are more likely to come to their conclusions quickly and use very little of the information available to them (see Findley, 2012; Findley \& Scott, 2006; Keinan, 1987; Wastell, Weeks, Wearing, \& Duncan, 2012). If the 
police investigator is under a lot of pressure to close a case it can also influence his or her decision-making abilities (Eerland \& Rassin, 2010). The increased pressure can also interfere with an investigator's attempt to methodically piece evidence together to form a scenario (preferably multiple scenarios) of how a crime was committed, why, and who may have been involved (i.e., creation of a tunnel vision effect; Fahsing \& Ask, 2013).

Confirmatory thinking may also be injected into a police investigation via the very nature of trying to solve a case. That is, experience, situational factors, and pre-existing beliefs are often the basis of police decision-making (Alpert, MacDonald, \& Dunham, 2005). However, pre-existing beliefs can interfere with objectivity, frame the behaviour of an investigating officer, and guide scenario creation when the belief becomes the most plausible explanation for the crime, despite contradictory information (Ditrich, 2015). Additionally, the procedural aspect of criminal investigations may be another source of confirmatory thinking and biased behaviour. For example, the way police investigators gather information and collect evidence is often posited as a reason for increased susceptibility to confirmatory behaviour (Rassin, Eerland, \& Kuijpers, 2010). Police investigators generally collect and receive information about criminal inquiries in a sequential manner. When information is acquired 
sequentially, confirmation bias increases as there is a stronger preference for information that supports any early theories. Police investigators then evaluate that information and decide who should be questioned, and where to look for additional information and potential evidence. A confirmatory cycle may be initiated when information that is perceived to support a favoured scenario is discovered, which results in an increased commitment to any decisions made based on that information (Jonas, Schultz-Hardt, Frey, \& Thelen, 2001).

Researchers have also demonstrated that obtaining prior information about a case can influence the way individuals assess a crime scene and evaluate the evidence (Van den Eeden, De Poot, \& Van Koppen, 2016). The way those first pieces of information are assessed (objectively versus biased), and the scenario(s) that are formulated as a result, may be crucial to how subsequent information is treated. Moreover, psycho-legal researchers have also demonstrated that officers who form theories early in an investigation are more likely to deem theory-disconfirming information as less reliable (Ask, Rebelius, \& Granhag, 2008; O'Brien, 2007). However, other researchers have found that officers may be more inclined to discredit the competing information altogether (Rassin, 2010). 
Police officers are also more likely to engage in confirmatory thinking about a suspect's guilt because identifying a prime suspect requires a belief that the suspect is involved in the crime (O'Brien, 2007). However, requiring a condition of guilt presumption before the interview has taken place is a dangerous one. Any scenario or hypothesis that is treated as truth (i.e., the suspect is involved with the crime) is more likely to be considered factual, and creates increased confidence in that belief (Koehler, 1991). For that reason, during the suspect's interview, officers may be more inclined to seek information or a confession to support that belief.

\subsection{POLICE QUESTIONING OF SUSPECTS}

How police officers elicit information from suspects, witnesses and victims has received a lot of attention from academics, policy-makers, and law enforcement organisations over the last 40 years (Kelly, Miller, \& Redlich, 2015). Much of that attention is due to highly publicised cases where police misconduct or questionable interview practises have contributed to false confessions and the conviction of innocent suspects (Kassin et al., 2009). As a result of those cases, some European countries started in the early 1990s to reform how the police question citizens - particularly suspects. There was a shift away from applying accusatory and confession driven interview techniques (i.e., interrogation), and the objective became one of information-gathering 
(i.e., interviewing) to facilitate case closure (Clarke \& Milne, 2001). It has only been in the last ten years that various law enforcement agencies in Canada, and even more recently in the United States, have started to make similar changes (see Snook \& House, 2008).

\subsubsection{Investigative interview versus}

interrogation. An interrogation is a high-pressure interaction used to obtain and confirm information that the interrogator believes to be true. It is generally used when the interrogator believes the suspect is lying or is likely to lie (Inbau, Reid, Buckley, \& Jayne, 2011). The goal of an interrogation is to persuade the suspect to tell the truth or to confess through confrontation, psychological manipulation, and rejection of denials (Meissner, Redlich, \& Bhatt, 2012). Conversely, an interview is a non-accusatory interaction centred around information gathering and credibility assessment. Interviewers will often use techniques such as rapport-building, active listening, and appropriately challenging conflicting information to seek the truth (College of Policing, 2016; Meissner, et al., 2012).

\subsubsection{Investigative Interview Frameworks.}

Police officers are generally trained to use specific types of interviewing frameworks or models when questioning suspects. These consist of an outline of the questioning processes and suggested tactics the interviewer can use. Some frameworks are 
associated more with either interrogations (e.g., Behavioural Analysis Interview or Reid Technique) or information-gathering interviews (e.g., PEACE model) based on how the interviewer is advised to handle suspect denials, deception, and uncooperative behaviour. However, most interviews contain elements of interrogative strategies as well as information-gathering techniques (e.g., General Interview Strategy). The following is a description of the interviews referred to throughout this book.

Behavioural Analysis Interview (BAI). The BAI, most commonly known as the Reid Technique (Inbau et al., 2011), is popular in the United States and parts of Canada. The objective of the BAI is to break down the suspect's resistance and increase the chance of obtaining a confession (Hartwig, Granhag, \& Vrij, 2005). The BAI begins with a non-accusatory interview in a custodial or non-custodial setting. If the interviewer believes the suspect is being deceitful or evasive, guilt is assumed, and an interrogation begins.

The BAI has received intense scrutiny by academics and practitioners for its increased likelihood to elicit false confessions from suspects, claims that guilty and innocent suspects can be differentiated, and innocent people are immune to the tactics outlined in the Reid Technique. Despite those claims by Inbau and colleagues, researchers have repeatedly demonstrated that innocent 
suspects are more susceptible to the tactics used in the BAI (Kassin et al. 2009). The nine steps to a confession as outlined in Inbau et al., (2011) are as follows:

1. Engage in positive confrontation

2. Develop a theme for questioning

3. Handle denials

4. Overcome objections

5. Procure and retain the suspect's attention

6. Handle the suspect's passive mood

7. Present alternative questions

8. Have the suspect verbally relate various details of the offense

9. Convert the oral confession to a written confession

PEACE Model. In the mid-1980s, England and Wales underwent a justice reform as a result of many high-profile miscarriages of justice, and frequent reports of police misconduct. From that reform, the Police and Criminal Evidence Act (PACE; 1984) emerged and the PEACE model was created. PEACE is not an interview technique, but the essence of the information-gathering objective is clearly defined within the seven guiding principles (see Appendix A).

Officers trained in PEACE predominantly use two types of questioning techniques: the cognitive interview (Geiselman et al., 1984) and conversation management (Shepherd, 1993). PEACE is the 
acronym for the steps that interviewers are expected to employ (College of Policing, 2016):

$P$ - Planning and Preparation

E - Engage and Explain

A - Account clarification and challenge

C - Closure

E - Evaluation of information, investigation, and interviewer

General Interview Strategy (GIS). The Dutch police have four interview strategies they can apply in various situations; however, the GIS is the most commonly used with suspects of serious crimes. The GIS was created by the Dutch police academy and is applied to any interview that meets three criteria: i) sufficient evidence, ii) the suspect has a normal tolerance for interrogative pressure, and iii) the suspect must be willing to talk (Van Amelsvoort, Rispens, \& Grolman, 2010).

The Dutch police conduct the GIS in three phases. The first phase is the Opening where the suspect has his rights and the process of the interview and any legalities explained. The second phase is the Person Oriented Interview. In this phase, the interviewers collect relevant personal information, attempt to build rapport, and determine whether the suspect is willing to talk about the case. The third and final phase is the Case Oriented interview. This is where most of the relevant information concerning the case is obtained and the 
following guiding principles of the GIS are applied (see Hoekendijk \& Van Beek, 2015):

1. Make use of internal pressure

2. Try to minimise eventual reluctance to provide an account

3. Rule out alternatives

4. Challenge the account

Earlier versions of the GIS also included the instructions to confront the suspect with evidence using circumventing questioning and to reward the suspect if the statement is adjusted to reflect the truth (Amelsvoort, et al., 2007). Based on the listed principles, the GIS has elements of both information gathering and interrogative strategies.

1.5.3 The human variable in interviewing. BAI and PEACE are the most well-known types of interview frameworks across North America, much of Europe, the UK and Australia (Meissner et al., 2012). However, each type of investigative interviewing framework is only as effective as the interviewer that uses it. Research has shown that interviews can quickly turn into interrogations, regardless of the type of framework used (Kassin et al., 2003; Hill et al., 2008). What differentiates an interview and an interrogation is not the frameworks used but the intent and the objectives of the interviewer. An interviewer could follow the process outlined in PEACE and still ask accusatory questions, reject denials, and employ manipulative tactics to elicit 
information from a suspect. Thus, it is the presumption of guilt that usually facilitates movement from interview to interrogation.

\subsection{CAN CONFIRMATORY THINKING BE BENEFICIAL TO THE INVESTGATIVE INTERVIEW?}

The most prevalent position throughout the literature is one that posits the negative effects of confirmatory thinking in relation to police work. However, some researchers and law enforcement practitioners have argued that focusing on specific information and using previous experience can be beneficial in police investigations (see Snook \& Cullen, 2008). As a police officer gains experience, he or she will begin to develop a type of cognition specific to their line of work (i.e., heuristics and schema). Having cognitions specific to the task helps with fast and efficient decision-making and execution. For example, police officers must make quick, and sometimes life and death decisions. They do not always have time to engage in reasoning, to evaluate cost-benefit rationalisations, or to entertain alternative scenarios. Thus, an automatic and intuitive decision-making technique is often beneficial in those types of situations (see Gigerenzer, 2006; Kahneman, 2003).

There are also researchers who have argued that confirmation bias is an adaptive cognitive strategy (Cosmides \& Tobby, 1992; Friedrich, 1993), 
and that tunnel vision could be necessary for the successful completion of tasks that require focus and dedication under high-pressure (see Gigerenzer, 2008; Tversky \& Kahneman, 1974). As previously mentioned, tunnel vision is described as a type of confirmatory thinking within police investigations where the police officer is so intently focused on a suspect, he or she fails to acknowledge the possibility of alternative scenarios, or even the possibility of suspect innocence (O'Brien, 2007; Rossmo, 2009). To this end, researchers have suggested that tunnel vision can be employed as a cognitive strategy to reduce potentially costly errors (e.g., wasted time and resources), maintain focus, and help keep superfluous information to a minimum (Snook \& Cullen, 2008).

Conversely, it can be argued that there is a difference between focused attention to do one's job and a bias that could potentially bias a criminal investigation. Although the nature of police work may influence officers to rely heavily on their schema and heuristics (Maguire, 2003), a police officer's instincts, beliefs, and prior experiences do not apply to every case he or she encounters. An alternative argument to the beneficial use of intuition based on schema and tunnel vision is that those behaviours can become ingrained in the officer's cognitive process and are then applied inappropriately (Holmberg, 2004; Williamson, 1993). Furthermore, reliance on instinct 
and an intense focus is not appropriate for the investigative interview because that is the part of the job where skills such as empathy and objectivity are more likely to assist with the task of informationgathering (Oxburgh, Ost, Morris, \& Cherryman, 2014) $)^{2}$.

Although focused thinking and reliance on heuristics may have a place in police work, the general consensus in the literature is that they should not be applied to the investigative interview. Researchers have found that interviewers who are engaged in focused and confirmatory thinking are more apt to use more coercive tactics (Narchet et al., 2011), ask more accusatory questions (Kassin et al., 2003), and rely more heavily on nonverbal behaviour for veracity assessment (Vrij, 1993). There is also a risk that the interview (focused on gathering information) will quickly become an interrogation (focused on obtaining a confession; see Kassin, 2005; Meissner \& Kassin, 2004).

Interrogations can be particularly detrimental to the innocent suspect, as they are more likely to

2 It should be noted that the opposing arguments in the literature regarding the benefits and detriment of confirmation bias highlights the necessity to ensure validity when measuring and drawing assumptions about interviewer behaviour within the context of this topic. That is, researchers must ensure they are measuring actual instances of confirmatory behaviour and not the focused behaviour that interviewers may be using to solve a case or evaluate a problem. 
waive their rights to silence and answer questions in an initial attempt to be helpful (Kassin, 2008). However, those who waive their rights are also more likely to falsely confess during a police-suspect interview (Kassin, 1997). Innocent interviewees also tend to underestimate the potential consequences of talking to an investigator who holds a guilt bias (Guyll et al., 2013). That is, an interviewee who is trying to be helpful or cooperative can also be worried or tense and may perceive their response as normal and understandable given the circumstances. However, increased nervousness and cognitive load can also influence an innocent suspect's nonverbal behaviour and facilitate inconsistent verbal responses (Akehurst \& Vrij, 1999). Furthermore, an interviewer who is more inclined to use the suspect's behaviour as a measure of trustworthiness, veracity, or guilt, is also more likely to be mistaken when interpreting the observed behaviour (Vrij, 1993), which can lead to an expectancy confirmation effect that results in increased interrogative pressure.

In sum, none of the findings to date indicate that focused, intuitive, or confirmatory behaviour in the interview room could be of any benefit to the outcome of an investigation or to the police-suspect interview.

\subsection{THE CURRENT DISSERTATION}

Although confirmation bias has been studied in many aspects of criminal investigations, no studies 
have been conducted to identify specific indicators of confirmation bias within police-suspect interviews, particularly within information-gathering frameworks. The present dissertation is an analysis of information-gathering type of investigative interviews, which aims to answer two overarching questions i) can indicators of confirmatory thinking be identified in investigative interviews, and ii) if present, how does confirmation bias influence the behaviour of the interviewer and the interviewee? To answer these questions, a mixed-methodological approach will be taken to identify evidence of biased behaviour and confirmatory thinking.

This thesis is divided into three parts. Part I (Chapters 2, 3, 4 and 5) examines potential indicators of confirmation bias and confirmation expectancy effects within the controlled environment of experimental studies. Part II (Chapters 6, 7, and 8) explores the beliefs of police officers concerning important factors of the investigative interview and examines transcripts of police-suspect interviews for indicators of confirmation bias. Part III (Chapters 9 and 10) contains a discussion of the overall research findings contained in this thesis, suggestions for researchers to approach the analyses of interviews in future studies, and implications of this research for future studies, practice (industry), and the benefit of society. 
1.7.1 Study rationales. The following section outlines the studies contained in this dissertation and the rationale for conducting each in context of research question:

Study 1: Chapter 3 . The first gap in the extant literature involved the presentation of expectancy confirmation effects in truth-telling suspects. Expectancy effects are known to influence behaviour so that what is expected appears to be true (Darley \& Fazio, 1980). However, little attention has been afforded to the interviewee's verbal and nonverbal behaviour. In previous studies, the effects of expectancy have been measured primarily with confessions as the outcome variable. Additionally, there have been few studies that examined the effects of expectancy in non-adversarial settings with non-accusatory questions.

Using structured behavioural observation techniques, verbal and nonverbal behaviour will be assessed between a group of control interviewees and interviewees primed to experience an expectancy confirmation effect. Expectancy is induced using (fabricated) information about honesty and specific group membership. Targets in a nonaccusatory interview environment are tested using neutral and information-gathering type questions. It is hypothesised that persons exposed to the negative information (the expectancy) will demonstrate behaviour consistent with increased cognitive load. 
Due to the investigative nature of the information gathering questions, Targets exposed to the expectancy are predicted to exhibit more of these behaviours in the investigative portion of the interview. If the hypotheses are supported, the findings in this study will provide a better understanding of how interviewee behaviour can be altered when the interviewee thinks they are being accused of wrong-doing.

Study 2: Chapter 4. One consistent finding throughout the extant literature regarding confession driven interviews is that presumptions of guilt about a suspect can influence an interviewer to ask more accusatory questions (Kassin, 2014). That type of questioning strategy has also been demonstrated in one study that used information-gathering techniques (see Hill, Memon, \& McGeorge, 2008). Additionally, findings in the linguistic literature have demonstrated that the verbs used in utterances can be indicative of biased beliefs about another person, and subtle hints of bias can be found when the main verbs of a question are closely examined (Semin \& Fiedler, 1991). This study is an experimental examination of guilt presumption and its influence on the words used by interviewers when preparing questions. The questions formulated by participants will be examined for accusatory language, as well as the use of word abstraction. Abstraction is a linguistic phenomenon that occurs when speakers hold biased 
or stereotypical beliefs about the topic or person being discussed.

All participants will be given details of a fabricated case that involved suspected academic dishonesty. The participants will naturally form their own guilt judgements (i.e., guilty, not guilty, need more information) based on details of the case, and will be asked to create 10 questions they would ask the suspect. The participants will also be divided into two groups. Half the participants will be given detailed instructions for conducting an informationgathering interview within the guidelines of the PEACE framework. The other half are given basic instructions for conducting an information-gathering interview. The two groups were created to determine whether participants exposed to the detailed PEACE instruction will form a guilt judgement or remain objective (need more information) as instructed within the PEACE guiding principles. Those participants exposed to PEACE are also expected to form less accusatory questions as they would have remained objective and would have no reason to make accusations. However, participants who make a guilt judgement (regardless of interview instructions) are expected to form accusatory questions and use more negative abstract words.

If the hypotheses of this study are supported, the findings will determine whether an instruction to remain objective and detailed instruction are 
effective tools to prevent guilt-judgements from forming. Although previous researchers have suggested that instruction to remain objective is not enough to thwart prejudicial thinking, it is prudent to test those findings in the interview context. The novel contribution of this study involves the linguistic analysis of the word abstraction. Although word abstraction has been examined in interviewing settings, it has not been tested where potential interviewers could formulate their own guilt judgements and their own questions. The findings will provide some insight to how word abstraction relates to guilt-presumption under those conditions.

Study 3: Chapter 5. This study expands on the findings of Study 2 by extending the investigation into the linguistics of the questions formulated by the interviewer. The design of the study mirrored that of Study 2 ; however, in this case there are interviewees who will be questioned by the interviewer. It is expected that interviewers who make an initial judgement of guilt will create more accusatory questions containing more negative abstract language. However, previous researchers have suggested that using more concrete words can influence who or what becomes the focus of the response (De Poot \& Semin, 1995; Semin, Rubini, \& Fiedler, 1995). It is predicted that interviewees will comply with this linguistic pattern, and ultimately focus on themselves, even if the question does not 
focus on them. Understanding how language contained within a question can influence the response is pertinent to the investigative interview as an interviewee's responses can be manipulated by the interviewer's word choices. Although word choices are not a conscious decision when it comes to word abstraction (Semin, 2011), if an interviewer holds a presumption of guilt, the interviewee's responses could be perceived as confirmation of that belief.

An exploration of interviewer motivations for creating each question, and well as changing guiltjudgements will also be conducted in this study. No hypotheses have been created for those variables as changing guilt judgements and motivations will rely on a host of factors contained within the interview and the interviewer. Both the motivations for question creation and the reasoning for making a particular guilt judgement will be captured via freetext responses from the interviewer. Those responses will then be analysed for any themes that could provide insight into the interviewers' decisionmaking over the course of the interview.

Study 4: Chapter 6. There is evidence in the extant literature that suggests confirmatory thinking begins with prior beliefs (Marietta \& Barker, 2007). In this study, the beliefs about factors that may influence interview outcomes with suspects are explored in police officers. Police officers from The 
Netherlands, North America, and the UK will be asked for responses on a 26-item survey that contains statements around three specific themes: best interview practices, confessions, and interviewee vulnerabilities. Officers will report their beliefs on each topic by indicating the level of agreement or disagreement with each statement. This exploratory initiative will gauge whether police officers' beliefs about the investigative interview were consistent with the findings in the academic literature. Understanding what officers believe about factors within the investigative interview may have implications for future training. It may also help explain why some officers do not consistently apply best practices (i.e., strong counterfactual beliefs) versus officers who reliably apply literature consistent practices to their interviews (i.e., knowledge consistent beliefs).

Study 5: Chapter 7. The fifth study in this dissertation is an applied examination of the language used during investigative interviews with suspects. The experimental studies contained in this dissertation aim to replicate previous findings in the literature and test linguistic analysis techniques for feasibility in interview settings. However, experimental constraints will not allow for full generalizations of the findings into police practice. Mainly, university students do not behave like police officers and suspects. Although the experimental 
studies will answer some questions about the influence of guilt-presumptive language on interviewee behaviour, the only way to fully understand the behaviour of police officers and suspects is to analyse actual interviews.

The investigative interview is a unique interaction that is influenced by many factors. One important factor in the interview is the dialectical exchanges between interviewer and interviewee and the context in which they occur (Haworth, 2017). Previous findings in the have suggested that the language used in a police-suspect interview can provide clues to the underlying guilt beliefs of the interviewer (Hill et al., 2009; Kassin et al., 2003; Narchet et al., 2011). This explorative study is an analysis of the discursive indicators of guilt presumption presented as instances of covert speech (i.e., insinuation of guilt), the utterances (locutions) that lead to the insinuation, and the influence of insinuation on the suspect's behaviour (perlocutionary force). The aim of this study is to determine how police interviewers use covert speech and how that language influences suspect behaviour.

Study 6: Chapter 8. Conventional methods for analysing interviews have primarily focused on the appropriateness of questions asked to gather information or to elicit a confession (see Oxburgh, Myklebust, \& Grant, 2010). Within the various question categorisations used by researchers, guilt- 
presumption is not featured as a questioning strategy; therefore, those types of utterances are not recorded. Instead, guilt-presumptive utterances are aggregated with other types of inappropriate opinion statements (e.g., Shepherd \& Griffith, 2013). Further to this, there is often more happening within an interview than is immediately identifiable by simply focusing on question types and opinions. Examining the interactivity and behaviours that lead to accusations can reveal subtleties that have a profound influence on the flow and outcome of the interviews. More applied research on guiltpresumptive language is needed in the investigative interviewing literature, particularly in the context of interviewer beliefs about suspect guilt as well as biased decision-making regarding questioning strategies.

The final study presented in this dissertation examines a sample of interviews from a Dutch murder case. In this study, six interviews from a single murder investigation are examined for guiltpresumptive language (accusations and insinuations of guilt) and question appropriateness. The suspect's behaviours immediately before and after incidence of guilt-presumptive language will also be analysed. The aim of this study is to determine how guiltpresumptive language may negatively influence suspect behaviour and impede the ability for interviewers to gain investigation relevant 
information (IRI). There is often more happening within an interview than is immediately identifiable by simply focusing on question types and opinions. Examining the interactivity and behaviours that lead to accusations can reveal subtleties that have a profound influence on the flow and outcome of the interviews 


\section{REFERENCES}

Akehurst, L., \& Vrij, A. (1999). Creating suspects in police interviews. Journal of Applied Social Psychology, 29, 192-210. doi:10.1111/j.1559-1816.1999.tb01381.x

Alpert, G. P., MacDonald, J. M., \& Dunham, R. G. (2005). Police suspicion and discretionary decision making during citizen stops. Criminology, 43, 407-434. doi:10.1111/j.0011-1348.2005.00012.x

Arkes, H. R. (1991). Costs and benefits of judgement errors: Implications for debiasing. Psychological Bulletin, 110, 486 - 498. doi:10.1037/0033-2909.110.3.486

Ask, K., Rebelius, A., \& Granhag, P. A. (2008). The 'elasticity' of criminal evidence: A moderator of investigator bias. Applied Cognitive Psychology, 22, 1245 - 1259. doi:10.1002/acp.1432

Breda Six found guilty of restaurant murder at retrial.

(October 14, 2015). DutchNews.nl. Retrieved from https://www.dutchnews.nl/news/2015/10/breda-sixfound-guilty-of-restaurant-murder-at-retrial/

Brewer, W. F., \& Nakamura, G. V. (1984). The nature and functions of schemas. Center for the Study of Reading [Technical Report No. 325]. Cambridge, MA: Bolt Beranek and Newman Inc.

Burgoon, J. K., \& Le Poire, B. A. (1993). Effects of communication expectancies, actual communication, and expectancy disconfirmation on evaluations of communicators and their communication behavior. Human Communication Research, 20, 67-96. doi:10.1111/j.1468-2958.1993.tb00316.x 
Chatman, C. M., \& Von Hippel, W. (2001). Attributional mediation of in-group bias. Journal of Experimental Social Psychology, 37, 267-272. doi:10.1006/jesp.2000.1457

Clarke, C., \& Milne, R. (2001). National evaluation of the PEACE investigative interviewing course [Report No. PRAS/149]. London: Home Office.

College of Policing. (2016, January 11). Investigative Interviewing. Retrieved from https://www.app.college.police.uk/appcontent/investigations/investigative-interviewing

Cosmides, L., \& Tooby, J. (1992). Cognitive adaptations for social exchange. In J. Barkow, L. Cosmides, \& J. Tooby (Eds.), The adapted mind: Evolutionary psychology and the generation of culture (pp. 117-182). New York, NY: Oxford University Press.

Darley, J. M., \& Fazio, R. H. (1980). Expectancy confirmation process arising in the social interaction sequence. American Psychologist, 35, 867-881. doi:10.1037/0003066X.35.10.867

Darley, J. M., \& Gross, P. H. (1983). A hypothesis-confirming bias in labeling effects. Journal of Personality and Social Psychology, 44, 20-33. doi:10.1037/0022-3514.44.1.0

Davis, D., \& Leo, R. A. (2012). Interrogation-related regulatory decline: Ego depletion, failures of self-regulation, and the decision to confess. Psychology, Public Policy, and Law, 18, 673-703. doi:10.1037/a0027367

De Rechtspraak. (2017). De zes van Breda. Retrieved from https://www.rechtspraak.nl/ Uitspraken-ennieuws/Bekende-rechtszaken/Doodslag-Chineesrestaurant-Breda

Ditrich, H. (2015). Cognitive fallacies and criminal investigations. Science and Justice, 55, 155-159. doi: 10.1016/j.scijus.2014.12.007 
Edmond, G., Tangen, J. M., Searston, R. A., \& Dror, I. E. (2015). Contextual bias and cross-contamination in the forensic sciences: the corrosive implications for investigations, plea bargains, trials and appeals. Law, Probability, and Risk, 14, 1-25.

doi:10.1093/lpr/mgu018

Eerland, A., \& Rassin, E. (2010). Biased evaluation of incriminating and exonerating (non)evidence. Psychology, Crime \& Law, 18, 351-358. doi: $10.1080 / 1068316$ X.493889

Fahsing, I., \& Ask, K. (2013). Decision making and decisional tipping points in homicide investigations: An interview of British and Norwegian detectives. Journal of Investigative Psychology and Offender Profiling, 10, 155-165. doi: $10.1002 /$ jip. 1384

Fazio, R. H., Effrein, E. A., \& Falender, V. J. (1981). Selfperceptions following social interaction. Journal of Personality and Social Psychology, 41, 232-242. doi:10.1037/0022-3514.41.2.232

Ferrari, J. R., \& Dovidio, J. F. (2001). Behavioral information search by indecisives. Personality and Individual Differences, 30, 1113-1123. doi:10.1016/S1918869(00)00094-5

Findley, K. A. (2012). Tunnel vision. In B. L. Cutler (Ed.), Conviction of the innocent: Lessons from psychological research (pp. 303-323). Washington, DC: American Psychological Association.

Findley, K. A., \& Scott, M. S. (2006). The multiple dimensions of tunnel vision in criminal cases. Wisconsin Law Review 2006, 2, 291-398. Retrieved from https://heinonline.org

Frey, D. (1982). Different levels of cognitive dissonance, information seeking, and information avoidance. Journal of Personality and Social Psychology, 43, 11751183.

doi: $10.1037 / 0022-3514.43 .6 .1175$ 
Geiselman, R. E., Fisher, R. P., Firstenberg, I., Hutton, L. A., Sullivan, S. J., Avetissian, I. V., \& Prosk, A. L. (1984). Enhancement of eyewitness memory: An empirical evaluation of the cognitive interview. Journal of Police Science \& Administration, 12, 74-80. Retrieved from http://psycnet.apa.org

Gigerenzer, G. (2008). Why heuristics work. Perspectives on Psychological Science, 3, 20-29. doi:10.1111/j.17456916.2008.00058.x

Gudjonsson, G. H. (2003). The psychology of interrogations and confessions: A handbook. West Sussex, England: John Wiley \& Sons, Ltd.

Guyll, M., Madon, S., Yang, Y., Lannin, D. G., Scherr, K., \& Greathouse, S. (2013). Innocence and resisting confession during interrogation: Effects on physiologic activity. Law and Human Behaviour,37, 366-375. doi: $10.1037 /$ lhb0000044

Hartwig, M., Granhag, P. A., \& Vrij, A. (2005). Police interrogation from a social psychology perspective. Policing \& Society, 15, 379-399. doi: $10.1080 / 10439460500309956$

Havinga, E., Hopman, S., Melis, P., Vastenburg, J., Zeeman, M., Nelen, H., \& van Koppen, P. J. (2008). De dood in het Chinese restaurant: En moord met vele verhalen. Netherlands: Boom Juridische uitgevers.

Hill, C., Memon, A., \& McGeorge, P. (2008). The role of confirmation bias in suspect interviews: A systemic evaluation. Legal and Criminological Psychology, 13, 357-371. doi:10.1348/135532507X238682

Hoekendijk, J., \& Van Beek, M. (2015). The GIS-model: A Dutch approach to gather information in suspect interviews. Investigative Interviewing: Research and Practice, 7, 19. Retrieved from http://www.iiirg.org/journal 
Holmberg, U. (2004). Police interviews with victims and suspects of violent and sexual crimes: Interviewees' experiences and interview outcomes (Doctoral Dissertation). Retrieved from https://www.divaportal.org/smash/get/diva2:345247/F ULLTEXT01.pdf

Inbau, F. E., Reid, J. E., Buckley, J. P., \& Jayne, B. C. (2011). Criminal interrogation and confessions ( $5^{\text {th }}$ ed.). Gaithersburg, Maryland: Aspen Publishers.

Jonas, E., Schultz-Hardt, S., Frey, D., \& Thelen, N. (2001). Confirmation bias in sequential information search after preliminary decisions: An expansion of dissonance theoretical research on selective exposure to information. Journal of Personality and Social Psychology, 80, 557-571. doi:10.1037//00223514.80.4.557

Kahneman, D. (2003). Maps of bounded rationality: Psychology for behavioural economics. American Economic Review, 93, 1449-1475. doi:10.1257/000282803322655392

Kaiser, C. R., \& Miller, C. T. (2001). Reacting to impending discrimination: Compensation for prejudice and attributions of discrimination. Personality and Social Psychology Bulletin, 27, 1357-1367. doi: $10.117 / 01461672012710011$

Kassin, S. M. (1997). The psychology of confession evidence. American Psychologist, 221-233. doi: 10.1037/0003-066X.52.3.221

Kassin, S. M. (2005). Does innocence put innocents at risk? American Psychologist, 60, 215-228. doi:10.1037/0003066X.60.3.215

Kassin, S. M. (2008). False confessions: Causes, consequences, and implications for reform. Current Directions in Psychological Science, 17, 249-253. doi:10.1111/j.1467-8721.2008.00584.x

Kassin, S. M., Bogart, D., \& Kerner, J. (2012). Confessions that corrupt: Evidence from the DNA exoneration case files. Psychological Science. doi:10.1177/0956797611422918 
Kassin, S. M., Drizin, S, A., Grisso, T., Gudjonsson, G. H., Leo, R. A., \& Redlich, A. D. (2009). Police induced confessions: Risk factors and recommendations. Law and Human Behavior, 34, 3-38. doi:10.1007/s10979009-9188-6

Kassin, S. M, Goldstein, C. C., \& Savitsky, K. (2003). Behavioral confirmation in the interrogation room: On the dangers of presuming guilt. Law and Human Behavior, 27, 187203. doi:10.1023/A: 1022599230598

Kassin, S. M., Gudjonsson, G. H. (2004). The psychology of confessions: A review of the literature and issues. Psychological Science in the Public Interest, 5, 33 - 67. doi:10.1111/j.1529-1006.2004.00016.x

Keinan, G. (1987). Decision making under stress: Scanning of alternatives under controllable and uncontrollable threats. Journal of Personality and Social Psychology, 52, 639-644. doi:10.1037//0022-3514.52.3.639

Klayman, J. (1995). Varieties of confirmation bias. In J. Busemeyer, D. L. Medin, \& R. Hastie (Eds.), Decision making from a cognitive perspective. San Diego, CA: Academic Press, Inc.

Koehler, D. J. (1991). Explanation, imagination, and confidence in judgement. Psychological Bulletin, 110, 499-519. doi:10.1037/0033-2909.110.3.499

Kunda, Z. (1990). The case for motivated reasoning. Psychological Bulletin, 108, 480-498.

Madon, S., Willard, J., Guyll, M., \& Scherr, K. (2011). Selffulfilling prophecies: Mechanisms, power, and links to social problems. Social and Personality Psychology Compass, 5, 578-590. doi:10.1111/j.17519004.2011.00375.x

Maguire, M. (2003). Criminal investigation and crime control. In T. Newburn (Ed.), Handbook of policing. Devon, UK: Willan

Meissner, C. A., \& Kassin, S. M. (2002). "He's guilty!": Investigator bias in judgements of truth and deception. Law and Human Behavior, 26, 469-480. doi:10.1023/A:1020278620751 
Meissner, C. A., \& Kassin, S. (2004). You're guilty, so just confess! In G.D. Lassiter (ed) Interrogations, Confessions, and Entrapment (pp. 85-106). Boston, MA: Springer.

Merton, R. K. (1948). The self-fulfilling prophecy. The Antioch Review, 8, 193-210. doi:10.2307/4609267

Miller, D. T., \& Turnbull, W. (1986). Expectancies and interpersonal processes. Annual Review of Psychology, 37 , 233-256. doi:10.1146/annurev.ps.37.020186.001313

Narchet, F. M., Meissner, C. A., \& Russano, M. B. (2011). Modeling the influence of investigator bias on the elicitation of true and false confessions. Law and Human Behavior, 35, 452-465. doi:10.1007/s10979-010-9257$\mathrm{x}$

Nickerson, R. (1998). Confirmation bias: A ubiquitous phenomenon in many guises. Review of General Psychology, 2, 175-220. doi:10.1037/10892680.2.2.175

Nelson, J. K. (2008). Laugh and the world laughs with you: An attachment perspective on the meaning of laughter in psychotherapy. Clinical Social Work Journal, 36, 41-49. doi: $10.1007 / \mathrm{s} 10615-007-0133-1$

O'Brien, B. (2007). Confirmation bias in criminal investigations: An examination of the factors that aggravate and counteract bias (Doctoral dissertation). Retrieved from https://deepblue.lib.umich.edu/handle/2027.42/12652 6

Oxburgh, G., Ost, J., Morris, P., \& Cherryman, J. (2014). The impact of question type and empathy on police interviews with suspects of homicide, filicide and child sexual abuse. Psychiatry, Psychology and Law, 21, 903 - 917. doi:10.1080/13218719.2014.918078

Rassin, E. (2007). A psychological theory of indecisiveness. Netherlands journal of psychology, 63, 2-13. doi: $10.1007 /$ BF03061056 
Rassin, E. (2010). Blindness to alternative scenarios in evidence evaluation. Journal of Investigative Psychology and Offender Profiling, 7, 153-163. doi:10.1002/jip.116

Rassin, E., Eerland, A., \& Kuijpers, I. (2010). Let's find the evidence: An analouge study of confirmation bias and criminal investigations. Journal of Investigative Psychology and Offender Profiling, 7, 231-246. doi: $10.1002 /$ jip. 126

Rassin, E., Muris, P., Booster, E., \& Kolsloot, I. (2008). Indecisiveness and informational tunnel vision. Personality and Individual Differences, 45, 96-102. doi:10.1016/j.paid.2008.03.006

Rosenthal, R. (1966). Experimenter effects in behavioral research. East Norwalk, CT: Appleton - Century Crofts.

Ross, L., Lepper, M. R., \& Hubbard, M. (1975). Perseverance in self-perception and social perception: Biased attributional Processes in the debriefing paradigm. Journal of Personality and Social Psychology, 32, 880892. doi: $10.1037 / 0022-3514.32 .5 .880$

Rossmo, D. K. (2009). Criminal investigative failures. Boca Raton, FL: CRC Press

Semin, G. R., \& Fiedler, K. (1991). The linguistic category model, its bases, applications and range. European Review of Social Psychology, 2, 1-30. doi: $10.1080 / 14792779143000006$

Semin, G. R., Rubini, M., \& Fiedler, K. (1995). The answer is in the question: The effect of verb causality on locus of explanation. Personality and Social Psychology Bulletin, 21, 834-841 . doi:10.1177/0146167295218006

Shepherd, E. (1993). Ethical interviewing. Issues in Criminological \& Legal Psychology, 18, 56 - 56. Retrieved from http://psycnet.apa.org

Snook, B., \& Cullen, R. M. (2008). Bounded rationality and criminal investigations: Has tunnel vision been wrongfully convicted? In D. K. Rossmo (Ed.), Criminal investigative failures (pp. 71-98). Boca Raton, FL: CRC Press. 
Snook, B., \& House, J. C. (2008, November). An alternative interviewing method. Blue Line Magazine, 11, 10-12. Retrieved from https://www.blueline.ca

Snyder, M. \& Swann, W. B. (1978). Behavioral confirmation in social interaction: From social perception to social reality. Journal of Experimental and Social Psychology, 14, 148-162. doi:10.1016/0022-1031(78)90021-5

The Amsterdam Herald. (2012, June 5). Supreme Court to review six murder convictions in Netherlands' worse miscarriage of justice case. The Amsterdam Herald. Retrieved from http://www.amsterdamherald.com/index.php/allnewslist/335-20120605-supreme-court-review-breda-sixmurder-convictions-worst-miscarriage-of-netherlandsdutch-justice

Tversky, A., \& Kahneman, D. (1974). Judgement under uncertainty: Heuristics and biases. Science, 185, 1124-1131. doi:10.1126/science.185.4157.1124

Van Amelsvoort, A., Rispens, I., \& Grolman, H. (2010). Handleiding verhoor. Amsterdam, NL: Reed Business.

Van den Eeden, C. A. J., De Poot, C. J., Van Koppen, P. J. (2016). Forensic expectations: Investigating a crime scene with prior information. Science and Justice, 56, 475-481. doi:10.1016/j.scijus.2016.08.003

Vrij, A. (1993). Credibility judgements of detectives: The impact of nonverbal behaviour, social skills, and physical characteristics on impression formation. The Journal of Social Psychology, 13, 601 - 610. doi:10.1080/00224545.1993.9713915

Wason, P.C. (1968). Reasoning about a rule. The Quarterly Journal of Experimental Psychology, 20, 273-281. doi: $10.1080 / 14640746808400161$

Wastell, C., Weeks, N., Wearing, A., Duncan, P. (2012). Identifying hypothesis confirmation behaviours in a simulated murder investigation: Implications for practice. Journal of Investigative Psychology and Offender Profiling, 9, 184-198. doi:10.1002/jip.1362 
Williamson, T. M. (1993). From interrogation to investigative interviewing; strategic trends in police questioning. Journal of Community \& Applied Social Psychology, 3, 89-99. doi:10.1002/casp. 2450030203

Zanna, M. P., \& Pack, S. J. (1975). On the self-fulfilling nature of apparent sex differences in behavior. Journal of Experimental Social Psychology, 11, 583-591. doi:10.106/0022-1031(75)90009-8 
PART I:

Detecting Confirmation Bias in Investigative Interviews 


\section{CHAPTER 2}

\section{Confirmation Bias in the Investigative Interview with Suspects: A Review of the Literature}

\section{ABSTRACT}

Confirmation bias is an extensively researched subject across a variety of disciplines and topics. Although it is not a new subject in the psycho-legal literature, it has been largely neglected as a key factor that may affect the investigative interview with suspects. In this chapter, I offer a critical review of the studies that have specifically explored confirmation bias and investigative interviews with suspects. The review concludes with the identification of current gaps in the literature, acknowledgement of the challenges associated with studying this phenomenon, and suggestions for future research.

Keywords: Confirmation bias, investigative interviews, guilt presumption, expectancy effects, tunnel vision. 


\section{INTRODUCTION}

When a person sets out to prove what they already believe to be true, they are demonstrating a type of cognitive fallacy called a confirmation bias. This bias is especially problematic in criminal justice contexts when it forms the basis of decision-making that could have serious consequences for individuals. The extant criminal justice literature is focused mainly on investigator bias and tunnel vision within criminal investigations. Inside that literature, researchers have examined how bias can influence evidence evaluation, perceptions of witness credibility, and judicial decisions (e.g., Ask \& Granhag, 2005). There is also a pervasive theme in the literature that suggests confirmation bias has a negative influence on interview outcomes with suspects. Specifically, confirmation bias has been linked to accusatory and coercive interviews, with false confessions as a potential outcome (e.g., Meissner \& Kassin, 2004). However, the existing findings do not provide enough support for confirmation bias as a problem for interview outcomes using information-gathering interview frameworks. Nor have researchers tested for reliable indicators that confirmation bias is present. In this chapter, I review the studies that have explored confirmation bias within police-suspect interviews. I then highlight the gaps and possible issues associated with this type of research. Finally, I suggest potential solutions to those challenges, as well as directions for further research. 


\subsection{CONFIRMATION BIAS IN INTERVIEWS WITH SUSPECTS}

\subsubsection{Guilt presumption alters behaviour.}

Kassin, Goldstein and Savitsky (2003) were the first to investigate expectancy and expectancy confirmation effects in the context of the investigative interview. The researchers approached expectancy as interviewer guilt presumptions and examined how confirmatory behaviours influenced the interview outcomes with both guilty and innocent suspects. Kassin and colleagues appeared to have started the endeavour with the intent of establishing a tested link between bias, unethical interview tactics, and false confessions. Based on evidence in the interpersonal interaction literature, the researchers hypothesised that guilt presumption would lead to the use of more coercive interviewing techniques (e.g., accusations, increased interrogative pressure). They sought to extrapolate those findings into the area of criminal justice and forensics. The researchers began their investigation with the thesis statement, "We believe that police interrogations are persuasive $[. .$.$] , in part because$ they are theory-driven social interactions founded upon a presumption of guilt" (p. 188).

Across two laboratory experiments, Kassin et al. (2003) explored how preconceived guilt judgements could influence the interviewers' tactics and questioning style. In the first study, the researchers manipulated guilt and innocence in participants who acted as suspects, as well as the guilt expectations of the participants who acted as interviewers. They found that interviewers who were primed to have a guilt bias asked more accusatory questions and applied more interrogative pressure to 
elicit a confession from the suspect. This effect was even more pronounced when biased interviewers were paired with innocent suspects. Furthermore, participants in the innocent suspect condition reported that their interviewers seemed to apply more pressure on them and worked harder for a confession. The findings suggested the potential for a process of behavioural confirmation to occur (i.e., expectancy and expectancy confirmation). Kassin and colleagues, however, did not explicitly measure confession behaviour in the study.

In the second study, Kassin et al. (2003) wanted to determine whether the outcomes of guilt expectancy found in the first study influenced the suspect's behaviour in a way that could be observed by neutral third-parties. The researchers found that third-party observers who listened to only the suspect's responses were able to discriminate between replies to interviewers who held a guilt bias and those who did not hold that bias. Based on the responses alone, the observers also reported that suspects in the guilty expectation condition seemed more defensive and guiltier, regardless of actual guilt or innocence. Kassin and colleagues interpreted that finding as evidence of expectancy confirmation effects. That is, there was an observable difference in the behaviour of suspects exposed to interviewers primed for a guilt judgement than those who were not.

The findings of Kassin et al. (2003) presented empirical evidence for guilt presumption as an influential factor on behaviour (interviewer and suspect), behavioural perception, and potential negative outcomes for the investigative interview. It is important to note, however, that the researchers 
employed a similar experimental method as Snyder, Tank and Berscheid (1977) in that the interviewers and interviewees never interacted within the same physical space. Participants (interviewers and suspects) were placed in separate cubicles, and the interview was conducted via headset and microphone. Using that method, Kassin and colleagues (2003) were able to demonstrate the effects of guilt presumption via verbal communication alone, and without the influence of judgements made on nonverbal behaviour. That design, however, left unanswered questions regarding the potential influence of nonverbal behaviour within the interaction. Nonverbal behaviour cannot be ignored in communication as it affects the subsequent behaviour of those engaged in the interaction (e.g., mirroring and mimicry; Akehurst \& Vrij, 1999). For example, police officers often report using body language to assess guilt and deception despite substantial evidence that has warned police interviewers against making judgements based on nonverbal behaviour (see Vrij \& Granhag, 2012).

\subsubsection{Guilt presumption influences}

question types. The next researchers to explore the effects of confirmation bias on the investigative interview were Hill, Memon, and McGeorge (2008). Over three studies the researchers examined the phenomenon in the context of the non-adversarial (information-gathering) interview. In the first study, they elicited confirmation bias by manipulating guilt presumption in their participants. They then explored any influence on the type of questions that were formulated. Despite the authors' claims they were undertaking a systematic investigation of 
conformation bias, in Studies 2 and 3 the researchers only investigated the effects of question type on confession rates and observer perception. In Study 2 , the researchers did not invoke or manipulate bias in the interviewer, but instead used research staff to create and ask participants interview questions. In Study 3 , the responses to the questions created by the researchers in Study 2 were used as the stimulus materials. That design subsequently affected the focus of the overall paper as the intention of each study was to build on the findings of the previous. Because the researchers did not use the questions formulated by the biased interviewers from the first study, they essentially cannot claim to have evaluated the effects of confirmation bias in the subsequent studies, as there was no bias present.

The first study conducted by Hill et al. (2008) was an investigation into confirmation bias, and the key findings demonstrated by Kassin et al. (2003) were replicated in the less adversarial conditions of an information-gathering interview. Hill and colleagues found that interviewers who were primed to form a guilt bias created more accusatory questions, rated the suspect as guiltier, and were more confident in their guilt judgements than interviewers who were not given an expectancy of guilt. Since the research conducted by Hill et al. (2008; Study 1) did not require the interviewers to ask the questions they formulated to suspects, there remained unanswered questions about interviewersuspect interactions. That is, how the nonverbal behaviour of both participants may have influenced the expectancy confirmation cycle and interview outcomes (e.g., confession rates). 


\subsubsection{Guilt presumption influences}

interview tactics. The next study in this area was conducted by Narchet, Meissner, and Russano (2011). In that experimental study, the researchers explored the influence of guilt bias on interview tactics, the suspect's perception of the interview, and the likelihood of a confession in suspects. The study also included a face-to-face interview between interviewer and mock-suspect. The researchers found that guilt bias increased the interviewer's use of minimisation tactics for the interviewees in the innocent condition (i.e., gain the suspect's trust and trivialise the seriousness of the offence; Kassin \& McNall, 1991), but they also found that guilty participants were more likely to confess than innocent participants. This latter finding was contrary to their hypotheses as well as the assertion that guilt presumption was a key factor in facilitating false confessions.

The predominant consensus in the false confession literature at the time of Narchet et al. (2011) posited that heavy-handed interview tactics were more likely to produce false confessions through a process of confirmation bias with Kassin et al. (2003) cited as evidence. It is unclear how the Kassin et al. (2003) study became empirical evidence for that hypothesis throughout the literature. As previously discussed, Kassin and colleagues did find evidence that a guilt bias initiated the expectancy confirmation effect. They also found that expectancy confirmation altered interviewers' questioning tactics and suspects' response behaviour. However, Kassin et al. (2003) did not measure confession rates; thus, the relationship between guilt presumptions (expectancy), question type, interview tactics, and 
confessions was not established. Narchet et al. (2011) did measure confession rates and found no evidence for the confirmation bias-false confession relationship.

It is important to note that the findings of Narchet and colleagues do not disprove a relationship between guilt presumptions and false confessions. There are many limitations of experimental studies that can influence the outcome variables in such a study (e.g., the way guilt expectancy was introduced, the pressure to provide a confession, and the perceived consequences of confessing). What the study does demonstrate is that interviewers who hold a presumption of guilt are more likely to employ interview techniques that are known to increase the likelihood of false confessions as demonstrated in related literature (see Gudjonsson \& Pearse, 2011; Kassin, 2005). However, false confessions are not the only detriment of guilt presumptive questioning and confirmatory thinking in police-suspect interviews. There is evidence that confirmation and guilt biases can also influence interviewer judgements of statement believability (Olson, 2013), interpretation of information (Ask, Rebelius, \& Granhag, 2008; Charman, Kavetski, \& Mueller, 2017), and considerations of alternative suspects and scenarios (Ask \& Granhag, 2005; O’Brien, 2009). 2.1.4 Guilt knowledge influences alibi information recall. The next study that examined the effects of guilt presumption in the police-suspect interview explored its relationship to interviewer judgements of alibi believability. Olson (2013) hypothesised that simply labelling a suspect's explanation of their whereabouts as an alibi could be enough to create a presumption of guilt in the 
interviewers. Olson then hypothesised that any presumptions of guilt could influence an interviewer to recall less alibi information. Guilt presumption was manipulated by telling participants the suspect was guilty, innocent or no information was given. Olson found that participants that were told the suspect was guilty, recalled less alibi relevant information. Although this finding is interesting from an attentional and recall perspective, it tells us very little about guilt presumption or confirmation bias. That is, guilt did not have to be presumed as it was established. The participants did not need to form or confirm beliefs about the suspect guilt; therefore, it is possible that the prior information regarding guilt may have been what influenced the interviewers to attend to, retain, and recall certain information about the alibi statements evaluated in that study.

\subsubsection{Measuring the influence of guilt presumption and stereotypes. The final study that} has specifically examined the influence of biases and guilt presumption within interviewing contexts is a measure developed by Minhas, Walsh, and Bull (2016). The researchers aimed to identify indicators of prejudicial stereotyping within the police suspect interview and designed a tool to identify interviewer biases that are based on the race and ethnicity of the suspect.

As part of the development, the researchers included five assumptions they posited were indicators that an interviewer held a guilt presumption: i) asking guilt presumptive questions, ii) asking emotionally provocative questions, iii) use of bluffing tactics, iv) inflexible stance in light of potentially exonerating information, and $v$ ) interviewer reacted to or commented on the 
suspect's nonverbal behaviour. Those five behaviours have been mentioned independently, or in some combination, within the literature as conduct that was observed when interviewers were suspected of having a guilt bias. Only one behaviour, however, has been consistently mentioned in all prior studies on this topic - accusatory questioning. The rest of the behaviours have not been consistently noted within the aforementioned studies in this chapter, or in studies that have examined confirmation bias in other aspects of criminal investigations (e.g., Ask \& Granhag, 2005; Leo, 2009). In sum, it is unclear as to why or how those particular behaviours were chosen as indicators of guilt presumption or bias. Moreover, if the behaviours listed in Minhas et al. (2016) are accepted as reliable indicators of guilt presumption and bias, is it enough to say that only one of the behaviours needs to be present? If so, does one of those behaviours hold more weight than the others for determining the presence of confirmatory beliefs? Perhaps it is some combination of those behaviours that solidifies the presence of guilt presumption and confirmatory thinking, but if so, which ones? It could even be the case that there are interviewer behaviours that are potentially indicative of confirmation bias that are missing from that list. All these questions are the reason why more research is needed to determine if the behaviours noted by Minhas et al. (2016) consistently emerge when confirmation bias is present.

\subsection{DIRECTIONS FOR FUTURE RESEARCH}

When taken together, those studies that explicitly examined confirmation bias in policesuspect interviews have provided important 
insights. ${ }^{3}$ There is some empirical evidence to suggest an influence of confirmation bias and guilt presumption on the interviewer's questioning behaviour, the use of minimisation tactics, the perceptions of third-party observers to the interaction, and on the judgements of suspect believability. However, there are still many unanswered questions beyond those previously discussed in this chapter. The following is a list of topics directly pertinent to the scope of this thesis that warrant further investigation.

\subsubsection{Observable behaviours of}

confirmation bias. There is still the question of what confirmation bias looks and sounds like. Although there is currently no theoretical reason to suspect that people can detect confirmation bias by simply observing others, further research could help answer any questions relevant to that area of study. Based on research in deception detection and individual differences, it is unlikely that reliable nonverbal cues to the presence of confirmatory thinking could be observed in guilt presumptive interviewers (see Riggio \& Friedman, 1983). As evidenced by the consistent appearance of accusatory questioning in guilt presumptive interviewers, the reliable indicators of confirmatory

3 There is also an extensive literature on the effects of confirmation bias and deception detection within suspect interrogations (see Meissner \& Kassin, 2002). Deception detection and veracity assessment is a related phenomenon and comes with a host of factors that can also influence the course of the investigative interview. For that reason, the deception detection literature has not been included as it is outside the scope of this thesis, which is to identify reliable indicators of confirmation bias exhibited by interviewers. 
thinking are most likely contained in the verbal interactions between interviewer and suspect. This notion is supported in the linguistic literature through the relationship between bias and verbalising stereotypes (see Beukeboom, 2012; Semin, 2011). For that reason, it may be best to concentrate on the language used by interviewers and their verbal behaviour as opposed to nonverbal behaviour that could vary significantly.

\subsubsection{Expectancy and expectancy effects.}

Stereotypes are expectancies that originate from heuristics and schema and applied to all members of a demographic group regardless of individual differences. Linguists have demonstrated that a person's stereotypic expectancies are reflected in their language by using negations (Beukeboom, Finkenauer, \& Wigboldus, 2010) and word abstraction (i.e., the verb can become removed from its concrete meaning through interpretation; Wigboldus, Semin, \& Spears, 2006). In fact, verb abstraction as a method of detecting expectancy is well documented in the linguistic literature (for a review see Beukeboom, 2012). There are also linguistic models to identify and measure the level of abstraction in utterances and text (Semin \& Fiedler, 1991).

Given the established relationship between stereotyping and expectancies, it also stands to reason that the effects of expectancy confirmation on the suspect may look like the effects of stereotype threat as demonstrated in the interpersonal interaction literature (e.g., reduced performance, defensiveness, and behavioural changes; Bargh, Chen, \& Burrows, 1996; Wheeler \& Petty, 2001). Najdowski (2012) provided some support for this 
possibility when she demonstrated behavioural changes in racial minorities who were asked information-gathering questions by a security guard. That study, however, was conducted in a country with well documented racial tensions between the target demographic and the police. Therefore, whether the effects of (non-racially motivated) expectancy effects can be observed as stereotype threat in suspects who do not themselves hold stereotypic expectancies about the interviewer remains to be tested.

\subsubsection{Creating confirmation bias}

experimentally. Confirmation bias is the action of attempting to confirm pre-existing beliefs. The challenge for researchers is to ensure that participants have first formed a belief to be confirmed, and it is important that the participant forms or accepts that belief. That is the starting point of confirmation bias. In the previous studies, guilt presumption was manipulated by leading the participants to believe the suspect was either guilty or innocent. This method relies heavily on the assumption that the participants will believe that information to be true. However, when researchers imply that the suspect is guilty, or innocent, they may have created a situation where the participant is simply attempting to confirm what they were told was ground truth by a person in authority (i.e., the researcher running the study). This also creates a generalisability issue because a police investigator would not have ground truth about a suspect's guilt or innocence, and any guilt expectancies would be created by an investigator's own evaluation of the information that was available. 
One possible method to create expectancies and beliefs without too much interference could be found in the studies by Narchet et al. (2011) and Olson (2013). Those studies included a control condition where the participant was not given any information about the suspect's guilt. It is likely that the interviewers who did not have their expectations of guilt primed (or outright communicated) may have developed an expectancy on their own (i.e., an actual guilt or innocence bias). If a bias was naturally formed in that group, the participants would no longer be a control group, but have become an experimental group.

In future studies, the natural formation of guilt judgements could be achieved by manipulating information (e.g., case facts) and then asking the potential interviewer whether he or she has an opinion about the suspect's guilt. There should also be an option for the interviewer to indicate if he or she has no opinion. Understandably, this approach would significantly reduce the control the researcher has over the experiment (e.g., group sizes for each judgement). However, that may be a necessary trade-off to ensure what is being investigated is actually guilt presumption and any subsequent confirmatory behaviours.

\subsubsection{Understanding interviewer behaviour.}

Another avenue for future research is determining why the interviewer behaved in a certain manner. There could be many different reason police officers have pre-existing beliefs that influence their decisions or result in confirmatory behaviour (e.g., racial stereotypes, previous experience, training, or intuition). Understanding the motivations behind the interviewer's behaviour is important to fully 
comprehend, and eventually develop measures to change that behaviour. One way to gather information about interviewer motives would be to simply ask the interviewers to justify the questions they choose to ask. That could also be an opportunity to confirm the presence of confirmatory questioning. That is, in the most extreme outcome, the interviewer may blatantly state that they asked a question to confirm guilt. When taken with other findings in a study, the interviewer's self-report of motives could help identify how those biases influenced their behaviour toward the suspect. Another approach would be to ask interviewers to identify and rank information they used to make their guilt judgement. This approach has not been previously used when examining bias in policesuspect interviews, but it has been examined in the context of investigator decision-making (e.g., O'Brien, 2007; Rassin, Eerland, \& Kuijpers, 2010).

\subsection{CONCLUSION}

Despite the potential problems that confirmation bias can cause within a criminal investigation, this review has demonstrated the topic has been largely neglected in the context of investigative interviews with suspects. Many unanswered questions remain on this topic, and the breadth and depth of the information yet to be discovered about this phenomenon leaves a range of opportunities for researchers. Answering those questions will require diverse methods and techniques. The most promising research avenue seems to involve exploring interviewer questioning techniques and language use. Although the extant literature has provided a solid base for future research, much work is left to be done before the effects of confirmation bias - in all its 
forms - are fully understood in the context of the police-suspect investigative interview. 


\section{REFERENCES}

Akehurst, L., \& Vrij, A. (1999). Creating suspects in police interviews. Journal of Applied Social Psychology, 29, 192-210. doi:10.1111/j.1559-1816.1999.tb01381.x

Ask, K., \& Granhag, P. A. (2005). Motivational sources of confirmation bias in criminal investigations: The need for cognitive closure. Journal of Investigative Psychology and Offender Profiling, 2, 43-63. doi:10.1002/jip.19

Ask, K., Rebelius, A., \& Granhag, P. A. (2008). The 'elasticity' of criminal evidence: A moderator of investigator bias. Applied Cognitive Psychology, 22, 1245-1259. doi:10.1002/acp.1432

Bargh, J. A., Chen, M., \& Burrows, L. (1996). Automaticity of social behavior: Direct effects of trait construct and stereotype activation on action. Journal of Personality and Social Psychology, 71, 230-244. doi:10.1037/00223514.71.2.230

Beukeboom, C. J. (2012). Mechanisms of linguistic bias: How words reflect and maintain stereotypic expectancies. In J. Laszlo, J. Forgas, \& O. Vincze (Eds.). Social Cognition and Communication. New York: NY: Psychology Press.

Beukeboom, C. J., Finkenauer, C., \& Wigboldus, D. H. (2010). The negation bias: When negations signal stereotypic expectancies. Journal of Personality and Social Psychology, 99, 978-992. doi:10.1037/a0020861

Charman, S. D., Kavetski, M., Mueller, D. H. (2017). Cognitive bias in the legal system: Police officers evaluate ambiguous evidence in a belief-consistent manner. Journal of Applied Research in Memory and Cognition, 6, 193 - 202. doi:10.1016/j.jarmac.2017.02.001

Gudjonsson, G. H., \& Pearse, J. (2011). Susoect interviews and false confessions. Current Directions in Psychological Science, 20, 33-37. doi:10.1177/0963721410396824

Hill, C., Memon, A., \& McGeorge, P. (2008). The role of confirmation bias in suspect interviews: A systemic evaluation. Legal and Criminological Psychology, 13, 357-371 . doi:10.1348/135532507X238682 
Kassin, S. M. (2005). Does innocence put innocents at risk? American Psychologist, 60, 215-228. doi:10.1037/0003066X.60.3.215

Kassin, S. M, Goldstein, C. C., \& Savitsky, K. (2003). Behavioral confirmation in the interrogation room: On the dangers of presuming guilt. Law and Human Behavior, 27, 187203. doi:10.1023/A: 1022599230598

Kassin, S. M., \& McNall, K. (1991). Police interrogations and confessions: Communicating promises and threats by pragmatic implication. Law and Human Behaviour, 233251. doi:10.1007/BF01061711

Leo, R. A. (2009). False confessions: Causes, consequences, and implications. Journal of the American Academy of Psychiatry and the Law, 37, 332-343. Retrieved from https://papers.ssrn.com

Meissner, C. A., \& Kassin, S. M. (2002). "He's guilty!": Investigator bias in judgements of truth and deception. Law and Human Behavior, 26, 469-480. doi:10.1023/A:1020278620751

Meissner, C. A., \& Kassin, S. (2004). You're guilty, so just confess! In G.D. Lassiter (ed) Interrogations, Confessions, and Entrapment (pp. 85-106). Boston, MA: Springer.

Minhas, R. A., Walsh, D., \& Bull, R. (2016). Developing a scale to measure the presence of possible prejudicial stereotyping in police interviews with suspects: The Minhas Investigative Interviewing Prejudicial Stereotyping Scale (MIIPSS). Police Practice and Research.

Retrieved from

http://dx.doi.org/10.1080/15614263.2016.1249870

Najdowski, C. J. (2012). Stereotype threat in police encounters: Why African Americans are at risk of being targeted as suspects (Doctoral dissertation, University of Texas at El Paso). Retrieved http://hdl.handle.net/10027/9525

from 
Narchet, F. M., Meissner, C. A., \& Russano, M. B. (2011). Modeling the influence of investigator bias on the elicitation of true and false confessions. Law and Human Behavior, 35, 452-465. doi:10.1007/s10979-010-9257$x$

O'Brien, B. (2007). Confirmation bias in criminal investigations: An examination of the factors that aggravate and counteract bias (Doctoral dissertation).

Retrieved from https://deepblue.lib.umich.edu/handle/2027.42/12652 6

O'Brien, B. (2009). Prime suspect: An examination of factors that aggravate and counteract confirmation bias in criminal investigations. Psychology, Public Policy, and Law, 15, 315-334. doi:10.1037/a0017881

Olson, E. A. (2013). "You don't expect me to believe that, do you?" Expectations influence recall and belief of alibi information. Journal of Applied Social Psychology, 43, 1238-1247. doi:10.1111/jasp.12086

Rassin, E., Eerland, A., \& Kuijpers, I. (2010). Let's find the evidence: An analouge study of confirmation bias and criminal investigations. Journal of Investigative Psychology and Offender Profiling, 7, 231-246. doi:10.1002/jip.126

Riggio, R. E., \& Friedman, H. S. (1983). Individual differences ND CUES TO DECEPTION. Journal of Personality ad Social Psychology, 45, 899-915. doi:10.1037/00223514.45.4.899

Semin, G. R. (2011). Language and social cognition. In F. Strack and J. Forster (eds.). Social Cognition - the Basis of Human Interaction. New York, NY: Psychology Press.

Semin, G. R., \& Fiedler, K. (1991). The linguistic category model, its bases, applications and range. European Review of Social Psychology, 2, 1-30. doi:10.1080/14792779143000006 
Snyder, M., Tanke, E. D., \& Berscheid, E. (1977). Social perception and interpersonal behaviour: On the selffulfilling nature of social stereotypes. Journal of Personality and Social Psychology, 35, 656-666. doi: 10.1037/0022-3514.35.9.656

Vrij, A. \& Granhag, P. A. (2012). Eliciting cues to deception and truth: What matters are the questions asked. Journal of Applied Research in Memory and Cognition, 1, 110117. doi:10.1016.j.jarmac.2012.02.004

Wheeler, S. C., \& Petty, R. E. (2001). The effects of stereotype activation on behavior: A review of possible mechanisms. Psychological Bulletin, 127, 797-826. doi:10.1037/0033-2909.127.6.797

Wigboldus, D. H. J., Semin, G. R., \& Spears, R. (2006). Communicating expectancies about others. European Journal of Social Psychology, 36, 815-824. doi: $10.1002 /$ ejsp. 323 


\section{CHAPTER 3}

\section{Interview Expectancies: Awareness of Potential Biases Influences behaviour in Interviewees}

This manuscript in its present form is accepted and available online at Psychiatry, Psychology, and Law:

Adams-Quackenbush, N. M., Horselenberg, R., Hubert, J., Vrij, A., \& van Koppen, P. (2019, in press). Interview expectancies: awareness of potential biases influences behaviour in interviewees. Psychiatry, Psychology, and

Law.http://dx.doi.org/10.1080/13218719.2018.1485522

\section{Abstract}

Expectancy effects are known to influence behaviour so that what is expected appears to be true. In this study, expectancy was induced using (fabricated) information about honesty and specific group membership. Targets were tested in a nonaccusatory interview environment using neutral and information-gathering type questions. It was hypothesised that those exposed to the negative information (the expectancy) would demonstrate behaviour consistent with increased cognitive load, and evidence was found to support this prediction. Due to the investigative nature of the information gathering questions, it was also expected that the Targets exposed to the expectancy would exhibit more of these behaviours in the investigative portion of the interview. Some behaviour was to support this prediction (i.e., shorter responses and increased speech disturbances); however, indicators of performance altering load were not observed during this phase of the interview. These findings support the hypothesis that expectancy effects can noticeably alter interviewee behaviour.

Keywords: investigative interviews, expectancy effects, cognitive load, interviewee behaviour, stereotype activation, information-gathering, truth-tellers. 


\section{INTRODUCTION}

Imagine a situation where someone in a position of authority is asking you questions about a recent event. The atmosphere is collegial, and the questions are not difficult or strongly worded. You may feel a bit nervous simply due to the difference in social status. Perhaps you are trying hard to recall a detail to impress this person, which only adds more pressure to the situation. Imagine that during one of your responses you suddenly get the impression this person is suspicious of your answers. This person has not said anything to imply suspicion, yet you feel as though something has changed between you. Was it something you said? Did your body language send the wrong signal? Perhaps it is neither, and your internalised insecurities have planted this doubt in your mind. How do you recover? What do you do? Now imagine a similar exchange with a police officer who is investigating a crime.

This scenario outlines a common interaction that occurs within a unique environment. A police investigative interview is generally a high-stakes, stressful, and cognitively taxing situation for everyone involved. Investigative interviews are wrought with factors that can directly affect the outcome (Gudjonsson, 2003), as well as influence the behaviour of the interviewer and interviewee (Kassin et al., 2009; Leo, 2009). In the exchange above, the dominant factor is an expectancy effect that originates in the person answering the questions. Given the prevalence of expectancy effects within most human interactions, this topic has started to receive more attention in forensic contexts such as criminal investigations (Hill, Memon, \& McGeorge, 2008), decision-making in judicial 
professionals (Porter \& Ten Brinke, 2009), and accusatory investigative interviews (Kassin, 2005; Kassin, Goldstein, \& Savitsky, 2003). Within the framework of the investigative interview, expectancy effects are often studied as a by-product of confirmation bias held by police officers or other judicial players (Narchet, Meissner, \& Russano, 2011; Powell, Hughes-Scholes, \& Sharman, 2012; Rassin, Eerland, \& Kuijpers, 2010). However, little research has been conducted in the area of the investigative interview to examine how expectancy effects may arise internally in the interviewee based on the interviewee's perception of the situation.

The present study is an attempt to apply aspects of social psychological theory on expectancy effects to the study of interviewee behaviour. To investigate the effects of expectancy, the focus is placed on the verbal and non-verbal behaviour of truth-telling interviewees. Of specific interest are behaviours that are conventionally associated with cognitive load but that are also (erroneously) cited as signs of suspicion or evasiveness. The implications of the impact of expectancy effects on investigative interviews are then discussed in the context of the existing literature.

\subsection{EXPECTANCY EFFECTS AS STEREOTYPE ACTIVATION}

When expectancy effects occur within a dyadic or polyadic interaction, it has been repeatedly demonstrated that the behaviour of the perceiver (the one who holds the expectation or false belief) can influence the behaviour of the target (the one 
whose behaviour is being perceived). ${ }^{4}$ In turn, the target's behaviour ultimately confirms the expectation of the perceiver, thus giving the perceiver evidence that his or her false belief is true (Merton, 1948; Snyder \& Haugen, 1994; Snyder \& Stukas, 1999). Darley and Fazio's (1980) model of the expectancy confirmation process illustrates how expectancy effects can be introduced into a normal sequence of social interaction. In their model, Darley and Fazio posit that expectancy effects are introduced into an interaction when the perceiver forms or holds expectancy about the target. The interaction is then subsequently influenced by both the target's and the perceiver's behaviour based on that expectancy. However, expectancy effects can also occur as an internal event for a single person based on his or her own beliefs and expectations. In the larger expectancy confirmation process model, an internally derived expectancy effect occurs at the phase described as the target interpreting the perceiver's behaviour (Darley \& Fazio, 1980, p. 872). In this case, the expectancy effect occurs in the absence of any behavioural cues from the perceiver; instead, the expectancy arises from the target's knowledge about beliefs that may be held by the perceiver. This phenomenon is most commonly seen in the presence of self-perceptions (Fazio, Effrein, \&

\footnotetext{
${ }^{4}$ Within an interaction, the target and perceiver roles frequently alternate. For the purpose of this paper, the perceiver is always the interviewer and the target are always the interviewee. Additionally, perceiver/ interviewer and target/interviewee are used interchangeably throughout the chapter, depending on the context.
} 
Falender, 1981) or because of an activated group stereotype (Wheeler \& Petty, 2001).

When an expectancy is activated based on a group stereotype, the target is in a situational predicament where he or she is at risk of conforming to negative beliefs about a group to which he or she belongs, regardless of whether he or she believes the stereotype or not (Bargh, Chen, \& Burrows, 1996; Steele \& Aronson, 1995). Subsequent research has identified three main conditions necessary for this type of expectancy to occur. The first condition, stereotype awareness, requires that the target is aware of the negative belief (Schmader, Major, \& Gramzow, 2001). The second condition, domain identification, requires that the target cares about doing well in the specific situation (Rosenthal, Crisp, \& Suen, 2007). The third condition, task difficulty, requires that the task has some level of difficulty for the target (Keller, 2007). When all three of these conditions are present, the effects of the stereotype have been shown to impede a target's performance (Schmader \& Johns, 2003), carry over into unrelated situations (Fazio et al., 1981) and inhibit working memory (Schmader, Johns, \& Forbes, 2008).

Although stereotyping as an expectancy effect is well documented in social psychological and educational research (see Pennington, Heim, Levy, \& Larkin, 2016), only recently has it been investigated within the legal context. Najdowski (2012) investigated racially motivated stereotypes to demonstrate that persons of African American heritage are significantly more likely to report feeling the effects of stereotyping than persons of White European heritage when in contact with lawenforcement officers. Moreover, these effects 
increase when questions are asked regarding a recent crime in the area. Najdowski's hypothesized that the effects of stereotyping in these encounters could influence African Americans to behave in ways that may indicate suspicion to a law-enforcement officer (e.g. increased nervousness, odd body language and decreased eye contact). In such cases, the target's awareness of the stereotypes concerning his or her group and criminal activity becomes activated when he or she is approached by a lawenforcement officer.

The effects of stereotyping in relation to expectancy are not solely limited to group membership based on race; research has demonstrated that these effects also occur based on age (Lamont, Swift, \& Abrams, 2015), sex (Leslie, Cimpian, Meyer, \& Freeland, 2015) and disability (Silverman \& Cohen, 2014). Therefore, it may be possible to induce this effect using negative beliefs about a variety of group membership types. For example, an expectancy response could be activated when a false belief concerns an individual's likelihood to commit a crime based on low socioeconomic status, low education level, gang membership, substance use and/or criminal history. However, reducing stereotype activation for these groups would be extremely challenging in a law-enforcement context. For example, a police officer may encounter many people who belong to one or more of these criminally stereotyped groups and may have formed an expectancy about the suspect based on past experiences with that group. Additionally, a false belief does not have to be explicitly stated to create the expectancy effect and alter the target's behaviour (Bargh et al., 1996). That is, if the false beliefs are 
implicitly present within the interaction, or unknowingly primed in the interviewee, stereotype activation may occur despite the officer's best efforts to put the interviewee at ease.

\subsection{EXPECTANCY EFFECTS AND BEHAVIOUR}

Comprehending behaviour in the context of the situation is important. The target's behaviour is what the perceiver observes and uses to confirm her or his beliefs and inform her or his consequent conduct towards the target. Once the beliefs have been confirmed, the perceiver may then use this information when encountering other members of the target's group, thus perpetuating the stereotype and the expectancy. Most investigations of expectancy effects rely on self-report measures completed by the target to determine their potential presence. Other studies also use measures such as heart rate, skin conductance and EEG outputs to understand the physiological symptoms involved (Pennington, Heim, Levy, \& Larkin, 2016). However, few studies use observational methods to investigate the verbal and non-verbal behaviours of targets who are experiencing expectancy effects.

Najdowski (2012) examined how expectancy effects in the form of a stereotype may translate into non-verbal behaviour by videotaping the interactions between targets and a law-enforcement officer. Najdowski investigated nine types of non-verbal conduct and found that two behaviours differentiated the targets by racial groups: African Americans appeared significantly more nervous during the interaction and used fewer manipulations (selftouching) and illustrators (gestures). The appearance of nervousness in Najdowski's study could be deemed a subjective measure that varies by perceiver; 
however, the reduced amount of movement is consistent with the findings of Vrij and Mann (2001). While observing videotaped interview sessions between a murder suspect and a police interviewer, the researchers noted that the suspect did not fidget much during the interview and remained unnaturally still when asked difficult or case-specific questions. The researchers concluded that the suspect may have exhibited a high level of control over his body movements to mask when he was being deceptive. However, these conclusions cannot explain why similar behaviour was seen in non-criminal, truthtelling targets during Najdowski's (2012) study.

In a subsequent study, Mann, Vrij, and Bull (2002) examined the videotaped behaviour of 16 police suspects during investigative interviews. They coded both verbal and nonverbal behaviours: gaze aversion, blink frequency, head movements, hand/arm movements, pauses in speech and speech disturbances (stutters, trips and verbal crutches). They found that the suspects blinked less and paused more often during speech when lying, and concluded that these behaviours are consistent with increased cognitive load in the suspect - that is, the act of lying, elements of the environment and the interrogative situation combined to tax the mental resources of the suspects in such a way that it affected their verbal and non-verbal behaviour (Gombos, 2006). This means that as the suspects experienced increased demands on their working memory, they had less control over their verbal and non-verbal behaviour (Engle, 2002). The combined findings of Najdowski (2012) and Mann et al. (2002) suggest that during an investigative interview there are increased cognitive demands that can be observed through 
interviewee behaviour, regardless of statement veracity.

\subsection{IMPLICATIONS OF EXPECTANCY EFFECTS IN THE INTERVIEW ROOM}

The aforementioned research findings demonstrate the impact of expectancy effects on cognition, inhibited learning, motivation and performance using various types of group membership (e.g. age, sex, race, socio-economic status, etc.). In summary, expectancy effects tax the cognitive resources of the person experiencing it in a way that impairs performance. Thus, an interviewee experiencing an expectancy effect, and the resulting increased cognitive load, may have fewer mental resources available to adequately identify and deal with the demands of the interview.

There is also evidence that the impacts of expectancy effects can linger and negatively influence performance in a broad range of situations that are unrelated to the nature of the expectancy (Inzlicht, Tullett, \& Legault, 2011). Croizet et al. (2004) demonstrated that individuals experiencing expectancy as stereotype show a decrease in performance due to increased mental load. This finding is especially significant in relation to investigative interviewing conditions, wherein the interviewee's cognitive resources may already be undermined by the perceived severity of the situation. Thus, if expectancy effects are also present, a suspect's behaviour may be affected. This meaning that the suspect's ability to fully comprehend the interviewer's questions and appreciate the implications of his or her responses to those questions may be impaired (Berggren, Richards, Taylor, \& Derakshan, 2013). 
Understanding expectancy effects as an inducer of cognitive load during investigative interviews is important for two reasons: i) increased load can undermine performance such as memory recall (Barrouillet, Bernardin, Portrat, Vergauwe, \& Camos, 2007) and question comprehension (Wallen, Plass, \& Brunken, 2005), and ii) some of the behaviour indicative of increased load can be misinterpreted by police interviewers as suspicious behaviour. For example, a suspect who appears nervous to an interviewer and who also has difficulty remembering timelines, details and events could be deemed to be uncooperative and evasive.

A suspect who appears distracted, avoids eye contact, exhibits increased speech disturbances and seems overtly nervous may also be considered shifty or guilty. Mann, Vrij, and Bull (2004) demonstrated that police officers most often use decreased eye gaze $(78 \%)$ and increased body movements (31\%) to determine veracity in a suspect. Judging deception in this manner is problematic, however, because these behaviours are faint and unreliable (De Paulo et al., 2003), even though they are often used as signs of deception across many cultures and countries (Global Research Deception Team, 2006). Mann, Vrij, Fisher, and Robinson (2008) suggest that attending to non-verbal behaviour may also strengthen the tendency for police officers to see deception.

If a police officer is accustomed to using nonverbal behaviour to determine deception and evasiveness, it may be enough to prompt him or her to believe that a suspect is lying or guilty. When this occurs, previous research has demonstrated that in a confession-driven investigative interview scenario, 
the interviewing officer may then increase interrogative pressure and engage in more coercive tactics (Kassin et al., 2003,2007, 2009). Although the extant literature has encouraged lawenforcement agencies to move away from coercive interview tactics (Kassin et al., 2009), the application of interrogative pressure to obtain a confession is still common practice in many countries (Areh, Walsh, \& Bull, 2016; Kassin et al., 2007).

Given the high-pressure, high-stakes nature of investigative interviews, it is easy to imagine how cognitive load can have an adverse effect on interviewees' performance. Some countries have abandoned confession-driven interviews in favour of information-gathering interviews (e.g. the PEACE model; see Clarke \& Milne, 2001). The goal of information-gathering interviews is to obtain as much information as possible from all interviewees (including suspects) without seeking an admission of guilt and without using intimidation, bluffs or promises. Although this type of interview is only used in a few countries - e.g. the United Kingdom (UK), Norway and Australia - it is widely regarded as an effective and more ethical type of investigative interviewing technique (Shawyer, Milne, \& Bull, 2009). However, many of the factors identified as problematic in the confession-driven interview have not been tested with the information-gathering interview; this means it is still unknown as to which phenomena are specific to one type of interview and which occur as an outcome of all types of investigative interview.

\subsection{THE PRESENT STUDY}

The effects of feeling as though you are being targeted or judged based on group membership is 
relevant to all human interactions, including encounters with law-enforcement officers. The aim of the present study is to investigate expectancy effects on behaviour when expectancies have only been implied through information about the participant's group membership. Given that most research on investigative interviews uses accusatory or confession-driven interview techniques to study interviewee behaviour (see Kassin et al., 2009; Meissner, Redlich, Bhatt, \& Brandon, 2012), little is known about expectancy confirmation effects in nonaccusatory environments while using informationgathering techniques. Additionally, inducing expectancy effects as a stereotype has not been investigated in a forensic setting using non-racially motivated false beliefs. To address these gaps in the literature, negative information about group membership and honesty was used to induce an expectancy effect because of its performanceimpairing properties, as well as its ability to generalize to a variety of situations.

A 2 (expectancy vs control) x 2 (neutral vs information-gathering questions) mixed design was employed to test the hypotheses. In line with previous research on expectancy effects and stereotype activation, it was expected that awareness of negative beliefs about group membership would influence the target's performance during the interview - that is, targets exposed to the expectancy would exhibit behaviour indicative of increased cognitive demands (decreased body movements, decreased blink rate, increased eye closure, increased gaze aversion, shorter response length and increased speech disturbances) during both types of interview questions. 
Additionally, it was predicted that targets exposed to the expectancy would exhibit more of these behaviours in the information-gathering phase of the interview due to the activation of the stereotype prime just prior to the beginning of the informationgathering questions, and the more investigative nature during this phase of the interview.

\subsection{METHOD}

3.5.1 Participants. A total of 52 targets ( 37 females and 15 males) were recruited from a university in The Netherlands based on a current grade point average (GPA) of less than 7.9. The targets were all recruited based on GPA to ensure that the negative information was specific to the domain of the academic environment. The targets volunteered to complete the study under the pretence that the researchers were investigating the relationship between GPA and sensory perception (i.e. a taste-testing task). Negative information about their grade range was fabricated and introduced to the targets as a belief through a series of fictitious scientific studies. The targets in the expectancy group were given information that people with a GPA of lower than 8 are more likely to lie and cheat on tasks to be successful. All targets were tested individually and were naive to the true purpose of the study.

One female participant was excluded from the analysis because she reported that her GPA improved in the time between recruitment and participation ( $N$ $\left.=51 ; M_{\text {Age }}=21.14, S D=1.84\right)$. Most Targets were undergraduate students $(72.6 \%)$ in their first $(21.9 \%)$, or third year of study $(23.5 \%)$. Targets recruited via the faculty participant pool received one research participation credit as an incentive. No 
incentive was offered to those recruited outside of the faculty participant pool.

3.5.2 Measures and materials. A blind tastetesting task was used to provide a task that would not betray the true nature of the study. The task also allowed for a situation wherein the participant would be left alone and could choose to complete the task honestly or just lift the covers on the juice bottles to obtain the answers. To set up the task, six different brands of apple juice were purchased at a local supermarket. The juice was poured into six identical $500-\mathrm{ml}$ plastic bottles with paper labels showing the brand name. For the blind portion of the test, opaque paper covers were slid over each bottle so that the brand name was no longer visible.

The study took place in a small room equipped with a table for the tasting task, a computer to record the questionnaire responses and present the stimulus material and an HD video camcorder to film the participant and record the interview. The digital video was saved on a data card and transferred to an encrypted external hard drive after every two or three testing sessions for later editing and analysis. Pre-interview, the targets completed a demographic questionnaire that captured their gender, age, year of study, GPA, current employment status and job title. As a manipulation check, targets provided selfreport ratings of mood and self-confidence on a scale from 1 (extremely negative mood, extremely low self-confidence) to 10 (extremely positive mood, extremely high self-confidence). This step was included to determine whether purposeful behaviours (countermeasures) or nervous behaviours could account for, or had an influence on, any of the outcome behaviours. The behaviours coded in this 
study were specifically chosen because they are reliable indicators of increased cognitive load. Other behaviours (i.e. smiling, laughing and serious affect) were coded as indicators of demeanour during questioning (see Table 3.1 for a complete list of behaviours).

Post-interview, the targets were asked to indicate from a checklist any symptoms of anxiety they may have experienced during the interview (see Appendix B). They were also asked to select any behavioural countermeasures that they may have purposefully employed during the interview in order to appear honest and truthful to the interviewer (Appendix B). They then rated their mood and selfconfidence again on scales from 1 to 10 . Finally, the targets rated each of the interview questions on a scale from 1 (extremely non-accusatory) to 10 (extremely accusatory).

3.5.3 Stimulus and Procedure. The study was conducted by a research assistant who was blind to the condition and the main hypotheses. All participants were tested individually, and the research assistant used a script to ensure consistency for each participant. The research assistant was instructed to act in a friendly but professional manner throughout the course of the study. A review of the video recordings by the primary investigator showed that the research assistant was consistent with each participant and that there were no deviations from the study script.

Prior to taking part the participants provided partial informed consent, as the true nature of the study was concealed. Exactly what portions of participation would be videotaped was vaguely worded to obscure the fact the participants would be 
secretly videotaped the entire time. Once they had been equally and randomly assigned to either the expectancy group $(n=26)$ or the control group ( $n=$ $25)$, they completed the demographics survey and rated their self-confidence and current mood. Next, the participants in the expectancy condition received a fabricated report about people with a GPA of less than 8 being more likely to lie and cheat to succeed at tasks. There was also fabricated information about the extremely low probability of someone with a GPA of less than 8 scoring $100 \%$ on any sensory perception task. This information was used to prime the participants in the expectancy group for an expectancy effect during the information-gathering stage of the study. The participants in the control group read general information about advertising and blind taste-testing.

The cover stories were presented in sections, and after each section there were multiple choice questions designed to ensure that the participant attended to, and understood, the information. Participants in both groups then received verbal instructions about the taste-test task. This task used six different brands of apple juice. The containers were uncovered, and the participant was asked to taste each and memorize the brand. The research assistant then asked the participant to turn away, putting covers over the juice containers and shuffling their order. The participant was then asked to taste the juice again and identify each brand by taste alone. Each participant made her or his choice by marking the letter on the covering to the corresponding brand on an answer sheet. During this part, the research assistant left the room under the pretence of needing to retrieve the study materials. 
Meanwhile, the camcorder was recording the participant to verify later whether she or he lifted the covers to get a good score or not. A review of all tapes revealed that $100 \%$ of the participants selfelected into an honest condition, as no one cheated on the task.

After three minutes, the research assistant returned and prepared the room for the interview by positioning the participant in front of the camera and pretending to turn the video camera on (it was already recording). Each participant was asked five neutral questions about the task (Table 3.2) in order to establish baseline behaviour in the interview environment. The research assistant then pretended to score the participants' taste-test results. Regardless of group, each participant was told that she or he had scored perfectly, which should be impossible based on her or his GPA (in fact, no one scored perfectly on the task). The research assistant then claimed that she needed to ask some additional questions to make sure that the participant's data could be used. Five information-gathering questions were then asked (Table 3.2). The order of neutral and information-gathering questions was not counterbalanced to mimic the natural flow of an investigative interview, which generally moves from person-oriented questions to case-oriented questions.

Once the interview was completed, the video camera was turned off and the self-report questionnaires were administered to capture the participants' ratings of nervousness and interview behaviours during the second set of questions (information-gathering), their perception of all the interview questions, a second self-confidence and 
current mood rating and their thoughts on the true nature of the study. In the final step, the participants received full written and verbal disclosure about the study. They were informed that they had been secretly taped during the taste-testing task, and consent for the use of their video in the study was obtained. The participants were also assured that their GPA did not indicate their inability to perform sensory tasks nor their likelihood to cheat or lie. They then watched a short humorous video to lift and possibly improve their mood in the event it worsened during the study.

\subsubsection{Coding and Intercoder Agreement.}

Each participant's video was edited into 10 clips that only included the participant's response to each question (51 participants 10 clips for each video = 510 video clips). Each clip was edited to start exactly when the interviewer finished talking and end just before the interviewer asked the next question. An event sampling technique was used to code the videos, with the duration of the video clip determining a single event. To control for variations in the duration of each video clip, all behavioural frequencies were standardized by dividing the counts by the duration of the video clip.

Three student interns, who were blind to condition and hypotheses, coded the video clips. These coders were first given training for one month that was designed to help them identify the target behaviours (see Table 3.1), and they were not permitted to analyse the study materials until they had achieved a preliminary interrater agreement of $80 \%$ on practice materials. The behaviours were recorded by counting the frequency of occurrences within the clip. Intercoder agreement was 
determined by having at least two coders score $30 \%$ of the same video clips, which were randomly selected from the sample. Krippendorff's alpha (a, Hayes \& Krippendorff, 2007) was calculated for each of the behaviours, which generated an individual behaviour agreement (see Table 3.1). Overall agreement was also calculated, $\mathrm{a}=0.986, \mathrm{CI}=$ $[.978, .990]$, which indicated an extremely high level of reliability. Acceptable K-alpha parameters were set at a minimum of $a=.85$ for all behaviours. This could be interpreted as a conservative limit; however, an a $=.80$ is regarded as "good reliability"

\subsection{RESULTS}

3.6.1 Preliminary analyses. During the endof-study questionnaire, the participants were asked if they had figured out the true nature of the study to determine whether or not this may have influenced their behaviours. No participant reported knowing what the study was about, and all data are therefore usable. Analyses were first conducted to determine if there are differences between groups for selfreported mood. Differences were tested for between the expectancy group and the control group on selfconfidence, anxiety and purposeful interview behaviours. A 2 (group) x 2 (time) mixed-design analysis of variance (ANOVA) was conducted which demonstrates that the mood ratings do not differ between the first self-report at Time 1 and the second rating at Time $2\left(M_{1}=7.49, S D=1.06\right.$ and $\left.M_{2}=7.49, S D=0.96\right), F(1,49)=.35, p=.556, \eta^{2}=$ .01 . Furthermore, the expectancy group $\left(M_{\text {Expectancy }}=\right.$ $7.65, S D=0.89$ ) did not differ from the control group (Mcontrol $=7.32, S D=1.22$ ) for overall rating of mood, $F(1,49)=2.68, p=.11, \eta^{2}=.05$. The analysis also demonstrated that ratings of self-confidence 
remained stable from time one to time two $\left(M_{1}=\right.$ $7.08, S D=1.14$ and $M_{2}=7.17, S D=1.01 ; F(1,49)=$ $\left..40, p=.531, \eta^{2}=.01\right)$. Moreover, the expectancy group ( $M_{\text {Expectancy }}=7.34, S D=1.29$ ) did not differ from the control group for overall reports of selfconfidence $\left(M_{\text {control }}=6.90, S D=0.79 ; F(1,49)=\right.$ 2.40, $\left.p=.128, \eta^{2}=.05\right)$.

When participants were asked if they purposefully tried to appear more truthful by using any specific behaviour during the interview, $70 \%$ of the sample indicated that they used at least one of the listed tactics (Appendix B), with the most common tactics reported as pausing to collect their thoughts $(31.4 \%)$ and maintaining open body language $(31.4 \%)$. The targets did not report having purposefully employed the behaviours of focus in the present study; therefore, the results in the main analysis were not influenced by the target's interview countermeasures. Furthermore, the most common symptoms of nervousness reported were stuttering or tripping over words $(23.5 \%)$, difficulty thinking $(17.6 \%)$ and feelings of defensiveness (17.6\%). An independent samples t-test shows that the targets in the control group (Mcontrol $=1.52, S D=1.36$ ) reported more symptoms of nervousness than Targets in the expectancy group ( $M_{\text {Expectancy }}=0.58$, $S D=0.94 ; t(49)=2.87, p=.006, d=.80,95 \%$ CI[0.28, 1.59]). However, control Targets reported only one symptom on average, which was not indicative of experiencing enough anxiety to influence the behaviours of interest.

The participants were also asked to rate the interview questions on a scale of 1 (not accusatory) to 10 (extremely accusatory) for both the neutral and the information-gathering phases of the interview. 
Although there is a difference in the ratings for the two types of question (neutral versus informationgathering), no single question is rated as overtly accusatory. Overall participants rated the information gathering questions as more accusatory than the neutral questions $(t(50)=-9.75, p=.001$, $d=1.46,95 \% \mathrm{CI}[-3.43,-2.26])$; however, the mean score for both types of questions did not exceed the mid-point on the rating scale $\left(M_{\text {Neutral }}=1.80, S D=\right.$ 1.50; $\left.M_{\text {Info-gathering }}=4.65, S D=2.36\right)$. Question ratings were also examined to determine whether they differed by target group. There were no significant difference in scoring the neutral questions between groups $\left(t(49)=-0.018, p=.99 ; M_{\text {Control }}=\right.$ $1.80, S D=1.38 ; M_{\text {Expectancy }}=1.81, S D=1.62$ ). There were also no differences between groups when scoring the information-gathering questions $(t(49)=$ $-0.372, p=.71 ; M_{\text {Control }}=4.52, S D=2.20 ; M_{\text {Expectancy }}$ $=4.77, S D=2.54)$.

3.6.2 Main analysis. There was some deviation from normality in many of the dependent variables when assessed by Shapiro-Wilk's test ( $p<$ .05); however, an inspection of the Q-Q plots revealed only a slight positive skew in the data. Due to the robustness of the parametric test used, the analysis proceeded without the need to transform the data. The subsequent analyses revealed there was homogeneity of variances, as assessed by Levene's test $(p>.05)$ and homogeneity of covariance, as assessed by Box's test $(p>.05)$ for all dependent variables. Any outliers in the data were dealt with using winsorization (Field, 2009).

The 10 observed behaviours of interest were analysed using a 2 (expectancy $v$. control) $\times 2$ (neutral questions $v$. information-gathering 
questions) mixed design ANOVA, where expectancy was the between-subjects factor, and question type was the within-subjects factor ${ }^{5}$. The analysis demonstrated that there were main effects of expectancy on blink frequency $F(1,49)=6.55, p=$ $.01, \eta^{2}=0.12$ with the targets in the expectancy group ( $M=1.25, S D=0.48)$ blinking less frequently than targets in the control group $(M=1.64, S D=$ $0.72)$. There was also a main effect of expectancy on response length, $F(1,49)=12.47, p=.001, \eta^{2}=$ .20 as the targets in the expectancy group ( $M=$ $39.56, S D=19.50$ ) gave shorter answers than targets in the control group $(M=57.35, S D=23.0)$.

There was also a main effect of expectancy on smiling behaviour, $F(1,49)=4.96, p=.03, \eta^{2}=$ 0.09 as the targets in the expectancy group ( $M$ $=0.36, S D=0.19)$ smiled less than Targets in the control group $(M=0.27, S D=0.17)$. Main effects of expectancy were also found for serious affect, $F(1$, $49)=4.76, p=.03, \eta^{2}=0.09$, with targets in the expectancy group exhibiting more instances of serious expression $(M=0.99, S D=0.12)$ than targets in the control group $(M=0.99, S D=0.12)$. Furthermore, a main effect of question type was found for gesturing behaviour (illustrators), $F(1,49)$ $=4.53, p=.04, \eta^{2}=0.09$ with targets in both groups using less illustrators (gestures) in the informationgathering phase $(M=0.94, S D=0.47)$ than in the neutral questioning phase $(M=1.06, S D=0.37)$.

There was a small interaction effect of expectancy and question type on speech disturbances $F(1,49)=$

\footnotetext{
${ }^{5}$ The research question investigates individual behaviours that may indicate the presence of expectancy effects. For that reason, individual ANOVA were conducted to test each dependant variable and answer the univariate research question (see Huberty \& Morris, 1989; Mitchell \& Jolley, 2012).
} 
4.86, $p=.03, \eta^{2}=.09$; however, it was not in the hypothesised direction. targets in the control group uttered more speech disturbances in the informationgathering phase of the interview $(M=1.11, S D=$ 0.44 ) than during the neutral questioning phase ( $M$ $=0.77, S D=0.37)$. It was suspected that this interaction effect might be an artefact of the differences in response length - that is, the control group spoke more, and thus had the opportunity to use more filler words and pauses. To test this, speech disturbances were reanalysed as a proportion of response duration. The interaction effect of question type and expectancy disappeared; however, main effects of expectancy emerged in the hypothesized direction, $F(1,49)=5.08, p=.03, \eta^{2}=.10$, with the expectancy targets $(M=0.24, S D=0.01)$ demonstrating more speech disturbances than the control targets $(M=0.14, S D=0.01)$.

No significant main effects of expectancy were found for laughter, $F(1,49)=1.91, p=.173, \eta^{2}=$ .04; however, a small interaction effect was found between groups and question type $F(1,49)=4.37$, $p=.04, \eta^{2}=0.08$. This was due to targets exhibiting more laughter in the information gathering phase of the interview $(M=0.10, S D=0.11)$ than during the neutral phase $\left(M=0.14, S D=0.14 ; p=.03, \eta^{2}=\right.$ .09). However, control targets drove this difference as they displayed more laughter $(M=0.18, S D=$ 0.20 ) in the information-gathering phase than expectancy targets $\left(M=0.10, S D=0.19 ; p=.05, \eta^{2}\right.$ $=0.08$ ). For the remaining behaviours of interest, no significant main effects were found for eye closures $F(1,49)=0.61, p=.44$; gaze aversion, $F(1,49)=$ $1.58, p=.22$; or manipulations $F(1,49)=0.22, p=$ .64 . 


\subsection{DISCUSSION}

The current study manipulated an expectancy effect in two groups of targets (those exposed to an expectancy and a control group) to examine how their behaviour might differ and change over the course of a non-accusatory interview that used information-gathering questions. The key findings in this study provide evidence that informationgathering questions do not seem to exacerbate expectancy effects; however, the presence of expectancy effects can be observed in certain interviewee behaviour over the course of the interview.

\subsection{1 \\ The Effects of information-gathering}

questions. Information-gathering questions were tested against the effects of expectancy by inducing stereotype activation in half of the targets. It was predicted that the resulting expectancy effect, paired with the more investigative style of the questions, would amplify the behaviours indicative of increased cognitive load. Contrary to the hypothesis, the present study suggests that information-gathering questions do not significantly increase the cognitive load that accompanies an existing expectancy effect. That is, unlike guilt-presumptive interview questions, information-gathering questions do not seem to create an expectancy effect on their own and in the absence of other interview tactics (Hill et al., 2008). Although both groups gestured less in the information-gathering phase of the interview, this reduced movement was likely due to only a slight increase in load. That is, the increased cognitive demands were not great enough to influence the other behaviours of interest. While this finding is 
Table 3.1

Definitions of verbal and nonverbal behaviours coded in the study, the corresponding Krippendorff's alpha (a) for interrater reliability, and the predicted direction of differences in behaviour for targets exposed to the expectancy.

\begin{tabular}{|c|c|c|c|}
\hline Behaviour & Operational Definition & $a$ & $\begin{array}{l}\text { Predicted } \\
\text { Direction } \\
\text { of } \\
\text { change }\end{array}$ \\
\hline $\begin{array}{l}\text { Response } \\
\text { Length }\end{array}$ & $\begin{array}{l}\text { Duration the Target speaks during } \\
\text { the video clip }\end{array}$ & .99 & $<$ \\
\hline $\begin{array}{l}\text { Blink } \\
\text { frequency }\end{array}$ & $\begin{array}{l}\text { Brief closure of both eyes lasting less } \\
\text { that one second. Includes blink } \\
\text { flurries and rapid blinking }\end{array}$ & .92 & $<$ \\
\hline Eye Closure & $\begin{array}{l}\text { Lids completely drawn together for } \\
\text { more than } 1 \text { second. No sclera, iris } \\
\text { or pupils are visible. }\end{array}$ & .92 & $>$ \\
\hline Manipulations & $\begin{array}{l}\text { Scratching, rubbing, tapping, } \\
\text { grooming, or touching the self. } \\
\text { Includes crossed arms and clasped } \\
\text { hands. }\end{array}$ & .94 & $<$ \\
\hline Illustrators & $\begin{array}{l}\text { Gestures used to accentuate speech. } \\
\text { Includes shoulder shrugs, head nods } \\
\text { and shakes while speaking. }\end{array}$ & .97 & $<$ \\
\hline Smile & $\begin{array}{l}\text { Corners of the mouth turned up to } \\
\text { form a pleased, friendly or kind facial } \\
\text { expression. Can be open or closed } \\
\text { mouth with teeth exposed or not. }\end{array}$ & .89 & $<$ \\
\hline Laugh & $\begin{array}{l}\text { Spontaneous sounds associated with } \\
\text { amusement or nervousness }\end{array}$ & .99 & $<$ \\
\hline $\begin{array}{l}\text { Gaze } \\
\text { aversion }\end{array}$ & $\begin{array}{l}\text { Frequency that Target breaks eye } \\
\text { contact with Interviewer }\end{array}$ & .97 & $>$ \\
\hline $\begin{array}{l}\text { Serious facial } \\
\text { expression }\end{array}$ & $\begin{array}{l}\text { Intense or semi-flat affect. Code only } \\
\text { if occurs for duration of the video } \\
\text { clip. }\end{array}$ & .99 & $>$ \\
\hline $\begin{array}{l}\text { Speech } \\
\text { Disturbances }\end{array}$ & $\begin{array}{l}\text { Inarticulate sounds made } \\
\text { throughout a statement that include } \\
\text { aahs, umm, etc., or elongation of } \\
\text { vowels. Includes periods of silence } \\
\text { lasting } 2 \text { seconds or more. Can occur } \\
\text { at the end of a statement or mid- } \\
\text { statement. }\end{array}$ & .93 & $>$ \\
\hline
\end{tabular}


Table 3.2

The neutral and information-gathering questions asked during the interview.

Neutral Questions

1. What did you like about the juice taste-testing task?

2. What did you think about the flavour of the juices we chose?

3. What brand did you like the most?

4. What brand was easiest for you to recognize?

5. How often do you usually drink apple juice? Information-gathering Questions

6. Describe to me in detail what you did while I was out of the room?

7. How long did it take you to complete the task?

8. How many times did you sample each juice?

9. Did you think about lifting to coverings to look at the labels while I was out of the room?

10. Have you spoken with other students who have already completed this task?

promising, further research investigating cognitive load setting needs to be conducted. There is also some evidence that the prime activation may have caused feelings of nervousness in the targets (i.e. once the targets had been told that their results were anomalous and that they needed to answer some additional questions).

Nervousness and cognitive load can be present at the same time; however, they often have opposite effects on behaviour. For example, nervous people tend to fidget more and use more manipulators (selftouch), whereas people who are cognitively taxed 
generally become more still. Therefore, only the effects that are having the greatest influence on behaviour are generally seen (Vytal, Cornwell, Arkin, \& Grillon, 2012). In the present study, it is possible that since the levels of nervousness and cognitive load were not extremely high, some behaviours for both increased mental load and nervousness were observable. For example, the control targets reported more symptoms of nervousness after the interview and exhibited more laughter during the information-gathering phase of the interview (Kasl \& Mahl, 1965). Because the targets who laughed were not conveying humorous information, it was determined that this laughter was used to relieve tension and appear non-threatening (Nelson, 2008).

\subsubsection{The effects of expectancy. The} findings in the present study demonstrate the ease with which an expectancy effect can be induced in a target. There are observable differences in the behaviour of the targets who experienced the expectancy effects compared to those in the control group. This finding lends support to the literature that cautions law-enforcement officers, and other legal personnel, against making important decisions based on their visual perceptions of a suspect or interviewee (Vrij, 2008). In the present study there are significant differences between the two groups for blinking, response length, speech disturbances, smiling and serious expression. When behaviour generally associated with increased cognitive load was examined, it was found that the frequency of blinking was decreased for the targets in the expectancy group, which is indicative of the increased mental load that accompanies an expectancy effect (Holland \& Tarlow, 1972; 
Rosenfield, Jahan, Nunez, \& Chan, 2015). This finding shows that merely planting the negative information was enough to increase the cognitive load and subsequently influence behaviour.

Similar findings are reported in other studies, supporting the notion that suggested expectancy effects can be primed and activated automatically with contextual cues (Bargh et al., 1996; Chen \& Bargh, 1997; Leslie et al., 2015). Contrary to expectations, increased eye closure and gaze aversion were not observed in the targets who were exposed to the expectancy. Closing one's eyes and breaking eye contact are tactics used by persons experiencing high amounts of mental load to reduce external visual stimulus (Doherty-Sneddon \& Phelps, 2005; Vredeveldt, Hitch, \& Baddeley, 2011).

The targets who experienced the expectancy also gave significantly shorter responses across both phases of the interview and demonstrated increased speech disturbances. Short and vague responses are often viewed as an indicator of being uncooperative and evasive (Mann et al., 2008). The targets in the present study had no reason to be ambiguous or unhelpful in their replies. It is possible that these targets did not want to say too much in fear of being perceived as dishonest and thus fulfilling the expectancy about their honesty. It is also reasonable to assume that the increased mental load experienced with the expectancy effect simply made shorter responses easier to deliver. It was anticipated that the targets in the expectancy group would exhibit more speech disturbances ('ums', 'ahhs', etc.) and pauses in their speech. It was assumed that the increased mental load associated with the expectancy effect would cause the targets in the 
expectancy group to use pauses and speech disturbances to collect their thoughts before responding, which was shown to be the case.

Three behaviours were also coded that could potentially provide some insight into demeanour (i.e. smiling, laughing and serious facial expression). Significant behavioural differences between groups and across question types were observed for these variables. The targets in the expectancy group smiled less and maintained more serious facial expressions throughout the questioning, despite reporting a positive mood that was consistent with the targets in the control group. It is likely that the change in demeanour during the information-gathering questions was due to the increased mental load experienced when the targets were informed that there was a potential problem with their task results. This suggests that when the targets were told of the improbability of their results, the situation was perceived as more serious. Note that the targets in both groups reported the information-gathering questions as more accusatory than the neutral questions. The scores for the information-gathering questions do not exceed the mid-point for the rating scale and thus the questions were not scored as overtly accusatory. However, this finding may be an indication of the targets' nervousness during this phase of the interview.

\subsubsection{Limitations and future research. The} targets in the present study were all persons telling the truth in a safe and non-threatening environment with a friendly interviewer. However, the presence of an expectancy effect about group membership and honesty was enough to significantly decrease the length of response, eye blinks and smiling while 
increasing speech disturbances and serious affect. There are clearly some limitations in the present study that need to be addressed to fully understand the implications of expectancy effects on investigative interviews. The findings presented herein have been tested in an academic setting in an attempt to extrapolate to a legal context. However, it cannot be concluded that the phenomenon of expectancy effects is a frequent occurrence during investigative interviews, nor can it be concluded that this finding will transfer to real-world situations. However, it has been demonstrated that expectancy effects are potentially another avenue to increased cognitive load in an already cognitively taxing situation. Further research is needed to determine how a non-racially-motivated stereotype may affect targets in a higher-pressure, high-stakes interview setting.

Another limitation is that the informationgathering phase of the interview does not realistically reflect a real-world investigative interview using information-gathering techniques. The aim was to choose questions that would incorporate free recall (see Question 6 in Table 3.2) and encourage more details about what went on in the room. The remaining questions are specific and focused on information that could be helpful in a real investigation. Because it was necessary to control for consistency with each target, the interviewer was directed to stick to a script; therefore, prompts, clarifying questions and follow-up questions were not used as they would be in a real investigation. Future research is needed to explore how the altered behaviour of targets, due to increased mental load and expectancy effects, may influence subsequent 
behaviours in perceivers during investigative interviews in real-world settings.

\subsection{CONCLUSION}

When the findings of this study are applied to the investigative interview, important insights emerge. Previous research has demonstrated the effects of cognitive load during mentally taxing tasks and high-stakes investigative interviews. In the present study, similar effects were elicited during a non-accusatory, low-stakes interview about a noncriminal event by using exposure to a false belief about group membership. Identifying how these effects translate into verbal and non-verbal behaviour during an investigative interview can help with understanding how this behaviour can potentially influence the outcome of the interview. Despite the extensive evidence in the literature, some law-enforcement officers still rely on observable behaviours to make decisions regarding the veracity and guilt of interviewees (see Vrij, 2008). The present study illustrates the erroneous nature of such judgements and highlights why legal decision-makers need to be cognisant of how expectations may influence some of the behaviour they observe. 


\section{REFERENCES}

Areh, I., Walsh, D., \& Bull, R. (2016). Police interrogation practice in Slovenia. Psychology, Crime \& Law, 22, 405419. doi:10.1080/1068616X.2015.1114113

Bargh, J. A., Chen, M., \& Burrows, L. (1996). Automaticity of social behavior: Direct effects of trait construct and stereotype activation on action. Journal of Personality and Social Psychology, 71, 230-244. doi:10.1037/00223514.71.2.230

Barrouillet, P., Bernardin, S., Portrat, S., Vergauwe, E., \& Camos, V. (2007). Time and cognitive load in working memory. Journal of Experimental Psychology, 33, 570585. doi: $10.1037 / 0278-7393.33 .3 .570$

Berggren, N., Richards, A., Taylor, J., \& Derakshan, N. (2013). Affective attention under cognitive load: Reduced emotional biases but emergent anxiety-related costs to inhibitory control. Frontiers in

Human Neuroscience, 7, $232-238$.

doi:10.3389/fnhum.2013.00188

Chen, M., \& Bargh, J. A. (1997). Nonconscious behavioral confirmation processes: The self-fulfilling consequences of automatic stereotype activation. Journal of Experimental Social Psychology, 33, 541-560. doi: $10.1006 /$ jesp.1997.1329

Clarke, C., \& Milne, R. (2001). National evaluation of the PEACE investigative interviewing course [Report No. PRAS/149]. London: Home Office.

Croizet, J. C., Despres, G., Gauzins, M. E., Huget, P., Leyens, J. P., \& Load, A. (2004). Stereotype threat undermines intellectual performance by triggering a disruptive mental load. Personality and Social Psychology Bulletin, 30, 721-731. doi:10.1177/0146167204263961 
Darley, J. M., \& Fazio, R. H. (1980). Expectancy confirmation process arising in the social interaction sequence. American Psychologist, 35, 867-881. doi:10.1037/0003066X.35.10.867

De Paulo, B. M., Lindsay, J. J., Malone, B. E., Muhlenbruck, L., Charlton, K., \& Cooper, H. (2003). Cues to deception. Psychological Bulletin, 129, 74 - 118. doi: 10.1037/0033-2909.129.1.74

Doherty-Sneddon, G., \& Phelps, F. G. (2005). Gaze aversion: A response to cognitive or social difficulty? Memory \& Cognition, 33(4), 727-733. doi:10.3758/BF03195338

Fazio, R. H., Effrein, E. A., \& Falender, V. J. (1981). Selfperceptions following social interaction. Journal of Personality and Social Psychology, 41, 232-242. doi:10.1037/0022-3514.41.2.232

Field, A. (2009). Discovering statistics using SPSS, third edition. London, UK: Sage Publications Ltd.

Global Research Deception Team. (2006). A world of lies. Journal of Cross

Cultural Psychology, 37, 60 - 74. doi: $10.1177 / 0022022105282295$

Gombos, V. A. (2006). The cognition of deception: The role of executive processes in producing lies. Genetic, Social and General Psychology Monographs, 132, 197-214. doi: 10.3200/MONO.132.3.197-214

Gudjonsson, G. H. (2003). The psychology of interrogations and confessions: A handbook. West Sussex, England: John Wiley \& Sons, Ltd.

Hayes, A. F., \& Krippendorff, K. (2007). Answering the call for a standard reliability measure for coding data. Communication Methods and Measures, 1, 77-89. doi: $10.1080 / 19312450709336664$

Hill, C., Memon, A., \& McGeorge, P. (2008). The role of confirmation bias in suspect interviews: A systemic evaluation. Legal and

Criminological Psychology, 13, 357-371.

doi: $10.1348 / 135532507 X 238682$ 
Holland, M. K., \& Tarlow, G. (1972). Blinking and mental load. Psychological Reports, 31, 119-127.

doi:10.2466/pr0.1972.31.1.119

Huberty, C. J., \& Morris, J. D. (1989). Multivariate analysis versus multiple univariate analyses. Psychological Bulletin, 105, 302-308. doi:10.1037/00332909.105.2.302

Inzlicht, M., Tullett, A. M., \& Legault, L. (2011). Lingering effects: Stereotype threat hurts more than you think. Social Issues and Policy Review, 5, 227-256. doi:10.1111/j.1751-2409.2011.01031.x

Kasl, S. V., \& Mahl, G. F. (1965). The relationship of disturbances and hesitations in spontaneous speech to anxiety. Journal of Personality and Social Psychology, 5, 425-433. Retrieved from https://www.ncbi.nlm.nih.gov/pubmed/14328758

Kassin, S. M. (2005). Does innocence put innocents at risk? American Psychologist, 60, 215-228. doi:10.1037/0003066X.60.3.215

Kassin, S. M., Drizin, S, A., Grisso, T., Gudjonsson, G. H., Leo, R. A., \& Redlich, A. D. (2009). Police induced confessions: Risk factors and recommendations. Law and Human Behavior, 34, 3-38. doi:10.1007/s10979009-9188-6

Kassin, S. M, Goldstein, C. C., \& Savitsky, K. (2003). Behavioral confirmation in the interrogation room: On the dangers of presuming guilt. Law and Human Behavior, 27, 187203. doi:10.1023/A:1022599230598

Kassin, S. M., Leo, R. A., Meissner, C. A., Richman, K. D., Colwell, L. H., Leach, A. M., \& La Fon, D. (2007). Police interviewing and interrogation: A self-report survey of police practices and beliefs. Law and Human Behavior, 31, 381-400. doi:10.1007/s10979-006-9073-5

Lamont, R. A., Swift, H. J., \& Abrams, D. (2015). A review and meta-analysis of age-based stereotype threat: Negative stereotypes, not facts, do the damage. Psychology and Aging, 30, 180-193. doi:10.1037/a0038586 
Leslie, S. J., Cimpian, A., Meyer, M., \& Freeland, E. (2015). Expectations of brilliance underlie gender distributions across academic disciplines. Science, 347, 262-265. doi: $10.1126 /$ science. 1261375

Mann, S., Vrij, A., \& Bull, R. (2002). Suspects, Lies, and videotape: An analysis of authentic high-stake liars. Law and Human Behavior, 26, 365-376. doi: $10.1023 / A: 1015332606791$

Mann, S., Vrij, A., \& Bull, R. (2004). Detecting true lies: Police officers' ability to detect suspect's lies. Journal of Applied Psychology, 89, 137-149. doi:10.1037/00219010.89.1.137

Mann, S., Vrij, A., Fisher, R. P., \& Robinson, M. (2008). See no lies, hear no lies: Differences in discrimination accuracy and response bias when watching or listening to police suspect interviews. Applied Cognitive Psychology, 22, 1062-1071. doi:10.1002/acp.1406

Meissner, C. A., Redlich, A., Bhatt, S., \& Brandon, S. (2012). Interview and interrogation methods and their effects on investigative outcomes. The British Journal of Criminology, 33, 325-352. doi:10.4073/csr.2012.13

Merton, R. K. (1948). The self-fulfilling prophecy. The Antioch Review, 8, 193-210. doi:10.2307/4609267

Mitchell, M. L. (2007). Research Design Explained. 6th Edition. Belmont, CA: Wadsworth Publishing.

Najdowski, C. J. (2012). Stereotype threat in police encounters: Why African Americans are at risk of being targeted as suspects (Doctoral dissertation, University of Texas at El Paso). Retrieved http://hdl.handle.net/10027/9525

Narchet, F. M., Meissner, C. A., \& Russano, M. B. (2011). Modeling the influence of investigator bias on the elicitation of true and false confessions. Law and Human Behavior, 35, 452-465. doi:10.1007/s10979-010-9257$\mathrm{x}$ 
Nelson, J. K. (2008). Laugh and the world laughs with you: An attachment perspective on the meaning of laughter in psychotherapy. Clinical Social Work Journal, 36, 41-49. doi:10.1007/s10615-007-0133-1

Pennington, C. R., Heim, D., Levy, A. R., \& Larkin, D. T. (2016). Twenty years of stereotype threat research. A review of psychological mediators. PLOS ONE, 11, e014648. doi:10.1371/journal.pone.0146487

Porter, S., \& ten Brinke, L. (2009). Dangerous decisions: A theoretical framework for understanding how judges assess credibility in the courtroom. Legal and Criminological Psychology, 14, 119-134. doi: $10.1348 / 135532508 \times 281520$

Powell, M. B. (2002). Specialist training in investigative and evidential interviewing: Is it having any effect on the behaviour of professionals in the field. Psychiatry, Psychology, and Law, 9, 44-55. doi: $10.1375 /$ pplt.2002.9.1.44

Rassin, E., Eerland, A., \& Kuijpers, I. (2010). Let's find the evidence: An analouge study of confirmation bias and criminal investigations. Journal of Investigative Psychology and Offender Profiling, 7, 231-246. doi:10.1002/jip.126

Rosenfield, M., Jahan, S., Nunez, K., \& Chan, K. (2015). Cognitive demand, digital screens and blink rate. Computers in Human Behavior, 51, 403-406. doi: $10.1016 /$ j.chb.2015.04.073

Rosenthal, H. E. S., Crisp, R. J., \& Suen, M-W. (2007). Improving performance expectancies in stereotypic domains: Task relevance and the reduction of stereotype threat. European Journal of Social Psychology, 37, 586597. doi:10.1002/ejsp.379

Schmader, T., \& Johns, M. (2003). Converging evidence that stereotype threat reduces working memory capacity. Journal of Personality and Social Psychology, 85, 440452. doi:10.1037/0022-3514.85.3.440 
Schmader, T., Johns, M., \& Forbes, C. (2008). An integrated process model of stereotype threat effects on performance. Psychological Review, 11, 336 - 356. doi: $10.1037 / 0033-295 X .115 .2 .336$

Schmader, T., Major, B., \& Gramzow, R. H. (2001). Coping with ethnic stereotypes in the academic domain: Perceived injustice and psychological disengagement. Journal of Social Issues, 57, 93-111. doi:10.1111/00224537.00203

Shawyer, A., Milne, B., \& Bull, R. (2009). Investigative interviewing in the UK. In T. Williamson, B. Milne, \& S. Savage (Eds.) International Developments in Investigative Interviewing. London, UK: Routledge.

Silverman, A. M., \& Cohen, G. L. (2014). Stereotypes and stumbling blocks: How coping with stereotype threat affects life outcomes for people with physical disabilities. Personality and Social

Psychology Bulletin, 40, 1330-1340. doi: $10.1177 / 0146167214542800$

Snyder, M. \& Haugen, J. A. (1994). Why does behavioral confirmation occur? A functional perspective on the role of the perceiver. Journal of Experimental Social Psychology, 30, 218-246. doi:10.1006/jesp.1994.1011

Snyder, M. \& Stukas Jr, A. A. (1999). Interpersonal processes: The interplay of cognitive, motivational, and behavioral activities in social interaction. Annual Review of Psychology, 50, 273-303. doi:10.1146/annurev.psych.50.1.273

Steele, C. M., \& Aronson, J. (1995). Stereotype threat and the intellectual test performance of African Americans. Journal of Personality and Social Psychology, 69, 797811. doi:10.1037/0022-3514.69.5.797

Vredeveldt, A., Hitch, G. J., \& Baddeley, A. D. (2011). Eyeclosure helps memory by reducing cognitive load and enhancing visualisation. Memory and Cognition, 39, 1253-1263. doi:10.3758/s13421-011-0098-8 
Vrij, A. (2008). Nonverbal dominance versus verbal accuracy in lie detection. Criminal Justice and Behaviour, 35, 13231336. doi: $10.1177 / 0093854808321530$

Vrij, A., \& Mann, S., (2001). Telling and detecting lies in a highstake situation: The case of a convicted murderer. Applied Cognitive Psychology, 15, 187-203. doi:10.1002/1099-0720(200103/04)15:2<187::AIDACP696>3.0.CO:2-A

Vytal, K., Cornwell, B., Arkin, N., \& Grillon, C. (2012). Describing the interplay between anxiety and cognition: From impaired performance under low cognitive load to reduced anxiety under high load. Psychophysiotherapy, 49, 842-852. doi: 10.1111/j.1469-8986.2012.01358.x

Wallen, E., Plass, J. L., \& Brunken, R. (2005). The function of annotations in the comprehension of scientific texts: Cognitive load effects and the impact of verbal ability. Educational Technology Research and Development, 53, 59-71. doi:10.1007/BF02504798

Wheeler, S. C., \& Petty, R. E. (2001). The effects of stereotype activation on behavior: A review of possible mechanisms. Psychological Bulletin, 127, 797-826. doi:10.1037/0033-2909.127.6.797 


\section{CHAPTER 4}

\section{Identifying Guilt Presumption through Question Phrasing and Word Abstraction}

Content from this chapter has been submitted for publication:

Adams-Quackenbush, N. M., Horselenberg, R., Vrij, A., Satchell, L. P., \& Van Koppen, P. (under review). Articulating guilt? The influence of guilt presumption on interviewer question phrasing and word abstraction.

\section{ABSTRACT}

Research has repeatedly shown that accusatory questions posed during an investigative interview are indicative of biased beliefs about suspect guilt. Linguistic research has shown that the verbs used in utterances can be indicative of biased beliefs about another person. In the present study, question type and the verbs used in question formulation were examined using non-police participants to explore the influence of guilt presumption on interview questions. The Linguistic Category Model (Semin \& Fiedler, 1991) was used to analyse verb abstraction and positive/ negative valence of the formulated interview questions. The findings revealed that interviewers who presumed guilt were more likely to formulate accusatory questions and use a higher verb abstraction with negative valence. The findings are in line with previous research in both guilt presumptive interviewing and linguistically biased language. However, this study expanded on previous research by allowing participants to come to their own conclusions regarding guilt, and to formulate their own questions for the suspect. The influence of detailed instruction for conducting an information-gathering interview using the foundation principles for PEACE was also examined. In line with previous findings, exposure to PEACE and its principles had no influence over the creation of accusatory questions or reducing guilt bias.

Keywords: Linguistic Category Model, linguistic bias, verb abstraction, investigative interview, question types 


\section{INTRODUCTION}

The investigative interview is one of the most important information gathering tools used by the police when trying to solve a crime (Walsh, 1994), and is especially helpful for obtaining statements that can be used as evidence in court. Thus, it is imperative that the interview is conducted in a way that will not call the validity or reliability of the statements into question. For that reason, factfinding or information-gathering type interviews are regarded as preferable to accusatory or confession driven interviews. Researchers and practitioners have made considerable efforts over the last two decades to improve information-gathering techniques for use in the investigative interview (see Meissner et al., 2012). However, more work is needed to understand the factors that may be detrimental to the interview outcomes, such as the guilt presumption and confirmation bias of the interviewing investigator. The aim of this study was to determine whether the language used in question formulation can help detect interviewer bias. In addition to question type, the specific words used by interviewers were evaluated together with interviewer guilt judgements.

\subsection{EXAMINING BIASES IN INFORMATION- GATHERING INTERVIEWS WITH SUSPECTS}

Police investigators must evaluate existing evidence and develop crime scenarios to determine who to question as a person of interest, or as a suspect in a case (Maguire, 2003). This part of the process can also be the source of problems in an investigation. Hypothesis construction can often lead to tunnel vision or investigator bias (Ditrich, 2015) where the investigating officer becomes so focused 
on confirming assumptions, they attend only to hypothesis confirming information (Eerland \& Rassin, 2010; Nickerson, 1998). Confirmation bias occurs in any type of interview. Even information-gathering and non-confession driven interviews can be influenced by the interviewer's preconceived ideas about interviewee involvement in the case, witness reliability, veracity judgements, and suspect guilt or innocence (Hill et al., 2008; Olson, 2013).

Preconceived judgements of suspect guilt are particularly problematic for the investigative interview because the interviewer can base decisions on biased beliefs or judgements (Ask \& Granhag, 2005; Smalarz, Madon, Yang, Gyull, \& Buck, 2016). Behavioural indicators of confirmation bias during the investigative interview may take the form of coercive interview tactics or guilt presumptive questioning (Kassin et al., 2003; Kassin et al., 2009; Meissner \& Kassin, 2004), which in turn perpetuates a biased chain of events (Darley \& Fazio, 1980). Moreover, third party observers who witness these interactions are also more likely to believe the interviewee is guilty (Hill, et al., 2008; Kassin et al., 2003; Narchet et al., 2011). There is also evidence that innocent interviewees who are asked more accusatory questions are more likely to falsely confess (see Kassin, 2005, 2014). However, research in this area has mainly been conducted on accusatory and confession driven interviews. There are very few studies that have examined the effects of biased interviewer judgements within an investigative interview where the objective was to gather information.

Police interviewers in the United Kingdom (UK) who are trained to conduct information-gathering 
interviews are instructed to: i) approach every interview without prejudice, ii) be prepared to believe any account they are given while exercising common sense, and ii) to set objectives to help them corroborate or disprove information (see College of Policing, 2016). These three items are part of seven principles that guide police interviewers and investigators. These principles are meant to facilitate an objective mindset for creating non-accusatory and information-gathering questions. The instruction to avoid prejudice intuitively seems as if it should safe guard against confirmation bias occurring; however, that is not always the case. Researchers have revealed that notwithstanding previous training, interviewers who are questioning suspects often revert to leading questions, inappropriate closed questions, and opinion or statement utterances (Griffith \& Milne, 2006; Heydon, 2012; Powell, Wright, \& Clark, 2009). However, current training practices and reduced supervision are often cited as the source of these errors (Scott, Tudor-Owen, Pedretti, \& Bull, 2014; Walsh \& Bull, 2010).

\subsection{THE LINGUISTIC CATEGORY MODEL (LCM) AS A TOOL TO DETECT BIASED LANGUAGE}

Linguistic bias is a systematic asymmetry in word choice used to transmit essential beliefs and expectancies about a person or social category (Beukeboom, 2012; Douglas \& Sutton, 2003). Researchers have shown that linguistic biases can be detected in the use of abstract language where a Perceiver judges and describes the actions of a Target as being indicative of stable characteristics (for a review see Wigboldus \& Douglas, 2007). Semin and Fiedler $(1988,1991)$ took an approach to language as a product of socio-cognitive actions and 
an influencer of socio-cognitive processes. To measure the level of bias conveyed through linguistic abstraction, Semin and Fiedler (1988) created a fourlevel classification model that differentiated verbs and adjectives within the interpersonal domain. The researchers eventually expanded this classification system to create the Linguistic Category Model (LCM; Semin \& Fiedler, 1991).

The LCM is a tool used to investigate the interplay between language and social cognition and is founded on three basic assumptions. First, language is considered a structure comprised of rules that are recognised by speakers who understand the language. Second, language is a complex skill; however, the speaker is not necessarily aware of the implications of his or her utterances on others (see Searle \& Vanderveken, 1985). Third, language is a medium for practical activity to enable communicative intent in a variety of social contexts. It is based on these assumptions that Semin and Fiedler posit - that the LCM transcends the semantics of a language. That is, the properties of the LCM apply across all aspects of language and are beyond consciousness (Douglas \& Sutton, 2008; Semin, 2011; Von Hippel, Sekaquaptewa, \& Vargas, 1997).

The LCM measures biased language through abstraction in terms of verbs and adjectives. Verbs can be used to describe actions (e.g., cheat, hurt, talk) or psychological states (e.g., like, hate, feel). Adjectives are used to describe the properties of a person's traits or perceived characteristics (e.g., aggressive, helpful, honest). Within the LCM categories, descriptive action verbs (DAV) are the first category. These verbs are the most concrete (i.e., kick, push, hug), refer to a single event, and 
are highly context bound. This means that the positive or negative perception of the action is completely circumstantial. Moving from most concrete to more abstract words, interpretive action verbs (IAV) are the next category. IAVs also refer to a single event, but they have a clear positive or negative valence and are perceived to be indicative of a person's internal motivations (e.g., cheat, influence, prepare). State verbs (SV) are the third category and do not refer to a single event, but instead refer to emotional or mental states with clear positive or negative connotations (e.g., hate, love, disagree). The final and most abstract category is adjectives (ADJ), which are used to describe a person using words that have positive or negative meanings and convey traits specific to that person (honest, pessimistic, reliable; see Semin \& Fiedler, 1988, 1991; Wigboldus \& Douglas, 2007).

As word abstraction increases, the likelihood of biased language also increases. More abstract words are seen to be more generalisable and indicative of the Target's stable traits (Brown \& Fish, 1983; Semin \& Fiedler, 1991). For example, the phrase John punched Ted is a more concrete term than John hurt Ted. Although punching seems to be a negative action, it is assessed within the context of the event, and thus the focus is on the specific situation. If John and Ted are boxing, this action is acceptable within the confines of the boxing match. However, if the punch was an act of physicality towards Ted in a business meeting, it becomes highly unacceptable. Nonetheless, the DAV 'to punch' is perceived as an action that occurred in an isolated event and not indicative of who John is as a person. Conversely, the IAV of John hurting Ted implies a negative 
connotation regardless of the situation (Semin, 2011; Semin \& Fiedler, 1991; Wigboldus \& Douglas, 2007). This event is further abstracted with the phrase John hates Ted. The SV 'hate' is understood within the confines of an individual's comprehension of what it means to hate (Semin, 2011); however, it also implies that hatred is a negative and stable trait of John, and thus, he is perceived as likely to be hateful towards others (Au, 1986, Brown \& Fish, 1983, Semin \& Fiedler, 1988). This assumption about John becomes more salient if he is explicitly described with the ADJ of 'hateful'.

Bias through verb abstraction has been demonstrated in research on person descriptions, stereotypic expectancies, and interpersonal interactions (for a review see Beukeboom, 2012; Wigboldus \& Douglas, 2007). Evidence in the literature suggests that linguistic choices when posing a question can convey whether the person posing the question has preconceived beliefs or ideas about the topic or the subject of the question (De Poot \& Semin, 1995; Douglas \& Sutton, 2006; Wigboldus, Spears, \& Semin, 2005); however, there has been little research of abstraction in investigative or forensic settings. Because it is an interpersonal interaction, verb abstraction is relevant to the investigative interview as a possible indicator of interviewer bias. For example, the phrases, "Explain to me why you killed Ted" and "Explain to me why you murdered Ted" both ask the respondent to provide details about why he or she ended Ted's life. However, the verb kill (DAV) is more concrete about the deed and implies nothing about motivation or the traits of the person who performed the action. Whereas the word murder (IAV) implies an unlawful 
action, with possibly some level of premeditation and motive. This last example is demonstrative of an epistemological bias called entailments (Recasens, Danescu-Niculescu-Mizil, \& Jurafsky, 2013). Although the word murder entails killing, by choosing the word murder the speaker is revealing an implicit assumption that the interviewee engaged in, and is capable of, the activities the word implies.

\subsection{CURRENT GAPS IN THE LITERATURE}

Within judicial contexts, the LCM has been used to detect specific language use in conscious case building endeavours (i.e., coding the Nuremburg Nazi Trials and Prosecution versus Defence closing statements; Schmid \& Fiedler, 1996, 1998). In those studies, it was found that defence attorneys elevated positive attributions to a higher level of abstraction, avoided direct references to their clients when making or recounting negative statements, projected any unavoidable negative references towards the Prosecution, and avoided any reference (if possible) to their client's group membership (e.g., criminal or Nazi). The LCM has also been used to show bias in simulated police-witness interview settings (Semin \& De Poot, 1997a); however, the LCM has not been previously utilised within police-suspect interviews to detect biased language.

In previous studies where the effects of guilt presumption in the investigative interview were examined, the interviewers did not generally formulate their own questions (e.g., Kassin et al., 2003). Additionally, researchers who have previously examined bias in questioning, have tightly controlled the types of questions that could be chosen by participants, in addition to the level of verb abstraction (e.g., Semin \& De Poot, 1997b). Whilst it 
is understandable why experimental controls were applied in those studies, there is little research to date that has investigated natural question formulation and guilt presumption within an interview context. Previous studies that examined guilt presumption have also manipulated the participant's perception of an event so that judgement biases were formed (e.g., Hill et al., 2008; Semin \& De Poot, 1997b). However, this approach does not answer questions about whether interviewers will naturally form biased guilt expectancies. Nor is it clear how a guilt bias may influence question formulation. Because bias is based in pre-existing beliefs, and confirmation bias is a subconscious confirmatory behaviour, there is a benefit to investigating whether participants will form their own biases. This will allow for an examination of whether those naturally formed biases influence language in the interview context.

\subsection{THE PRESENT STUDY}

The present study aimed to answer two research questions. The first was to determine if detailed instruction on performing an informationgathering interview would influence guilt judgements and question formulation (training question). The second examined how guilt assumption influenced question type and verb usage when non-police participants formulated questions (linguistic question). To investigate the training question the level of detail for creating information-gathering questions between groups was manipulated. This would show whether exposure to the principles of PEACE would influence question type and guilt judgements. Two hypotheses were formulated to test the question: 
1. The group exposed to PEACE principles would create less accusatory questions than the control group.

2. The group exposed to PEACE principles would attempt to remain objective and less likely than the control group to form a judgement of guilt or innocence.

These hypotheses are based on specific language included within the guiding principles of PEACE (College of Policing, 2016), and the participants were expected to conduct the interview in accordance with the instructions they received (i.e., to 'not approach any interview with prejudice' and to 'elicit reliable accounts from the interviewee'). Findings from Hill et al. (2008) suggested that exposure to PEACE training did not influence the amount of accusatory questions created by participants. However, the training was administered a bit differently in the present study, which may produce different findings. To test this question, exposure to the PEACE principles is the independent variable (IV), and question type and guilt judgements are the dependent variables (DV).

To examine the linguistic question, steps were taken to replicate previous research that demonstrated guilt presumption leads to more accusatory question choices in interviewers (see Hill et al., 2008; Kassin et al., 2003; Narchet et al., 2011). In the present study, that research was expanded upon to determine whether those findings held true when participants were left to formulate their own guilt assumptions. To establish whether interviewers who developed a guilt presumption used more biased language, the LCM was employed to assess abstraction levels and positive or negative valence of the words used by interviewers. For this 
question, guilt presumption was the IV, whereas question types and word abstraction were the dependent variables (DV). An additional three hypotheses were proposed:

3. Participants with a guilt presumption will create more accusatory questions than participants without guilt presumptions.

4. Participants who made judgements of guilt would use more abstract words in their questions than participants who did not make guilt judgements. This will be demonstrated by higher abstraction scores.

5. Participants who made judgements of guilt would use more negative words in their questions than participants who did not make guilt judgements.

For hypothesis \#4, whether the abstract words would be state verbs (SV) or adjectives (ADJ) was left purposefully unspecified. Each type of word serves a different purpose. If the participants used predominantly SVs, the focus shifts to the subject's behaviour, whereas the use of ADJ would create a focus on the subject's characteristics. Because the LCM has not been previously used to detect bias in investigative type settings with suspects, it can only be proposed that bias will be evident through abstraction scores. An exploratory analysis of the type of words used will also be conducted.

\subsection{METHOD}

4.5.1 Participants. Participants were invited to take part in an on-line study that would examine decision-making and the formulation of interview questions. Individuals were recruited using an on-line survey platform $(N=117)$. Participants completed the study wherever they chose to access the survey, 
which took approximately 30 minutes to complete. Prior to analysis, 10 participants' data were removed from the sample for not fully completing the study $\left(N=107 ; 69\right.$ females and 38 males; $M_{a g e}=33.39, S D$ $=14.50)$. Participants were randomly assigned to either an experimental group $(n=54)$ or a control group ( $n=53$ ) by the survey software. Those who signed up for the study through the psychology faculty participant pool $(n=25)$ were allotted one research participation credit. No incentive was offered to persons who signed up outside of the participant pool $(n=92)$. The Ethical Committee for Psychology at the participating university approved this study.

4.5.2 Procedure. Participants first provided informed consent and some demographic information (sex, age, and profession). Participants were informed that the researchers required their assistance to help formulate questions that could be asked to a person suspected of cheating on an academic task. Participants were then directed to a brief training to assist them with their question formulation.

To answer the training question, the experimental group was provided with detailed instructions on how to conduct an ethical interview. These instructions were based on the seven principles of investigative interviewing as outlined by the UK College of Policing. These principles were chosen because they provided expected conduct for interviewers who are using the PEACE framework (College of Policing, 2016). For simplicity, this is called the PEACE group. Exposing the control group to any accusatory or confession driven strategies was intentionally avoided. This step was taken to prevent 
confounding question type creation with an inflated number of accusatory questions. Instead, the control group was provided with six broad objectives for an information-gathering interview that were also gleaned from information found at the College of Policing website (see Appendix A). Participants in both groups were asked to complete a short quiz to ensure they understood the information presented to them.

Participants were then consecutively given five typical pieces of information regarding the case and asked to formulate two questions after each presentation of information (Appendix C), for a total of 10 questions. In the final step of the study, each participant indicated whether they felt the person of interest was guilty, innocent, or if they needed more information to decide. They also provided a confidence rating for their decision. Confidence ratings were reported on a scale of 1 to 5 with anchors at 1 (unconfident), 3 (neither unconfident or confident), and 5 (confident).

4.5.3 Coding procedure and reliability. This study yielded 1070 questions for coding on question type and word abstraction. In the case where there was more than one question present, only the first question was coded. For example, if the question read, "Why did you cheat? Were you feeling pressure?" the question was coded as accusatory (why did you cheat?), the verb "cheat" was coded as an IAV, and 'cheat' was assigned a negative valence. Auxiliary verbs were not coded.

Question type. To determine question type, the formulated questions were coded as neutral (nonaccusatory), other (defined as pleasantries or rapport-building), or accusatory questions. 
Accusatory questions were defined as overt accusations with the use of words that stated or implied cheating or dishonesty in questions or opinion statements. Twenty-nine percent $(n=310)$ of the questions were randomly selected and coded by three independent raters on the variable of question type. An overall Krippendorff's alpha for question type agreement indicated an $\mathrm{a}=0.876, \mathrm{CI}$ $=[.86, .88]$, which is considered moderately high reliability.

LCM coding. Word abstraction was coded from least to most abstract: Descriptive action verb (DAV $=1)$, Interpretive action verb (IAV = 2), State verb $(S V=3)$, and Adjectives (ADJ $=4$ ) as outlined in Semin and Fiedler (1991). Word valence was left to coder perception of the negative or positive connotations of the word. Questions and statements containing negative words were coded as -1 and positive words were coded as 1 . DAVs were excluded from this analysis as they have no negative or positive valence. To determine intercoder agreement, $58 \%(n=610)$ of the questions were randomly selected and coded by two independent raters on the verb abstraction variable, with an overall $a=0.962, C I=[.95 .97]$ and valence level $a$ $=0.986, \mathrm{CI}=[.97 .99]$. Both variables indicated $\mathrm{a}$ high level of reliability.

\subsection{RESULTS}

Only one participant considered the person of interest 'not guilty'; therefore, this data point was removed from further analysis involving guilt judgements, and guilt judgements became a binary variable (guilty vs. need more information).

4.6.1 Influence of Question Formulation Guidance. The PEACE group was predicted to create 
less accusatory questions than the control group to remain unbiased and objective as outlined in the guiding principles. A Mann Whitney test on question type categories revealed that the PEACE group did not create more neutral questions, and thus hypothesis \#1 was not supported: Accusatory $(U=$ $1154.50, p=.082, \delta=.18)$, Neutral $(U=1333.00$, $p=.534, \delta=.07)$, and Other $(U=1191.00, p=$ $.125, \delta=.17)$.

It was also predicted that the PEACE group would form less guilt judgements in an attempt to remain objective. A Chi-squared test to examine the difference between groups (control vs PEACE) on judgements (guilty vs need more information) indicated no overall difference between groups for guilt judgement $\mathrm{X}^{2}(1, N=105)=.02, p=.881, V=$ .02 , as both groups were evenly split between guilty (Control $=44 \%$, PEACE $=46 \%$ ) and needing more information (Control $=56 \%$ and PEACE $=55 \%$ ). Thus, hypothesis \#2 was not supported. Additionally, both the PEACE group $(M=2.78, S D=.81)$ and the control group $(M=2.94, S D=.81)$ reported moderate levels of confidence in their judgements on a 5 -point scale that did not significantly differ, $t(105)$ $=.934, p=.352$.

\subsubsection{Influence of guilt judgements on} question formulation. It was expected that regardless of level of detail in the interview instructions, guilt judgements would have an influence on question type, the level of verb abstraction, and the presence of negative words used in question formulation. Participants formulated their own guilt judgements, and this resulted in $44.3 \%$ ( $n$ $=47$ ) of the participants indicating that the person of interest was guilty, and $55.7 \%(n=59)$ reporting 
that they needed more information. Mann-Whitney $U$ tests revealed that accusatory questions were more present in guilty (Median $=5.00$, Mean Rank $=$ 62.66) than in need more information judgments (Median $=3.00$, Mean Rank $=45.17$ ); $U=909.00, p$ $=.003, \delta=.41$ and thus, hypothesis \#3 was supported.

Hypothesis \#4 was not supported as both the guilt presumptive group $(M=2.23, S D=.27)$ and the need more information group $(M=2.27, S D=$ .30) had similar abstraction scores, $t(104)=.687, p$ $=.49$. However, in an exploratory analysis to determine what types of words were predominantly used, a Mann-Whitney test revealed the number of state verbs varied between guilt judgements $(U=$ $1037.50, p=.013, \delta=.28$ ), with the participants who judged guilt using more state verbs (Median = 4.50, Mean Rank $=60.54$ ) than the need more information group (Median $=3.00$, Mean Rank $=$ 45.62). There was no difference in the types of questions created using DAVs $(U=1230.50, p=$ $.199, \delta=.14)$, ADJs $(U=1298.00, p=.301, \delta=.09)$, or IAVs $(U=1182.00, p=.112, \delta=.17)$.

When the number of positive and negative words used in question formation was analysed, no significant differences emerged. Participants who reported that they believed the person of interest was guilty used just as many negative words ( $M=-$ $3.12, S D=-2.33$ ) as participants who reported needing more information to make a judgement ( $M$ $=2.90, S D=2.73), t(104)=0.415, p=.68$. Therefore, hypothesis \# 5 was not supported.

\subsection{DISCUSSION}

The aim of the present study was to examine the influence of interview instructions and the 
presence of guilt presumption on question formulation. The questions formulated by participants who formed their own judgements of guilt were analysed for type of question (accusatory, neutral, or other), as well as indicators of bias and negative valence using the LCM (Semin \& Feidler, 1988, 1991). A review of the extant literature suggests that this is the first study that has investigated confirmation bias using naturally occurring guilt judgements in an experimental investigative interview setting with the LCM.

In the present study, interviewers who formed a presumption of guilt were more likely to create accusatory questions (Hill et al., 2008; Kassin et al., 2003, Narchet et al., 2011) despite being instructed to conduct information gathering interviews and being exposed to the guiding principles of the PEACE framework. These findings are in line with Hill et al. (2008) who also found that interviewers trained in information-gathering techniques still created accusatory questions when a guilt bias was present. When the types of words used by the participants was explored, those who presumed guilt most commonly chose abstract state verbs when formulating their questions. Although there were no differences between guilt judgements and abstraction scores, there was a difference in the type of words used. Participants who judged the person of interest guilty used more state verbs in their questions. State verbs are known to focus on behaviour and disambiguate to the sentence object, which removes the focus from the sentence subject (see Beukeboom, 2012; Douglas \& Sutton, 2006; Semin, 2011). 
Some theories on linguistic abstraction posit that language choices are generally produced unconsciously (see Semin \& Fiedler, 1991; Von Hippel et al., 1997), there is also literature that suggests language choices can be intentionally used to influence beliefs in others when speakers are consciously choosing their words. In two experiments, Douglas and Sutton (2008) demonstrated that communicators could inhibit biased word choices when they were aware of their bias and given the opportunity to choose their words carefully (Study 1 and 2). With those findings in mind, I posit that the participants in the present study may have also employed a similar strategy. That is, participants were told they needed to formulate questions to determine whether the person of interest completed the task honestly or not, and they were given as much time as needed to create their questions. It is possible that participants may have deliberately phrased their questions to appear objective and non-accusatory. However, when taken together with their guilt judgements the participant's underlying motivations may have been revealed. Although choosing the abstract words would have been an unconscious behaviour, the basic theory of linguistic bias proposes that it is this unconscious behaviour that reveals the speaker's true beliefs (see Beukeboom, 2012; Semin, 2011). However, further examination into the relationship between abstraction and confirmatory motivations is warranted.

4.7.1 Methodological considerations. A shortcoming in the present study may be the use of non-police interviewers, who were not fully trained in information-gathering strategies. Before requesting 
the time and resources of law enforcement personnel, it was prudent to test the phenomena and the bias detection tools (LCM) in a controlled environment. Another limitation of the present study is the forced question preparation and lack of interview interaction. In practice, police interviewers would not generally prepare questions in such a manner (College of Policing, 2016). A few key questions and themes would be identified, and subsequent questions would depend on responses to previous questions and the ongoing dialogue. This means that most utterances produced during the interview are spontaneous and may be influenced by factors such as the immediate situation, suspect behaviour, and previous questions and responses. Each of those factors may influence the words used by the interviewer, and thus, findings may differ in an applied setting. Further research is needed to determine whether the findings in the present study hold true in interactive environments and real policesuspect interviews.

Finally, an interviewer's guilt presumptions may change over the course of the interview, which could also change the language used by interviewers. Therefore, further investigation is needed to determine whether interviewers adjust their judgements over the course of the interaction, and what information they use during the interview to inform their perceptions of guilt and any related judgements.

\subsection{CONCLUSION}

Accusatory questions remain the most significant indicator of guilt bias; however, language abstraction may also be a good indication of guilt presumptive judgements when specific word usage is 
examined. If the language chosen in questions is not a conscious decision made by interviewers, subtle language cues can provide insight to the underlying beliefs about suspect guilt. However, the findings in the present study prompt questions about whether biases detected in language are indicative of underlying confirmatory motives, and how word choices influence suspect responses. It also remains unclear whether high levels of verb abstraction (SV and ADJ) are consciously used to effectively soften or mask an accusatory, yet information-gathering question. More applied research is needed before any definite conclusions can be drawn. 


\section{REFERENCES}

Ask, K., \& Granhag, P. A. (2005). Motivational sources of confirmation bias in criminal investigations: The need for cognitive closure. Journal of Investigative Psychology and Offender Profiling, 2, 43-63. doi:10.1002/jip.19

$\mathrm{Au}, \mathrm{T} . \mathrm{K}$. (1986). A verb is worth a thousand words: The causes and consequences of interpersonal events implicit in language. Journal of Memory and Language, 25, 104122. doi: $10.1016 / 0749-596 \times(86) 90024-0$

Beukeboom, C. J. (2012). Mechanisms of linguistic bias: How words reflect and maintain stereotypic expectancies. In J. Laszlo, J. Forgas, \& O. Vincze (Eds.). Social Cognition and Communication. New York: NY: Psychology Press.

Brown, R. \& Fish, D. (1983). The psychological causality implicit in language. Cognition, 14, 237-273. doi.10.1016/0010-0277(83)90006-9

College of Policing. (2016, January 11). Investigative Interviewing. Retrieved from https://www.app.college.police.uk/appcontent/investigations/investigative-interviewing

Darley, J. M., \& Fazio, R. H. (1980). Expectancy confirmation process arising in the social interaction sequence. American Psychologist, 35, 867-881. doi:10.1037/0003066X.35.10.867

De Poot, C., \& Semin, G. R. (1995). Pick your verbs with care when you formulate a question! Journal of Language and Social Psychology, 14, 351-368. doi:10.1177/0261927X950144002

Ditrich, H. (2015). Cognitive fallacies and criminal investigations. Science and Justice, 55, 155 - 159. doi: $10.1016 /$ j.scijus.2014.12.007

Douglas, K. M., \& Sutton, R. M. (2003). Effects of communication goals and expectancies on language abstraction. Journal of Personality and Social Psychology, 84, 682-696. doi:10.1037/00223514.84.4.682 
Douglas, K. M., \& Sutton, R. M. (2006). When what you say about others says something about you: Language abstraction and inferences about describers' attitudes and goals. Journal of Experimental Social Psychology, 42, 500-508. doi:10.1016/j.esp.2005.06.001

Douglas, K. M., \& Sutton, R. M. (2008). Could you mind your language? An investigation of communicators' ability to inhibit linguistic bias. Journal of Language and Social Psychology, doi: $10.1177 / 0261927 \times 07313655$

Eerland, A., \& Rassin, E. (2010). Biased evaluation of incriminating and exonerating (non)evidence. Psychology, Crime \& Law, 18, 351-358. doi: $10.1080 / 1068316 X .493889$

Griffiths, A., \& Milne, R., (2006). Will it all end in tiers? Police interviews with suspects in Britain. In T. Williamson (Ed.), Investigative Interviewing, (pp. 167-189). Abingdon, UK: Willan Publishing.

Heydon, G. (2012). Helping the police with their enquires: Enhancing the investigative interview with linguistic research. The Police Journal, 85, 101-122. doi:10.1350/pojo.2012.85.2.581

Hill, C., Memon, A., \& McGeorge, P. (2008). The role of confirmation bias in suspect interviews: A systemic evaluation. Legal and Criminological Psychology, 13, 357-371. doi: $10.1348 / 135532507 \times 238682$

Kassin, S. M. (2005). Does innocence put innocents at risk? American Psychologist, 60, 215-228. doi:10.1037/0003066X.60.3.215

Kassin, S. M. (2015). The social psychology of false confessions. Social Issues and Policy Review, 9, 25-51. doi: $10.1111 /$ sipr.12009

Kassin, S. M., Drizin, S, A., Grisso, T., Gudjonsson, G. H., Leo, R. A., \& Redlich, A. D. (2009). Police induced confessions: Risk factors and recommendations. Law and Human Behavior, 34, 3-38. doi:10.1007/s10979009-9188-6 
Kassin, S. M, Goldstein, C. C., \& Savitsky, K. (2003). Behavioral confirmation in the interrogation room: On the dangers of presuming guilt. Law and Human Behavior, 27, 187203. doi:10.1023/A: 1022599230598

Maguire, M. (2003). Criminal investigation and crime control. In T. Newburn (Ed.), Handbook of policing. Devon, UK: Willan

Meissner, C. A., \& Kassin, S. (2004). You're guilty, so just confess! In G.D. Lassiter (ed) Interrogations, Confessions, and Entrapment (pp. 85-106). Boston, MA: Springer.

Meissner, C. A., Redlich, A., Bhatt, S., \& Brandon, S. (2012). Interview and interrogation methods and their effects on investigative outcomes. The British Journal of Criminology, 33, 325-352. doi:10.4073/csr.2012.13

Narchet, F. M., Meissner, C. A., \& Russano, M. B. (2011). Modeling the influence of investigator bias on the elicitation of true and false confessions. Law and Human Behavior, 35, 452-465. doi:10.1007/s10979-010-9257$\mathrm{x}$

Nickerson, R. (1998). Confirmation bias: A ubiquitous phenomenon in many guises. Review of General Psychology, 2, 175-220. doi:10.1037/10892680.2.2.175

Olson, E. A. (2013). "You don't expect me to believe that, do you?" Expectations influence recall and belief of alibi information. Journal of Applied Social Psychology, 43, 1238-1247. doi: $10.1111 /$ jasp. 12086

Powell, M., Wright, R., \& Clark, S. (2010). Improving the competency of police officers in conducting investigative interviews with children. Police Practice and Research, 11, 211-226. doi:10.1080/15614260902830070

Recasens, M., Danescu-Niclescu-Mizil, C., \& Jurafsky, D. (2013). Linguistic models for analyzing and detecting biased language. Association for Computational Linguistics, 51, 1650-1659. Retrieved from http://www.aclweb.org. 
Schmid, J., \& Fiedler, K. (1996). Language and implicit attributions in the Nuremberg trials analysing prosecutors' and defense attorneys' closing speeches. Human Communication Research, 22, 371-398. doi: 10.1111/j.1468-2958.1996.tb00372.x

Schmid, J., \& Fiedler, K. (1998). The backbone of closing speeches: The impact of prosecution versus defense language on judicial attributions. Journal of Applied Social Psychology, 28, 1140-1172. doi:10.1111/j.15591816.1998.tb01672.x

Scott, A. J., Tudor-Owen, J., Pedretti, P., \& Bull, R. (2014). How intuitive is PEACE? Newly recruited police officres'plans, interviews and self-evaluatrions. Psychiatry, Psychology and Law, 22, 355-367. doi: $10.1080 / 13218719.2014 .949397$

Searle, J. R., \& Vanderveken, D. (1985). Speech acts and illocutionary logic. In D. Vanderveken (Ed.) Logic, Thought and Action: Logic Epistemology and the Unity of Science, vol 2. Dordrecht, NL: Springer.

Semin, G. R. (2011). Language and social cognition. In F. Strack and J. Forster (eds.). Social Cognition - the Basis of Human Interaction. New York, NY: Psychology Press.

Semin, G. R., \& De Poot, C. (1997a). Bringing partiality to light: Question wording and choice as indicators of bias. Social Cognition, 15, 91-106. doi:10.1521/soco.1997.15.2.91

Semin, G. R., \& De Poot, C. (1997b). The Question-Answer paradigm: You might regret not noticing how a question is worded. Journal of Personality and Social Psychology, 73, 472-480. doi:10.1037/00223514.73.3.472

Semin, G. R., \& Fiedler, K. (1988). The cognitive functions of linguistic categories in describing persons: Social cognition and language. Journal of Personality and Social Psychology, 54, 558-568. doi:10.1037/00223514.54.4.558 
Semin, G. R., \& Fiedler, K. (1991). The linguistic category model, its bases, applications and range. European Review of Social Psychology, 2, 1-30. doi: $10.1080 / 14792779143000006$

Smalarz, L., Madon, S., Yang, Y., Guyll, M., \& Buck, S. (2016). The perfect match: Do criminal stereotypes bias forensic evidence analysis? Law and Human Behavior, 40, 420-429. doi:10.1037/lhb0000190

Von Hippel,W., Sekaquaptewa, D., \& Vargas, P. (1997). The linguistic intergroup bias as an implicit indicator of prejudice. Journal of Experimental Social Psychology, 33, 490-509. doi:10.1006/iesp.1997.1332

Walsh, M. (1994). Interactional styles in the courtroom: An example from Northern Australia. In J. Gibbons (ed.), Language and the Law (pp. 217-233). UK: Pearson Education Group.

Walsh, D., \& Bull, R. (2010). What really is effective in interviews with suspects? A study comparing interviewing skills against interviewing outcomes. Legal and Criminological Psychology, 15, 305-321. doi: $10.1348 / 135532509 \times 463356$

Wigboldus, D. H. J., \& Douglas, K. M. (2007). Language, expectancies and intergroup relations. In $\mathrm{K}$. Fiedler (Ed.), Social communication. New York, NY: Psychology Press.

Wigboldus, D. H. J., Spears, R., \& Semin, G. R. (2005). When do we communicate stereotypes? Influence of the social context on the linguistic expectancy bias. Group Processes \& Intergroup Relations, 3, 215-230. doi: $10.1177 / 1368430205053939053939$ 


\section{CHAPTER 5}

\section{Articulating Guilt? The Influence of Guilt Presumption on Interviewer and Interviewee Behaviour}

Content from this chapter has been submitted for publication: Adams-Quackenbush, N. M., Horselenberg, R., Vrij, A., Satchell, L. P., \& Van Koppen, P. (under review). Articulating guilt? The influence of guilt presumption on interviewer question phrasing and word abstraction.

\section{ABSTRACT}

Evidence in the literature suggests that accusatory questions posed during an investigative interview is an indicator of guilt presumption. However, there may be more to a question than just the accusatory nature. Linguistic research has demonstrated that the use of abstract words in questions can indicate bias on the part of the speaker through increasingly abstract language. This study expands on the findings presented in Chapter 4 by using the Question-Answer Paradigm (QAP; Semin, Rubini, \& Fiedler, 1995) to determine if guilt presumption and word abstraction influenced interviewee responses. The QAP theory suggests that more abstract language in the question will shift the focus of the response to be interviewee focused. This creates the illusion that the interviewee is more involved with or is central to the events in question. The present study, examined guilt presumption and word abstraction in a mock investigative interview. Changing guilt presumptions over the course of the interview and motivations for question choices were also explored. The findings suggest that interviewers who presumed guilt were more likely to formulate accusatory questions and to use higher linguistic abstraction (ADJ). Questions were also phrased in a manner that prompted the suspect to respond with themselves as the focus - regardless of context. Over the course of the interview, interviewers who presumed guilt were less likely to change their views and were more likely to report using behavioural cues to solidify their guilt presumptions.

Keywords: Question-Answer Paradigm, linguistic abstraction, guilt presumption, confirmation bias, investigative interview. 


\section{INTRODUCTION}

In the countries that use information-gathering techniques to conduct investigative interviews with suspects, interviewers are encouraged to obtain investigation relevant information (IRI), and to 'discover the truth' as opposed to seeking a confession (see Baldwin, 1993; College of Policing, 2016; Hoekendijk \& Van Beek, 2015). However, even in information-gathering frameworks, the methods used by interviewers to achieve those objectives are subjective and influenced by the interviewer's guilt beliefs (Hill, Memon, \& McGeorge, 2008). That can result in a situation where the interview becomes less about fact or truth finding and more about proving the interviewer's beliefs to be true (Kassin, Goldstein, \& Savitsky, 2003). When an interviewer exhibits belief confirming behaviours (i.e., confirmation bias), researchers have demonstrated that the types of questions posed become more accusatory (Kassin et al., 2003; Olson, 2013), the tactics become more coercive (Narchet, Meissner, \& Russano, 2011., 2011), and the obtained information is framed to justify the guilt belief (see Ditrich, 2015; Eerland \& Rassin, 2010). However, little is known about how guilt presumption may influence the language used by interviewers when questioning suspects, how it may influence suspect responses, and whether an interviewer's guilt presumption changes over the course of the interview. The current experimental study examined all these factors, as well as any influence on the mock suspect's responses and perceptions of the interview. 


\subsection{INVESTIGATIVE INTERVIEW: INTERVIEWER JUDGEMENT AND SUSPECT BEHAVIOUR}

Police interviewers have the difficult job of extracting IRI from people who are suspected of committing a crime. For obvious reasons, those suspects may not be eager to share their intimate knowledge of the event so not to incriminate themselves. Conversely, the suspect may not have been involved in the event, and thus, genuinely has no information to offer. It is the latter type of suspect that has the most to lose should they not be able to convince an interviewer of their innocence. Unfortunately for this type of suspect, the fact they are being questioned indicates that the police have strong reason to believe they are involved (O'Brien, 2007). That puts the innocent suspect at a disadvantage as now they must try to change the interviewer's beliefs, which is a difficult task (Arkes, 1991; Frey, 1982; Ross, Lepper, \& Hubbard, 1975).

Police officers who use information gathering frameworks (e.g., PEACE and GIS: General Interview Strategy; Van Amelsvoort, Rispens, \& Grolman, 2010), are trained to obtain a free narrative from the suspect and then to ask questions designed to elicit needed IRI (College of Policing, 2016; Van der Sleen, 2009). Although officers are also trained to remain objective when gathering information, there is evidence in the literature that officers allow their beliefs to influence the interview (e.g., Chaplin \& Shaw, 2016; Lilienfeld \& Landfield, 2008). That is, an interviewing officer who strongly believes in the suspect's guilt may inadvertently conduct the interview in a way to prove guilt as opposed to gathering case relevant information. 
Guilt presumption can influence interviewer's assessments of statement veracity (e.g., Mann, Vrij, \& Bull, 2004) and alibi believability (Olson, 2013). In this situation, the interviewer's belief in the suspect's guilt renders all information provided by the suspect that is contrary to that belief as attempts at deception (Meissner \& Kassin, 2002). The interviewer who believes the suspect is lying may become more adversarial and frustrated (Walton, 2003) and apt to increase interrogative pressure or apply more coercive interview tactics to elicit the responses and information he or she seeks (Kassin \& Gudjonsson, 2004). Over various studies, guilt presumption has been shown to increase the number of accusatory questions asked during an investigative interview with a suspect (see Hill et al., 2008; Kassin et al., 2003; Narchet et al., 2011). Thus, accusatory questions seem to be the most consistent indicator of interviewers' beliefs that a suspect is guilty.

The type of question an interviewer uses to gather information is also crucial to the investigative interview. For example, if the question is accusatory (e.g., Why did you assault your partner?), a suspect may simply use the opportunity to deny involvement. If the questions are phrased in a way that the suspect constantly feels the need to defend him or herself then gathering IRI halts and the interviewer is left collecting a number of denials. Moreover, easily influenced, or vulnerable suspects may be inclined to respond in a way they believe is desired by the interviewer, which can lead to eventual false confessions (see Kassin, 2005, 2015). Using an information-gathering type of question (e.g., Describe the events that lead to the altercation with your partner) is likely to get the suspect talking. The 
description of events may also give the interviewer more information to work with for further questioning. Conversely, if the interviewer believes in the suspect's guilt, the suspect's elaborated answer could provide the interviewer with more support for his or her guilt presumption. For those reasons, further examination of the influence of question type on interviewee responses is warranted.

\subsection{QUESTION TYPE AND LANGUAGE ABSTRACTION AS POSSIBLE INDICATORS OF BIAS}

There is evidence in the literature that the types of words used when describing others (Beukeboom, 2012; Wigboldus \& Douglas, 2007) can identify a speaker's bias. The most common tool used to identify linguistic bias is the Linguistic Category Model (LCM; Semin \& Fiedler, 1988, 1991). The LCM measures biased language through the linguistic abstraction of verbs and adjectives. Verbs are used to describe actions (e.g., cheat, hurt, talk) or psychological states (e.g., like, hate, feel), whilst adjectives are used to describe the properties of a person's traits or perceived characteristics (e.g., aggressive, helpful, honest). As the word abstraction increases, the likelihood of biased language also increases as more abstract words are seen to be more generalisable and suggestive of the Target's stable traits (Brown \& Fish, 1983; Semin \& Fiedler, 1991).

The LCM has also allowed researchers to examine the influence of language abstraction on the responses to questions. Over several independent studies, researchers have found verb abstraction in questions can influence the subject focus in responses (see De Poot \& Semin, 1995; Semin, 
Rubini, \& Fiedler, 1995). For example, when posing interview questions to a person suspected of wrongdoing, the subject of the sentence is predominantly the interviewee, indicated by the personal pronoun 'you'. However, the use of state verbs can remove the focus from the interviewee (you) to the thing or person in the sentence that is being acted upon. For example: 'Did you cheat on the test?' contains an action verb with focus on subject, whereas 'Did you dislike the test?' contains a state verb and a focus on an object. Whilst both example questions are posed to the interviewee and contain the word 'you' to indicate the subject who took the actions of cheating or disliking, the question containing the state verb clearly put the focus on the test as opposed to the interviewee. Semin and colleagues (1995) have coined this phenomenon the Question-Answer Paradigm (QAP).

Although the QAP response pattern is not a deliberate linguistic tactic used by interviewers (see Searle \& Vanderveken, 1985; Semin, 2011), it can become problematic in the context of confirmation bias during the investigative interview. For example, Semin and De Poot (1997b) investigated the effects of verb abstraction on the perceptions of response focus in an experimental interview setting using the QAP. They extracted details from police sexual assault interview transcripts and formulated a fictitious case, along with pre-fabricated questions for the study. They also manipulated participants' perception of the complainant in the case (i.e., trusted, did not trust, or neutrality towards the victim). Participants who were primed to distrust the victim consistently chose questions where the response was more likely to put the victim as the 
subject of focus in the answer. Conversely, participants who were primed to trust the victim chose questions that were more likely to put the suspect as the focus in the reply. In sum, participants were found to choose investigative questions that were congruent with their expectancies of the victim (i.e., either a blameless person who was assaulted or a person whose behaviour somehow provoked the assault).

If the findings of Semin and De Poot (1997b) are applied to the police-suspect interview, we may see that a guilt bias prompts questions that elicit certain responses. That is, replies that place the suspect as the focus and the instigator of any action. Those types of responses can create the perception that the suspect was more involved in the events than they were. That type of responding could also be viewed by a biased interviewer as evidence to support the interviewer's guilt presumption. This type of outcome would be problematic for innocent suspects or suspects that perhaps played only a minor role in the crime.

\subsection{OUTSTANDING QUESTIONS IN THE LITERATURE}

At first glance the underlying theories of the LCM and QAP may seem counterintuitive to those familiar with interviewing tactics and accusations. First, accusatory questions are often associated with direct assertations that use concrete language. But, this may not be the case in interview environments where the officers are generally trained to employ ethical tactics and engage the suspect with professionalism. In those situations, accusations may be phrased using linguistic hedging that softens the accusation and masks the bias (see Recasens, 
Danescu-Niclescu-Mizil, \& Jurafsky, 2013). Douglas and Sutton (2008) found that when people were given time to consider their language choices, speakers could inhibit biased language. When speakers were not given the opportunity to consider additional information, however, they were unable to inhibit biased language. Douglas and Sutton concluded that when speakers do not intend to be biased, language abstraction could work against them in exposing their underlying beliefs. Those conclusions also need to be tested in an interactive interview setting.

A second counterintuitive aspect of the QAP concerns phrasing questions in a manner that prompts the suspect to put themselves as the focus of the answer. This may seem like the entire purpose of a police-suspect interview. However, if formulating questions in this manner is motivated by an underlying guilt bias, the interviewer could be unconsciously manipulating the suspect's responses to confirm his or her beliefs that the suspect was involved. Even if every question and response does not implicate the suspect in the commission of the crime, it is possible that increased focus on the suspect will give the perception of increased involvement (Semin \& De Poot, 1997a).

Other gaps in the extant literature involve the underlying motivations of interviewers to create specific questions. Although interviewers may be unaware of their guilt bias and resulting behaviour, they may be able to provide some insight to their cognitions by explaining what they hope to achieve by posing certain questions to a suspect. For example, whether the question was intended to confirm or falsify a pre-existing guilt presumption. 
Changing perceptions of guilt over the course of the interview is yet another area where there have been no previous investigations. Measuring guilt presumption at different time intervals throughout the interview may allow insight to any behavioural factors that influence subsequent guilt judgements.

\subsection{THE PRESENT STUDY}

The present study had four aims. The first aim was to replicate and expand on previous research findings that have demonstrated an increased use of accusatory questions in interviewers who held a presumption of guilt. In the present study, interviewers will be asked to justify what they hoped to achieve with each question. Taking this exploratory step may provide some insight into the interviewer's motivations (i.e., confirm or falsify guilt beliefs; Jonas, Schultz-Hardt, Frey, \& Thelen, 2001). In the second aim, the LCM and the QAP will be used to analyse the questions and responses in an investigative interview context. The third aim was to explore whether interviewers changed their guilt presumptions over the course of the interview. The final aim was to explore the interviewees' perceptions of the questions asked and their desire to cooperate with the interviewer.

To achieve these research aims, four hypotheses were tested, and three exploratory analyses were conducted:

1. Interviewers with an initial guilt presumption would create more accusatory questions than interviewers who presumed innocence or needed more information.

2. Interviewers who held an initial presumption of guilt would formulate questions with more 
abstract language than interviewers who did not hold an initial presumption of guilt.

3. Regardless of interviewer guilt presumptions, questions that contained action verbs where the suspect is the subject, or that contained a state verb where the suspect is the object, will produce more suspect focused responses in line with the QAP response pattern.

4. Interviewees would perceive the control questions to be more accusatory in their wording and meaning than the interviewer formulated questions. It is suspected this may be due to the more direct (although nonaccusatory) nature of those questions.

For the exploratory analysis, the interviewer's justifications for creating his or her questions, changing guilt judgements, and the factors that may have influenced those changes were examined.

\subsection{METHOD}

5.5.1 Participants. Non-police participants were recruited for a study that investigated decisionmaking during an investigative interview setting. Partial deception was employed so not to prime the participants to prepare in advance, and to avoid introducing experimental expectancy effects. The participants were only informed that they would each take on a separate role for the study and in the final phase they would come together for a video recorded interview. Thirty-three participant pairs $(N=66)$ were recruited from a university in the UK through the faculty on-line recruitment system and faculty wide advertisement $\left(M_{a g e}=20.32, S D=3.41\right.$; Males $=13$, Females $=53)$. Individuals who signed up for the 
study through the psychology faculty participant pool $(n=58)$ were allotted one research participation credit and a $£ 5$ gift card to a local grocery. People who signed up outside of the participant pool $(n=8)$ received the $£ 5$ gift card. The gift card was not mentioned in the advertisement as it was needed to motivate the participants during the study. Participants were randomly assigned to an interviewer or an interviewee role by a coin flip.

5.5.2 Materials. Tasks and environment. A blind taste-testing task was used to allow for a situation where the interviewee would be left alone and could choose to complete the task honestly, or to cheat (see Appendix D for a complete taste-testing procedure). The taste test and the interview portion of the study took place in an interview suite equipped with a table for the tasting task, and a computer to record questionnaire responses and to present the stimulus material. To record the interaction, an HD video camcorder was used to film the interview from the interviewer's point of view, and there were multiple surveillance cameras and a sound recording system to capture the interview from multiple angles. The interviewers completed their tasks in a separate research cubicle that contained a table and computer to record their responses.

Control questions. Three control questions were created for the second round of interviewing. These questions were neutral information-gathering questions categorised as action verb sentences:

1. Can you tell me in detail what you did while the researcher was out of the room?

2. Did you think about lifting the covers to look at the brand names? 
3. Have you spoken to anyone who has already completed this study?

5.5.3 Procedure. Both participants were met by two research assistants and taken to a research cubicle to sign consent forms. A coin flip decided tasks, and only one participant pair's tasks were decided due to an aversion to apple juice. One participant stayed in the cubicle with a research assistant and became the interviewer. The other participant was taken to the interview suite with the other researcher and became the interviewee. Questionnaires, ratings, tasks, and judgements were completed independently. However, the participants came together for the two interview portions during the study.

Interviewer procedure. The interviewer was informed of their role and told that the other participant (the interviewee) was taking part in a task where they could choose to complete it honestly or cheat. The interviewer was told that their job would be to review some details about what the interviewee had done, and to formulate five interview questions to find out whether the task was completed honestly or not. They were told that if their questions prompted the interviewee to give a lot of information, they would be rewarded with a $£ 5$ gift card.

After completing demographic questions, interviewers were all exposed to the same detailed ethical principles of investigative interviewing (see Appendix A). They were then given case facts under the guise that those were direct observations of the interviewee's performance. This was a falsehood told to make the interviewer believe they were receiving unique case information. All facts of the case were adapted from the vignette used in the study 
presented in Chapter 4 to ensure consistent information upon which guilt judgements and question formulation were made. The interviewer then formulated five questions and justified what they hoped to achieve with each one. They then indicated whether they thought the interviewee was guilty, not guilty, or if they needed more information (Judgement 1), along with a confidence rating on a 5 -point scale $(1=$ not confident, $5=$ Extremely confident). Finally, the interviewer was asked to choose their best three of the five questions to ask the interviewee.

The interviewer was then taken to the interview suite to conduct the interview. Once completed, the interviewers returned to the research cubicle, and provided a second guilt judgement (Judgement 2) and a confidence rating. Interviewers were then told they should seek additional information from the interviewee using three questions the researchers had formulated for them (control questions). The interviewer was taken back to the suite for the second round of interviewing. After the interview was complete, they returned to the cubicle and provided the final guilt judgement (Judgement 3 ) and confidence ratings.

Interviewee procedure. Upon arriving at the interview room, the research assistant took the interviewee to a table set up seemingly outside the range of the surveillance cameras (there is one discreet camera that captures the entire room). The interviewee was informed that they would be questioned by the other participant about the tasks they were about to do. The interviewee then performed a taste test of apple juice and was asked to note the distinctions between the different juices 
and to try to memorise the brand (Appendix D). The researcher told the interviewee if they could match at least five out of the six juices to the brands, they would receive a $£ 5$ gift card.

Interviewees then repeated the test, but with the juice bottles covered and randomised. During this time the researcher left the room under the pretence of checking on the progress of the other participant. Leaving the interviewee alone provided him or her with an opportunity to cheat or complete the task honestly. It also aligned with the information given to the interviewer that the interviewee was left alone for 3-minutes and may or may not have cheated. The surveillance camera footage indicated that all participants completed the task honestly, and thus, were considered innocent interviewees.

The interviewee was informed that the other participant had some questions to ask them about the task, and there was a possibility of more than one interview. The interviewee was then questioned twice by the other participant (interviewer). After each round of questioning, the interviewee provided a 5point rating of the questions from Strongly Disagree (1) to Strongly Agree (5): (i) These questions were worded in an accusatory manner, (ii) I found these questions shocking, (iii) The question made me want to cooperate with the interviewer, (iv) The questions made me feel like I was being accused of something, and $(v)$ The questions were clear in their meaning.

End of study and debriefing. Once both participants were finished with the final questionnaires, they were brought together in the research cubicle and given full disclosure about the true nature of the study. The interviewee was informed that they were secretly videotaped the 
entire time and were asked to sign an additional consent form acknowledging this and giving permission to use their data. All participants consented.

\subsubsection{Coding procedure. Question type and} linguistic coding. To determine question type, the formulated questions were coded as neutral (nonaccusatory), other (defined as pleasantries or rapport-building), or accusatory questions. Verb abstraction was coded in accordance to the classification outlined by Semin and Fielder (1988, 1991; see Linguistic coding in Chapter 4). The videotaped interviews were transcribed verbatim and the questions were coded using the LCM for verb category. The interviewee responses were coded for locus of causality (self or other) using the QAP. That is, when the question was phrased with an action verb and the interviewee referred to themselves as the subject it was coded as self-focused. The same held true when the question was phrased with a state verb and the response has the interview as the object of the response (see Semin \& De Poot, 1997a).

Identifying justification themes. The interviewers were asked to justify why they chose to create each question and what they hoped to learn with the responses. Interviewers were also asked to justify their guilt judgements at time two (judgement 2 ) and time three (judgement 3 ). These justifications were grouped into main themes and subthemes for each (Braun \& Clarke, 2006). 
5.5.5 Inter-coder reliability. This study yielded 165 formulated questions and 99 questions that were chosen by interviewers for presentation to the interviewees. Forty percent of the formulated questions were randomly selected $(n=66)$ and coded by two independent raters on the variables of question type and verb abstraction. Krippendorff's alpha indicated an overall agreement of $\mathrm{a}=0.95, \mathrm{CI}$ $=[.92, .98]$ and $\mathrm{a}=0.91, \mathrm{CI}=[.89, .93]$ respectively. Both variables indicated high levels of agreement.

\subsection{RESULTS}

5.6.1 Influence of Judgements on Question Formulation. In the initial judgement, only one interviewer considered the interviewee 'not guilty'; therefore, this data point was removed and judgement 1 became a binary variable (guilty vs. need more information). A logistic regression analysis was completed to predict the initial interviewer bias using abstraction scores and question types (accusatory and neutral) as predictors. Our first hypothesis was supported as the predictors significantly explained the variance in interviewer bias, $X^{2}(3, N=30)=10.653, p=.014$, Nagelkerke's $R^{2}=.428$. The model accurately predicted bias at $78.8 \%$ ( $88.5 \%$ for unbiased and $42.9 \%$ for biased). Only the accusatory questions made a significant contribution to the prediction $W$ $(33)=5.218, p=.02,95 \%$ CI $[1.27,24.37]$. Abstraction scores and neutral questions were not significant predictors of bias (see Table 3.1).

5.6.2 Influence of Verb Abstraction on Questions and Responses. When the frequency of the verbs used were evaluated, a Mann Whitney test revealed that biased interviewers (Mean Rank = 
23.50) were likely to use more adjectives (highest level of abstraction) in their questions than unbiased interviewers (Mean Rank $=14.88 ; U=36.0, p=$ $.007, \delta=.53$ ) and these findings support our second hypothesis. A test of equality of proportions showed that interviewers constructed questions using more action verbs $(67 \%)$ than state verbs $(33 \%)$ overall, $\mathrm{X}^{2}(1, N=107)=23.56, p<.001,95 \% \mathrm{CI}=[.21$, $.48]$, and the responses followed the predicted QAP pattern, which supports our third hypothesis. In action verb questions where interviewees were placed in the grammatical subject position ( $83 \%)$ as opposed to the object position (20\%), they replied with themselves as the response focus, $X^{2}(1, N=$ $107)=78.84, p<.001,95 \% \mathrm{CI}=[.51, .74]$. When the question was phrased with a state verb and the interviewee was implicated in the grammatical object position (37\%) as opposed to the subject position $(13 \%)$, they also focused the response on themselves, $X^{2}(1, N=107)=14.93, p<.001,95 \%$ $\mathrm{CI}=[.12, .36]$.

\subsubsection{Interviewee perceptions of}

questioning. Partial support was found for the fourth hypothesis. That is, interviewees would find the control questions both accusatory in wording and overall theme. There was no significant difference between the interviewer questions $(M=3.75, S D=$ 1.99) and the control questions $(M=4.12, S D=$ $0.59)$ for how accusatory the interviewee found the question wording $t(32)=-1.55, p=.129,95 \% \mathrm{CI}=$ $[-.83, .11]$; however, a t-test revealed that there was a statistically significant difference between the questions in whether the interviewee felt like they were being accused of something. Interviewees felt less accused during the interviewer questions ( $M=$ 
$1.81, S D=1.04)$ than during the control questions $(M=2.84, S D=1.07), t(32)=-3.97, p<.001, d=$ $.98,95 \%$ CI $=[-2.08,-0.32]$. Additionally, interviewees reported that they wanted to cooperate more during the interviewer questions $(M=4.03, S D$ $=.88)$ than during the control questions $(M=2.66$, $S D=1.42), t(32)=-4.05, p<.001, d=1.14,95 \%$ $\mathrm{CI}=[-1.88,-.41]$. There were no significant differences between perceived clarity $[t(32)=3.49$, $p=.73$ ] of the questions, or whether the questions were surprising, $t(32)=1.46, p=.12$.

\subsubsection{Guilt judgements across the}

interview. A test of equality of proportions revealed a statistically significant difference in the number of initial guilt judgements $(n=6)$ and interviewers who needed more information $(n=26), \mathrm{X}^{2}(1, N=32)=$ $21.89, p=.00$. The frequencies also indicated that very few interviewers who began with a biased guilt judgement changed their minds as there was no difference in the proportions, $X^{2}(1, N=32)=2.66$, $p=.10$. The movement from the initial judgements to the final judgements was mainly from the interviewers who 'need more information'. Of those interviewers, $31 \%(n=8)$ changed the judgement to guilty by the end of the interview. The proportions for those who needed more information were significantly different from judgement 1 to judgement $3, X^{2}(1, N=32)=21.89, p=.001$. The one interviewer who initially assumed innocence also changed to a judgement to guilt in the end, and the proportions for the final judgement showed an almost even split between guilt and innocence (see Table $5.2)$. 
Table 5.1

Logistic regression table for predictors of bias (abstraction and question type) in question formulation.

\begin{tabular}{|c|c|c|c|c|}
\hline \multirow{2}{*}{$\begin{array}{l}\text { Bias } \\
\text { Predictors }\end{array}$} & \multirow[b]{2}{*}{$\mathrm{B}(\mathrm{SE})$} & \multicolumn{3}{|c|}{ 95\% Confidence Interval } \\
\hline & & Lower & $\begin{array}{l}\text { Odds } \\
\text { Ratio }\end{array}$ & Upper \\
\hline Constant & $\begin{array}{l}-10.03 \\
(4.77)\end{array}$ & & & \\
\hline Abstraction & $\begin{array}{c}2.71 \\
(1.78)\end{array}$ & .459 & 15.11 & 500.07 \\
\hline $\begin{array}{l}\text { Accusatory } \\
\text { Questions }\end{array}$ & $\begin{array}{c}1.72 \\
(.752)\end{array}$ & 1.276 & $5.57 *$ & 24.37 \\
\hline $\begin{array}{l}\text { Info-gathering } \\
\text { Questions }\end{array}$ & $\begin{array}{c}.14 \\
(.549)\end{array}$ & .393 & 1.15 & 3.37 \\
\hline
\end{tabular}

5.6.5 Interviewer insights. Three main themes in the interviewer justifications were identified: (i) Falsification/ Alternative Scenarios, (ii) Confirmation of Guilt, and (iii) Informationgathering. In the 165 original questions created, there were four questions that did not fit any of the three main themes and these were removed from the analysis $^{6}$ ( $\left.n=162\right)$ Proportionally, confirmatory motivations were divided with biased (guilty and not guilty) interviewers reporting $48 \%$ and neutral interviewers (need more information) reporting $42 \%$ of questions were to confirm preconceived ideas about guilt, $X^{2}(1, N=161)=1.00, p=.31$. Therefore, the hypothesis that bias would influence interviewers to show more confirmatory motivations was not supported. When the proportions for the

6 These questions involved rapport building and pleasantries with the interviewee, but there were no clear justifications as to why the interviewer chose to ask them. 
other motivational themes were explored, biased and neutral interviewers both reported $42 \%$ informationgathering motivations. Biased interviewers reported $10 \%$ of falsifying justifications, and objective interviewers reported $16 \%$.

When the justifications for the questions the interviewers chose to ask were examined $(n=99)$, a similar trend was found. Biased interviewers choose $43 \%$ confirmatory, $57 \%$ information-gathering, and no $(0 \%)$ falsifying questions. This was comparable with neutral interviewers who chose $41 \%$ confirmatory, 50\% information gathering, and $9 \%$ falsifying questions. Two subthemes also emerged in the justifications for the asked questions. First, a subtheme of expectation management (9\%) was found solely in the information-gathering justifications. Here the interviewer indicated that asking the question a certain way could make the interviewee feel less accused and more likely to offer information. The second subtheme was behavioural observation $(21 \%)$. Here the interviewers made some mention of observing specific physical behaviours to help them draw conclusions. This subtheme mainly occurred in confirmatory justifications $(71.4 \%)$, and less frequently in information-gathering justifications $(23.8 \%)$ and falsifying justifications (4.8\%).

Interviewers were also asked to justify their subsequent judgements throughout the interview (see Table 5.3). At judgement 2 (after the interviewers asked their own questions), two clear themes emerged for interviewers who judged the interviewee as guilty or innocent. Some interviewers made explicit references to the interviewees' behaviour as cues that guided subsequent guilt 
judgements (e.g., posture, confusion/ consistency about sequence of events, lack/ abundance of eye contact), whereas others cited quality of the interviewee's verbal utterances (e.g., unsure/ confident language, perceived evasiveness/ openness in answering, and presence/ lack of speech disturbances). There was also a small proportion of interviewers who made innocent judgements (4\%) whose justifications did not fit within the main themes. Because those justifications differed, they were classified as 'other'. All interviewers that judged that they needed more information $(100 \%)$ at this time point cited that there was just not enough information available to make a judgement. This was not classified as a theme as it was descriptive of the judgement category.

\section{Table 5.2}

Proportions (\%) of guilt judgements over the course of the interview sessions. $T 1$ is pre-interview judgement, $T 2$ is judgement after the interviewer asked own questions, and T3 is judgement after control questions.

\begin{tabular}{llll}
\hline $\begin{array}{l}\text { Judgement } \\
(N=33)\end{array}$ & T1 & T2 & T3 \\
\hline Guilty & $18.2^{\mathrm{a}}$ & 27.3 & 39.4 \\
Not Guilty & $3.0^{\mathrm{bc}}$ & 45.4 & $42.4^{\mathrm{c}}$ \\
Need More Info & $79.8^{\mathrm{abd}}$ & 27.3 & $18.2^{\mathrm{d}}$ \\
\hline
\end{tabular}

Note: proportions with the same postscripts are significantly different from each other at $p<.001$

At judgement 3 (after the interviewers asked control questions), the same two themes emerged for interviewers that judged the suspects as guilty or innocent (behaviour and utterances). However, some 
of the interviewers who judged 'need more information' also cited the same two themes as reasons they could not make a guilt judgement $(49 \%)$. In those instances, the interviewers reported conflicting behaviours, or the believability of some answers versus others, as reasons they could not make a guilt judgement. From this category of guilt judgements, $51 \%$ of interviewers reported simply not having enough information to decide.

Across both time points interviewers reported using behaviour and utterances to inform their guilt judgements. However, interviewers who made guilt judgements at each time point based their decisions primarily on behavioural cues (66.3 and $61.5 \%$ respectively). Interviewers who made judgements of innocence mainly used the interviewee's answers to guide their judgements (63 and 71.4\%). Moreover, at the final guilt judgement, those interviewers who were undecided, based on the interviewee's behaviour and utterances mainly, reported behaviour as the primary source of their confusion (61.8\%; Table 5.3).

\subsection{DISCUSSION}

The present study aimed to replicate previous findings on the relationship between guilt presumption and accusatory questioning as well as word abstraction and language use within an interactive interview environment. The study also aimed to explore the interviewer's justifications for creating their questions, whether interviewers changed their judgements over the course of the interview, and the factors that may have influenced those changes.

Consistent with the findings reported in Chapter 4 and by previous researchers (e.g., Hill et 
al., 2008, Kassin et al., 2003; Narchet et al., 2011), formulating accusatory questions was a significant predictor of also reporting a judgement of guilt. An additional finding from the study reported in Chapter 4 was also replicated. In that study, interviewers who assumed guilt were more likely to use abstract words when formulating questions. Interviewers with a guilt bias specifically used more adjectives, which are the most abstract of the words measured by the LCM (Semin \& Fiedler, 1988, 1991; Wigboldus \& Douglas, 2007). Adjectives are the most indicative of biased language because they show that the speaker believes that the word used, describes the subject and is generalisable to the subject's characteristics across specific events (Semin 2011; Semin \& Fiedler, 1991).

Table 5.3

Proportions (\%) of factors (behaviour or utterances) that guided guilt judgements across the interview as well as the change in guiding factors between both time points.

\begin{tabular}{lll}
\hline$(n=99)$ & Behaviour & Utterances \\
\hline Judgement T2 & & \\
\hline Guilty & 66.3 & 33.7 \\
Innocent & 33 & 63 \\
Need More Info & 0 & 0 \\
\hline Judgement T3 & \\
\hline Guilty & 61.5 & 38.5 \\
Innocent & 28.6 & 71.4 \\
Need More Info & 30.0 & 19.0 \\
\hline \multicolumn{2}{l}{ Change in guiding factor between time points T2 and T3 } \\
\hline Guilty & $(7.3)$ & 16.7 \\
Innocent & $(15.3)$ & 13.5 \\
\hline
\end{tabular}

The way interviewers phrased their questions was found to have influenced the subject of the 
interviewee's response. Unlike the previous study, the questions in the present study were not analysed in the context of guilt presumption. This was due to the findings in Chapter 4 that indicated guilt judgement had no bearing on whether the interviewer used concrete or abstract words (only specific word type was influenced, e.g., DAV, IAV, SV or ADJ). The same pattern occurred in the present study as most of the interviewers, regardless of guilt presumption, used more action verbs and concrete language overall. When an interviewer used action words (concrete language) and placed the interviewee in the subject position of the question, the interviewee replied with themselves as the subject of the response (Semin \& De Poot, 1997a). The same held true when state and descriptive words (abstract language) were used in the question, but the interviewee was placed in the object position. The important take away message from this finding is that the interviewee's responses can be manipulated by the interviewer's word choices.

Evidence in the literature suggests that the way action and state verbs are used can effectively manipulate perceptions about who initiates an event, or in this case, the level of involvement ( $\mathrm{Au}, 1986$; Brown \&Fish, 1983). Word choices may not be a conscious decision when it comes to word abstraction (Semin, 2011); however, if the interviewer holds a presumption of guilt, the interviewee's responses could be perceived as confirmation of that belief. Considering that over $30 \%$ of interviewers judged innocent interviewees guilty based on the interviewee's responses to questions this finding warrants further investigation as to what exactly 
interviewers were basing those judgements on within the response.

Despite their responses being manipulated by the interviewers' word choices, the interviewees did not perceive the interviewers' questions to sound or feel accusatory. This contrasted with the interviewees' perceptions of the control questions. Although interviewees reported no differences in how accusatory the wording was between the sets of questions, they indicated the control questions felt more accusatory. The disparity found between ratings for interviewer formulated versus control questions may be a direct result of the actual question regardless of verb type. That is, the direct (but non-accusatory) approach of the control questions left nothing to the imagination. It was clear that the interviewer was seeking information about whether the task was completed honestly, whereas the interviewer formulated questions may have been more ambiguous in purpose. Thus, the interviewee may have thought the interviewer was simply trying to find out more information about the taste-testing task. Interviewees also reported that they didn't want to cooperate as much when asked the control questions. Although the feelings of non-cooperation were not predicted, it makes sense that questions perceived as accusatory would prompt this response as overt accusations may make an interviewer appear less empathetic, which has a direct influence of cooperation and IRI obtained (Oxburgh, Ost, \& Cherryman, 2012)

When guilt judgements over the course of the interview were examined, most interviewers who initially made a guilty judgement also made a final judgement of guilt. When examining the proportions 
of the judgements throughout the interview, the belief in the interviewee's guilt or innocence became more polarised with the final judgement. This was due to many interviewers who initially reported needing more information eventually deciding guilt or innocence by the end of the interview. A possible explanation for the shift in guilt judgements during the interviews may come from a need for cognitive closure where the interviewer felt it was necessary to make a clear-cut decision or judgement about the interviewee's guilt (Ask \& Granhag, 2005). Those seemingly objective interviewers in the initial and second judgments may have harboured a biased belief about guilt. Then, by the end of the interview, those who needed more information made a decision that may have been congruent with their original, but unreported judgement (Nickerson, 1998).

Further support for this conclusion can be seen in the analysis of question justification. Interviewers revealed three motives for creating their questions: to look for alternative scenarios, to confirm their beliefs, or to gather more information. Some interviewers who claimed to need more information also provided bias confirming justifications for their questions. If this group was expected to be purely neutral; thus, more hypothesis falsifying and information-gathering explanations would have been anticipated. It is also important to note that the interviewers were not made to feel like they needed to make a judgement.

5.7.1 Methodological considerations. The current study has some limitations that should be considered when interpreting the findings. One shortcoming is the lack of experience in formulating interview questions. When interviewers were tasked 
with asking their questions to interviewees, most of the questions were concretely worded, but may not have been constructed to retrieve the desired information, which was to determine whether the tasting task was completed honestly. The lack of solid information elicited when using their own questions may help to explain the shift in guilt judgements over the course of the interview. That is, during judgement 2, most of the interviewers reported needing more information; however, after asking the more focused control questions, there was almost an even split between guilt and innocence. Perhaps it was then that the interviewers received the information they needed to decide; however, this remains unknown.

Another limitation is the use of non-police interviewers, specifically those trained in information-gathering strategies. The relevance a specialised police sample would bring to this research, namely a wealth of job experience, unique heuristics, specialised training, and motivation to do one's job is essential to fully understand whether the findings replicate in practice. However, before the time and resources of law enforcement personnel is requested, it is prudent to test the phenomena, and the bias detection tools, in more controlled environments. Furthermore, the low stress and low motivation to be believed may have influenced the interviewees' responses. Although attempts were made to increase stress levels with the presence of video recording equipment, and to increase motivation with the gift card reward, none of these interventions compare to the real-world stressors associated with being questioned by the police. 
Finally, the LCM is a reliable tool for detecting underlying bias in a variety of situations, however, it may have some limitations in applied settings such as police-suspect interviews. Due to the labourintensive process of coding interview transcripts, the LCM could only be used retrospectively to detect possible guilt presumption or other biases. It would be impossible to notice language abstraction in realtime, and thus, any harm caused through subjecting a suspect to a biased interview would have already occurred. For this reason, it is imperative that researchers continue to explore other venues of detecting bias in real-time, or to find ways to reduce or prevent guilt presumptions from influencing the interview. Although the findings in the present study have demonstrated that subtle language cues may directly influence the outcome of the interview, more applied research is needed before any definite conclusions can be drawn. The logical next steps for this area of research would be to observe the interview interaction between actual police officers and suspects. This may provide additional, or even different, linguistic cues. For that reason, this research is headed toward testing our assumptions with such a sample.

\subsection{CONCLUSION}

The present study demonstrated how question type and word choices can reveal clues to an interviewer's underlying guilt presumptions towards a subject. The findings also suggest that question phrasing can influence the respondent to place themselves as the subject in their answers. That type of responding may give the impression that the suspect was involved in the event (even if they were not) and could increase the perception of 
involvement by keeping the focus on the suspect. If such questions are formulated by an interviewer who has a presumption of guilt, the suspect's responses may inadvertently influence the responder to confirm these beliefs. In short, if an interviewer is looking for confirmation of their guilt judgement, that is exactly what they may receive. 


\section{REFERENCES}

Arkes, H. R. (1991). Costs and benefits of judgement errors: Implications for debiasing. Psychological Bulletin, 110, 486-498. doi:10.1037/0033-2909.110.3.486

Ask, K., \& Granhag, P. A. (2005). Motivational sources of confirmation bias in criminal investigations: The need for cognitive closure. Journal of Investigative Psychology and Offender Profiling, 2, 43-63. doi:10.1002/jip.19

$\mathrm{Au}, \mathrm{T} . \mathrm{K}$. (1986). A verb is worth a thousand words: The causes and consequences of interpersonal events implicit in language. Journal of Memory and Language, 25, 104122. doi: $10.1016 / 0749-596 \times(86) 90024-0$

Baldwin, J. (1993). Police interviewing techniques: Establishing truth or proof? The British Journal of Criminology, 33, 325-352. doi:10.1093/oxfordjournals.bjc.a048329

Beukeboom, C. J. (2012). Mechanisms of linguistic bias: How words reflect and maintain stereotypic expectancies. In J. Laszlo, J. Forgas, \& O. Vincze (Eds.). Social Cognition and Communication. New York: NY: Psychology Press.

Brown, R. \& Fish, D. (1983). The psychological causality implicit in language. Cognition, 14, 237-273. doi.10.1016/00100277(83)90006-9

Chaplin, C., \& Shaw, J. (2016). Confidently wrong: Police endorsement of psych-legal misconceptions. Journal of Police and Criminal Psychology, 31, 208-216. doi: $10.1007 /$ s11896-015-9182-5

College of Policing. (2016, January 11). Investigative Interviewing. Retrieved from https://www.app.college.police.uk/appcontent/investigations/investigative-interviewing

De Poot, C., \& Semin, G. R. (1995). Pick your verbs with care when you formulate a question! Journal of Language and Social Psychology, 14, 351-368. doi: $10.1177 / 0261927 X 950144002$

Ditrich, H. (2015). Cognitive fallacies and criminal investigations. Science and Justice, 55, 155-159. doi: $10.1016 /$ j.scijus.2014.12.007 
Douglas, K. M., \& Sutton, R. M. (2008). Could you mind your language? An investigation of communicators' ability to inhibit linguistic bias. Journal of Language and Social Psychology, 27, 123-139. doi: $10.1177 / 0261927 \times 07313655$

Eerland, A., \& Rassin, E. (2010). Biased evaluation of incriminating and exonerating (non)evidence. Psychology, Crime \& Law, 18, 351-358. doi: $10.1080 / 1068316 X .493889$

Frey, D. (1982). Different levels of cognitive dissonance, information seeking, and information avoidance. Journal of Personality and Social Psychology, 43, 1175-1183. doi: $10.1037 / 0022-3514.43 .6 .1175$

Hill, C., Memon, A., \& McGeorge, P. (2008). The role of confirmation bias in suspect interviews: A systemic evaluation. Legal and Criminological Psychology, 13, 357-371. doi: $10.1348 / 135532507 X 238682$

Hoekendijk, J., \& Van Beek, M. (2015). The GIS-model: A Dutch approach to gather information in suspect interviews. Investigative Interviewing: Research and Practice, 7, 19. Retrieved from http://www.iiirg.org/journal

Jonas, E., Schultz-Hardt, S., Frey, D., \& Thelen, N. (2001). Confirmation bias in sequential information search after preliminary decisions: An expansion of dissonance theoretical research on selective exposure to information. Journal of Personality and Social Psychology, 80, 557-571. doi:10.1037//00223514.80.4.557

Kassin, S. M. (2005). Does innocence put innocents at risk? American Psychologist, 60, 215-228. doi:10.1037/0003066X.60.3.215

Kassin, S. M, Goldstein, C. C., \& Savitsky, K. (2003). Behavioral confirmation in the interrogation room: On the dangers of presuming guilt. Law and Human Behavior, 27, 187203. doi:10.1023/A: 1022599230598 
Kassin, S. M., Gudjonsson, G. H. (2004). The psychology of confessions: A review of the literature and issues. Psychological Science in the Public Interest, 5, 33 - 67. doi: $10.1111 /$ j.1529-1006.2004.00016.x

Lilienfeld, S. O., \& Landfield, K. (2008). Science and pseudoscience in law enforcement: A user-friendly primer. Criminal Justice and Behaviour, 35, 1215-1230. doi: $10.1177 / 0093854808321526$

Mann, S., Vrij, A., \& Bull, R. (2004). Detecting true lies: Police officers' ability to detect suspect's lies. Journal of Applied Psychology, 89, 137-149. doi:10.1037/00219010.89.1.137

Meissner, C. A., \& Kassin, S. M. (2002). "He's guilty!": Investigator bias in judgements of truth and deception. Law and Human Behavior, 26, 469 - 480. doi:10.1023/A:1020278620751

Narchet, F. M., Meissner, C. A., \& Russano, M. B. (2011). Modeling the influence of investigator bias on the elicitation of true and false confessions. Law and Human Behavior, 35, 452-465. doi:10.1007/s10979-010-9257$\mathrm{x}$

Nickerson, R. (1998). Confirmation bias: A ubiquitous phenomenon in many guises. Review of General Psychology, 2, 175-220. doi:10.1037/10892680.2.2.175

O'Brien, B. (2007). Confirmation bias in criminal investigations: An examination of the factors that aggravate and counteract bias (Doctoral dissertation). Retrieved from https://deepblue.lib.umich.edu/handle/2027.42/12652 6

Olson, E. A. (2013). "You don't expect me to believe that, do you?" Expectations influence recall and belief of alibi information. Journal of Applied Social Psychology, 43, 1238-1247. doi: $10.1111 /$ jasp. 12086 
Oxburgh, G., Ost, J., \& Cherryman, J. (2012). Police interviews with suspected child sex offenders: does use of empathy and question type influence the amount of investigation relevant information obtained? Psychology, Crime \& Law, 18, 259-273. doi:10.1080/1068316X.2010.481624

Recasens, M., Danescu-Niclescu-Mizil, C., \& Jurafsky, D. (2013). Linguistic models for analyzing and detecting biased language. Association for Computational Linguistics, 51, 1650-1659. Retrieved from http://www.aclweb.org.

Ross, L., Lepper, M. R., \& Hubbard, M. (1975). Perseverance in self-perception and social perception: Biased attributional Processes in the debriefing paradigm. Journal of Personality and Social Psychology, 32, 880892. doi: $10.1037 / 0022-3514.32 .5 .880$

Searle, J. R., \& Vanderveken, D. (1985). Speech acts and illocutionary logic. In D. Vanderveken (Ed.) Logic, Thought and Action: Logic Epistemology and the Unity of Science, vol 2. Dordrecht, NL: Springer.

Semin, G. R. (2011). Language and social cognition. In F. Strack and J. Forster (eds.). Social Cognition - the Basis of Human Interaction. New York, NY: Psychology Press.

Semin, G. R., \& De Poot, C. (1997a). Bringing partiality to light: Question wording and choice as indicators of bias. Social Cognition, 15, 91-106. doi: $10.1521 /$ soco.1997.15.2.91

Semin, G. R., \& De Poot, C. (1997b). The Question-Answer paradigm: You might regret not noticing how a question is worded. Journal of Personality and Social Psychology, 73, 472-480. doi:10.1037/00223514.73.3.472

Semin, G. R., \& Fiedler, K. (1988). The cognitive functions of linguistic categories in describing persons: Social cognition and language. Journal of Personality and Social Psychology, 54, 558-568. doi:10.1037/00223514.54.4.558 
Semin, G. R., \& Fiedler, K. (1991). The linguistic category model, its bases, applications and range. European Review of Social Psychology, 2, 1-30. doi:10.1080/14792779143000006

Semin, G. R., Rubini, M., \& Fiedler, K. (1995). The answer is in the question: The effect of verb causality on locus of explanation. Personality and Social Psychology Bulletin, 21, 834-841. doi: $10.1177 / 0146167295218006$

Van Amelsvoort, A., Rispens, I., \& Grolman, H. (2010). Handleiding verhoor. Amsterdam, NL: Reed Business.

Van der Sleen, J. (2009). A structured model for investigative interviewing of suspects. In R. Bull, T. Valentine, \& T. Williamson (Eds.), Handbook of Psychology of Investigative Interviewing. Chichester, UK: John Wiley \& Sons.

Walton, D. (2003). The interrogation as a type of dialogue. Journal of Pragmatics, 35, 1771-1802. doi: 10.1016/S0378-2166(02)00201-1

Wigboldus, D. H. J., \& Douglas, K. M. (2007). Language, expectancies and intergroup relations. In $\mathrm{K}$. Fiedler (Ed.), Social communication. New York, NY: Psychology Press. 


\section{PART II:}

Exploring Confirmation Bias in Applied Settings 


\section{CHAPTER 6}

\section{Where Bias Begins: A snapshot of police officers' beliefs about the investigative interview with suspects}

This manuscript in its present form is accepted for publication and available online at the Journal of Police and Criminal Psychology:

Adams-Quackenbush, N. M., Horselenberg, \& van Koppen, P. J. (2018, in press). Where bias begins: a snapshot of police officer's beliefs about factors that influence the investigative interview with suspects. Journal of Police and Criminal Psychology. https://doi.org/10.1007/s11896-018-9301-1

\section{ABSTRACT}

The aim of the current study was to obtain a snapshot of police officer's beliefs about factors that may influence the outcome of the investigative interview with suspects. We created a 26-item survey that contained statements around three specific themes: best interview practices, confessions and interviewee vulnerabilities. Police officers $(N=101)$ reported their beliefs on each topic by indicating the level of agreement or disagreement with each statement. The findings indicated that this sample of officers held beliefs that were mostly consistent with the literature. However, many officers also responded in the mid-range (neither agree nor disagree) which may indicate they are open to developing literature-consistent beliefs of the topics. Understanding what officers believe about factors within the investigative interview may have implications for future training. It may also help explain why some officers do not consistently apply best practices (i.e. strong counterfactual beliefs) versus officers who reliably apply literature-consistent practices to their interviews (i.e. knowledge-consistent beliefs).

Keywords: Investigative interview, Beliefs, Knowledge, Bias, Survey 


\section{INTRODUCTION}

Decades of research has demonstrated that despite the best efforts of police trainers and academics, police interviewers do not always adhere to training on how to conduct an investigative interview, nor do officers always employ best practices to elicit optimal information from victims, witnesses and suspects (see Powell, 2002). Researchers have examined police interview training programs (Clarke \& Milne, 2001; McGurk, Carr, \& McGurk, 1993) and procedures (Blackstock et al., 2014) to improve interview performance and safeguard suspects' legal rights. Whilst those research endeavours have resulted in valuable insights for improving training programs, and creating interview processes and frameworks (e.g., PEACE; Milne \& Bull, 1999), the underlying problem may be less structural and more individual. That is, it could be that police officers rely more on personal or pseudoscientific beliefs concerning the investigative interview and less on their training and education in certain interview situations.

In this paper, we discuss how prior beliefs may disrupt the process of implementing training into evidence-based practice during the investigative interview. We then examine the knowledge of a sample of police officers regarding factors that can influence the investigative interview with suspects (i.e. training, practices, interviewee vulnerabilities and confessions), and compare the officers' beliefs to empirical evidence in the psycho-legal literature. We posit that officers who disagree with scientifically tested findings within the psycho-legal literature may be basing their responses on personal or pseudoscientific beliefs. 


\subsection{BELIEFS AND KNOWLEDGE}

$A$ belief is the acceptance that something is true, without empirical evidence to support it (Richardson, 1996; Shermer, 2011) ${ }^{7}$. Beliefs can be obtained through information transfer (i.e. communicated by media or another person who holds the belief) or created within the individual's mind as a tool to understand incomprehensible phenomena or personal experiences (Shermer, 2002). Moreover, the longer a belief is held, the stronger the belief becomes (Burns, 2004; Marietta \& Barker, 2007). Even though a belief holds little credence outside an individual's perception, people often make decisions based solely on their beliefsparticularly in situations where the individual is faced with belief conflicting information (De Neys \& Glumicic, 2008), or when faced with increased cognitive load (e.g., stress or time constraints; Evans, 2006). When making decisions in highstress/high-cognitive load situations, individuals are more likely to come to their conclusions quickly and use very little of the information available to them (Keinan, 1987; Trippas, Handley, \& Verde, 2013; Wastell, Weeks, Wearing, \& Duncan, 2012). Belief-based decisions under pressure occur because the likelihood of evaluating all available information is reduced (Rassin, Muris, Booster, \& Kolsloot, 2008).

7 The distinction between beliefs and knowledge is not simplistic as presented in this chapter (see Southerland, Sinatra, \& Mathews, 2001). Beliefs and knowledge have a complex relationship in that one can acquire knowledge and then incorporate it into their belief system. Thus, the definition that beliefs are untested assumptions would no longer apply. This is a longstanding debate within many disciplines and outside the scope of the present study. For that reason, I adopted the definitions that keep those cognitive phenomena separate. 
Instead, when fast decisions are required, low-effort belief heuristics can override knowledge and expertise (De Neys, 2012; Kozhevnikov \& Hegarty, 2001; Shah \& Oppenheimer, 2008).

Some researchers and law enforcement practitioners have argued that using previous experience and heuristics can be beneficial in police investigations (see Snook \& Cullen, 2008). As a police officer gains experience in investigations, he or she will begin to develop a type of cognition specific to their line of work. Having cognitions specific to the task helps with fast and efficient decision-making and execution, and an automatic and intuitive decision-making technique is often beneficial in those types of situations (see Kahneman, 2003). Notwithstanding the decisionmaking benefits of some belief-based heuristics (cf. Gigerenzer \& Todd, 1999), those types of cognitions can also act as a barrier to objective and logical thinking, which can lead to a biased behaviour (Kahneman, 2003). For example, researchers have repeatedly demonstrated that police officer's beliefs about suspect guilt and stereotypical deception cues can influence the interviewing officer's behaviour towards the suspect (e.g. Meissner \& Kassin, 2002, 2004; Olson, 2013). That is, in a criminal investigation, a judgement about a suspect's guilt may be based on stereotypical beliefs about how guilty or deceptive people behave during questioning (Vrij, 1993). Likewise, an interviewer who believes only guilty people confess, and simultaneously holds a guilt judgement towards a suspect, may be more likely to push for a confession (Kassin, 2015; Kassin, Goldstein, \& Savitsky, 2003; Narchet, Meissner, \& Russano, 2011). 
It is important to note that some police officers hold counterfactual beliefs about human behaviour because they have been given information based on outdated and pseudoscientific beliefs (see Lilienfeld \& Landfield, 2008). For example, some police officers believe that isolating a suspect in a small interrogation room and interrupting a suspect's denials are good interview practices for eliciting a confession (Kassin et al., 2007). Through research endeavours, much has been learned about interviewing suspects, witnesses and victims. For example, more ethical interviewing practices were created (e.g. information-gathering interviews), frameworks were established to help guide police officers to conduct effective and professional interviews (e.g. PEACE; see Crime Academy and Review Group, 2016; Van der Sleen, 2009), and more effective information-eliciting techniques were developed (e.g. cognitive interview; Fisher \& Geiselman, 2010).

\subsection{BELIEFS AS BARRIERS TO EVIDENCE- BASED PRACTICE IN INVESTIGATIVE INTERVIEWS}

One way to combat the use of pseudoscience and personal beliefs in policing is through the use of evidence-based practices. Evidence-based practice involves using critically appraised and scientifically tested methods in applied settings (Telep, 2017). Some researchers have posited that the opposite of a belief is knowledge, which is the attitude towards information that is known to be true and is based on fact and evidence (e.g. formal learning, presentation of information to be stored in memory is testable; Dienes \& Perner, 1999). Over the last 30 years, the investigative interview has been the subject of 
extensive focus for researchers and practitioners who have sought to understand how miscarriages of justice occur (see De Roos \& Nijboer 2011; Griffin 2001), how interviewers ascertain interviewee veracity (e.g. Mann, Vrij, \& Bull, 2004), and what interviewer tactics elicit the most reliable information from interviewees (e.g. Hakkanen, Ask, Kebbell, Alison, \& Granhag, 2009).

Intuitively, it would seem that simply providing police officers with training based on empirically tested findings should be enough to combat any personal or pseudoscientific beliefs; however, this is not the case. Research conducted within the educational and clinical literature had demonstrated that changing behaviours and integrating knowledge into practice requires that some barriers in cognition must be overcome. First, there must be a desire to learn or a positive attitude towards the new information. Second, there needs to be discontent with any current knowledge on the subject. This means that the individual must accept that their current knowledge is no longer sufficient to explain the topic. Third, the new knowledge must appear immediately plausible, credible and reliable in its explanation of an event and similar events. Finally, and most importantly, the new knowledge cannot conflict with pre-existing beliefs or personally held conceptions about the topic (Posner, Strike, Hewson, \& Gertzog, 1982; Richardson, 1996).

Once knowledge is acquired, there is no guarantee that those who possess the information will always use it at the appropriate time. Attitude about the obtained knowledge is likely an important factor to accepting the information (Alexander, Murphy, Buehl, \& Sperl, 1998). For example, a 
police officer with prior intuitive or pseudoscientific beliefs about what works in an investigative interview may be resistant to new knowledge about effective techniques-especially if they seem counter intuitive or in opposition to his or her experiences. Moreover, researchers have demonstrated that presenting contradictory information to existing beliefs can strengthen the intensity of the belief if the individual is not ready to accept the new information (Batson, 1975; Nickerson, 1998).

Despite an extensive literature on scientifically tested factors that can affect the investigative interview, pseudoscientific and intuitive beliefs are still prevalent within police organisations (Lilienfeld \& Landfield, 2008; Chaplin \& Shaw, 2016). Retrospective examinations of investigations often reveal that untested or intuitive interview techniques (e.g. Reid Technique), pre-existing beliefs, as well as confirmatory thinking by the police are where things start to go wrong with cases (Rossmo, 2006). For that reason, it is important to understand interviewer beliefs and knowledge about factors that could influence the outcome of the interview.

\subsection{PRESENT STUDY}

Underlying beliefs about factors in the investigative interview, whether they were acquired via the transfer of pseudoscientific information, anecdotal experience or intuition can lead to problematic practice within interview settings (Lilienfeld \& Landfield, 2008). The present study surveyed police officers who have conducted investigative interviews to determine if their knowledge is in line with current empirical evidence 
in the literature. By gaining this insight, we may begin to understand how to better approach interviewer training for effective knowledge transfer. To achieve this, we created a questionnaire comprised of statements about factors that are important to the effectiveness and outcomes of the interview.

We did not hypothesise any findings for this exploration of police officer's beliefs; however, we suggest that a pattern of response may be indicative of belief strength or knowledge acquisition. That is, officers who respond with strong agreement to statements that contradict current findings may hold strong beliefs on that topic. As demonstrated by the aforementioned research, individuals who hold such beliefs could be more resistant to acquiring new knowledge and integrating that knowledge into practice. We also suggest that officers who respond in high agreement with empirically tested statements may have accepted the information presented in the literature. Additionally, officers who respond more moderately (in the mid-range), may be indicating that they have not fully accepted the empirical support for the statements; however, they may not be ready to fully dismiss the information either. There are many reasons for mid-range responding on surveys (see Sturgis, Roberts, \& Smith, 2012); however, in the context of the present survey, mid-range responding would be a promising result as those officers may be more receptive to balanced arguments aimed at positively changing their perception of the literature (Alexander et al., 1998). 


\subsection{METHOD}

6.4.1 Participants. Police officers were recruited via the global and professional contacts of the authors and colleagues, and snowball sampling was used to disseminate the survey. Officers from The Netherlands $(n=79)$, the UK $(n=16)$ and North America $(n=6)$ participated in the study $(n=101$; male $n=49$,

female $\left.n=42 ; M_{\text {Age }}=46.17, S D=8.84\right)$.

Participating officers had many years of experience $(M=22.6$ years, $S D=10.25)$ with 4 years minimum experience to a maximum of 45 years. Officers' highest level of formal education spanned from vocational training to post-graduate specialisation: basic vocational $(47.5 \%)$, high school $(10.9 \%)$, university $(25.7 \%)$, masters $(10.9 \%)$, specialisation or PhD (2\%) and other unspecified (3\%).

To participate in the study officers must have conducted at least one investigative interview with a suspect in their career. All participating officers reported having conducted frequent interviews throughout their years of service: one interview per month $(29.7 \%)$, two per month $(19.8 \%)$, three per month $(18.8 \%)$, four per month (5.9\%) and five or more per month (25.7\%). Most officers also reported having received specialised interview training $(72.3 \%)$ at least once during their career.

6.4.2 Materials. A survey comprised of 26 statements was created for this study (see Table 6.1). The statements within the survey were operationalised as either consistent or contradictory with the current literature on investigative interviewing. The statements focused on three specific themes: best practices for interviewing, confessions and interviewee vulnerabilities. Each 
statement reflected findings from empirical evidence in the psycho-legal literature and was either positively or negatively worded. Participants were asked to rate their agreement with each statement on a 10-point scale from strongly agree (1) to strongly disagree (10), with anchors only at 1 and 10. Prior to distribution, the survey was examined by two subject matter experts for clarity and plausibility of the statements. The survey was created in both English and Dutch, and both versions are identical in meaning and content (Table 6.1: English; Appendix E: Dutch).

6.4.3 Procedure. Officers were invited to complete the survey via a link to the Qualtrics online survey platform. Once informed consent to participate was given, officers were asked if they had conducted investigative interviews with suspects during their career. Officers who answered 'no' to this question were directed to the end of the survey. There, it was explained that the study required officers who had experience interviewing suspects and they were thanked for their time. Officers who answered 'yes' to the inclusion criteria question were permitted to proceed with the study. Next, participating officers completed nine demographic questions to collect the following information: age, sex, country, tenure, rank/title, number of interviews per month, education level and specialised interview training.

Once the demographic information was obtained, the officers received instructions on completing the survey. The instructions began with an assurance that the survey was not a test and that officers should respond to each statement without too much thought. Officers completed the 26-item 
survey by indicating their agreement/ disagreement with each statement. After the statements were answered, officers were asked to provide a response to an open question about the presence of legal counsel in the interview room. This item was included as part of a separate project and the findings are not presented as part of the current study. Finally, officers were thanked for their participation and directed out of the survey platform.

\subsubsection{Scoring and Analysing Responses.}

Responses to the statements contained in the survey were recorded on a 1 to 10 scale to give distance in the extremes for the analysis of biased responding (i.e., strongly agree or disagree). When evaluating the responses by theme and overall pattern of responding, negatively worded items were reversescored prior to analysis. Therefore, items scored as 1 (Strongly Disagree) to 10 (Strongly Agree) were changed as follows: $1=10,2=9,3=8,4=7,5=6$, $6=5,7=4,8=3,9=2,10=1$.

The responses on the 10 -point scale were then indexed into categories and assigned a score (indicated in the parentheses) from 1 to 5 : disagree $(1)=$ response scores of 1 and 2, somewhat disagree (2) $=3$ and 4 , neither agree nor disagree $(3)=5$ and 6 , somewhat agree (4) $=7$ and 8 and agree $(5)=9$ and 10 . This step was taken to reduce the data to a 5-point Likert type scale to gain a more concise picture of how the police officers' responses were clustered on the scale of agreement. The scores from each category were then used to calculate a response mean for each theme and the overall survey. 


\subsection{RESULTS}

The overall survey responses were positively skewed towards agreement with the literature consistent statements. More officers chose agreement with the statements $(52.3 \%)$ than disagreement $(23.7 \%), \mathrm{X}^{2}(1, N=101)=16.70, p=$ $.001,95 \% \mathrm{CI}=[.23, .52]$ whilst $24 \%$ of the officers chose the mid-range response (neither agree or disagree; see Figure 6.1), or strongly agreed with statements on confessions (62\%); however, agreement was a bit lower for best practices (49.5\%) and interviewee vulnerabilities ( $47.4 \%$; see Figure 6.2).

When the responses were analysed by theme, more insight was gained regarding the topics in which officers have the most knowledge (see Figure 6.2). Most of the sample somewhat

When the proportions for officers who agreed with the statements were compared to officers who disagreed with the statements, significant differences emerged across all themes with officers agreeing more than disagreeing: best practice, $X^{2}(1, N=101)$ $=11.53, p=.001,95 \% \mathrm{CI}=[.38, .10]$; interviewee vulnerabilities, $\mathrm{X}^{2}(1, N=101)=8.00, p=.004,95 \%$ $\mathrm{CI}=[.27, .47]$; confessions, $\mathrm{X}^{2}(1, N=101)=39.38$, $p=.001,95 \% \mathrm{CI}=[.17, .61]$.

A Kruskal-Wallis test indicated that there was also a small difference between officers' responses on the theme of vulnerability. The UK officers' (Mean rank $=67.56$ ) significantly differed in their responses on vulnerability from the Dutch police (mean rank = 47.09), $\mathrm{X}^{2}(2, N=101)=6.90, p=.03, \eta^{2}=.07$. There were no differences on the theme of 'best 
practices', $X^{2}(2, N=101)=3.46, p=.18$ or confessions, $\mathrm{X}^{2}(2, N=101)=3.46, p=.16^{8}$.

\subsection{DISCUSSION}

Police officers from The Netherlands, the UK and North America were surveyed about factors that could influence interview outcomes to ascertain their beliefs on the themes of best practices, confessions and vulnerabilities. Although the officers in each country (the UK, Netherlands and North America) may have received different interview training and may use different interview techniques (e.g. information gathering versus accusatory techniques), the sample who participated in the survey was fairly homogeneous in their responses. Only one difference emerged among the themes, and it was on the topic of vulnerability. The UK police officers responded with a significantly higher level of agreement than the Dutch and North American officers. This may be due to the extensive training that UK officers receive on interviewee vulnerabilities (see Crime Academy and Review Group, 2016).

Overall, the participating officers responded with the highest agreement for confession statements. That is not surprising as the topic of confessions has a large and longstanding literature base-particularly false confessions (see Kassin et al., 2007). Knowledge in that area is evident in the strong level of disagreement for the negatively worded statements on confession and innocence, as well as threats and promises. Moreover, cases that

${ }^{8}$ Comparisons were not made with the North American sample as it was too small $(n=6)$ to draw any meaningful conclusions. 
are reviewed for miscarriages of justice often become high-profile news and receive increased media and public attention.

There was a trend of mid-range responding on each topic. Mid-range responding could be understandable for topics where there are contradictory findings in the literature; however, efforts were made to formulate the statements for knowledge with strong supporting evidence. Officers may have also used the mid-range responses to answer in a socially desirable manner; however, efforts were also made in the survey instructions to inform officers that this was not a test

and that we were seeking their beliefs. A likely scenario is that the officers may have used the midrange to indicate conditional agreement or disagreement (Sturgis et al., 2012). By choosing to 'somewhat agree' with the statements, officers may be indicating their knowledge and acceptance of empirical findings on the topic, whilst recognising those findings do not hold true in all situations. For example, when the officers overall median scores were examined (10-point scale), responses to the statement 'It is good practice to prepare interview questions in advance' was met with a high level of agreement $(\tilde{x}=8)$. However, the officers responded with mid-range agreement $(\tilde{x}=6)$ to the statement, 'Preparing interview questions in advance can stifle the natural flow of the interview'. This may be an acknowledgement of the benefits to having some interview questions prepared but knowing also that if not done properly, it can stifle the interaction. 
Table 6.1

Survey statements and police officer's overall median scores (all countries combined). Scale of agreement is 1 (strongly disagree) to 10 (strongly agree).

\begin{tabular}{|c|c|}
\hline Best Practice Statements & $\begin{array}{l}\text { Median } \\
\text { Score }\end{array}$ \\
\hline $\begin{array}{l}\text { 1. Preparing interview questions in advance can stifle the } \\
\text { natural flow of the interview. }(R)\end{array}$ & 3 \\
\hline $\begin{array}{l}\text { 2. Trained officers can distinguish between truth and lies } \\
\text { with high accuracy. (R) }\end{array}$ & 3 \\
\hline
\end{tabular}
suspect's answer to get to the truth more quickly. (R) 4. Having a theory about who committed the crime and 4 the motive is useful when conducting an investigative interview.

5. Suspects should be confronted with the evidence 1 against them early on in the interview. ( $R$ )

6 . It is good practice to tell the suspect what you think 4 happened and seek confirmation. (R)

7. It is better to imply disbelief in a suspect's answer 4 through body language than to explicitly state it. (R)

8. Interviewers should summarize the suspect's answers aloud and check that the summary is correct.

9. Information gathering is the primary objective when 4 conducting investigative interviews.

10. It is good practice to prepare interview questions in 4 advance

11. Knowing all the facts of a case makes for a better 3 interview.

12. An effective interview tactic is to let the suspect 5 know that you think they are guilty. (R)

Confession Statements

1. Implied threats or promises can lead to true 4 confessions. ( $R$ )

2. Explicit promises of leniency can lead to true 3 confessions.

3. A confession must be true if it contains accurate 3 details of the crime. (R)

4. Sympathy from the interviewer can lead people to 2 infer leniency, which may lead them to falsely confess. 
5. Innocent people never give false confessions 4 voluntarily. ( $R$ )

6. Police interviewers can tell the difference between a 4 false and true confession. (R)

7. Innocent people do not confess to crimes. (R) 5

Vulnerability Statements

1. Hunger and poor sleep can impair judgement and 4 decision-making in suspects.

2. Signs of nervousness and anxiety are good indicators 4 of guilt. (R)

3. Innocent suspects are more likely to waive their right 3

to have a lawyer present.

4. Mentally ill people are more vulnerable to suggestion 4 during investigative interviews than mentally healthy persons

5. Adolescents are more vulnerable than adults to 3 suggestion during investigative interviews.

6. Signs of nervousness and anxiety are good indicators 4 of lying. (R)

7. Persons with developmental problems are vulnerable 4 to suggestion during investigative interviews.

Note: (R) denotes a negatively worded statement that has been reverse coded for agreement. 


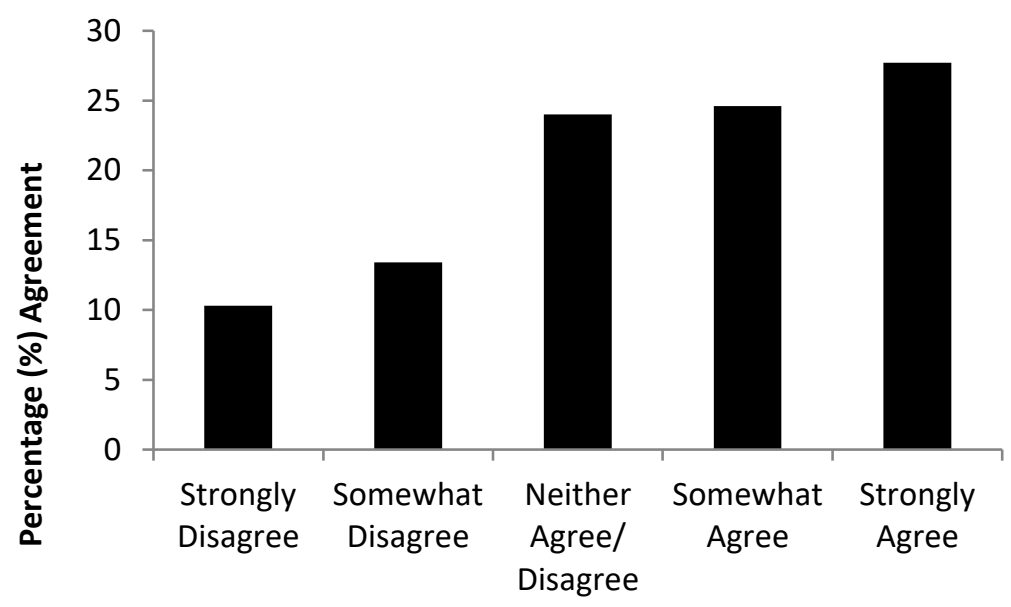

\section{Agreement Anchors}

Figure 6.1. Overall percentage of police officer agreement with the 26 statements contained in the survey.

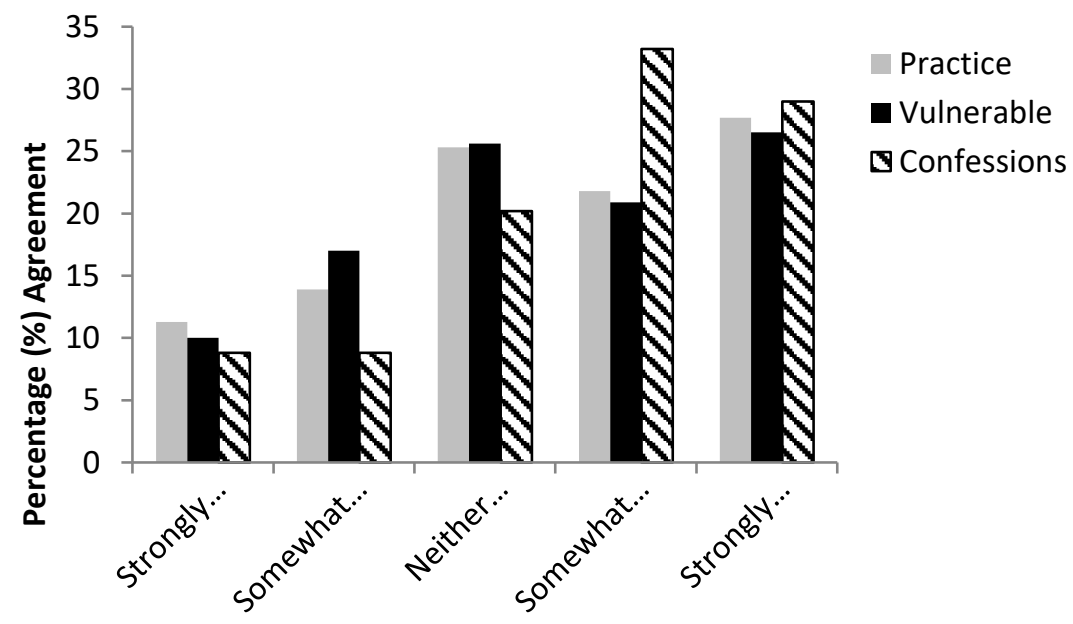

Figure 6.2. Percentage of police officer agreement with the 26 survey statements by theme: best interview practices, confessions, and interviewee vulnerabilities. 
Officers may have also used the mid-range to indicate that they do not have enough knowledge on the topic to respond at either extreme (agree or disagree). Thus, the middle range becomes an option for ' $I$ 'm not sure'. In the context of this study, any motive for the mid-range responses creates an opportunity for conceptual change. Alexander et al. (1998) found that individuals with a moderately favourable stance towards a topic, high interest and some knowledge were more susceptible to be persuaded by literature. Thus, the officers who responded in the mid-range may not have formed strong beliefs about the topics and could be susceptible and open to acquiring more knowledge on the subjects.

The high level of agreement with the statements is a promising indication that police officers' beliefs for this particular sample are in-line with current knowledge and consensus in the academic literature. However, the findings from this study contradict the findings of Chaplin and Shaw (2016). In that study, the authors found that a small sample of UK officers held just as many counterfactual beliefs to the literature as knowledge on the topic of police interrogations and procedures. Although the present study did not use the same statements as Chaplin and Shaw, the themes around the questions appear to be similar (confessions, practice and vulnerabilities). Whilst the majority of the sample in the present study is Dutch, there was no difference in overall response medians by country of origin, and UK officers responded with higher agreement on the theme of vulnerabilities. 
6.6.1 Limitations and future research. The difference in the findings between the present study and Chaplin and Shaw's (2016) study may be due to sample demographics. The Chaplin study surveyed 44 officers from a small rural department in the UK. The current study recruited participants via professional contacts with the authors and their colleagues and did not exclusively target any one country or region. Thus, the participating officers may be more knowledgeable with the literature. For that reason, we cannot corroborate the claim that there is a knowledge-science gap for officers in the UK or elsewhere. A wider scale survey of officers who conduct interviews is needed to gain a more accurate view of any beliefs versus knowledge disparity. Additionally, to avoid making inferences about officer belief versus knowledge, officers should be asked whether he or she received explicit information about the topic or statement or if the officer is responding based on experience or intuition.

Whilst the current study acquired a snapshot of officer's beliefs, we cannot make claims regarding how the beliefs translate into practice. Based on the theoretical underpinnings of belief-based heuristics, we can posit that officers who hold counterfactual beliefs to the current literature may be more likely to resort to those beliefs under the constraints the pressure experienced in the investigative interview. We can also speculate under this same theory that officers who hold beliefs consistent with the current literature are more likely to behave with that knowledge in mind. There is evidence in the literature that increased cognitive load and time constraints can interfere with the application of 
knowledge into practice (Kozhevnikov \& Hegarty, 2001); however, there is no information in the literature regarding knowledge-consistent beliefs. Therefore, it is uncertain how officers who hold knowledge-consistent belief heuristics will perform under increased pressure. This gap in the literature needs to be addressed to gain more understanding of how beliefs can influence practice.

\subsection{CONCLUSION}

The findings in the present study indicate that a highly experienced and educated sample of officers from three countries have adequate knowledge of empirically tested phenomena that may influence interview outcomes with suspects. Therefore, those officers are potentially more likely to apply this knowledge into practice as opposed to officers who hold strong beliefs that are counterfactual to the current literature. Officers who responded in the mid-range (neither agree nor disagree) with the statements are most likely the ones that should be identified and approached by trainers and academics. Personal or pseudoscientific beliefs can be a barrier to implementing knowledge into practice for police officers, thus, focused training for officers who do not hold strong beliefs in either direction may bring their beliefs more in line with current scientific knowledge about interview factors. This in turn could implement positive change towards a more effective interview. However, further research is needed to determine how beliefs and knowledge translate into police interview practice under varying levels of pressure and cognitive load. 


\section{REFERENCES}

Alexander, P. A., Murphy, P. K., Buehl, M. M., \& Sperl, C. T. (1998). The influence of prior knowledge, beliefs, and interest on learning from persuasive text. National Reading Conference, 47, 167-181. Retrieved from https://eric.ed.gov/?id=EJ587432

Batson, D. C. (1975). Rational processing or rationalization? The effect of disconfirming information on a stated religious belief. Journal of Personality and Social Psychology, 32, 176-184. doi:10.1037/h0076771

Blackstock, J., cape, E., Hodgson, J., Ogorodova, A., Spronken, T., \& Vanderhallen, M. (2014). Inside police custody: Training framework on the provisions of suspects'rights. Cambridge, UK: Intersentia Ltd.

Burns, B. D. (2004). Heuristics as beliefs and as behaviors: The adaptiveness of the "hot hand". Cognitive Psychology, 48, 295-331. doi:10.1016/j.cogpsych.2003.07.003

Chaplin, C., \& Shaw, J. (2016). Confidently wrong: Police endorsement of psych-legal misconceptions. Journal of Police and Criminal Psychology, 31, 208-216. doi: $10.1007 /$ s11896-015-9182-5

Clarke, C., \& Milne, R. (2001). National evaluation of the PEACE investigative interviewing course [Report No. PRAS/149]. London: Home Office.

Crime Academy and Review Group (2016). Investigative interviewing policy. London, UK: Metropolitan Police.

De Neys, W. (2012). Bias and conflict: A case for logical intuitions. Perspectives on Psychological Science, 7, 2338. doi: $10.1177 / 1745691611429354$

De Neys, W., \& Glumicic, T. (2008). Conflict monitoring in dual process theories of thinking. Cognition, 106, 1248-1299. doi: $10.1016 / j$.cognition.2007.006.002

De Roos, T. A., \& Nijboer, J. F. (2011). Wrongfully convicted: How the Dutch deal with the revision of their "miscarriages of justice". Criminal Law Reform, 22, 567 - 591. doi:10.1007/s10609-011-9159-8 
Dienes, Z., \& Perner, J. (1999). A theory of implicit and explicit knowledge. Behavioral and Brain Sciences, 22, 735-808. doi.10.1017/50140525X99522188

Fisher, R. P., \& Geiselman, R. E. (2010). The cognitive interview method of conducting police interviews:

Eliciting extensive information and promoting therapeutic jurisprudence. International Journal of Law and Psychiatry, 33, $321-328$. doi: $10.1016 /$ j.ijlp.2010.09.004

Gigerenzer, G., \& Todd, P. M. (1999). Fast and frugal heuristics: The adaptive toolbox. In G. Gigerenzer, P. M. Todd, \& The ABC Research Group, Evolution and cognition: Simple heuristics that make us smart (pp. 3 - 34). New York, NY: Oxford University Press.

Griffin, L. (2001). The correction of wrongful convictions: A comparative perspective. American University International Law Review, 16, 1241 - 1308. Retrieved from https://heinonline.org

Hakkanen, H., Ask, K., Kebbell, M., Alison, L., \& Granhag, P. A. (2009). Police officers' views of effective interview tactics with suspects: The effects of weight of case evidence and discomfort with ambiguity. Applied Cognitive Psychology, 23, 468-481. doi:10.1002/acp.1491

Kahneman, D. (2003). Maps of bounded rationality: Psychology for behavioural economics. American Economic Review, 93, 1449-1475. doi:10.1257/000282803322655392

Kassin, S. M. (2015). The social psychology of false confessions. Social Issues and Policy Review, 9, 25-51. doi: $10.1111 /$ sipr.12009

Kassin, S. M, Goldstein, C. C., \& Savitsky, K. (2003). Behavioral confirmation in the interrogation room: On the dangers of presuming guilt. Law and Human Behavior, 27, 187203. doi:10.1023/A: 1022599230598

Kassin, S. M., Leo, R. A., Meissner, C. A., Richman, K. D., Colwell, L. H., Leach, A. M., \& La Fon, D. (2007). Police interviewing and interrogation: A self-report survey of police practices and beliefs. Law and Human Behavior, 31, 381-400. doi:10.1007/s10979-006-9073-5 
Keinan, G. (1987). Decision making under stress: Scanning of alternatives under controllable and uncontrollable threats. Journal of Personality and Social Psychology, 52, 639-644. doi:10.1037//0022-3514.52.3.639

Kozhevnikov, M., \& Hegarty, M. (2001). Impetus beliefs as default heuristics: Dissociation between explicit and implicit knowledge about motion. Psychonomic Bulletin \& Review, 8, 439-453. doi:10.3758/BF03196179

Lilienfeld, S. O., \& Landfield, K. (2008). Science and pseudoscience in law enforcement: A user-friendly primer. Criminal Justice and Behaviour, 35, 1215-1230. doi: $10.1177 / 0093854808321526$

Mann, S., Vrij, A., \& Bull, R. (2004). Detecting true lies: Police officers' ability to detect suspect's lies. Journal of Applied Psychology, 89, 137-149. doi:10.1037/00219010.89.1.137

Marietta, M., \& Barker, D. C. (2007). Values as heuristics: Core beliefs and voter sophistication in the 2000 Republican nomination contest. Journal of Elections, Public Opinion and Parties, 1, 49-78. doi: $10.1080 / 13689880601132554$

McGurk, B. J., Carr, M. J., \& McGurk, D. (1993). Investigative interviewing courses for police officers: An evaluation [Paper No. 4]. London, UK: Home Office.

Meissner, C. A., \& Kassin, S. M. (2002). "He's guilty!": Investigator bias in judgements of truth and deception. Law and Human Behavior, 26, 469-480. doi: $10.1023 /$ A: 1020278620751

Meissner, C. A., \& Kassin, S. (2004). You're guilty, so just confess! In G.D. Lassiter (ed) Interrogations, Confessions, and Entrapment (pp. 85-106). Boston, MA: Springer.

Milne, B., \& Bull. R. (1999). Investigative interviewing: Psychology and practice. Chichester, UK: John Wiley \& Sons. 
Narchet, F. M., Meissner, C. A., \& Russano, M. B. (2011). Modeling the influence of investigator bias on the elicitation of true and false confessions. Law and Human Behavior, 35, 452-465. doi:10.1007/s10979-010-9257$\mathrm{x}$

Nickerson, R. (1998). Confirmation bias: A ubiquitous phenomenon in many guises. Review of General Psychology, 2, 175-220. doi:10.1037/10892680.2.2.175

Olson, E. A. (2013). "You don't expect me to believe that, do you?" Expectations influence recall and belief of alibi information. Journal of Applied Social Psychology, 43, 1238-1247. doi:10.1111/jasp.12086

Posner, G. J., Strike, K. A., Hewson, P. W., \& Gertzog, W. A. (1982). Accommodation of a scientific conception: Toward a theory of conceptual change. Science Education, 66, 211-227. doi:10.1002/sce.3730660207

Powell, M. B. (2002). Specialist training in investigative and evidential interviewing: Is it having any effect on the behaviour of professionals in the field. Psychiatry, Psychology, and Law, 9, 44-55. doi:10.1375/pplt.2002.9.1.44

Rassin, E., Muris, P., Booster, E., \& Kolsloot, I. (2008). Indecisiveness and informational tunnel vision. Personality and Individual Differences, 45, 96-102. doi: $10.1016 /$ j.paid.2008.03.006

Richardson, V. (1996). The role of attitudes and beliefs in learning to teach. In J. Sikula (Ed.), Handbook of research on teacher education (pp. 102-119). New York, NY: Simon \& Schuster/ Macmillan.

Rossmo, D. K. (September, 2006). Criminal investigative failures: Avoiding the pitfalls. FBI Law Enforcement Bulletin, 1, 1- 8. Retrieved from https://heinonline.org

Shah, A. K., \& Oppenheimer, D. M. (2008). Heuristics made easy: An effort-reduction framework. Psychological Bulletin, 134, 207-222. doi:10.1037/00332909.1342.2.207 
Shermer, M. (2002). Why people believe weird things. New York, NY: Henry Holt and Company, LLC.

Shermer, M. (2011). The believing brain. New York, NY: Times Books/ Henry Holt and Company, LLC.

Snook, B., \& Cullen, R. M. (2008). Bounded rationality and criminal investigations: Has tunnel vision been wrongfully convicted? In D. K. Rossmo (Ed.), Criminal investigative failures (pp. 71-98). Boca Raton, FL: CRC Press.

Sturgis, P., Roberts, C., \& Smith, P. (2012). Middle alternatives revisited. Sociological Methods \& Research, 43, 15-38. doi: $10.1177 / 0049124112452527$

Telep, C. W. (2017). Police officer receptivity to research and evidence-based policing: Examining variability within and across agencies. Crime \& Delinquency, 63, 976999. doi: $10.1177 / 0011128716642253$

Trippas, D., Handley, S. J., \& Verde, M. F. (2013). The SDT model of belief bias: Complexity, time, and cognitive ability mediate the effects of believability. Journal of Experimental Psychology: Learning, Memory, and Cognition, 39, 1393-1402. doi:10.1037/a0032398

Van Beek, M., \& Hoekendijk, J. (2015). The interview table: A toolbox-approach for suspect interviewing. Investigative Interviewing: Research and Practice, 1020. Retrieved from http://www.iiirg.org/journal/

Van der Sleen, J. (2009). A structured model for investigative interviewing of suspects. In R. Bull, T. Valentine, \& T. Williamson (Eds.), Handbook of Psychology of Investigative Interviewing. Chichester, UK: John Wiley \& Sons.

Vrij, A. (1993). Credibility judgements of detectives: The impact of nonverbal behaviour, social skills, and physical characteristics on impression formation. The Journal of Social Psychology, 13, 601-610. doi:10.1080/00224545.1993.9713915 
Wastell, C., Weeks, N., Wearing, A., Duncan, P. (2012). Identifying hypothesis confirmation behaviours in a simulated murder investigation: Implications for practice. Journal of Investigative Psychology and Offender Profiling, 9, 184-198. doi:10.1002/jip.1362 


\section{CHAPTER 7}

\section{When Guilt is Presumed: Discursive Indicators of Confirmation Bias During an Interrogation}

\section{ABSTRACT}

The language used in a police-suspect interview can provide clues to the underlying guilt beliefs of the interviewer. This chapter presents an analysis of the discursive indicators of guilt presumption and how it appears through covert speech acts (i.e., insinuation). The utterances (locutions) that led to the insinuation, and how the insinuation influenced the suspect's behaviour (perlocutionary force), were identified through the analysis of instances of covert speech. The findings revealed that suspect denials were the most common speech acts prior to and immediately after the interviewer's use of insinuation. The predominant influence of the covert speech act on the interviewee was to create defensive behaviours, which led to a break down in the dialogue of the interview. The findings in this study suggest that police interviewers may be using covert speech as a tactic to instil a guilt belief in the suspect. However, this tactic does not create optimal conditions for truth-finding or information-gathering during the investigative interview.

Keywords: Covert speech acts, insinuation, guilt presumption, investigative interview, suspect behaviour 


\section{INTRODUCTION}

An investigative interview is a socially organised interaction that occurs within a complex set of circumstances. Although both the interviewer and the interviewee influence the dynamic of the interaction, the interviewer arguably exerts the most influence on the overall outcome of the interview (Hudson, Satchell, Adams-Quackenbush, 2018). For example, an interviewer can manipulate the tone, topic, direction, and questioning techniques of the interview through his behaviour or underlying objectives (e.g., information-gathering or confession seeking; Edvardsson, 2009; Haworth, 2017; Mason, 2016; Moston \& Engleberg, 1993). The interviewer can also influence a suspect's responses and behaviour through questions and statements. That is, during the dialogue of the interview, an interviewer may explicitly state disbelief in a suspect's utterance, directly accuse the suspect of lying, or express guilt presumption (Oxburgh, Myklebust, \& Grant, 2010).

Explicit statements of guilt are rare, however, and beliefs are generally uttered using more implied language (Kassin \& McNall, 1991; Shuy, 1998). The present study examines a series of police-suspect interviews for discursive indicators of confirmation bias. Specifically, guilt presumptive language expressed as a covert speech act (i.e., insinuation) is examined. The detrimental influence of guilt presumption and covert speech relative to the objectives of the police-suspect interview are discussed (i.e., truth finding and information gathering). Using excerpts from a sample of policesuspect interviews, this influence is presented through examining the suspect's speech before and 
after a covert speech act is uttered by the interviewers.

\subsection{INFLUENCE OF GUILT PRESUMPTION IN INTERVIEWS WITH SUSPECTS}

The investigative interview is a complex and distinctive type of interaction between a person in authority and a person in the custody of that authority (Melinder \& Gilstrap, 2009; Powell, Fisher, \& Wright, 2005). That dynamic has a distinct effect on the dialogue of the police-suspect interview as the goals of the interview are often in opposition (Walton, 2003). The primary objective of the interviewer is to obtain as much information as possible to assist in case closure, truth-finding, and to facilitate a confession if appropriate (see College of Policing, 2016; Shuy, 1998; Van der Sleen, 2009). Conversely, the suspect weighs the costs and benefits of revealing information against his own interests, as well as any sense of obligation for disclosure (see Brooks, 2000). The opposing objectives and interests can lead to adversarial dialogue and increased tensions - especially when interviewers confront suspects with potentially incriminating evidence or when the interviewer challenges the suspect's account of the events (Walton, 2003). It is also during those tenser phases of the interview where interviewers are likely to apply more interrogative pressure to elicit information, obtain a confession, or will employ specific tactics to manipulate and control the direction of the interview (Van Eemeren \& Grootendorst, 1984). That would be the confrontation stage of the dialogue.

During a police-suspect interview one of the most influential factors on outcome may be the presence of guilt presumptive bias (Kassin, 
Goldstein, \& Savitsky, 2003; Moston, Stephenson, \& Williamson, 1992). Guilt presumption can have negative effects on the interview (e.g., eliciting less information, increased conflict, decreased effective questioning, and increased acquiescence; see Kassin \& Gudjonsson, 2004). Attitudes and beliefs about the interviewee's guilt can have a large influence on the interviewer's choice of tactics (Narchet, Meissner, \& Russano, 2011), questions (Hill, Memon, \& McGeorge, 2008; Kassin et al., 2003), as well as interviewee behaviour (Darley \& Fazio, 1980; Narchet et al., 2011). Whilst those factors influence all types of interviews and interviewees, they can be particularly significant for interviews with suspects. That is, interviewers hold the power to make decisions and frame information in a way that will ultimately affect the suspect's life (i.e., eliminate or retain as a suspect).

Despite the detrimental effects of guilt presumption on interviewer and suspect behaviour, the belief that the suspect is involved in the crime is the starting point for a police-suspect interview. There must be some information or belief that an individual is involved in the crime to be considered a suspect (O'Brien, 2007). The challenge for interviewers is one of assuming the suspect was involved while behaving objectively. Police officers must ask questions to gather more information about the case, and account for the previous information they have gathered, while not actively seeking a confession or accusing the suspect of the crime. However, remaining objective and seeking belief disconfirming evidence is a skill that needs to be trained and practiced as those traits are counter intuitive to normal human tendency (see Nickerson, 
1998). If the interview is conducted in a way to confirm the interviewer's pre-existing belief of a suspect's guilt, it can have serious consequences for the potentially innocent suspect, up to and including a miscarriage of justice (Baldwin, 1993; Ditrich, 2015).

\subsection{IMPLICATURE AND COVERT SPEECH ACTS: INSINUATING GUILT}

Language is used to construct and convey meaning, and thus, has the power to transform perceptions of reality (Semin, 2011). In situations where there is a power imbalance between interlocutors, language can be used to instil helplessness or to imply threats and negative outcomes (Farinde, Olajuyigbe, \& Matthew, 2015). That type of language is often associated with adversarial and confession driven interviews in the literature (e.g., Behavioural Analysis Interview; Inbau, Reid, Buckley, \& Jayne, 2001). However, researchers are finding that problems persist within the supposedly less adversarial informationgathering frameworks found throughout parts of Europe and in the United Kingdom. For example, interviewers in the UK (PEACE) and The Netherlands (General Interrogation Strategy: GIS) are trained to remain non-judgemental and only seek the truth during the interview, yet accusatory and guilt presumptive language is still found within these frameworks (see Clarke, Milne, \& Bull, 2011; Hoekendijk \& Van Beek, 2015). This is may be due to interviewers deviating from their training and engaging in more intuitive questioning and confrontational behaviour (Griffiths \& Milne, 2006).

The investigative interview is an information seeking interaction that can also contain elements of 
various types of dialogue (e.g., persuasion, negotiation, inquiry, argumentation, conflict; Walton, 2003). The purpose of the interview is to obtain information from an individual who may or may not be willing to share it with the interviewer. In policesuspect interviews, the objectives of the interviewer and the interviewee are often in conflict, and thus, the dialogue does not follow the normal rules of discussion. Walton (2003) posited that in policesuspect interviews the dialogue can be extremely adversarial and follows its own set of dialectical rules that include: concealment, coerciveness, deception, probing, critical calculation, argumentation, and insinuation by both parties. The adversarial nature of the police-suspect interview dialogue can also create prime conditions for covert speech acts such as guilt insinuation or insinuating consequences for noncompliance.

The complex nature of an interrogative or investigative dialogue can make linguistic analysis difficult as context, implicature, and intent need to be considered to gain insight to the utterances of both the interviewer and the interviewee (Walton, 2003). The study of pragmatics is a branch of linguistics in which language use is examined within the context it occurs and how context contributes to the meaning of an utterance. Within speech act theory (Austin, 1962), an utterance (locutionary act) encompasses and communicates the attitude and intention of the speaker (illocutionary acts), which allows the listener to infer meaning and draw conclusions (Bertuccelli Papi, 2014). For a listener to fully comprehend the meaning behind a speaker's utterance, he or she must be aware of both the overt (meaning) and covert (contextual assumption) 
information contained in the utterance (Moeschler, 2013). Moreover, for effective communication to occur, both the speakers and listener must be aware of the other's perspective and intentions - explicit or implied (Holtgraves, 2002; Searle,1975).

Speech act theory is also concerned with the ways language and utterances influence the listener through actions or state of mind (perlocutionary force). Perlocutionary acts occur because of, and regardless of, illocutionary force. Consider the following excerpt taken from an interview with a murder suspect and a Dutch police officer:

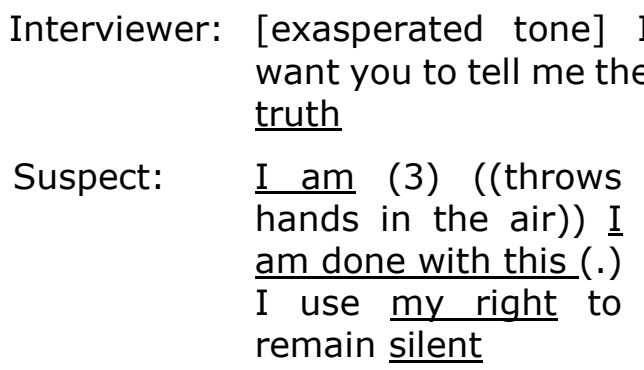

In this example the illocutionary force of the interviewer's utterance seems to request that the suspect tell him the truth. The suspect then makes a response because of the request; however, the perlocutionary force results in rebuttal, frustration, and defiance (respectively). The intent was a request for truth-telling; however, the consequence was reduced cooperation - which occurred regardless of intent. When there appears to be a disconnection between the illocutionary and perlocutionary forces there is generally more happening within the implicature than is immediately apparent (Attardo, 1999; Douglas \& Sutton, 2003). When speakers do not intend for the listener to be instantly aware of the illocutionary act of the utterance, they may have employed a covert speech act to get their message 
across (Bertuccelli Papi, 2014). In the excerpt presented above (1), the interviewer sought to achieve a specific perlocutionary force using insinuation as a covert speech act (Attardo, 1999). The interviewer's utterance insinuates that the suspect has not been telling the truth, without explicitly stating the interviewer believes he has been lied to, and without calling the suspect a liar. The suspect then understands that he has been accused of lying, believes that the interviewer thinks that he is a liar, and reacts to that belief.

When a speaker uses insinuation as part of their communication they are intending to implant a belief in the listener through an utterance without being held accountable for the listener's belief in the truth of that utterance (Bertuccelli Papi, 2014; Haugh, 2013). Insinuation is different than hinting or suggesting and comes with its own set of felicity conditions. First, insinuation does not contain clues to the underlying meaning as found when a speaker uses hints. Second, insinuation is a covert speech act whereas hinting and suggesting are overt acts where the speaker is committed to the truth of what he or she is hinting at, or the likely truth of the suggestion. Third, the speaker can make an explicit statement when insinuating, however, the final requirement is that when insinuating, the speaker cannot make his or her intentions known openly by using performatives such as 'I am insinuating that...' (Attardo, 1999; Parret, 1993), or as in the following example: Suspect: I don't know (3) I stick to my earlier statement (.) I just can't picture it happening that way 


\begin{tabular}{|c|c|}
\hline & $\begin{array}{l}\text { (.) I can't picture } \\
\text { that was the day } \\
\text { when [name] picked } \\
\text { up the car= }\end{array}$ \\
\hline Interviewer: & $\begin{array}{l}=\text { [confrontational } \\
\text { tone] No (.) I } \\
\text { understand you } \\
\text { can't put your finger } \\
\text { on it }\end{array}$ \\
\hline Suspect: & $\begin{array}{l}\text { [confused] Why do } \\
\text { you understand } \\
\text { that? }\end{array}$ \\
\hline Interviewer: & $\begin{array}{l}\text { [confrontational } \\
\text { tone] Because it's } \\
\text { inconvenient for you }\end{array}$ \\
\hline & $\begin{array}{l}\text { [suspect's name] } \\
\text { It's inconvenient for } \\
\text { vour story }\end{array}$ \\
\hline
\end{tabular}

In this example, the interviewer attempted to insinuate that the suspect was choosing to forget details about the day in question. The tone of the interviewer, however, did not match the words he spoke, which caused confusion for the suspect. The locution appears to be one of understanding and agreement, but there is a confrontational tone that accompanied the utterance. The confusion then prompted the suspect to seek clarification as to what the interviewer was trying to insinuate. The request for clarification then caused the interviewer to make a clear statement, which violated one of the felicity requirements for covert speech (i.e., being committed to the truth that the forgetting is intentional; Attardo, 1999).

Covert speech can also have a negative influence on the suspect in a way that breaks down communication between the speaker and the listener. This occurs when, as demonstrated in the previous excerpt (2), the listener understands that 
an insinuation has been made, but he or she cannot comprehend it within the context of their reality. Another way insinuation breaks down communication is by causing conflict as demonstrated in the following excerpt (3). When people use insinuation, they are not trying to communicate something positive to the listener. An interviewer can use insinuation as a veiled accusation or as verbal manipulation to make the suspect believe something that is implied (Bertuccelli Papi, 2014; Kassin \& McNall, 1991). In the following excerpt, the interviewer is making two insinuations meant to manipulate the suspect's perception of his chances of being found innocent of the crime. In the first insinuation, the interviewer implied that the suspect's lawyer is just doing a job and isn't as invested as the suspect believes, so the suspect should confess to help himself:

$$
\begin{aligned}
& \text { Suspect: } \quad \text { This can't be true } \\
& \text { Interviewer: WE'RE NOT MAKING } \\
& \text { THIS UP YOU KNOW } \\
& \text { Suspect: [defensive tone] } \\
& \text { Well I'm not making } \\
& \text { it up either (.) My } \\
& \text { lawyer will look into } \\
& \text { this. } \\
& \text { Interviewer: [raised voice] Yes (.) } \\
& \text { but your lawyer is } \\
& \text { like us as well! She } \\
& \text { sits on this side of } \\
& \text { the table as well (.) } \\
& \text { NOT the other side } \\
& \text { Suspect: I have nothing to hide. } \\
& \text { Interviewer: [raised voice] It's } \\
& \text { work to that lady (.) } \\
& \text { It's work to us (.) } \\
& \text { But this is a part of }
\end{aligned}
$$




\section{your life and you just need to come clean}

In the second part of the exchange, the suspect responds with a denial of involvement and an assertion that his innocence will be proven in court. The interviewer then insinuates that the suspect's lawyer cannot help him prove his innocence because there is too much evidence against the suspect:

Suspect: It will come out in court that I am not the perpetrator and my lawyer will prove $\underline{\text { this }}$

Interviewer: How is she supposed to prove you didn't do it

Suspect: That's something for my lawyer to work on

Interviewer: [raised voice] The moment she $=$ Suspect: $\quad$ I didn't do it $=$

Interviewer: =The moment she begins, she'll

already be down 10 games.

Suspect: But you keep saying I did this. I didn't do it

Interviewer: [raised voice] Yeah but she is going to be down 10 games, isn't she?

Suspect: [sarcastically] Yup, down 10 to 0.

The suspect responded to this insinuation with sarcasm and the interviewer then continued with a direct accusation of lying. After that exchange, the interview quickly dissolved into a back and forth of accusation, sarcastic rebuttals, and conflict for another five minutes. The suspect eventually declared that he has had enough and invoked his 
right to silence (non-cooperation). The interviewers then suggest a break. They speak to the suspect more conversationally during the break, and when the interview resumes, they start with a new line of questioning. However, the suspect is wary and defensive for the remainder of the interview.

\subsection{PRESENT STUDY}

Researchers have extensively investigated interviewer questioning techniques and behaviour to determine how each can influence interview outcomes (e.g., quality and quantity of information and confession elicitation from suspects; see Meissner, Redlich, Bhatt, \& Brandon, 2012; Walsh \& Bull, 2015). However, the effects of interviewer statements or opinion has been largely unexplored. Griffith and Milne (2006) reported that when interviewers resort to opinionated statements, this is usually an indication of frustration, which increases as the interviewer is unable to obtain an admission of guilt from the suspect. Of course, not all instances of interviewer opinion or statements include insinuations, nor are insinuations definitive evidence of interviewer frustration. The consensus in the limited literature, however, is that interviewer statements can be inappropriate and counter to information-gathering objectives (see Griffiths \& Milne, 2006; Oxburgh et al., 2010). When an interviewer deviates from truth-finding and information gathering towards opinion and statements it creates more opportunity to integrate coercion and covert speech acts into the dialogue.

The exchanges presented in the first part of this paper are examples of how guilt presumptive insinuation can have detrimental effects on the interview outcomes. When interviewers used covert 
speech acts to express their belief in the suspect's guilt, it resulted in a verbal exchange that did not further the objective of truth finding or information gathering. In the following study, situations that lead to the covert speech act of insinuation are explored by analysing the dialogue that occurs in various police-suspect interviews. The dialectic factors and events that prompted the insinuation are examined within the context that the speech act occurred. The suspects' speech acts immediately prior to and post insinuation are also examined. This provided insight to the overall outcome of the exchange. The goal for this analysis was to determine how the insinuation may have influenced the progression and outcome of the interview.

\subsection{METHOD}

7.4.1 Interviews. Twenty- three investigative interviews with murder suspects were obtained from the National Police force in The Netherlands. However, ten 'no comment' interviews were immediately excluded. Those interviews consisted of a barrage of direct questions posed to a silent suspect. No covert language was used by the interviewers when asking those questions. Another four interviews were also excluded from the final analysis although the suspect interacted with the interviewers. Those interviews also contained no instances of covert language or insinuations of guilt. The average length of the remaining interviews ( $N=$ 9) was 141.05 minutes $(S D=69.30)$. The shortest interview was 40 minutes in length and the longest interview was 265 minutes.

The interviewers were a mix of female $(n=4)$ and male ( $n=14)$ police interviewers from The Netherlands. Each interview had two interviewers 
present and one suspect. No legal counsel was visible, nor were they heard, in any of the analysed videos. All the suspects were male $(n=9)$ and were interviewed for their suspected involvement in cases of homicide. All the interview participants spoke Dutch.

7.4.2 Preparing the materials. Due to the severity of the crimes, the interviews were audio and visually recorded at various police interview suites throughout The Netherlands. Each interview was viewed and transcribed verbatim in Dutch by a bilingual (Dutch/ English) research assistant who was naive to the purpose of the study. The Dutch transcriptions were then translated into English by the same assistant. The Dutch-English transcriptions were checked by a second bilingual (Dutch/ English) research assistant for accuracy of translation. I then viewed the interviews with both language transcriptions to verify speaker tone of voice, interruptions, speaker volume, inflection, and nonverbal behaviours such as gesturing to gain more insight to the atmosphere and context of the interactions.

\subsubsection{Identifying and Analysing the}

Speech Acts. The translated English transcripts were analysed for occurrences of covert speech through insinuation by the interviewer within turn taking. Turns were defined as a complete interaction that was initiated by an interviewer's question or comment. The turn continued until the interviewer asked a new question or made a statement on a topic unrelated to the current topic under discussion. Each interview included for analysis contained at least one instance of insinuating language. Once an instance was identified, the suspect's utterances immediately 
prior to, and immediately after, the insinuation were categorised into speech acts. The exchange was also analysed within the context of the broader interaction from start to finish. The speech acts, outcomes, and overall context were then aggregated, and the proportions for occurrences were calculated.

\subsection{FINDINGS}

Within the nine police-suspect interviews analysed, there were 17 instances where the interviewer used insinuating language. The instances where insinuations were used by the interviewers occurred within five different contexts: informationseeking $(11.8 \%)$, suspect refusal to respond $(11.8 \%)$, presentation of evidence $(17.6 \%)$, confrontation of inconsistencies (17.6\%), and opinion statements about the suspect's behaviour or involvement in the crime $(41.2 \%)$.

Prior to the insinuations, 11 different speech acts were identified and post insinuation, eight different speech acts occurred (see Table 7.1). Within this sample of interviews, insinuation primarily came after the suspect made a denial of involvement in the crime $(34.5 \%)$. Post insinuation, the most common speech act used by the suspect was also denial of involvement $(21.4 \%)$, closely followed by a rejection (rebuttal) of the insinuation (17.8\%; see Table 7.1 ). The overall perlocutionary force of the insinuations in the interviews was analysed by examining the remainder of the interaction until the interviewer asked a different question, the interviewer changed topics, or the interviewer suggested a break. In $75 \%$ of the instances, the overall effect on the suspect was to create defensive behaviours. In $12.5 \%$ of the instances the suspects responded with noncooperation (e.g., exercising their right to silence, or 
closed posture and minimal utterances), and in a further $12.5 \%$ of instances, the suspect responded with anger or frustration.

Table 7.1

Suspect's speech acts and proportions of occurrence immediately prior to and after the interviewer's covert speech act of guilt insinuation.

\begin{tabular}{ll|ll}
\hline $\begin{array}{l}\text { Speech Act Pre- } \\
\text { insinuation }(n=11)\end{array}$ & $\%$ & $\begin{array}{l}\text { Speech Act Post- } \\
\text { insinuation }(n=8)\end{array}$ \\
\hline Confusion & 6.8 & Resignation & 7.2 \\
Resignation & 3.5 & Confront & 10.7 \\
Confront & 13.8 & Deny & 21.4 \\
Deny & 34.5 & Justify & 10.7 \\
Justify & 10.5 & Rebuttal & 17.8 \\
Disbelief & 6.8 & Defiance & 7.2 \\
Rebuttal & 3.5 & Inquire & 14.3 \\
Inquire & 3.5 & Covert Speech & 10.7 \\
& & (Sarcasm) & \\
Anger/ Frustration & 3.5 & & \\
Covert Speech & 6.8 & & \\
(Sarcasm) & & & \\
Non-cooperation & 6.8 & & \\
\hline
\end{tabular}

\subsection{DISCUSSION}

Instances of covert speech acts presented as insinuations were examined within police-suspect investigative interviews. In the original sample obtained by the Dutch police $(N=23), 39 \%$ of the interviews contained instances of insinuation and were analysed for covert speech. Interviewers mainly insinuated the suspect was guilty of the crime immediately after the suspect made a denial of involvement. Thus, it is possible that interviewers were using insinuation as a tactic. That is, the interviewers may have attempted to imply that the 
suspect's denials were not believed, and only the suspect's involvement would be considered as an option. Thus, the implication of guilt at that moment in the interview may have been a covert way of seeking a confession. Baldwin (1993) noted that in police-suspect interviews officers used statements to integrate unfair provocation into the interaction. This is what a covert speech act achieves. A tactic of this type could be used in interview frameworks where confessions are considered optimal, but not overtly sought (i.e., information gathering interviews; see College of Policing, 2016; Van der Sleen, 2009).

Conversely, the use of insinuations may not have been a conscious tactic and instead merely a symptom of the frustration the officer felt when the suspect consistently denied involvement (Griffiths \& Milne, 2006). For an interviewer who has a strong belief in the guilt of a suspect, a denial may be perceived as a challenge to his or her ability to persuade the suspect to reveal information or admit involvement (Moston et al., 1992). Thus, the presence of a denial offered an opportunity to respond to that challenge and refute it by insinuating a belief in the suspect's guilt. In this manner, the interviewer implied that the denial was unimportant because guilt had already been established and believed. Speech acts of denial prior to and following the insinuation are supported by Baldwin's (1993) findings that suspects tend to adhere to their initial position. In this case, the suspects denied involvement, and regardless of the interviewer's beliefs and insinuations, they maintained that position. Employing a denial in response to an insinuation may also have contributed to the interviewer's frustration and sense of challenge. That 
is, the denial essentially implied to the interviewer that the illocutionary force of the covert speech act did not influence the suspect.

Where the denial implies that the covert speech act had no effect on the suspect, an outright rejection of the insinuation is an explicit act of defiance within the dialogue. In the rejection speech acts, the suspect called out the insinuation by using explicit language and then refuted the implication of the utterance. A rejection of an insinuation is demonstrated in the following excerpt taken from our sample:

$$
\begin{aligned}
& \text { Suspect: You also thought I } \\
& \text { read the case file (.) } \\
& \text { when in fact I don't } \\
& \text { even have it }
\end{aligned}
$$

file.

$\begin{array}{ll}\text { Suspect: } & \text { [laughs] That doesn't } \\ & \text { make any sense(.) You } \\ \text { imply I know these } & \text { things because I was } \\ \text { at the scene (.) But } & \text { these are things you } \\ \text { told me that people } \\ \text { already stated }\end{array}$

In this excerpt the interviewer insinuated that the suspect had specific knowledge because he was at the scene of the crime. However, the suspect rejects the insinuation and calls out the absurdity of it. The suspect then used the interviewer's previous actions against him by drawing attention to the fact the interviewer gave the suspect the information in question. This behaviour seems to be a bold move, and one that would require confidence on behalf of the suspect considering the perceived power 
imbalance within the interview. Although suspect demographic information was not available for this study, it would be interesting to know if the speech act of rejection occurred more frequently with suspects who had a criminal past versus those arrested for the first time.

The type of speech act demonstrated in the previous example (5), also warrants further attention in future research as it entails the suspect actively identifying and responding to a guilt presumption presented as a covert speech act. It is also noteworthy that the suspect's claim of being leaked information was never addressed or acknowledged by the interviewers. The act of leaking information to a suspect throughout the interview is known to be problematic if the suspect eventually confesses to the crime or admits partial involvement. The suspect is apt to incorporate those details into his statements (Kassin, 2005). In those cases, the confessions are often seen as more credible as they contain details of the crime that allegedly only the perpetrator, or an accomplice, would know. Thus, understanding when and why a suspect exposes an insinuation of guilt could be valuable for research on confessions. Moreover, further research that examines how a suspect's rejection of an insinuation influences the subsequent tactics used by the interviewer, as well as ensuing dialogue, is also warranted.

A breakdown in communication and reduced cooperation by the suspect was the primary outcome of the interviewer's insinuations of guilt, which did not create ideal conditions for information-gathering endeavours. Those outcomes were most likely due to the suspect correctly identifying the insinuations as a display of interviewer dominance during the 
interview. The insinuation of guilt implied that those who held the power (the police) already believed the suspect was guilty. The suspect would immediately comprehend that the interviewers were trying to get him to admit guilt and prove the police correct. That understanding of the situation may have caused the suspect to attempt protect his interests by denying the insinuation and refusing to further engage with the interviewers. In forthcoming studies, researchers may wish to investigate why police interviewers use covert speech acts such as insinuation when it clearly undermines the objectives of the interview. Determining whether such utterances occur due to negative emotions, frustration, or as a conscious tactic could further initiatives aimed at improving police-suspect interviews. Often researchers focus on the presence of overt tactics or behaviours observed, and more subtle cues to guilt bias are missed.

Insinuative language is not generally listed as a coercive behaviour during the police-suspect interview (c.f. Moston \& Fisher, 2007). However, an interviewer's language can be subtle but have a large influence on the behaviour of the suspect - including wearing down suspects, instilling perceptions of helplessness, and facilitating confessions that may not be true (Kassin, 2005). Police interviewers may not be fully aware of how their speech can reveal underlying beliefs of guilt, nor how insinuations of guilt can influence the progression of the interview dialogue. For this reason, there may be training benefits and possibilities for interview improvement with the ability to identify biased language and understand how it influences the suspect, as well as the overall outcome of the interview. 


\subsection{CONCLUSION}

The investigative interview is an important yet complex aspect of police work. In this study, evidence was presented that suggests that covert speech acts are not a productive addition to the police-suspect interview. To determine if the pattern of speech acts presented here hold true across many interviews, more interviews need to be analysed. Whilst insinuation of guilt may provide some insight to the underlying beliefs of the interviewer, it is impossible to know why the interviewer chose to make such utterances that were not optimal for acquiring case relevant information. However, the findings lend support for the notion that using guilt presumptive speech is detrimental for achieving the objective of truth-finding and information gathering. 


\section{REFERENCES}

Attardo, S. (1999). Covert speech acts and their meaning. Deseret Language and Linguistic Society Symposium, 25, 202-217.

Retrieved from

https://scholarsarchive.byu.edu/dlls/vol25/iss1/19

Austin, J. L. (1962). How to do things with words. Cambridge, UK: Clarendon Press.

Baldwin, J. (1993). Police interviewing techniques: Establishing truth or proof? The British Journal of Criminology, 33, 325-352. doi:10.1093/oxfordjournals.bjc.a048329

Bertuccelli Papi, M. (2014). Insinuating: The seduction of unsaying. Pragmatics, 6, 191-204. doi:10.1515/ip2014-001

Brooks, P. (2000). Troubling confessions: Speaking guilt in law and literature. Chicago, IL: University of Chicago Press.

Clarke, C., \& Milne, R. (2001). National evaluation of the PEACE investigative interviewing course [Report No. PRAS/149]. London: Home Office.

College of Policing. (2016, January 11). Investigative Interviewing. Retrieved from https://www.app.college.police.uk/appcontent/investigations/investigative-interviewing

Darley, J. M., \& Fazio, R. H. (1980). Expectancy confirmation process arising in the social interaction sequence. American Psychologist, 35, 867-881. doi:10.1037/0003066X.35.10.867

Ditrich, H. (2015). Cognitive fallacies and criminal investigations. Science and Justice, 55, 155-159. doi: $10.1016 /$ j.scijus.2014.12.007

Douglas, K. M., \& Sutton, R. M. (2003). Effects of communication goals and expectancies on language abstraction. Journal of Personality and Social Psychology, 84, 682-696. doi:10.1037/00223514.84.4.682 
Edvardsson, B. (2001). Content strategy in police interviews of children in alleged child sexual abuse cases. Retrieved from http://www.diva-portal.org

Farinde, R. O., Olajuyigbe, O. A., \& Matthew, A. (2015). Discourse control strategies in police-suspect interrogation in Nigeria. International Journal of English Linguistics, 5, 146-158. doi:10.5539/ijel.v5n1p146

Griffiths, A., \& Milne, R., (2006). Will it all end in tiers? Police interviews with suspects in Britain. In T. Williamson (Ed.), Investigative Interviewing, (pp. 167 - 189). Abingdon, UK: Willan Publishing.

Haugh, M. (2013). Speaker meaning and accountability in interaction. Journal of Pragmatics, 48, 41-56.

doi:10.1016/j.pragma.2012.11.009

Haworth, K. (2017). The discursive construction of evidence in police interviews: Case study of a rape suspect. Applied Linguistics, 38, 194 - 214. doi:10.1093/applin/amv009

Hill, C., Memon, A., \& McGeorge, P. (2008). The role of confirmation bias in suspect interviews: A systemic evaluation. Legal and Criminological Psychology, 13, 357-371. doi:10.1348/135532507X238682

Hoekendijk, J., \& Van Beek, M. (2015). The GIS-model: A Dutch approach to gather information in suspect interviews. Investigative Interviewing: Research and Practice, 7, 19. Retrieved from http://www.iiirg.org/journal

Holtgraves, T. (2002). Language as social action: Social psychology and language use. Mahwah, NJ: Lawrence Erlbaum Associates, Inc.

Hudson, C. A., Satchell, L. P., \& Adams-Quackenbush, N. M. (2019). It takes two to make an interview go right: Round-robin designs to demonstrate interviewer and witness variance. Frontiers in Psychology. doi: 10.3389/fpsyg.2018.02181

Inbau, F. E., Reid, J. E., Buckley, J. P., \& Jayne, B. C. (2001). Criminal interrogation and confessions ( $4^{\text {th }}$ ed.). Gaithersburg, Maryland: Aspen Publishers. 
Kassin, S. M. (2005). Does innocence put innocents at risk? American Psychologist, 60, 215-228. doi:10.1037/0003066X.60.3.215

Kassin, S. M, Goldstein, C. C., \& Savitsky, K. (2003). Behavioral confirmation in the interrogation room: On the dangers of presuming guilt. Law and Human Behavior, 27, 187203. doi:10.1023/A: 1022599230598

Kassin, S. M., Gudjonsson, G. H. (2004). The psychology of confessions: A review of the literature and issues. Psychological Science in the Public Interest, 5, 33-67. doi:10.1111/j.1529-1006.2004.00016.x

Kassin, S. M., \& McNall, K. (1991). Police interrogations and confessions: Communicating promises and threats by pragmatic implication. Law and Human Behaviour, 233251. doi:10.1007/BF01061711

Mason, M. (2016). The 'preparatory' and 'argumentation' stages of a police interrogation: A linguistic analysis of a criminal investigation. Language and Communication, 48, 79-87. doi:10.1016/j.langcom.2016.03.001

Meissner, C. A., Redlich, A., Bhatt, S., \& Brandon, S. (2012). Interview and interrogation methods and their effects on investigative outcomes. The British Journal of Criminology, 33, 325-352. doi:10.4073/csr.2012.13

Melinder, A., \& Gilstrap, L. L. (2009). The relationships between child and forensic interviewer behaviours and individual differences in interviews about a medical examination. European Journal of Developmental Psychology, 6, 365-395. doi:10.1080/17405620701210445

Moeschler, J. (2013). Is speaker-based pragmatics possible? Or how can a hearer infer a speaker's commitment? Journal of Pragmatics, doi: $10.1016 /$ j.pragma.2012.11.019 48, 84-97.

Moston, S., \& Engelberg, T. (1993). Police questioning techniques in tape recorded interviews with criminal suspects. Policing and Society, 3, 223-237. doi:10.1080/10439463.1993.9964670 
Moston, S., \& Fisher, M. (2007). Perceptions of coercion in the questioning of criminal suspects. Journal of Investigative Psychology and Offender Profiling, 4, 85-95. doi: $10.140023 /$ jip. 66

Moston, S., Stephenson, G. M., \& Williamson, T. (1992). The effects of case characteristics on suspect behaviour during police questioning. British Journal of Criminology, 32, 23-39. doi:10.1093/oxfordjournals.bjc.a048178

Narchet, F. M., Meissner, C. A., \& Russano, M. B. (2011). Modeling the influence of investigator bias on the elicitation of true and false confessions. Law and Human Behavior, 35, 452-465. doi:10.1007/s10979-010-9257$\mathrm{x}$

Nickerson, R. (1998). Confirmation bias: A ubiquitous phenomenon in many guises. Review of General Psychology, 2, 175-220. doi:10.1037/10892680.2.2.175

O'Brien, B. (2007). Confirmation bias in criminal investigations: An examination of the factors that aggravate and counteract bias (Doctoral dissertation). Retrieved from https://deepblue.lib.umich.edu/handle/2027.42/12652 6

Oxburgh, G. E., Myklebust, T., \& Grant, T. (2010). The question of question types in police interviews: $A$ review of the literature from a psychological and linguistic perspective. The International Journal of Speech, Language and the Law, 17, 45-66. doi:10.1558/ijsll.v17il.45

Parret, H. (1993). Indirection, seduction and manipulation in discourse. In $\mathrm{H}$. Parret (Ed.). Pretending to Communicate. Berlin, GE: de Gruyer.

Powell, M. B., Fisher, R. P., \& Wright, R. (2005). Investigative interviewing. In N. Brewer \& K. D. Williams (Eds.), Psychology and Law. New York, NY: The Guilford Press.

Searle, J. R. (1975). Indirect speech acts. Syntax and Semantics, 3, 59-82. Retrieved from www.library.tudelft.nl 
Semin, G. R. (2011). Language and social cognition. In F. Strack and J. Forster (eds.). Social Cognition - the Basis of Human Interaction. New York, NY: Psychology Press.

Shuy, R. (1998). The language of confession, interrogation, and deception. Thousand Oaks, CA: Sage Publications, Inc.

Van der Sleen, J. (2009). A structured model for investigative interviewing of suspects. In R. Bull, T. Valentine, \& T. Williamson (Eds.), Handbook of Psychology of Investigative Interviewing. Chichester, UK: John Wiley \& Sons.

Van Eemeren, F. H., \& Grootendorst, R. (1984). Speech acts in argumentative discussions. Dordrecht, NL: Foris Publications Holland.

Walsh, D., \& Bull, R. (2015). Interviewing suspects: Examining the association between skills, questioning, evidence disclosure, and interview outcomes. Psychology, Crime \& Law, 21, 661-680. doi: $10.1080 / 1068316 X .2015 .1028544$

Walton, D. (2003). The interrogation as a type of dialogue. Journal of Pragmatics, 35, 1771-1802. doi:10.1016/S0378-2166(02)0020-1 


\section{CHAPTER 8}

\section{Detecting Guilt-Presumption in a Police- Suspect Interview: An Evaluation of the Questions in a Dutch Murder Case}

This chapter has been accepted to the Journal of Investigative Interviewing Research and Practice:

Adams-Quackenbush, N. M., Tomas, F., Horselenberg, R., \& Van Koppen, P. J. (in press). Detecting Guilt-presumption in a police-suspect interview: An evaluation of the questions in a Dutch murder case. Journal of Investigative Interviewing Research and Practice. 


\section{ABSTRACT}

Controlled studies have demonstrated that guilt-presumptive questions are the most reliable indicator of interviewer guilt bias and accusatory behaviours towards a suspect. When evaluating police-suspect interviews, however, conventional methods primarily focus on the appropriateness of questions asked to gather information or elicit a confession. Within the various question categorisations used by researchers' guiltpresumption is not featured as a questioning strategy; therefore, those types of utterances are not recorded. Instead, guilt-presumptive utterances are aggregated with other types of inappropriate opinion statements. Moreover, there is often more happening within an interview than is immediately identifiable by simply focusing on question types and opinions. Examining the interactivity and behaviours that lead to accusations can reveal subtleties that have a profound influence on the flow and outcome of the interviews. In the present study we analysed $N=6$ interviews from a single murder investigation for guilt-presumptive language (accusations and insinuations of guilt) and question appropriateness. The interactions within the interview that occurred prior to, and immediately after the guiltpresumptive language was used were then analysed. The findings demonstrate that direct accusations prompted suspect denials, facilitated a drastic decline in suspect cooperation, and impeded the ability for interviewers to gain investigation relevant information (IRI). We argue that more applied research on guilt-presumptive language is needed in the investigative interviewing literature, particularly in the context of interviewer beliefs about suspect guilt as well as biased decision-making regarding questioning strategies.

Keywords: Investigative Interview, Evaluation, Analysis, Guilt Presumption, Accusations 


\section{INTRODUCTION}

Research findings have resulted in a consensus that guilt presumption is a significant underlying factor when police officers employ confrontational and accusatory interview techniques (e.g., Kassin, Goldstein, \& Savitsky, 2003; Narchet, Meissner, \& Russano, 2011). Despite the potential for detrimental effects on suspect behaviour and interview outcome, guilt-presumptive questions are not generally identified or assessed in research designed to examine question types. Researchers and practitioners have primarily opted to categorise questions using a variety of typologies that do not explicitly include guilt-presumption (for an overview see Oxburgh, Myklebust, \& Grant, 2010). Whilst those typologies may be suitable for obtaining a summary of the questions used during the interview, they may not be suitable for when a full understanding of the interview is required. For example, if a confession is called into question or the handling of a criminal case is investigated.

In this study, we examined a selection of interviews from a single Dutch murder case to demonstrate the importance of identifying and understanding the interactivity between the interviewer and the suspect. In the first part of this paper, we analysed the interviews by question type, suspect cooperation, and amount of investigation relevant information obtained. In the second part of the paper, we analysed those same interviews for insinuative and accusatory guilt presumptive language. We then discuss the influence of such language on the suspect's behaviour as well as the dynamic of the interview. We make an argument that guilt-presumptive language should be identified 
when evaluating interviews, as it may provide insight to the interviewer's guilt presumptions and help explain subsequent interview outcomes (e.g., reduced information obtained and reduced suspect cooperation).

\subsection{GUILT PRESUMPTION AND INFORMATION- GATHERING INTERVIEWS}

The investigative interview is a crucial tool for gathering investigation relevant information (IRI) from witnesses, victims and suspects. Suspect interviews generally occur at a crucial stage in the investigation (Baldwin, 1993), and it is imperative that the interview is conducted in a way that does not impede the investigation. However, factors of the criminal investigation such as scenario creation and identifying a prime suspect can introduce an expectancy of guilt once the suspect interview commences (O'Brien, 2007; Walton, 2003). The challenge for interviewers is then to remain objective whilst attaining the suspect's account, and this must be achieved considering the information they already have - no matter how incriminating that information may seem.

Weak information against a suspect can also be framed in a way to justify arrest and questioning (Kassin, 2005). Researchers have demonstrated that when police investigators do not have strong evidence against a suspect more coercive and undesirable interview tactics are employed to break down suspect denials (Ofshe \& Leo, 1997), as most case closure still relies on suspect confessions (Moston \& Fisher, 2007). However, some of the tactics used during suspect interviews can facilitate false confessions and lead to eventual miscarriages of justice through coercive tactics and guilt- 
presumptive questioning (Kassin, 2005). In fact, the most consistent finding throughout the literature suggests that interviewers are more likely to use guilt-presumptive language when they have an expectation of guilt about the suspect (Hill, Memon, \& McGeorge, 2008; Kassin et al., 2003; Moston \& Engelberg, 1993; Narchet et al., 2011; Ofshe \& Leo, 1997). Guilt presumption in police- suspect interviews has been shown to taint judgements of veracity (Meissner \& Kassin, 2002), influence the perceptions of others who may witness the interview (Vrij, Mann, Kristen, \& Fisher, 2007), alter innocent suspect behaviour (Adams-Quackenbush, Horselenberg, Hubert, Vrij, \& Van Koppen, 2018), and subject other aspects of the investigation to investigator bias (e.g., evidence evaluation, Ditrich, 2015).

Guilt-presumption is generally linked to confrontational interviews but can also be present within information-gathering contexts (see Hill et al., 2008). Van der Sleen (2009) highlighted factors that can contribute to false confessions and juxtaposed those factors with the practices and techniques in one of the more prominent Dutch information-gathering interview methods - the GIS (General Interview Strategy; Van Amelsvoort, Rispens, \& Grolman, 2010). Van der Sleen discussed how proper use of the GIS can prevent undesirable interview outcomes. That is, miscarriages of justice often occur when interviewers assume guilt from the beginning due to confirmatory behaviours (Lassiter, 2004) and employ improper questioning techniques. Although officers are trained to use these types of frameworks, there is evidence in the literature to suggest that police interviewers do occasionally diverge from their 
training and resort to accusatory strategies and coercive tactics to increase interrogative pressure and reduce suspect denials (Griffiths \& Milne, 2006; Moston \& Engelberg, 1993).

8.1.1 Guilt presumptive language. Guiltpresumptive language can occur in all types of interviews because humans typically have the need to confirm their beliefs (Nickerson, 1998). Within the police-suspect interview, a confession could be perceived as proof that a guilt presumption was correct, and the police were right to focus on the suspect as the perpetrator. When guilt presumption is present, some interviewers may unconsciously employ questioning techniques that help confirm their guilt beliefs. In some situations, this is done through accusations that are presented as statements posed as questions (for examples see Komter, 2003), or as direct opinion statements designed to highlight a power imbalance, instil helplessness, or imply threats to a suspect (see Farinde, Olajuyigbe, \& Matthew, 2015). However, the prevalence of those tactics in information-gathering interviews is suspected to be rare (Moston \& Engelberg, 1993), but is currently unknown. The authors of this paper could not locate any literature that specifically evaluated police-suspect interviews for accusatory or guilt presumptive language in information-gathering contexts. However, there is some emerging research that suggested outright accusations of involvement in a crime may be infrequent in information-gathering contexts and more insinuative accusations of guilt may be used to break down suspect denials or resistance (authors, 2018). 
Insinuations are a type of covert speech act that are defined by a set of felicity conditions that remove accountability for the truth of the statement from the speaker and the intention of the insinuation is not explicitly stated (Attardo, 1999; Bertuccelli Papi, 1996). In an investigative interview, insinuations may be used in the interview to imply guilt or instil doubt or helplessness in the suspect. That type of language can cause the suspect to respond defensively or to become uncooperative. Both of those behaviours can directly affect the course of the interview dialogue and change the interpersonal dynamic of the interview. Insinuations can occur during questioning; however, they are most likely to be found when the interviewer deviates from inquiry and offers opinion statements or engages in argumentative dialogue with the suspect (authors, 2018). Opinion statements are also where many interviewers deviate from their training and employ poor interviewing practices (Griffiths \& Milne, 2006; Van der Sleen, 2009), and where insinuative language is most likely to occur.

\subsection{EVALUATING INVESTIGATIVE INTERVIEWS FOR GUILT PRESUMPTIVE LANGUAGE}

When evaluating police-suspect interviews, conventional methods primarily focus on the appropriateness of questions asked to gather information or elicit a confession. Within the various question categorisations used by researchers, guiltpresumption is not featured as a questioning strategy; therefore, those types of utterances are not generally captured. Instead, guilt-presumptive utterances are aggregated with other types of inappropriate opinion statements. In the broadest format, some typologies include categories for 
appropriate and inappropriate questions (Milne \& Bull, 1999; Shepherd \& Griffiths, 2013). Some researchers have examined the purpose of the questions more closely and included categories for open, closed, probing, and leading questions, as well as opinion statements (e.g., Davies, Westcott, \& Horan, 2000; Griffiths \& Milne, 2006). There is no consensus or standardised question types amongst researchers or practitioners regarding those categories. There is, however, overall agreement that certain question types (i.e., leading, rapid/ multiple questions, and forced-choice questions) should be avoided in all types of interviews (i.e., witness, victim, and suspect; Oxburgh et al., 2010).

Including guilt-presumptive language as a question type is important to draw attention to its presence within the interview. It is generally understood that utterances have intention, convey meaning, and occur in context of a situation. Those elements taken together can help interview analysists have a more in-depth understanding of what is happening within the dialogue (e.g., Haworth, 2006; Heydon, 2005). Simply knowing that guilt presumption was present in the interview can provide valuable insight about how the interview was conducted, and perhaps raise some important questions about any confession outcomes (e.g., obtained voluntarily and without coercion). However, simply identifying insinuations or accusations is not sufficient to fully comprehend any negative influences either may have on the interview interaction. For that, a more thorough evaluation of the content is needed. Further insight into the exchanges within an interview is often required to fully understand the effect that guilt-presumptions 
have on eliciting information and influencing suspect behaviour. Therefore, linguistic techniques rooted in pragmatics and content analysis may be the best approach for identifying guilt presumptive language and behaviours consistent with confirmation bias (Oxburgh et al., 2010; Grant, Taylor, Oxburgh, \& Myklebust, 2015).

Analysing the content of the interview allows the evaluator to focus on the utterances in context, as well as the consequences of the utterances. From an applied and practitioner standpoint, analysing the speech content and the function of the utterances in an interview is also a feasible approach for single cases. Investigative interviews are sometimes subjected to scrutiny because some aspect of the interview has been called into question. In those instances, interview evaluation is conducted by experts who are usually asked to inform a judge on the reliability of a confession ${ }^{9}$. That type of evaluation is only possible if the expert examines the language, tactics, and interactions that occur throughout the interview and has a full understanding of the questions posed to the suspect. Although a report on the types of questions used in the interview would not provide useful information to a court, a report identifying accusatory language as an indicator of guilt presumption and its negative

9 Courts will often ask experts to provide opinion on the reliability of confessions; however, this legal phrasing is erroneous from a measurement perspective. A reliable confession would be one that is consistently given in the same way over several time points. A valid confession is one that accurately portrays the details of the crime and is obtained voluntarily without coercion. 
effects - backed up by empirical findings - could be valuable guidance for a judge.

\subsection{THE PRESENT STUDY}

Many controlled studies have highlighted the negative effects of guilt-presumptive questions in interviews (see Hill et al., 2008; Kassin et al., 2003; Meissner \& Kassin, 2002; Narchet et al., 2011; Olson, 2013). Those studies have also emphasised the relationship between guilt-presumption, biased decision-making (e.g., confirmation bias), and false confessions. However, when question types are evaluated for police-suspect interviews, guiltpresumptive language is absent from the more popular question typologies used by practitioners and researchers. In the remainder of this article, we will demonstrate the benefits of identifying guilt presumptive language through question classification. We then provide further insights to any negative effects of guilt-presumptive language on information-gathering endeavours, the interviewersuspect interaction, and suspect cooperation. To demonstrate this, we present the data from a portion of interviews in a single murder investigation conducted in The Netherlands.

\subsubsection{Background on the Dutch GIS model.}

The GIS is an interview model loosely based on the PEACE interview framework used in countries such as the UK, Norway, and Australia (see College of Policing, 2016; Hoekendijk, \& Van Beek, 2015). Dutch interviewers who use the GIS will plan and prepare for the interview (Van Beek \& Hoekendijk, 2015). The interviewers are trained to engage and explain with the suspect, and the within their pursuit of the truth, interviewers will also obtain the suspect's account, clarify information, and challenge 
statements as needed. Each interview should end with a review of the interview questions and suspect responses. Finally, the investigators will evaluate any information obtained to further the investigation and decide if more interviews are needed (Van der Sleen, 2009). This is where the similarities with the PEACE framework ends. The GIS also contains instructions to 'build interrogative pressure', 'break down suspect denials' and 'reward with praise if the suspect's statement is adjusted to reflect the truth' (see Clement, Van de Plas, Van den Eshof, \& Nierop, 2012; Van Amelsvoort, et al., 2010).

8.3.2 Case background. A man was found dead in a small town in The Netherlands. The police conducted an extensive investigation and interviewed many people in relation to the case. Various CCTV information, from multiple locations, showed the victim with an unidentified adult male, hours before his death. The unknown individual was identified by the Dutch rail police through the CCTV footage, and his identity was given to the investigators on the case. It was eventually revealed through interviewing other witnesses that the man (henceforth referred to as the suspect) was an acquaintance of the victim. Based on the CCTV footage of the suspect and victim leaving the train station together, the investigators believed the suspect was the last person with the victim before his death. The suspect was arrested and brought in for questioning. Some of the physical evidence collected at the scene was traced back to the suspect after a search and confiscation of his personal items. However, the evidence was weak and did not implicate the suspect in the commission of a crime. To further the case, the police needed the suspect to 
provide his account of events and explain the evidence against him. In accordance with Dutch custody procedures, the suspect was remanded for questioning, which was extended for a little over two months while the investigation continued. During that period, the suspect was interviewed 17 times by two interviewers who used the GIS framework (Van Amelsvoort et al., 2010). The suspect maintained his innocence throughout the process and was eventually freed due to a lack of evidence that implicated him as the killer.

Although the suspect was released from custody, the 2.5 months he was remanded had negative effects in his personal life. During the remand period, the suspect lost his job and placement in a drug rehabilitation program. As a result, he became a financial burden to his family, and returned to drugs, which deteriorated the family dynamic. Ten months after his release, the suspect returned to the police station and offered to confess to the murder if a number of conditions could be met (e.g., specific prison to serve his time, a bible, and access to drug rehabilitation). The conditions were agreed upon, and in the interview that followed he gave his account of the murder. However, the suspect did not reveal key information that only the murderer would know. The investigators conducted four subsequent interviews in an attempt to obtain a statement that was consistent with the evidence; however, the interviewers did not succeed. Prior to trial, all 23 interviews and the case file were sent to an expert for an opinion on the reliability of the confession. Despite initially maintaining his innocence for 17 interviews and providing an inconsistent confession to the crime, the suspect was 
sentenced to 18 years in prison. The case has been appealed and legal proceedings are ongoing at the time of this writing.

\subsection{Method}

8.4.1 Interviews. Twenty-three interviews with a murder suspect were obtained from the expert involved in the analysis of the police suspect interviews. During each interview session, two interviewers and the suspect were present. There was no legal counsel present in any of the interviews. All the interviewers and the suspect spoke Dutch.

The last six interviews were excluded from this study because they occurred 10 months after the suspect was released with no charges due to lack of evidence. Moreover, those last six interviews occurred under a different set of circumstances and were unsuitable for evaluating interviewer guilt presumption. All 17 remaining interviews were coded for speech content and interview theme; however, only six $(N=6)$ interviews were randomly chosen for analysis on question types ${ }^{10}$. The mean interview length of the six interviews was 113 minutes ( $S D=$ 14.77). The first (\#1) interview was purposefully chosen as a natural starting point as it contained the free narrative from the suspect. An additional five interviews were then randomly selected from the remaining sample (interviews $\# 2, \# 3, \# 8, \# 10$, and \#16). Five of the interviews had the same two male interviewers. The primary male interviewer asked most of the questions and is indicated by I1. The

\footnotetext{
${ }^{10}$ The pattern of questioning and question types was repetitive throughout the 17 interviews. Because the objective of the case study is to demonstrate the type of information that can be obtained by different methods of interview evaluation, the authors decided a random sampling of six interviews was sufficient for this purpose.
} 
second interviewer occasionally engaged in asking questions, but his primary role was to type the suspect's responses to each question (I2 typed almost continuously throughout the interviews). He is indicated by I2. In interview \#16, the primary interviewer (I1) was replaced with a female detective who is indicated as I3.

8.4.2 Coding procedure. Due to the severity of the crime, the interviews were audio and visually recorded. All 17 interviews were viewed and transcribed in strict verbatim style in Dutch by a bilingual (Dutch/ English) research assistant (RA) who was naive to the purpose of the study. The RA used Jeffersonian transcription notation for conversational analysis with small variations for denoting overlapping speech, nonverbal behaviour, and contextual notes (Jefferson, 1984; see Appendix $\mathrm{F}$ for transcription notation). Each complete phrase uttered by all parties in the interview room received its own line number. The Dutch transcripts were then translated into English by the same assistant. The Dutch-to-English transcripts were checked by a second bilingual (Dutch/ English) RA for accuracy of translation. The first author of this paper then viewed the interviews with both language transcriptions to verify and take notes on: speaker tone of voice, interruptions, speaker volume, and inflection. Nonverbal behaviours (e.g., gestures) were also noted to gain additional insight to the demeanour and context of the interactions.

\subsubsection{Coding the techniques. The}

translated transcripts were divided into turns for coding purposes. Turns were defined as a complete interaction that was initiated by an interviewer's question or comment. The turn continued until the 
interviewer asked a new question or made a statement on a topic unrelated to the current topic under discussion. Only questions directly relevant to obtaining IRI or clarification were coded. Questions such as, "can I get you a drink?" or "what did you have for lunch?" were not coded for analysis. Additionally, only statements that pertained to the case were coded. Informative statements such as "your sister dropped off clothes and cigarettes for you" or an interviewer response to questions posed by the suspect during small talk and banter were also not included (e.g., "I'll see what I can do about getting you some warmer clothing"). To calculate intercoder reliability, $20 \%$ of the interviewer questions and $20 \%$ of the suspect's responses were randomly selected and recoded by a third RA who was also blind to the purpose of the study. Percent agreement was calculated for each factor and conservative agreement thresholds were applied: < $.80=$ poor, $.80-.86=$ fair, $.87-.93=$ good, and $.94-.10=$ excellent.

The codable questions asked by the interviewers were first categorized by broad question types (appropriate and inappropriate; Milne \& Bull, 1999; Shepherd \& Griffiths, 2013). Interrater agreement was $89.9 \%$, which suggested a high level of consistency. Questions were then coded using more specific types (open, probing, appropriate closed, inappropriate closed, leading, forced choice, multiple, and opinion/ statement; see Appendix G for definitions). Interrater agreement was $87.3 \%{ }^{11}$. All discrepancies in the coding were due to the

\footnotetext{
${ }^{11}$ All interrater disagreement was resolved by checking the transcripts. In cases where subjective decisions were needed, the first author along with a subject matter expert made the final decision when appropriate.
} 
distinction between appropriate and inappropriate for the closed question category. The disputed questions were then presented within the contextual dialogue to a subject matter expert (in investigative interview questions) for a final decision on 'appropriateness'.

8.4.4 Identifying and Analysing the Speech Acts. The translated English transcripts were analysed for occurrences of guilt-presumptive language (direct accusations and insinuations of guilt) within each turn. Once an instance was identified, the suspect's utterances immediately prior to, and immediately after, the insinuation were evaluated for information elicited during the exchange as well as suspect cooperation. A linguist who was blind to the purpose of the study also reviewed the occurrences of insinuation to ensure objectivity in the analysis. There was $100 \%$ agreement in all instances.

8.4.5 Investigation relevant information (IRI). The responses to each question were examined for IRI within each turn to assess question efficacy. Relevant information was coded using established schemes adapted from previous studies (see Hutcheson, Baxter, Telfer, \& Warden, 1995; Milne \& Bull, 2003; Oxburgh, Ost, Morris, \& Cherryman, 2014). The IRI was defined as: Person information,

Action information,

Location information, Item information, and Temporal information (PALIT). Each piece of information obtained was coded only once across all interviews and only new information was included. Interrater agreement was $94.2 \%$.

8.4.6 Suspect cooperation. If the suspect responded to a question with an answer that gave information or explanation (regardless of detail or 
length), it was coded as cooperative. If the suspect refused to respond, invoked his right to silence, or evaded the question, it was coded as uncooperative. Interrater agreement was $96.8 \%$.

\subsection{RESULTS}

\subsubsection{PART I ANALYSIS: QUESTION TYPOLOGIES AND OUTCOMES}

Across the six analysed interviews there were 1942 codable utterances made to the suspect ( $n=$ 1049 questions, $M_{\text {questions }}=174.8, S D=58.9 ; n=$ 893 statements, $\left.M_{\text {statements }}=148.8, S D=88.8\right)$. The GIS interviewing framework requires interviewers to conduct two types of interviews: suspect oriented and case oriented. Moreover, interviewers who use the GIS approach start each interview with a theme for questioning and some prepared questions (see Table 8.1 for additional information on each interview). To determine whether interview type influenced the types of questions asked, ANOVAs were conducted between interview types to compare the variables of interest. No significant differences emerged whether the interviewers focused on the suspect (person-oriented) or the information and evidence (case-oriented). Frequency of accusatory questions $[F(4,1)=.75, p=.44]$, number of appropriate questions $[F(4,1)=1.01, p=.37]$, and number of inappropriate questions $[F(4,1)=2.15, p$ $=.22]$ did not differ across interview types.

Question types. There were no occurrences of accusatory questions in these interviews, however there were 13 direct accusations of involvement in the crime and 12 insinuations of involvement that were all presented as statements. All guiltpresumptive language occurred within the category of inappropriate opinion statements $(7 \%$ of 
utterances). Within the overall statements made by the interviewers, $38.8 \%(n=347)$ of the interviewer utterances were categorised as inappropriate. The remaining $61.2 \%$ of the overall statements pertained to the case and were considered appropriate utterances. However, within the coding structure there was no category for appropriate statements (e.g., explanation of charges, presentation of evidence, or paraphrasing of suspect responses). Thus, appropriate statements were not included in the subsequent analyses of appropriate and inappropriate utterances.

Most of the questions posed to the suspect were appropriate $(61.9 \%)$, which was attributed to the high number of closed-appropriate questions overall $(34.4 \%)$. The interviewers use of open (Tell Explain Describe: TED) questions was negligible across the interviews $(<1 \%)$. The most commonly used inappropriate questions were leading questions $(16.1 \%)$ followed closely by inappropriate closed questions (11\%). Guilt-presumptive language featured more prominently, in relation to other types of questioning, at interviews \#2 and \#8, which were both case-oriented interviews (see Table 8.1).

Interviewers obtained 198 pieces of investigation relevant information (IRI) within the six analysed interviews. Most of the IRI was acquired during the suspect's free narrative within the first interview $(40.9 \%)$. The amount of IRI attained steadily decreased over the course of the interviews with sharp drops at interviews \#8 and \#16 and a small spike at interview \#10. A similar trend was observed with suspect cooperation. In the first interview, the suspect cooperated with interviewers $90 \%$ of the time, with a sharp decrease at interview \#3 to 
cooperating $15 \%$ of the time. The suspect maintained a low level of cooperation for the remainder of the interviews with a small increase in cooperation in interview \#10 (13\%; see Figure 8.1).

In the previous analysis, we demonstrated the type of information that can be obtained from policesuspect interviews when the question type, IRI, and suspect cooperation are coded. An overview revealed that the majority of questions were appropriateclosed. Whilst those types of questions are not considered the best for gaining IRI, they are effective for confirming information and obtaining short and specific responses. When used excessively, appropriate-closed questions are an indication of amateur or poor questioning practices (Shepherd \& Griffiths, 2013).

\subsubsection{PART II ANALYSIS: GUILT PRESUMPTION AND ACCUSATIONS IN CONTEXT}

In the analysis that follows, we examined the context, words, and interaction between the interviewers and suspect for each interview. We provided a sample of instances of accusation and insinuation to demonstrate the type of information that can be obtained with a more in-depth type of evaluation.

According to the GIS, the first interview of this case should be a free-narrative or 'first contact' interview (Van Amelsvoort et al., 2010). The interviewers initially followed the standard GIS process and informed the suspect of his rights and the process of the interview. The interviewers then provided the suspect with procedural information and the reason for his arrest. The free narrative was 
Table 8.1

Descriptive information about the interviews: primary interviewer, interview length, interview type and the themes for questioning.

\begin{tabular}{|c|c|c|c|}
\hline $\begin{array}{l}\text { Interview } \\
\#\end{array}$ & $\begin{array}{l}\text { Length } \\
\text { (min) }\end{array}$ & $\begin{array}{l}\text { Interview } \\
\text { Type }\end{array}$ & $\begin{array}{l}\text { Questioning Themes \& } \\
\text { Topics }\end{array}$ \\
\hline 1 & 148 & $\begin{array}{l}\text { Opening/ } \\
\text { Case }\end{array}$ & $\begin{array}{l}\text { Charges } \\
\text { Free narrative } \\
\text { Alibi } \\
\text { Suspect knowledge }\end{array}$ \\
\hline 2 & 123 & Case & $\begin{array}{l}\text { Acquaintances } \\
\text { Transportation } \\
\text { Cell phone use (Suspect) } \\
\text { Cell phone use (Victim) } \\
\text { Drug use } \\
\text { Alibi (clarification) }\end{array}$ \\
\hline 3 & 124 & Person & $\begin{array}{l}\text { Religion } \\
\text { Residence } \\
\text { Finances } \\
\text { Employment } \\
\text { Belongings } \\
\text { Social Media } \\
\text { Cell phone use \& Contacts } \\
\text { Drug use } \\
\text { Shared clothing \& items }\end{array}$ \\
\hline 8 & 155 & Case & $\begin{array}{l}\text { Witness statements } \\
\text { Confront inconsistencies }\end{array}$ \\
\hline 10 & 128 & Person & $\begin{array}{l}\text { Relationship with daughter } \\
\text { Phone contacts }\end{array}$ \\
\hline 16 & 132 & Case & Presentation of evidence \\
\hline
\end{tabular}

prompted with an open question about the day the suspect was seen travelling with the victim. That allowed the suspect to provide a response that was punctuated with some probing, clarifying, and appropriate- closed questions from the interviewers. Approximately 40 minutes into the interview, the suspect gave his first denial of involvement. He then gave some resistance when prompted for the name 
of his drug dealer. The suspect felt that information was unrelated to the murder and did not want to cause the dealer unnecessary problems with the police. After some discussion about the importance of knowing who the dealer was (for alibi substantiation), the first accusation occurred at 0:42:26 minutes into the interview:

I1: Yes, but those are people at that moment who can confirm whether some people were or were not present at the time.

S: Um::: I think it's such a minor detail (.) I mean $=$

I1: = Yes to you to you it is a::: it is a small detail (.) but on the other hand ((points at the suspect with dramatic emphasis)) YOU are here $=$

S: = Yes I do know that, but //

I1: /And you are sitting here because you are involved in the death of [Victim]/

S: $=$ Yes

I1: And if you say yes but I have nothing to do with it then really use this opportunity that YOU now have // to say like yeah so and so can confirm that I (.) wasn't there // that I was somewhere else $=$

S: /Yes/

S: /Yes but I keep saying that, [person name] eh (mumbles)/

S: $=$, oh him him him too (inaudible) [male name] [3] I do know I do know the address number (hhh) anyway he is still using and eh he always comes there too eh/

The accusation is a clear statement that the suspect is being interviewed because he was certainly involved in the victim's death. The phrasing of this statement to indicate actual involvement was very 
important. The interviewer could have delivered that message with less accusatory phrasing, but that would not have led to the desired effect to increase interrogative pressure and reduce denials. That is, the guilt-presumptive language was possibly used as a tactic to reduce the resistance of the suspect and remind him of the severity of the situation. In this instance, the suspect responded to the accusation with cooperation and attempted to provide the name of a male drug-user who could verify the alibi instead of naming the dealer. That response also provided the interviewers with additional IRI (person). However, accusations as a tactic can also backfire. The use of accusatory and confrontational questions has been shown to have negative effects on suspect cooperation that can last up to 15-minutes (Kelly, Miller, \& Redlich, 2015).

Another tactic used within the GIS is to conduct a person-oriented interview early in the process. This is often the second step after the free narrative or 'first contact' interview. The personoriented phase allows interviewers to establish rapport, gain some insight into the person they are interviewing, and to get the suspect talking (Geijsen, Vanbelle, Kop, \& De Ruiter, 2018; Van Amelsvoort et al., 2010). The interviewers in this case opted not to employ this tactic and at the next interview, they continued with their efforts from the previous day to gather case specific information. That decision to diverge from the GIS process may have impeded their ability to attain meaningful IRI. 


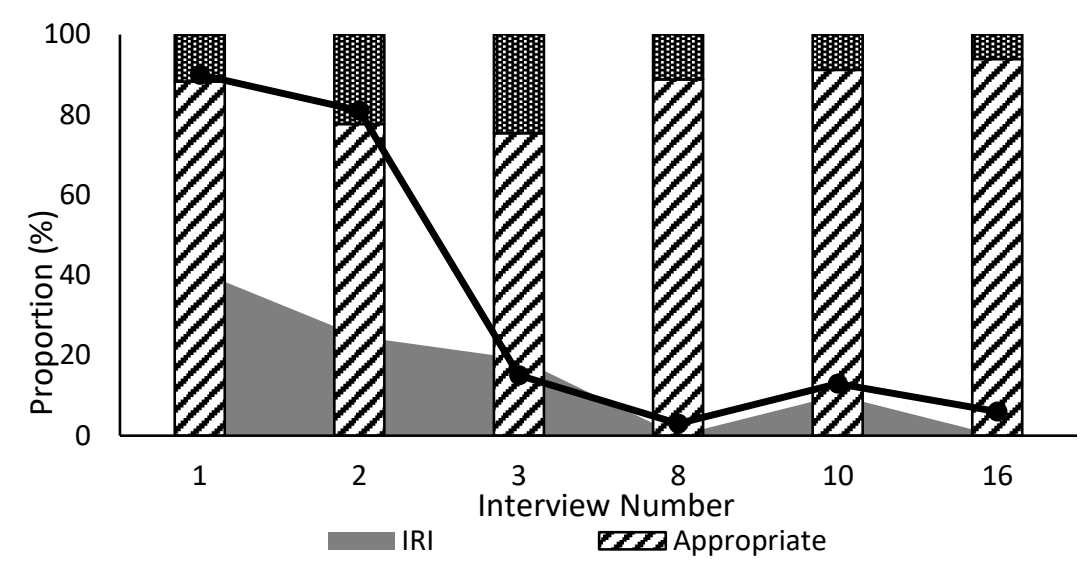

Figure 8.1. Proportion of appropriate questions and inappropriate questions asked, investigation relevant information obtained, and suspect cooperation over six interviews.

Throughout most of the second interview, the interviewers asked pointed questions about specific pieces of information that the suspect already provided in the first interview (appropriate closed questions). The suspect answered the questions and some additional IRI was obtained. However, towards the end of the interview there was a sudden shift in interviewer behaviour when I1 asked I2 if he had any questions. I2 responded with an insinuation that the suspect was lying. It should be noted that I2's primary role within the interviews was to record the suspect's responses into an interview table that was located on a computer. That document likely contained a list of topics, themes, and specific questions that the interviewers used as a guide, as well as information that had been collected about the case (Van Beek \& Hoekendijk, 2015). I2 would have 
information that raised questions about the truthfulness of the suspect's response (revealed in a later interview). Because it was too soon to confront the suspect with that information, I2 may have chosen to express his disbelief by accusing the suspect of lying:

I1: I am eh::: running out of questions so I am looking at [I2's name] ((looks at I2))

I2: (hhh) I think he really needs to think very hard right now

S: About?

I2: You came back by train (.) yes?

S: ((nods))

I2: Then you're telling a story

The suspect then stated that it was a regular day to him, so he could not recollect the exact minute details about his whereabouts, the people he spoke to, and the phone calls he may have made that the interviewers were pressing him for. I2 and I1 then use the suspect's utterances as a starting point for a stream of guilt-presumptive language that included statements as questions and insinuations of involvement:

I2: That is a very crucial day right? // Look it might be a day like any other day to you $=$

S: /(mumbles) (inaudible)/

S: = Yes but I'm saying -

I2: So do remember that that day was the last day eh:: : that [victim] saw the light of day (.) Yes?

S: (nods) Yes but I -

I1: And you are simply one of the last (.) maybe the last person who saw him (.) So, eh::: you can say that is an ordinary day to me and I went from 
there to there and I really don't remember everything (.) And as [I2] already mentioned a few times (.) you need to start to think really hard right now

S: Yes because I'm telling you -

I2: SOMEONE HAS BEEN KILLED AND YOU WERE THERE $=$

S: $=$ [defensively] But I just know (.) Look

(.) if I was so to say there (.) and if I had done it (.) then it would have been a special moment (.) special day (.) then I would know about that and that

I2: $=$ Mhrm =

S: [defensively] ((gestures for emphasis))

To me it's a day like any other day and I can't say like (.) well I come across him and so and so often (.) so many different people (.) it's just (.) to me really nothing special happened that day

I1: Now (.) very briefly [suspect's name] (.) you went to [town in The Netherlands] with [victim] $=$

$\mathrm{S}:=$ Yes $=$

I1: AND HE WAS FOUND DEAD AFTER

The exchange continued with the interviewers repeating that the suspect was with the victim on the day of his death another three times. The suspect retorted by asking the interviewers how they know that he was the last person with the victim if they lost track of the victim's whereabouts after he left the train station. The interviewers did not respond to the question. The interview dialogue deteriorated over the next seven minutes into an argument filled with sarcastic replies, and further guilt-presumptive language uttered by the interviewers. The dialogue was never recovered, and the suspect became 
uncooperative. The interviewers decided to end the session and start again after lunch.

The third interview (conducted a few hours after the previous exchange) was when the interviewers finally attempted to conduct a personoriented interview designed to build trust and rapport. This interview, however, contained the highest proportion of inappropriate questions and one instance of guilt-presumptive language, neither of which are considered conducive for building rapport or obtaining IRI. Most of the inappropriate questions came from the category of inappropriateclosed questions. It was also during this interview that the most drastic decline in suspect cooperation occurred, which also influenced the amount of IRI obtained.

Most of the issues with the third interview can likely be attributed to the confrontational and accusatory behaviour exhibited by the interviewers in the interview directly preceding it. When the suspect returned to the interview room after lunch he appeared to be in a foul and uncooperative mood. The interviewers spent a significant amount of time negotiating the suspect's cooperation, to no avail. His demeanour was closed, and his posture was defensive. Periodically throughout interview \#3, the suspect answered some questions and divulged a bit of new information. At one point in the interview, he spoke about a serious health issue concerning one of his family members. He explained how being incarcerated was troubling him, because he could not be there for that person while he was in custody. The suspect also lamented that he had been doing well in his life and now the arrest had changed that. Those moments would have been perfect opportunities for 
the interviewers to build rapport and open the dialogue to learn more about the suspect. Instead, this was where the I1 insinuated his belief that the suspect was involved in the victim's death:

S: [The suspect's utterance is omitted as it was almost completely comprised of identifying information]

I1: Yes, but there is a reason why you are here (.) isn't there! And t-that silly thing that happens (.) I don't want to hear that and that (.) You do it to yourself (.) Its that you - At some point when we are discussing normal questions you just go and say like well I'm not going to cooperate any more.

S: Yes =

I1: = I can - (.) My gut feeling is not getting any stronger about you [suspect] to say that guy really has nothing to do with it

S: No way (.) eh::: I have (.) that's why I'm saying (.) I told you to the point where I saw [victim] and what happened and the last time I saw him (.) But otherwise I have nothing to do with it! And I'm not going to tell you stuff or put words in your mouths because that's where that I'm thinking like (.) well you (.) you all know it too

The exchange between I1 and the suspect around his involvement in the crime continues. It eventually ended with the suspect invoking his right to silence and the interviewers once again attempting to negotiate cooperation. The interview dialogue was not regained within this interview, and rapport building did not occur.

Interview \#8 was case-oriented and occurred four days after interview \#3. In that time, four other interviews were conducted. In the four unanalysed 
interviews, the suspect was mostly confronted with witness statements. Those statements potentially called into question the suspect's account of his whereabouts, as well as the suspect's knowledge of why the victim travelled to the town where he was found dead. Interview \#8 contained mainly appropriate questions $(88.83 \%$; probing and appropriate-closed); however, no IRI was obtained and suspect cooperation was at the lowest point over the six analysed interviews. It could be argued that by the eighth interview, the suspect simply had no more information to offer, or perhaps he was overwhelmed with the evidence against him. But a closer look at the 10 instances of guilt-presumptive language identified within the interview provide a different perspective.

The interview started as usual with a reminder of the suspect's rights, re-introductions, and some inquiries about the suspect's well-being (e.g., health, warmth, if he has eaten, etc.). The interviewers then made some small talk about their roles in the investigation and that they were simply assigned to be his interviewers. They told the suspect they do not judge him and there were no hard feelings toward him. The suspect seemed to be mildly embarrassed but appreciative of the gesture. The interviewers then made some inquiries about the suspect's religious faith and what that meant for his morality and honesty. The suspect engaged in the banter until eight minutes into the interview. At that point, I1 suddenly moved the topic of discussion to his belief that the suspect had been lying to them over the previous interviews. That led to the first explicit statement of guilt: 
I1: Look (.) we are investigating all things that are AGAINST you (.) but if there are things that work in your favour (.) I want to investigate those too

S: Mm:: :

I1: You are here for murder. Not me

S: (hhh) Yes (.) no that's why -

I1: And there are things coming to light that are not right (.) I do believe that! But I think that most of the things that come up are things that you stated that are not true.

S: So eh (hhh) We will see when this goes to the judge (hhh)

The interviewer made an explicit mention that the suspect is in custody for murder and that he does not believe some of the suspect's statements. The suspect responds with an insinuation of innocence as he believes everything will be cleared up once the case goes before a judge. Immediately after the exchange, the theme of the interview was revealed as case oriented- presentation of evidence (see Table 8.1) and the suspect was presented with more witness statements.

Within the GIS, a case oriented- presentation of evidence interview is supposed to be an opportunity for the suspect to hear the evidence and respond to it, or offer further explanation (Van Amelsvoort et al., 2010; Van der Sleen, 2009). In this instance, the witness statements were presented as facts and the suspect statements were consistently challenged. The suspect was confronted with two witness statements that claimed the suspect confessed to a murder whilst having a religious moment and that God had confirmed to one of the witnesses that the suspect was a murderer. The suspect found those statements incredulous and denied such a confession or being involved in the 
murder of the victim. The interviewers stated that the witnesses never indicated who was murdered and concluded that the suspect had in fact killed someone, even if it wasn't the murder currently under investigation. They pressed the suspect using repeated (inappropriate) questions asking him who he had killed. The interviewer's behaviour resulted in multiple suspect denials, sarcastic exchanges, arguments about involvement, and increased suspect non-cooperation.

The tenth interview was a person-oriented interview centered around a member of the suspect's family for whom the suspect had a great deal of concern. The interviewers presented the suspect with a partial statement from that person, which had mixed results on the suspect's behaviour. Initially, the suspect was upset that the police approached the family member and he attempted to close the dialogue with uncooperative behaviour. The interviewers read the statement anyway, which invoked an emotional response in the suspect. The suspect's demeanour softened a bit and he became responsive to some of the questions, which resulted in a slight increase of IRI. Interview \#10 contained no direct accusations and only one instance of insinuative language after the interviewers attempted to gain information about the suspect's conversations with a behavioural management therapist. The suspect did not want to provide therapy information and claimed it had nothing to do with the case. The interviewers disagreed and then implied that they could tell by the suspect's nonverbal behaviour that he was involved in the murder:

I1: Yes (.) you don't want to talk about anything that has to do with this case 
S: (mumbles) I am talking about it (.) That has nothing to do with that case (.) what I said to the behavioural therapist then what or how -

I1: Ye::s (.) that that (.) your behaviour tells us something too right? I can see now on some of the questions how you eh (.) how you react and what kind of body language you use. There are almost no words necessary anymore [suspect]

S: Yes yes (hhh) (laughs) I think that's great. Then you only ((points to video camera)) need that kind of thing and then you see how they react and they are like that ((makes closed posture)) closed (.) like ((makes open posture)) open and eh ((shrugs)) Yes ((shrugs))

See what you want

In this situation, the suspect immediately caught on to the interviewer's implication that his body language was indicative of his guilt and made a sarcastically humorous retort about it. Some banter about body language ensued, and the exchange ended with the interviewer making some inquiries about people the suspect had in this mobile phone contact list. This is where all the IRI (person information) for this interview was obtained.

The sixteenth and penultimate interview occurred before the suspect was released due to lack of sufficient evidence to proceed to trial. The interview was composed almost entirely of appropriate questions (93.9\%); however, no IRI was obtained. The sole purpose of interview \#16 was to confront the suspect with all the evidence against him. The interview was conducted by a detective who was assigned to the case and consisted of an elaborate (and sometimes dramatic) unveiling of 
information through a visual presentation using well known presentation software. The suspect was asked to remain silent during the demonstration and told he would get an opportunity to respond after all the evidence had been disclosed. Once the presentation was completed, the suspect seemed confused as to how he was supposed to respond. Based on the ensuing dialogue, it appeared that the investigators now believed that the suspect was not the killer but was at the crime scene and was protecting whomever killed the victim. There were no guilt presumptive language or insinuations uttered during the interview; however, all evidence was presented in an accusatory manner and the interviewers frequently raised their voices.

\subsection{DISCUSSION}

The objective of the analysis presented in this article was to demonstrate the importance of identifying guilt-presumptive questioning and statements within the police-suspect interview. We evaluated a portion of the interviews in a murder case to demonstrate the type of information that can be obtained by identifying question types and the outcome of those questions (i.e., IRI and suspect cooperation). The analysis revealed that important information can be missed when evaluating interviews using typical question typologies. Evaluating the question types alone, gave the impression that these interviews contained mainly appropriate questions overall, even if they were not the most sophisticated types of questions. However, closer examination into the content revealed that although relatively infrequent, the guilt-presumptive language influenced the amount of IRI and suspect cooperation. An evaluation of the content that 
occurred immediately prior to and after the guiltpresumptive language suggested that direct accusations and insinuations of involvement had negative effects on dialogue, rapport, cooperation, and IRI (see author, 2018). For example, the negative effects from the very first interview tainted subsequent interviews with the suspect. Those effects could be particularly detrimental in jurisdictions where multiple interviews are a regular part of the processes, such as in The Netherlands.

Finally, it is up to the courts to ultimately decide guilt based on the available evidence and the 'reliability' of a confession. Judges will sometimes approach experts to help guide them in those decisions. An expert in this area would know that guilt-presumptive questioning has been repeatedly shown to indicate interviewer bias. An expert would also know that there is an abundance of literature that highlights the relationship between biases, coercive tactics, and false confessions. Thus, question type becomes an important factor when advising a judge on the 'reliability' of a confession. For that reason, more research is needed that captures guilt presumptive language as a questioning type and definitively demonstrates its detrimental effects on the interview. With enough evidence in that area, an expert would be able to advise a judge that the presence of such questioning indicates a probability of psychological coercion, which could call the confession evidence into question.

8.6.1 Methodological considerations. We acknowledge that this case is exceptional in that i) it is a single case, and ii) it was previously evaluated by an expert for confession reliability (i.e., validity), which implies at least one judicial player questioned 
the overall appropriateness. We do not propose that the interviews analysed here, or the fragments chosen as examples, are representative of all interviews that contain guilt-presumptive language, nor are they an example of a typical Dutch suspect interview. We do, however, present this analysis as a contribution to the plethora of extant literature that cautions against guilt-presumption, biased interviewing, and the potential for both to contribute to miscarriages of justice. That is, the pattern of behaviours described from the content of the interviews follows the findings previously outlined by other researchers who have examined suspect denials, uncooperative behaviours, and poor interviewing practices (e.g., Baldwin, 1993; Kassin, 2005; Kelly et al., 2015; Moston \& Engelberg, 1993; Ofshe \& Leo, 1997).

We also acknowledge that the ground truth of the interviewer beliefs was not known. This means we cannot comment explicitly on the presence of confirmation bias in the interviewers. Granted, the first interview contained an accusation of guilt, which may suggest that the interviewers assigned to the investigation believed the suspect was guilty. It is also possible that the accusations were merely used as a tactic to reduce resistance and the insinuations were uttered in frustration due to suspect denials (Griffiths \& Milne, 2006; Kelly et al., 2015). That is, the interviewers may have held no strong beliefs about guilt one way or the other. Yet, when all the interviews were taken together, it became clear that the investigators entered the interview with the intention to prove one scenario correct - that the suspect was involved in the murder of his acquaintance. It is not until the final interviews that 
the dialogue suggested the interviewers may have entertained a second scenario - that the suspect was at the scene and knew who committed the murder or was an accomplice. Nevertheless, in both scenarios the suspect was guilty of something and that remained the focus of the interviewers until the final interview.

\subsection{CONCLUSION}

The typologies currently used by researchers to evaluate question types do not contain a specific category for guilt-presumptive language. Identifying those types of utterances can prompt evaluators to investigate the interviews more closely, which may reveal how an interviewer's accusatory and insinuative language can negatively influence the interview outcomes. A cursory evaluation of interview question types can provide useful information about how the interview was conducted overall. However, there is a need for researchers to examine the content of interviews more closely, to identify guilt-presumptive language, and to build a literature that can be used to further research in investigative interviewing, improve the interviewing process, and inform the practitioners who use interview outcomes in their legal decision-making. 


\section{REFERENCES}

Adams-Quackenbush, N. M., Horselenberg, R., Hubert, J., Vrij, A., \& Van Koppen, P. J. (2019). Interview expectancies: Awareness of potential bias influences behaviour in interviewees. Psychiatry, Psychology, and Law. doi:10.1080/13218719.2018.1485522

Adams-Quackenbush, N. M., Tomas, F., Horselenberg, R., \& Van Koppen, P. J. (in preparation). When guilt is presumed: Discursive indicators of guilt presumption in police-suspect interviews.

Attardo, S. (1999). Covert speech acts and their meaning. Deseret Language and Linguistic Society Symposium, 25, 202-217.

Retrieved from https://scholarsarchive.byu.edu/dlls/vol25/iss1/19

Baldwin, J. (1993). Police interviewing techniques: Establishing truth or proof? The British Journal of Criminology, 33, 325-352. doi:10.1093/oxfordjournals.bjc.a048329

Bertuccelli Papi, M. (2014). Insinuating: The seduction of unsaying. Pragmatics, 6, 191 - 204. doi:10.1515/ip2014-001

Clement, S., Van de Plas, M., Van den Eshof, P., \& Nierop, N. (2012). Police interviewing in France, Belgium and The Netherlands: something is moving. In T. Williamson, B. Milne, \& S. P. Savage (Eds), International developments in investigative interviewing. Abington, UK: Routledge.

College of Policing. (2016, January 11). Investigative Interviewing. $\quad$ Retrieved from https://www.app.college.police.uk/appcontent/investigations/investigative-interviewing

Davies, G. M., Westcott, H. L., \& Horan, N. (2000). The impact of questioning style on the content of investigative interviews with suspected child sexual abuse victims. Psychology, Crime and Law, 6, 81-97. doi:10.1080/10683160008410834

Ditrich, H. (2015). Cognitive fallacies and criminal investigations. Science and Justice, 55, 155-159. doi: $10.1016 /$ j.scijus.2014.12.007 
Farinde, R. O., Olajuyigbe, O. A., \& Matthew, A. (2015). Discourse control strategies in police-suspect interrogation in Nigeria. International Journal of English Linguistics, 5, 146-158. doi:10.5539/ijel.v5n1p146

Geijsen, K., Vanbelle, S., Kop, N., \& De Ruiter, C. (2018). The interrogation of vulnerable suspects in The Netherlands: An exploratory study. Investigative Interviewing: Research and Practice, 9, 34-51. Retrieved from http://www.iiirg.org/journal

Grant, T., Taylor, J., Oxburgh, G., \& Myklebust, T. (2015). Exploring types and functions of questions in police interviews. In G. Oxburgh, T. Myklebust, \& R. Milne (Eds.), Communication in Investigative and Legal Contexts. Chichester. UK: John Wiley \& Sons, Ltd.

Griffiths, A., \& Milne, R., (2006). Will it all end in tiers? Police interviews with suspects in Britain. In T. Williamson (Ed.), Investigative Interviewing, (pp. 167 - 189). Abingdon, UK: Willan Publishing.

Haworth, K. (2006). The dynamics of power and resistance in police interview discourse. Discourse \& Society, 17, 739759. doi: $10.1177 / 0957926506068430$

Heydon, G. (2012). Helping the police with their enquires: Enhancing the investigative interview with linguistic research. The Police Journal, 85, 101-122. doi:10.1350/pojo.2012.85.2.581

Hill, C., Memon, A., \& McGeorge, P. (2008). The role of confirmation bias in suspect interviews: A systemic evaluation. Legal and Criminological Psychology, 13, 357-371. doi: 10.1348/135532507X238682

Hoekendijk, J., \& Van Beek, M. (2015). The GIS-model: A Dutch approach to gather information in suspect interviews. Investigative Interviewing: Research and Practice, 7, 19. Retrieved from http://www.iiirg.org/journal

Hutcheson, G. D., Baxter, J. S., Telfer, K., \& Warden, D. (1995). Child witness statement quality: Question type and errors of omission. Law and Human Behaviour, 19, 631648. doi:10.1007/BF01499378 
Jefferson, G. (1984). Transcription notation. In J. Atkinson and J. Heritage (Eds.), Structures of Social Interaction. New York, NY: Cambridge University Press.

Kassin, S. M. (2005). Does innocence put innocents at risk? American Psychologist, 60, 215-228. doi:10.1037/0003066X.60.3.215

Kassin, S. M, Goldstein, C. C., \& Savitsky, K. (2003). Behavioral confirmation in the interrogation room: On the dangers of presuming guilt. Law and Human Behavior, 27, 187203. doi:10.1023/A: 1022599230598

Kelly, C. E., Miller, J. C., \& Redlich, A. D. (2015). The dynamic nature of interrogation. Law and Human Behaviour, 40, 295-309. doi:10.1037/lhb0000172

Komter, M. (2003). The interactional dynamics of eliciting a confession in a Dutch police interrogation. Research on Language and Social Interaction, 36, 433 - 470. doi:10.1207/S15327973RLSI3604_5

Lassiter, D. (2004). Interrogations, confessions, and entrapment. New York, NY: Kluwer Academic/ Plenum Publishers.

Meissner, C. A., \& Kassin, S. M. (2002). "He's guilty!": Investigator bias in judgements of truth and deception. Law and Human Behavior, 26, 469 - 480. doi:10.1023/A:1020278620751

Milne, B., \& Bull. R. (1999). Investigative interviewing: Psychology and practice. Chichester, UK: John Wiley \& Sons.

Milne, B., \& Bull. R. (2003). Does the cognitive interview help children to resist the effects of suggestive questioning? Legal and Criminological Psychology, 8, 21-38. doi: $10.1348 / 135532503762871219$

Moston, S., \& Engelberg, T. (1993). Police questioning techniques in tape recorded interviews with criminal suspects. Policing and Society, 3, 223-237. doi:10.1080/10439463.1993.9964670

Moston, S., \& Fisher, M. (2007). Perceptions of coercion in the questioning of criminal suspects. Journal of Investigative 
Psychology and Offender Profiling, 4, 85-95. doi: $10.140023 /$ jip.66

Narchet, F. M., Meissner, C. A., \& Russano, M. B. (2011). Modeling the influence of investigator bias on the elicitation of true and false confessions. Law and Human Behavior, 35, 452-465. doi:10.1007/s10979-010-9257$\mathrm{x}$

Nickerson, R. (1998). Confirmation bias: A ubiquitous phenomenon in many guises. Review of General Psychology, 2, 175-220. doi:10.1037/10892680.2.2.175

O'Brien, B. (2007). Confirmation bias in criminal investigations: An examination of the factors that aggravate and counteract bias (Doctoral dissertation). Retrieved from https://deepblue.lib.umich.edu/handle/2027.42/12652 6

Ofshe, R. J., \& Leo, R. A. (1997). The social psychology of police interrogation: The theory and classification of true and false confessions. Studies in Law, Politics \& Society, Volume $16 . \quad$ Retrieved from https://www.reid.com/pdfs/doj2301_2399.pdf

Olson, E. A. (2013). "You don't expect me to believe that, do you?" Expectations influence recall and belief of alibi information. Journal of Applied Social Psychology, 43, 1238-1247. doi: $10.1111 /$ jasp. 12086

Oxburgh, G. E., Myklebust, T., \& Grant, T. (2010). The question of question types in police interviews: A review of the literature from a psychological and linguistic perspective. The International Journal of Speech, Language and the Law, 17, 45-66. doi:10.1558/ijsll.v17il.45

Oxburgh, G., Ost, J., Morris, P., \& Cherryman, J. (2014). The impact of question type and empathy on police interviews with suspects of homicide, filicide and child sexual abuse. Psychiatry, Psychology and Law, 21, 903917. doi:10.1080/13218719.2014.918078

Shepherd, E., \& Griffiths, A. (2013). Investigative Interviewing: The conversation management approach. Oxford, UK: Oxford University Press. 
Van Amelsvoort, A., Rispens, I., \& Grolman, H. (2010). Handleiding verhoor. Amsterdam, NL: Reed Business.

Van Beek, M., \& Hoekendijk, J. (2015). The interview table: A toolbox-approach for suspect interviewing. Investigative Interviewing: Research and Practice, 10-20. Retrieved from http://www.iiirg.org/journal

Van der Sleen, J. (2009). A structured model for investigative interviewing of suspects. In R. Bull, T. Valentine, \& T. Williamson (Eds.), Handbook of Psychology of Investigative Interviewing. Chichester, UK: John Wiley \& Sons.

Vrij, A., Mann, S., Kristen, S., \& Fisher, R. P. (2007). Cues to deception and ability to detect lies as a function of police interview styles. Law and Human Behaviour, 31, 499518. doi:10.1007/s10979-006-9066.4

Walton, D. (2003). The interrogation as a type of dialogue. Journal of Pragmatics, 35, 1771 - 1802. $10.1016 /$ S0378-2166(02)00201-1 


\section{PART III:}

Implications of the Research for the Police-Suspect Interview 


\section{CHAPTER 9}

General Discussion: Identifying Confirmation Bias in PoliceSuspect Interviews 


\section{DISCUSSION}

Within legal contexts, confirmation bias begins as a belief that a suspect is guilty. Previous researchers have demonstrated that guilt presumptive beliefs can have detrimental effects on the police-suspect interview in terms of tactics used (Narchet et al., 2011; Olson, 2013), and suspect confession behaviour (Hill et al., 2008; Kassin et al., 2003; Meissner \& Kassin, 2002). In this thesis, past research has been expanded upon and attempts were made to identify reliable indictors of confirmation bias via interviewer guilt presumption.

The overarching research question was approached from both an experimental and applied methodology. In the first part of this thesis, the experiments were designed to replicate and expand upon previous findings regarding guilt presumption and question formulation in information-gathering contexts (Hill et al., 2008). In the second part of this thesis, police-suspect interviews were obtained and analysed using linguistic techniques to examine the utterances of interviewers and the behaviour of the suspects. The six studies presented in Chapters three through to eight demonstrate that guilt presumptive language (i.e., accusatory questions, insinuations, and direct accusations of involvement) are consistently found in guilt presumptive interviewers. When taken with previous findings (Hill et al., 2008; Kassin et al., 2003; Narchet et al., 2011; Olson, 2013) there is strong evidence that guilt presumptive language (i.e., covert speech and direct accusations), should be investigated as reliable indicators of an interviewer's guilt confirmatory cognitions and behaviours. 
In this final chapter, the overall findings of those six studies are discussed in context of current knowledge about questioning practices within policesuspect investigative interviews. Implications of these findings for police practice are also discussed along with the methodological considerations that may influence the interpretation of the overall findings contained in this thesis. Finally, avenues for future research are presented as there are still many unanswered questions concerning guilt presumption and confirmation bias in relation to the police-suspect interview.

\subsection{RESEARCH SCOPE}

The scope of this thesis has narrowed from an attempt to identify behavioural indicators of confirmation bias to examining the influence of guilt presumption as a precursor to biased behaviour. This shift occurred once the results of the experimental studies contained in the first part of this thesis were considered within the context of the extant literature. The common finding within the investigative interviewing literature was that interviewers who held guilt presumptive beliefs about the suspect were more likely to use accusatory questions. The results of the studies presented in Chapters three through to five were consistent with those previous studies (Semin \& De Poot, 1997b; Hill et al., 2008; Kassin et al., 2003; Narchet et al., 2011). Those findings, however, remained untested in applied settings where the ground truth of interviewer guilt judgements was unknown, and explicit accusatory questioning was said to be rare in informationgathering frameworks (Moston \& Engelberg, 1993). Thus, the next logical step appeared to be a focus on interviewer utterances in applied settings. 
It was also at that time it became necessary to apply linguistic techniques to find solutions to the research problems. Within the linguistic literature there was an abundance of evidence that suggested biased language could be identified though word abstraction. This was achieved by analysing the content of the utterances within the context of the situation (e.g., speech act theory; Austin, 1962). The infrequency of accusations became apparent when analysing the transcripts used in the study presented in Chapter 7. Many of the interviews contained language that was more implicit, thus, a more indepth analyse of the interviews was employed. The speech events were closely analysed to determine what was occurring in those situations (e.g., Grant et al., 2015). The application of speech act theory helped to demonstrate what the interviewer was intending to achieve with his or her utterances (illocutionary force) and the outcome of the utterance on the suspect (perlocutionary force; Holtgraves, 2002; Searle,1975). The analysis revealed that the interviewers were using covert speech acts to make insinuations of guilt and that guilt presumptive language had a direct and immediate influence on suspect behaviour. The findings of Chapter 7 then prompted the case study analysis of Chapter 8 . There were many factors that needed to be considered when examining the effects of guilt presumption and confirmation bias. It became increasingly apparent that using only one approach to evaluate interviews was to ignore the depth and breadth of the information available. 


\subsection{INDICATORS OF GUILT PRESUMPTION IN INTERVIEWERS}

Chapter 2 of this thesis contains a comprehensive review of confirmation bias and how it occurs in various settings and interactions. A plethora of literature on confirmation bias has demonstrated that confirmatory thinking stems from pre-existing beliefs and the need to find evidence to support those beliefs despite contradictory information (Kunda 1990; Nickerson, 1998). Researchers have previously found evidence for the effects of confirmation bias in criminal justice contexts on the evaluation of evidence (Ask \& Granhag, 2005), during suspect interviews (Kassin et al., 2003), within witness and victim interviews (DePoot \& Semin, 1997b; Olson, 2013), and when performing veracity assessments (Meissner \& Kassin, 2002). The effects of confirmation bias have also been found to negatively influence jury decisions (Hope, Memon \& McGeorge, 2004), and judicial decisions (Porter \& Ten Brinke, 2009). Those studies have provided valuable insight to some of the possible outcomes associated with confirmatory thinking.

The findings in this thesis add to the extant literature by providing additional support for the detrimental effects of guilt presumption on the police-suspect investigative interview. The findings also help to demonstrated that false confessions are not the only consequences of guilt presumptive questioning. When taken together with the findings in the false confession literature, however, there is strong evidence that implied or explicit assertions of suspect guilt have detrimental effects on the investigative interview and may have an influence on 
the entire criminal investigation, as highlighted by the case study presented in Chapter 8 . Despite the evidence of its negative influence on the criminal justice process, sufficient efforts have not been made to identify reliable indicators of confirmation bias and guilt presumptive behaviours in relation to the policesuspect interviewer.

\subsection{ACCUSATORY QUESTIONING AND INFORMATION-GATHERING FRAMEWORKS}

The presence of accusatory questioning has been largely under studied in interviews that used information-gathering frameworks (e.g., PEACE and GIS). The information-gathering frameworks that are used in various countries (e.g., UK, Norway, Australia, The Netherlands, and parts of Canada) are not technically focused on obtaining a confession, however, most case closure still relies on obtaining an admission of guilt (Moston \& Fisher, 2007; Stephenson \& Moston, 1994). Thus, interviewers may continue to seek confessions during the confront and challenge phases of the interview. This type of behaviour was demonstrated in the questioning style and utterances of the interviewers discussed in Chapter 8. If those confessions were sought based on confirmatory beliefs as opposed to strong evidence against the suspect, miscarriages of justice could occur (see Belloni \& Hodgson, 2000; Ditrich, 2015; Wagenaar, Israels, \& Van Koppen, 2009). Although accusatory and insinuative utterances occurred infrequently throughout the interview, the interviewers did not create optimal conditions for gaining suspect cooperation or eliciting IRI.

It is widely believed that information gathering frameworks help to reduce biased behaviour because they are not confession driven (Van der Sleen, 2009). 
Some researchers have demonstrated that false confessions can be significantly reduced by information-gathering interviews compared to confession driven interviews (see Meissner et al., 2014). However, those studies were not conducted within the context of interviewer biases. Until empirical research can establish otherwise, it should not be assumed that information-gathering methods are impervious to the effects of confirmatory thinking and guilt presumption. The simple fact remains that interviews are conducted by interviewers who are vulnerable to the effects of guilt presumption and confirmatory thinking.

As demonstrated in previous studies, as well as this thesis, interviewers can easily deviate from their training and the principles outlined in informationgathering frameworks such as PEACE (Griffiths \& Milne, 2006). Interviewers then employ poor questioning techniques as a result (Heydon, 2012; Powell, 2002). For example, the study presented in Chapter 5 and the interviews evaluated in Chapter 8 demonstrated that accusatory questioning can occur in information-gathering frameworks (Hill et al., 2008). However, more evidence is needed to make a definitive link between accusations, guilt presumption, and confirmatory behaviour in nonconfession driven interviews.

\subsection{GUILT PRESUMPTION AND}

ACCOMPANYING LANGUAGE IN

\section{INFORMATION-GATHERING INTERVIEWS}

The studies that comprise Chapters 4 and 5 were designed to determine whether guilt presumption could naturally form in interviewers that were exposed to the guiding principles of the PEACE framework (College of Policing, 2016), and how guilt 
presumption influenced question formulation in information-gathering contexts (Hill et al., 2008). In those studies, approximately half of the interviewers naturally formed a presumption of guilt that was accompanied by the increased formulation of accusatory questions. The questions formulated in the first study (Chapter 4) were more explicitly accusatory. This may have been a result of the interviewers not having to pose their questions to a suspect. Those assumptions were confirmed with the findings of the second study (Chapter 5). In that study, the interviewers knew they needed to interview the suspect with their questions, and thus, they formulated less overt accusations.

The change in the nuances of how the questions were phrased prompted queries about how language was being used to convey the interviewer's presumptions of guilt. For that reason, the linguistic properties of the questions in both studies became the focus (Chapters 4 and 5). Efforts were made to determine if the word choices revealed any additional insights to the relationship between the guilt judgements and the biased behaviour. Both studies revealed that interviewers who presumed the suspect was guilty showed patterns of biased language through increased word abstraction.

The finding that guilt presumptive interviewers used more abstract wording in their questions was pivotal for this research. Not only did the interviewers self-report a guilt bias, but their word choices confirmed the presence of biased beliefs about the suspect in both the explicit and implicit accusatory questions. The use of abstract words is a well-tested linguistic indicator of biased beliefs about the person or topic of an utterance (Beukeboom, 2012). 
Speakers who held a bias against the subject of their utterance tended to choose more abstract language whether they were aware of those biases or not (Semin \& Fiedler, 1988, 1991). Although most literature suggests that word choice is unconscious, some researchers have posited that communicators can inhibit biased language when given the opportunity to choose their words carefully (Douglas \& Sutton, 2008). In those cases, it is possible that interviewers made choices to 'soften the language' of the question using epistemological hedging. Hedging occurs when speakers use a mitigating word or phrase construction to soften a bold statement or appear polite (Recasens, et al., 2013). However, the phrasing was still revealed as accusatory when the question was evaluated by question type. Moreover, the use of abstract language betrayed the underlying bias, which in these situations was a presumption of guilt.

Conversely, one may argue that the motivations of the interviewer when asking accusatory questions or using covert speech is paramount for determining whether their actions are driven by a guilt presumption. That possibility was explored in Chapter 5. To provide insight to any underlying motivations of guilt confirmation, the nonpolice interviewers were asked to justify their questions by explaining what they hoped to achieve by asking them. Interestingly, there was no difference in the justifications between interviewers who self-reported a guilt presumption and those who reported needing more information. That is, both groups created a similar amount of questions designed to confirm suspect guilt. The most likely interpretation is that the interviewers who reported 
needing more information were undecided about guilt and were truly seeking more information to confirm their guilt beliefs before reporting one way or another. Indecisiveness has also been associated with the tendency to gather information about the option that is ultimately chosen (Rassin et al., 2008). Evidence for this behaviour was found in the changing guilt judgements that occurred in that group across the course of the interview.

Abstract language, however, cannot be used to detect guilt presumption in applied settings. Previous research has demonstrated that people can use speech to convey messages, even when they don't personally believe in the message. Over five studies, Douglas and Sutton (2003) demonstrated that communication goals have a strong influence on language abstraction. When using the LCM to detect biased language, the researchers determined that language abstraction occurred independent of the speaker's actual beliefs and expectancies. They concluded that abstract language may be used consciously or subconsciously to convey beliefs. However, abstraction could also be consciously used by communicators to create new beliefs to an intended audience, regardless of a speaker's actual beliefs on the topic. Therefore, ground truth of a guilt bias would be needed to ensure the officer held the belief of suspect guilt. In sum, word abstraction remains a reliable indicator of biased language, but it is not a reliable indicator of biased beliefs. Therefore, more consistent indicators need to be identified.

A potential avenue of research for a reliable indicator of guilt presumption is covert speech acts such as insinuation of guilt. In Chapter 7 , a review of police-suspect interview transcripts involving serious 
crimes revealed that direct accusations were indeed rare (Kassin \& McNall, 1991; Shuy, 1998). In fact, none of the transcripts contained any accusatory questions, overt statements of guilt belief, or adversarial techniques. However, each analysed interview contained at least one instance where the interviewer insinuated suspect guilt or involvement in the crime. Those speech events were analysed and found to have occurred primarily when the suspect denied involvement. It is likely that those utterances were made by the interviewer in a moment of frustration (Griffiths \& Milne, 2006) because the interviewer was seeking an admission and received a denial (Moston et al., 1992).

It is also a possibility that the interviewers used insinuative language as a tactic to send a message that the denial was not believed. Evidence for both the use of insinuation as a tactic and an expression of frustration was found in the case study presented in Chapter 8. That is, the interviewers appeared to use insinuative language to convey irritation, get the upper hand with the suspect, and to break down resistance (denials). The multiple uses of insinuation show that further investigation is needed before it can be cited as a reliable indicator of guilt presumption. Covert speech exhibits more promise as a reliable indicator because the speaker must believe the intended message is true. The premise of a covert speech act is to convey a negative message without being accountable for the intended truth of that message (Bertuccelli Papi, 2014; Parret, 1993); however, the speaker must believe in the truth of their message (Attardo, 1999). When applied to the police-suspect interview, this means there must be 
some belief that the suspect is guilty for an insinuation of guilt to be uttered.

\subsection{THE EFFECTS OF GUILT PRESUMPTION ON THE SUSPECT}

Although the primary objective of this thesis was not to focus on how guilt presumption affected the suspect (e.g., confessions, behaviour, and cooperation), its influence on the interview outcome is an important aspect of this research. Studies that have examined interview tactics and questioning techniques are generally conducted to understand the factors involved. This allows researchers and practitioners to improve upon current interview practices, and to provide evidence-based information that interviewers can use to inform procedural decisions. More research is certainly needed to fully understand the scope and implications of perceived wrong doing on a suspect's behaviour and the overall interview outcomes. The findings presented in this thesis provide additional insight to some of the cognitive and behavioural factors that need to be considered in future investigations on confirmation bias.

An interesting finding regarding interviewee behaviour was demonstrated in Chapter 3 . The ease in which confirmation expectancy effects were created in the experimental group of participants was unexpected. The participants did not need to believe they had done anything wrong for the slightest suggestion of wrongdoing to alter their behaviour (Bargh et al., 1996; Najdowski, 2012). The expectancy effect was activated when the interviewer implied a problem with the test results and stated she needed to ask a few more questions. The influence of perceived interviewer beliefs of wrongdoing was then 
demonstrated as observable behaviours in the suspects primed for an expectancy effect. The changes in the nonverbal behaviour suggested there was an increase in cognitive load (stillness and blink rate), which is known to impede performance (Croizet et al., 2004) and impair comprehension (Berggren et al., 2013). The participants in the study also reported difficulty thinking (Barrouillet et al., 2007) and feelings of defensiveness, although the questions posed to them were information-gathering and presented in a professional and nonconfrontational manner. Other noticeable behaviour changes included shorter answers and less smiling.

The expectancy effects in the study (Chapter 3 ) were powerful enough to have small but significant influence on the behaviour of the suspects within the non-adversarial and low stress environment of the study. That finding suggested that in the more stressful environment of the police-suspect interview, the suspect may be further disadvantaged due to the high stress and cognitively taxing nature of the interview. Thus, interviewers should be cognisant of the effects of their behaviour and language on the suspect's behaviour. Especially if a suspect's behaviour could be interpreted by an interviewer as support for his or her guilt presumptions. Many police interviewers have reported using body language to inform decisions about veracity (Vrij \& Mann, 2001) and perceptions of cooperation and guilt (Meissner \& Kassin, 2004). It was also clear from the findings in Chapter 5 that most non-police interviewers who held an initial guilt presumption used behavioural cues to inform their subsequent judgements of guilt. 
The effects of guilt presumption on suspect behaviour were also found when analysing the content of police-suspect interviews. In Chapter 7, examining the speech events revealed that insinuations of guilt mostly occurred just after a suspect denied involvement, which then prompted further denials and reduced suspect cooperation. Those findings were supported further in Chapter 8 where each accusation and insinuation caused further damage to the interview dialogue and impeded the effectiveness of the interview (Kelly et al., 2015). In Chapter 8, there was also a tendency for interviewers to note and rely on nonverbal cues. In one of the interviews, the police officer implied that the suspect's body language was providing proof of the suspect's involvement in the crime.

It should be noted that it remains unclear whether the interviews evaluated in the second part of this thesis were conducted on guilty or innocent suspects. However, most miscarriages of justice begin when a prime suspect has been identified and is subsequently interviewed (see Griffin, 2001; O'Brien, 2007). The very nature of the police-suspect interview dictates that there must be some belief that the suspect is involved as that is the starting point (O'Brien, 2009). That basic truth means that the suspect may experience the effects of perceived interviewer guilt expectancy by simply being present (Darley \& Fazio, 1980). It can also be argued that regardless of suspect involvement, guilt presumptive language is not beneficial to the objectives of the information-gathering interview and should be avoided. 


\subsection{IMPLICATIONS OF RESEARCH FINDINGS FOR POLICE PRACTICE}

The most relevant finding in this thesis for police practice involves the manner in which interviews are evaluated. A common method to rate an interview for effectiveness and appropriateness is to base performance on the types of questions asked and information elicited (IRI). Simply evaluating the question types in the interviews revealed that the interviewers asked mainly appropriate questions designed to seek clarification. The analysis in Chapter 8 also revealed that whilst technically appropriate, most questions posed were closed or clarifying. On the surface, an abundance of those questions categories may prompt a trainer or supervisor to refresh the interviewer on the use of open (TED) questions (Shepherd \& Griffiths, 2013). However, a closer evaluation of the interviews by question type and speech event revealed that the most damaging utterances were captured in the broad category of opinion statements.

Including a separate category for guilt presumptive utterances could have valuable applied implications. The main argument in Chapter 8 involved the typologies used to classify interview questions as appropriate or inappropriate. Currently, those categories do not capture the presence of accusatory language and provided no insight to the potential negative outcomes of those accusations or insinuations. When guilt presumptive language did occur, the influence of those statements on obtaining IRI and suspect cooperation were lost in the question type analysis. The decrease in IRI and cooperation could have been easily explained as phenomena that naturally occurred over time as a result of the 
suspect being challenged and confronted with evidence. As demonstrated in Chapter 8, and in previous research, accusatory language can derail even the best laid interview plan and undo or impede any efforts to build rapport and gather IRI (Kelly et al., 2015). It was when interviewers deviated from their training or got frustrated, that accusations occurred (Griffiths \& Milne, 2006).

Analysing interviews by question type is a popular method amongst researchers (see Oxburgh et al., 2010), and may gain some momentum with practitioners since the creation of interview evaluation tools such as the Griffith's Question Map (GQM; Shepherd \& Griffiths, 2013). There is no reason to dissuade practitioners from using question typologies as a method to track and improve upon interview performance. Based on the findings presented in Chapter 7 and 8, however, those who train interviewers should be aware of the negative effects that guilt presumptive utterances can have on the interview. The plethora of literature extolling the negative influence of accusatory utterances on the police-suspect interview cannot be ignored within information-gathering interview frameworks.

The evaluation technique presented in Chapter 8 could be further developed into a tool to identify specific utterances and problematic behaviour in the context of the interaction. That type of approach could make interviewers aware of how their beliefs and emotions can be conveyed through their language. Moreover, an evaluation of the interaction during accusations and insinuations highlights the detriment of covert speech. Those small comments can have a big influence on the interview by eliciting defensiveness and uncooperative behaviour from the 
suspect. Thus, an inclusion of a separate categorisation for assumptions and insinuations of guilt is strongly suggested. This would mean that the context, lead-up, and outcome of those interactions could be explored closely, and any opportunities for learning and development could be identified.

Unless more in-depth methods are used to evaluate the interview performance on multiple features, opportunities for development could be missed. Police officers who conduct interviews in the UK are encouraged to perform self-evaluations and seek feedback from supervisors and peers regarding their interview techniques (Griffiths \& Milne, 2006). Moreover, factors such as appropriate use of language, avoiding accusations and insinuations of guilt, and maintaining a professional demeanour should become regular areas for peer and supervisory feedback.

Improving interview techniques and questioning strategies ultimately resides in interviewer self-evaluation and quality training. A preventative measure to ensuring guilt presumptions do not guide the interview is education and knowledge about the dangers of presuming guilt and the negative influence it can have on the interview. More specifically, training officers on how to remain objective and create alternative scenarios for the evidence (including alternative suspects) could be beneficial (O'Brien, 2007). The best time to introduce police officers to objectivity training would be early in their career with periodic refresher training. When people do not hold strong beliefs on a topic, they can be enticed to form an opinion by presenting them with convincing information (Alexander et al., 1991). In Chapter 6, the police officers who completed the 
survey reported a mid-range level of agreement on the topics of interest (i.e., confessions, suspect vulnerabilities, and best interview practices), which may indicate a potential opportunity for conceptual change. Convincing evidence regarding the survey topics could be well received and incorporated into practice under the right conditions (Alexander et al., 1991), particularly for those officers who held no strong beliefs one way or the other.

On a cautionary note, police officers' understanding of the literature is not enough evidence to suggest that they apply their knowledge into practice. Previous research has demonstrated that even trained interviewers can deviate from best interview practices and employ inappropriate question types such as accusations and opinion statements (Griffiths \& Milne, 2006). This was evident in the case study presented in Chapter 8 where interviewers who were trained in GIS (as evidenced by their use of the strategies contained in that framework) made some fundamental errors when conducting the interview. One such deviation from the recommended practice of conducting a GIS interview was expressing their belief in the suspect's guilt from the very first interview (Van der Sleen, 2009). That initial guilt presumption dictated the tone of the interaction from that moment forward.

Despite over 25 years of interviewing reform in countries such as the UK and The Netherlands, inappropriate questions and accusatory statements still occur in information-gathering frameworks. It may be the case that interviewers have a fallacious belief that using accusatory language will assist them in obtaining IRI or help to establish the truth. Interviewers may not be acting on grounds of a guilt 
or confirmation bias, but merely employing an inappropriate technique. If that is the case, interviewers need to be made fully aware of how detrimental their language can be to the objectives of the investigative interview - regardless of their motivation. Although more research is needed to make definitive links between the guilt beliefs of interviewers and their interview behaviours, there is strong evidence in the literature that this type of language is associated with guilt presumptions and support that guilt bias can lead to confirmatory behaviours.

\subsection{METHODOLOGICAL CONSIDERATIONS}

This thesis is the first empirical work that has focused on identifying indicators of guilt presumption and confirmation bias within information-gathering frameworks. Various methodologies to explore the research questions were employed and the research problem was approached from several perspectives (e.g., question type evaluation, content analysis, and linguistic techniques). However, there are limitations to this research that need to be considered when drawing conclusions from the overall findings. For example, some of the experimental findings were unable to be tested using the applied materials. The LCM (Semin \& Feidler, 1991) is a good linguistic tool for identifying biased language in texts, political speeches, and experimental studies. It may even be appropriate for analysing transcripts of free narratives provided by suspects, victims, or witnesses. The LCM was certainly insightful to understand how language was used to convey biased beliefs in the experimental studies. However, interaction and language structure were different in the police-suspect transcripts than in the 
experimental studies. Due to the focused (and often closed) nature of the questions that were designed to clarify or obtain information, analysing the verb abstraction was not suitable. The properties of the questions also made using the QAP (Semin et al., 1995) inappropriate in the applied studies. It is possible that the LCM could be an effective evaluation tool during the confront and challenge stage of the interview, where the interviewer is expected to do most of the talking. However, that type of analysis would only be feasible for research purposes. It is unlikely that law enforcement organisations would employ trained linguists to analyse interviews on that level as it is complex and labour-intensive work.

The influences of expectancy confirmation effects on suspect behaviour identified in Chapter 3 could also not be tested with the applied materials. The most appropriate study to examine the suspect's nonverbal behaviours would have been in the interviews evaluated in Chapter 8. However, the poor quality of the video recordings made it impossible to code behaviours such as blink rate, which is a reliable indicator of cognitive load. Moreover, the suspect tended to excessively use verbal fillers and crutches (ums and ahs). With no baseline behaviours for comparison it would have been difficult to glean any meaningful conclusions from that analysis. It may have been possible to compare suspect behaviours between interviews by type (person versus case oriented) or by using the first interview as a baseline; but by the final study, the scope of the thesis had shifted to question types and interviewer utterances. For that reason, behavioural analysis would not have been appropriate within the case study analysis. 
Language could also be a limitation with the interview evaluations. The interviews analysed in Chapters seven and eight were limited to materials obtained within The Netherlands from the Dutch Police and an expert witness. Those interviews were translated to English from Dutch prior to analyses. Although every precaution was taken to ensure the translations were accurate, some of the nuances of the interactions could have been lost when converting from one language to another. If that occurred, there is a possibility some very nuanced insinuations may have been missed. However, if translation is to be maintained as a potential limitation for the interview evaluation, it must also be accepted that the number of insinuative utterances reported in the findings may be less than the actual number of occurrences within the interviews. Due to the type of analysis conducted within both studies, there is no reason to believe that missing some of the more nuanced insinuations could have significantly influenced the research findings.

Another limitation to the applied studies in this thesis is the generalisability of the findings. It could be argued that the findings from the applied studies are only applicable to interviews conducted in The Netherlands and with police interviewers who use the GIS. Attempts were made to obtain interviews from UK law enforcement agencies, however, participation was declined with no explanation. Whilst the findings from the Dutch interviews mirror patterns of behaviour reported in studies conducted in North America (e.g., Kassin et al, 2003; Ofshe \& Leo, 1997), no conclusions can be drawn for guilt presumptive language and behaviour for police officers who work within the PEACE framework. Some 
researchers in the UK have suggested that poor interview practices occur when officers do not adhere to their training (e.g., Griffiths \& Milne, 2006); but the extent and consequences of non-adherence remains unknown.

A final methodological consideration concerns the limited sample sizes for the two applied studies. Although the sample size was constrained by the materials made available, the analysis revealed that examining the interview content for guilt presumptive language is a viable avenue for further research. It is important to note that the case study presented in Chapter 8 was obtained because of perceived issues with the way the interview was conducted, which limits the generalisability of the findings. Although it was an exceptional case, those interviews clearly demonstrated the consequences of guilt presumptive language on the investigative interview. Whilst interviewer beliefs were not explicitly known, there was compelling evidence contained within the interview transcripts that suggested the interviewers held a bias towards suspect guilt. The subsequent interviewer behaviours followed established patterns demonstrated in experimental studies (e.g., accusations, insinuations, poor interviewing behaviour), and there were explicit assertions of guilt beliefs. Therefore, the applied studies provide support for further investigations into guilt presumptive language during informationgathering interviews.

\subsection{FUTURE DIRECTIONS}

In Chapter 2, it was argued that more research is needed to determine whether guilt presumption and confirmation bias produced similar outcomes in applied settings as in laboratory studies. Possible 
methods to identify guilt presumptive language and improve interview evaluations were presented. However, any tactics or techniques that could be used by police interviewers to reduce the occurrences in real-time interviews were not provided. Thus, this may be the most appropriate avenue for future research. The methods used here are most suited for retrospective analysis of investigative interviews for evaluation and training purposes.

To further our understanding of guilt presumption and the police-suspect interview, the most successful research endeavours will likely require the cooperation, collaboration, and participation of law enforcement agencies (see Innes, 2010). Police participation in this type of research is paramount because police organisations are more likely to implement evidence-based practices when they are directly involved in the research (Telep, 2017). There are valid explanations as to why law enforcement agencies frequently deny requests to participate in empirical studies. For example, operational and human resource constraints are often cited as reasons for non-participation. The importance of the job requires officers to be engaged in active policing and there is little to no down time during working hours. This means the only time officers are available participate would be during their personal time, which many are not keen to offer.

Many of the remaining questions regarding guilt presumptive behaviours and confirmation bias cannot be answered without access to interview transcripts and/ or audio and visual recording of police-suspect interviews. If those materials cannot be made available, researchers are left with limited 
options for investigating the phenomena. Considering those limitations regarding access to applied materials, the following are suggestions for undertaking possible experimental and quasiexperimental investigations. There is still much research to do to fully comprehend the various factors associated with confirmation bias and guilt presumption in police-suspect interviews.

9.8.1 Alternative scenarios. An area of study that has received a lot of attention in the legal decision-making and crime investigation literature is the formulation of alternative scenarios (e.g., Rassin et al., 2010). Whilst formulating alternative scenarios may seem like a viable solution for reducing confirmatory thinking, it can be a difficult endeavour (Koehler, 1991). When people are required to imagine or explain a possible scenario, there is a moment when they must believe the scenario is true. In this moment, confidence in the truthfulness of the scenario increases, as does the likelihood that confirmatory information searchers will occur (Koehler, 1991). The first belief formed by police investigators is one of suspect involvement, which must be believed, if only for a moment. To create an alternative scenario, the police officer must then suspend any belief of suspect involvement and replace it with a new belief. There is also the possibility that the belief of suspect guilt is more plausible than a scenario where he or she is not guilty. Thus, the motivation to be accurate in the guilty scenario increases, which also increases the likelihood of seeking information that confirms the presumption (Kunda, 1990). Recent research has suggested that weighting criminal evidence using pencil and paper to make notes, whilst considering 
alternative scenarios, helps to reduce confirmation bias in criminal investigation contexts (see Rassin, 2018). Further examination of such a tool is warranted for the police-suspect interview and could be employed in the planning and preparation phases present in both the PEACE and the GIS framework.

9.8.2 Debiasing. As discussed in Chapter 1, recognising and disrupting confirmatory behaviours in the self is an extremely difficult task for a variety of reasons grounded in human cognition and behaviour (Arkes, 1991; Frey, 1982; Merton, 1948; Miller \& Turnbull, 1986; Ross et al., 1975). That also holds true when others attempt to disrupt a cycle of confirmation bias as they too may form the same expectancies based on the nature of the situation (Narchet et al., 2011) or by belonging to the same social group (Chatman \& Von Hippel, 2001). However, attempts to debias or dissuade biased behaviour have not been tested on law enforcement populations in the context of police-suspect interviews.

Investigations on successful debiasing strategies could involve designing studies where interviewers conduct questioning in pairs (as is customary in countries such as The Netherlands). Various debiasing strategies can be tested using this method. For example, interview pairs could be instructed to develop an interview plan and preliminary questions based on case information. Participant pairs could then be instructed to consider the opposite (Arkes, 1991; Lord, Lepper, \& Preston, 1984; Mussweiler, Strack, \& Pfeiffer, 2000) and create alternative scenario questions contrary to their initial guilt judgements. Then, question type and question appropriateness could be compared. If 
researchers are interested in the polyadic interaction between interviewer participants and mock-suspects, interviewers could be permitted to ask the questions from each plan (original judgement and considered opposite) to determine any effects on interviewer and suspect behaviour.

Researchers could also investigate the ability of peers to effectively dissuade guilt presumption or confirmatory behaviour in their interviewer counterparts. That design would most likely require the use of a confederate to ensure consistent biased behaviours and language toward the suspect. The non-confederate participant could be exposed to various strategies for identifying guilt presumptive behaviour (e.g., accusatory questioning, insinuations of guilt, direct accusations or even inappropriate interview tactics such as raised voice or shouting). Depending on the outcome variables of interest, participants could be instructed to intervene if they notice guilt presumptive behaviour or left to make their own decisions.

9.8.3 Hypothesis disconfirmation. In terms of identifying confirmation bias in applied settings, more research is needed regarding hypothesis confirming or disconfirming strategies. In experimental studies, this can be achieved by asking participants to provide justification for their questions (as demonstrated in Chapter 5) or rationale for their behaviours. In applied studies, this could be achieved by analysing the interviewer's utterances for evidence of underlying motivations (as demonstrated in Chapters 7 and 8). Although that technique would require the researcher to draw conclusions with no ground truth of interviewer motivation, this is a common method used in linguistic and social 
interaction research (e.g., Farinde et al., 2015; Haworth, 2017). Perhaps conducting more in-depth analysis of a larger sample of interviews, obtained from a variety of sources, is needed to advance this area of study.

9.8.4 Belief perseverance. Due to the cognitive tendencies of police officers and the requirements of police work, confirmatory thinking is a difficult phenomenon to disrupt and prevent (Ross et al., 1975; Brewer \& Nakamura, 1984). If the interviewer has a strong belief in suspect guilt, he or she is likely to become more persistent in their attempts to prove their assumptions are true (Kunda, 1990). The findings in Chapter 6 suggested that highly educated police interviewers had the highest agreement about factors that can influence confessions as their responses were most in line with findings in the literature. Nevertheless, the aggregated data tells us very little about the individual officer's beliefs and how they conduct police-suspect interviews. In the least, the survey presented in Chapter 6 could be expanded upon to capture additional demographic information so meaningful relationships between training, education, beliefs and knowledge can be reported.

The best approach to influence change in police practice is through effective training and awareness of personal biases and presumptions. Based on previous research in belief perseverance, the police officers most likely to be receptive to that type of training are those who have not formed interview habits based on anecdotes, pseudoscience, or personal beliefs (Burns, 2004; De Neys \& Glumicic, 2008; Lilienfeld \& Landfield, 2008; Marietta \& Barker, 2007). Whilst the cooperation and collaboration of 
police agencies would be needed to bring a training initiative to fruition, researchers should continue to conduct high quality research that can be used by police organisations and individual police officers to inform their practice and procedures.

\subsection{CONCLUSIONS}

It was evident in the findings of this thesis that insinuations of guilt are generally a rare occurrence and direct accusations are even rarer (Stephenson \& Moston, 1994). Therein may lie the problem for further research and implementing changes to training and interview evaluation. That is, the rarity of such interviewer utterances may lessen the perception of this type of interview behaviour as a problem (underweighting; Kahneman \& Tversky, 1984). However, it was evident from the interviews analysed in this thesis that it may not be the frequency of guilt presumptive utterances that matter, but the mere presence of that type of language. For that reason, the detrimental influence of guilt presumptive questioning on the interview cannot be ignored, regardless of infrequency.

Despite its importance for the criminal investigation, attempts to detect guilt presumption in police-suspect interviews outside the laboratory have been scarce. The primary problem that researchers face is the ground truth regarding interviewer guilt bias. Interviewer beliefs are not known unless explicit statements of guilt presumption are made, and those types of statements rarely occur in informationgathering contexts. In applied research, having reliable indicators of a phenomenon allows for assertion that the phenomenon is present with a probability higher than chance. That is beneficial in 
situations where the ground truth of interviewer beliefs is unknown.

The studies contained in this thesis provide additional support for guilt presumptive language as a potential indictor of guilt presumptive beliefs. The study findings, taken with previous research, suggest that even in information-gathering contexts, an investigative interview can quickly become a search for proof of guilt and have detrimental effects on the information gathering objectives that guide such interviews. For that reason, it is important for interviewers to have the ability to recognise their own guilt bias, as well as the biases of others. 


\section{REFERENCES}

Alexander, P. A., Murphy, P. K., Buehl, M. M., \& Sperl, C. T. (1998). The influence of prior knowledge, beliefs, and interest on learning from persuasive text. National Reading Conference, 47, 167-181. Retrieved from https://eric.ed.gov/?id=EJ587432

Arkes, H. R. (1991). Costs and benefits of judgement errors: Implications for debiasing. Psychological Bulletin, 110, 486-498. doi:10.1037/0033-2909.110.3.486

Ask, K., \& Granhag, P. A. (2005). Motivational sources of confirmation bias in criminal investigations: The need for cognitive closure. Journal of Investigative Psychology and Offender Profiling, 2, 43-63. doi:10.1002/jip.19

Attardo, S. (1999). Covert speech acts and their meaning. Deseret Language and Linguistic Society Symposium, 25, 202-217. Retrieved from https://scholarsarchive.byu.edu/dlls/vol25/iss1/19

Austin, J. L. (1962). How to do things with words. Cambridge, UK: Clarendon Press.

Bargh, J. A., Chen, M., \& Burrows, L. (1996). Automaticity of social behavior: Direct effects of trait construct and stereotype activation on action. Journal of Personality and Social Psychology, 71, 230-244. doi:10.1037/00223514.71.2.230

Barrouillet, P., Bernardin, S., Portrat, S., Vergauwe, E., \& Camos, V. (2007). Time and cognitive load in working memory. Journal of Experimental Psychology, 33, 570585. doi:10.1037/0278-7393.33.3.570

Belloni, F., \& Hodgson, J. (2000). Criminal Injustice: An evaluation of the criminal justice process in Britain. London, UK: Pallgrave Macmillan.

Berggren, N., Richards, A., Taylor, J., \& Derakshan, N. (2013). Affective attention under cognitive load: Reduced emotional biases but emergent anxiety-related costs to inhibitory control. Frontiers in Human Neuroscience, 7, 232-238. doi:10.3389/fnhum.2013.00188 
Bertuccelli Papi, M. (2014). Insinuating: The seduction of unsaying. Pragmatics, 6, 191-204. doi:10.1515/ip2014-001

Beukeboom, C. J. (2012). Mechanisms of linguistic bias: How words reflect and maintain stereotypic expectancies. In J. Laszlo, J. Forgas, \& O. Vincze (Eds.). Social Cognition and Communication. New York: NY: Psychology Press.

Brewer, W. F., \& Nakamura, G. V. (1984). The nature and functions of schemas. Center for the Study of Reading [Technical Report No. 325]. Cambridge, MA: Bolt Beranek and Newman Inc.

Burns, B. D. (2004). Heuristics as beliefs and as behaviors: The adaptiveness of the "hot hand". Cognitive Psychology, 48, 295-331. doi:10.1016/j.cogpsych.2003.07.003

Chatman, C. M., \& Von Hippel, W. (2001). Attributional mediation of in-group bias. Journal of Experimental Social Psychology, 37, 267-272. doi:10.1006/jesp.2000.1457

College of Policing. (2016, January 11). Investigative Interviewing. Retrieved from https://www.app.college.police.uk/appcontent/investigations/investigative-interviewing

Croizet, J. C., Despres, G., Gauzins, M. E., Huget, P., Leyens, J. P., \& Load, A. (2004). Stereotype threat undermines intellectual performance by triggering a disruptive mental load. Personality and Social Psychology Bulletin, 30, 721-731. doi:10.1177/0146167204263961

Darley, J. M., \& Fazio, R. H. (1980). Expectancy confirmation process arising in the social interaction sequence. American Psychologist, 35, 867-881. doi:10.1037/0003066X.35.10.867

De Neys, W., \& Glumicic, T. (2008). Conflict monitoring in dual process theories of thinking. Cognition, 106, 1248-1299. doi: 10.1016/j.cognition.2007.006.002

De Poot, C., \& Semin, G. R. (1995). Pick your verbs with care when you formulate a question! Journal of Language and Social Psychology, 14, 351-368. doi:10.1177/0261927X950144002 
Ditrich, H. (2015). Cognitive fallacies and criminal investigations. Science and Justice, 55, 155-159. doi: $10.1016 /$ j.scijus.2014.12.007

Douglas, K. M., \& Sutton, R. M. (2003). Effects of communication goals and expectancies on language abstraction. Journal of Personality and Social Psychology, 84, 682-696. doi:10.1037/00223514.84.4.682

Douglas, K. M., \& Sutton, R. M. (2008). Could you mind your language? An investigation of communicators' ability to inhibit linguistic bias. Journal of Language and Social Psychology, 27, 123-139. doi: $10.1177 / 0261927 \times 07313655$

Farinde, R. O., Olajuyigbe, O. A., \& Matthew, A. (2015). Discourse control strategies in police-suspect interrogation in Nigeria. International Journal of English Linguistics, 5, 146-158. doi:10.5539/ijel.v5n1p146

Frey, D. (1982). Different levels of cognitive dissonance, information seeking, and information avoidance. Journal of Personality and Social Psychology, 43, 1175-1183. doi: $10.1037 / 0022-3514.43 .6 .1175$

Grant, T., Taylor, J., Oxburgh, G., \& Myklebust, T. (2015). Exploring types and functions of questions in police interviews. In G. Oxburgh, T. Myklebust, \& R. Milne (Eds.), Communication in Investigative and Legal Contexts. Chichester. UK: John Wiley \& Sons, Ltd.

Griffin, L. (2001). The correction of wrongful convictions: A comparative perspective. American University International Law Review, 16, 1241-1308. Retrieved from https://heinonline.org

Griffiths, A., \& Milne, R., (2006). Will it all end in tiers? Police interviews with suspects in Britain. In T. Williamson (Ed.), Investigative Interviewing, (pp. 167 - 189). Abingdon, UK: Willan Publishing.

Haworth, K. (2017). The discursive construction of evidence in police interviews: Case study of a rape suspect. Applied Linguistics, 38, 194-214. doi:10.1093/applin/amv009 
Heydon, G. (2012). Helping the police with their enquires: Enhancing the investigative interview with linguistic research. The Police Journal, 85, 101-122. doi:10.1350/pojo.2012.85.2.581

Hill, C., Memon, A., \& McGeorge, P. (2008). The role of confirmation bias in suspect interviews: A systemic evaluation. Legal and Criminological Psychology, 13, 357-371. doi:10.1348/135532507X238682

Holtgraves, T. (2002). Language as social action: Social psychology and language use. Mahwah, $\mathrm{NJ}$ : Lawrence Erlbaum Associates, Inc.

Hope, L., Memon, A., \& McGeorge, P. (2004). Understanding pretrial publicity: Predecisional distortion of evidence by mock jurors. Journal of Experimental Psychology: Applied, 10, 111-119. doi:10.1037/1076-898X.2.111

Innes, M. (2010). A 'mirror' and a 'motor': Researching and reforming policing in an age of austerity. Policing: $A$ Journal of Policy and Practice, 4, 127 - 134. doi:10.1093/police/pap058

Kahneman, D., \& Tversky, A. (1984). Choices, values, and frames. American Psychologist, 39, 341-350. doi:10.1142/9789814417358_0016

Kassin, S. M, Goldstein, C. C., \& Savitsky, K. (2003). Behavioral confirmation in the interrogation room: On the dangers of presuming guilt. Law and Human Behavior, 27, 187203. doi:10.1023/A: 1022599230598

Kassin, S. M., \& McNall, K. (1991). Police interrogations and confessions: Communicating promises and threats by pragmatic implication. Law and Human Behaviour, 233 - 251. doi:10.1007/BF01061711

Kelly, C. E., Miller, J. C., \& Redlich, A. D. (2015). The dynamic nature of interrogation. Law and Human Behaviour, 40, 295-309. doi:10.1037/lhb0000172

Koehler, D. J. (1991). Explanation, imagination, and confidence in judgement. Psychological Bulletin, 110, 499-519. doi:10.1037/0033-2909.110.3.499 
Kunda, Z. (1990). The case for motivated reasoning. Psychological Bulletin, 108, 480-498. doi:10.1037/0033-2909.108.3.480

Lilienfeld, S. O., \& Landfield, K. (2008). Science and pseudoscience in law enforcement: A user-friendly primer. Criminal Justice and Behaviour, 35, 1215-1230. doi: $10.1177 / 0093854808321526$

Lord, C. G., Lepper, M. R., \& Preston, E. (1984). Considering the opposite: A corrective strategy for social judgement. Journal of Personality and Social Psychology, 47, 12311243. doi:10.1037/0022-3514.47.6.1231

Marietta, M., \& Barker, D. C. (2007). Values as heuristics: Core beliefs and voter sophistication in the 2000 Republican nomination contest. Journal of Elections, Public Opinion and Parties, 1, 49-78. doi:10.1080/13689880601132554

Meissner, C. A., \& Kassin, S. M. (2002). "He's guilty!": Investigator bias in judgements of truth and deception. Law and Human Behavior, 26, 469-480. doi:10.1023/A:1020278620751

Meissner, C. A., \& Kassin, S. (2004). You're guilty, so just confess! In G.D. Lassiter (ed) Interrogations, Confessions, and Entrapment (pp. 85-106). Boston, MA: Springer.

Meissner, C. A., Redlich, A., Michael, S. W., Evans, J. R., Camilletti, C. R., Bhatt, S., \& Brandon, S. (2014). Accusatorial and information-gathering interrogation methods and their effects on true and false confessions: a meta-analytic review. Journal of Experimental Criminology, 10, 459-486. doi: $10.1007 / \mathrm{s} 11292-014-9207-6$

Merton, R. K. (1948). The self-fulfilling prophecy. The Antioch Review, 8, 193-210. doi:10.2307/4609267

Miller, D. T., \& Turnbull, W. (1986). Expectancies and interpersonal processes. Annual Review of Psychology, 37 , 233-256. doi:10.1146/annurev.ps.37.020186.001313 
Moston, S., \& Engelberg, T. (1993). Police questioning techniques in tape recorded interviews with criminal suspects. Policing and Society, 3, 223-237. doi: $10.1080 / 10439463.1993 .9964670$

Moston, S., \& Fisher, M. (2007). Perceptions of coercion in the questioning of criminal suspects. Journal of Investigative Psychology and Offender Profiling, 4, 85-95. doi: $10.140023 /$ jip. 66

Moston, S., Stephenson, G. M., \& Williamson, T. (1992). The effects of case characteristics on suspect behaviour during police questioning. British Journal of Criminology, 32, 23-39. doi:10.1093/oxfordjournals.bjc.a048178

Mussweiler, T., Strack, F., \& Pfeiffer, T. (2000). Overcoming the inevitable anchoring effect: Considering the opposite compensates for selective accessibility. Personality and Social Psychology Bulletin, 26, 1142-1150. doi: $10.1177 / 01461672002611010$

Najdowski, C. J. (2012). Stereotype threat in police encounters: Why African Americans are at risk of being targeted as suspects (Doctoral dissertation, University of Texas at El Paso). Retrieved http://hdl.handle.net/10027/9525

from

Narchet, F. M., Meissner, C. A., \& Russano, M. B. (2011). Modeling the influence of investigator bias on the elicitation of true and false confessions. Law and Human Behavior, 35, 452-465. doi:10.1007/s10979-010-9257$\mathrm{x}$

Nickerson, R. (1998). Confirmation bias: A ubiquitous phenomenon in many guises. Review of General Psychology, 2, 175-220. doi:10.1037/10892680.2.2.175

O'Brien, B. (2007). Confirmation bias in criminal investigations: An examination of the factors that aggravate and counteract bias (Doctoral dissertation). Retrieved from https://deepblue.lib.umich.edu/handle/2027.42/12652 6

O'Brien, B. (2009). Prime suspect: An examination of factors that aggravate and counteract confirmation bias in 
criminal investigations. Psychology, Public Policy, and Law, 15, 315-334. doi:10.1037/a0017881

Ofshe, R. J., \& Leo, R. A. (1997). The social psychology of police interrogation: The theory and classification of true and false confessions. Studies in Law, Politics \& Society, Volume $16 . \quad$ Retrieved from https://www.reid.com/pdfs/doj2301_2399.pdf

Olson, E. A. (2013). "You don't expect me to believe that, do you?" Expectations influence recall and belief of alibi information. Journal of Applied Social Psychology, 43, 1238-1247. doi: $10.1111 /$ jasp. 12086

Oxburgh, G. E., Myklebust, T., \& Grant, T. (2010). The question of question types in police interviews: A review of the literature from a psychological and linguistic perspective. The International Journal of Speech, Language and the Law, 17, 45-66. doi:10.1558/ijsll.v17il.45

Parret, H. (1993). Indirection, seduction and manipulation in discourse. In $\mathrm{H}$. Parret (Ed.). Pretending to Communicate. Berlin, GE: de Gruyer.

Porter, S., \& ten Brinke, L. (2009). Dangerous decisions: A theoretical framework for understanding how judges assess credibility in the courtroom. Legal and Criminological Psychology, 14, 119-134. doi: $10.1348 / 135532508 \times 281520$

Powell, M. B. (2002). Specialist training in investigative and evidential interviewing: Is it having any effect on the behaviour of professionals in the field. Psychiatry, Psychology, and Law, 9, 44-55. doi:10.1375/pplt.2002.9.1.44

Rassin, E. (2018). Reducing tunnel vision with a pen-and-paper tool for the weighting of criminal evidence. Investigative Psychology and Offender Profiling, 15, 227-233. doi: $10.1002 /$ jip. 1504

Rassin, E., Eerland, A., \& Kuijpers, I. (2010). Let's find the evidence: An analouge study of confirmation bias and criminal investigations. Journal of Investigative Psychology and Offender Profiling, 7, 231-246. doi: $10.1002 /$ jip. 126 
Rassin, E., Muris, P., Booster, E., \& Kolsloot, I. (2008). Indecisiveness and informational tunnel vision. Personality and Individual Differences, 45, 96-102. doi: $10.1016 /$ j.paid.2008.03.006

Recasens, M., Danescu-Niclescu-Mizil, C., \& Jurafsky, D. (2013). Linguistic models for analyzing and detecting biased language. Association for Computational Linguistics, 51, 1650-1659. Retrieved from http://www.aclweb.org

Ross, L., Lepper, M. R., \& Hubbard, M. (1975). Perseverance in self-perception and social perception: Biased attributional Processes in the debriefing paradigm. Journal of Personality and Social Psychology, 32, 880 892. doi: $10.1037 / 0022-3514.32 .5 .880$

Searle, J. R. (1975). Indirect speech acts. Syntax and Semantics, 3, 59-82. Retrieved from www.library.tudelft.nl

Semin, G. R., \& Fiedler, K. (1988). The cognitive functions of linguistic categories in describing persons: Social cognition and language. Journal of Personality and Social Psychology, 54, 558-568. doi:10.1037/00223514.54.4.558

Semin, G. R., \& Fiedler, K. (1991). The linguistic category model, its bases, applications and range. European Review of Social Psychology, 2, 1-30. doi: $10.1080 / 14792779143000006$

Semin, G. R., Rubini, M., \& Fiedler, K. (1995). The answer is in the question: The effect of verb causality on locus of explanation. Personality and Social Psychology Bulletin, 21,834-841. doi: $10.1177 / 0146167295218006$

Shepherd, E., \& Griffiths, A. (2013). Investigative Interviewing: The conversation management approach. Oxford, UK: Oxford University Press.

Shuy, R. (1998). The language of confession, interrogation, and deception. Thousand Oaks, CA: Sage Publications, Inc.

Stephenson, G. M., \& Moston, S. J. (1994). Police interrogation. Psychology, Crime \& Law, 1, 151-157. doi:10.1080/10683169408411948 
Telep, C. W. (2017). Police officer receptivity to research and evidence-based policing: Examining variability within and across agencies. Crime \& Delinquency, 63, 976999. doi: $10.1177 / 0011128716642253$

Van Amelsvoort, A., Rispens, I., \& Grolman, H. (2010). Handleiding verhoor. Amsterdam, NL: Reed Business.

Van der Sleen, J. (2009). A structured model for investigative interviewing of suspects. In R. Bull, T. Valentine, \& T. Williamson (Eds.), Handbook of Psychology of Investigative Interviewing. Chichester, UK: John Wiley \& Sons.

Vrij, A., \& Mann, S., (2001). Telling and detecting lies in a highstake situation: The case of a convicted murderer. Applied Cognitive Psychology, 15, 187-203. doi:10.1002/1099-0720(200103/04)15:2<187::AIDACP696>3.0.CO:2-A

Wagenaar, W. A., Israels, H., \& Van Koppen, P. J. (2009). De slapende rechter. Amsterdam, NL: Uitgeverij Bert Bakker. 


\section{Appendix $A$ \\ Interviewer Information: PEACE Guidelines}

Detailed and Broad instructions given to interviewers in Study 1, Chapter 4. In Study 2, Chapter 4, only the detailed instructions were given.

Ethical Information-gathering Interview (DETAILED)

In any interview, it is extremely important for the investigator to behave in a professional manner and conduct themselves with integrity. Here are some guidelines you will need to create questions to conduct a good interview:

\section{Establish a professional relationship}

If people trust you, they are more likely to give you the information you are asking for. Your goal is to get an accurate and reliable version of events.

\section{Be methodical}

Being logical, precise, and orderly in formulating your questions will help you get the most information. Think about what you want to know and ask questions that will allow the interviewee to give you this information. You are free to ask a wide range of questions.

\section{Personal Style}

What you say and your body language can affect how the interviewee responds to you. Remain open and friendly. Be genuinely interested in the responses. Be genuinely interested in the interviewee's feelings and well-being.

\section{Be Fair}

Be prepared to believe any account of events the interviewee tells you unless you have evidence to the contrary. It is okay to challenge information that is known to be untrue; however, common sense and good judgement are better than personal beliefs when making this judgement.

\section{Deal with suggestibility issues}

Sometimes interviewees can be influenced by what they think you want to hear. Make sure you formulate your questions in a way that does not imply the answer you want. Also, make sure you do not accuse the interviewee of wrong-doing. 


\section{Admissions of Guilt}

Your role here is to find out as much information as possible from the interviewee so we can continue our investigation. If the interviewee admits to wrong doing early on, ask more fact-finding questions to make sure their admission matches with known information

\section{Principles of Investigative Interviewing (Control Group)}

Principles of Investigative Interviews:

1. To obtain accurate and reliable accounts of events.

2. Interviewees must be treated fairly and equally in accordance with human rights

3. Accounts from the individual should always be tested against what the interviewer already knows.

4. You are free to ask a wide range of questions to get to the information you need for the investigation.

5. Interviewers should recognize the benefits of an early admission.

6. Interviewers do not have to accept an answer that is given, especially if they have information to the contrary.

7. Even when a suspect exercises the right to silence, investigators have a responsibility to question them 


\section{Appendix B \\ Countermeasures and symptoms of nervousness included in a self-report measure for participants in Chapter 3.}

\section{Countermeasures}

Think about how you responded to the interviewer today. Did you do anything to purposefully appear more truthful? (Check all that apply):

a. Increased eye contact without being asked

b. Used hands and body to illustrate your words

c. Decreased eye contact

d. Smiled

e. Used pauses to collect your thoughts and formulate the lie

f. Did not include a lot of detail in your responses

g. Used your hands and body less while talking

h. Tried to answer the question immediately once asked

i. Reduced smiling

j. Tried to appear honest through facial expression and body language

k. Tried to control your body movements

l. Put on a serious face

$\mathrm{m}$. Tried to control symptoms of nervousness

\section{Nervousness}

Did you have any of the following symptoms during the interview (check all that apply):

a. Sweating or cold/damp skin

b. Fast heartbeat

c. Tightening of chest

d. Shortness of breath

e. Difficulty thinking clearly

f. Stuttering or tripping over words

g. Fluttery feeling in stomach

h. Indigestion

i. Feelings of defensiveness

j. Feeling like you wanted to run away 


\section{Appendix C \\ Case Vignette}

Interviewers in both studies received the following information. In Study 1, the participants were presented with the information as facts of the case. In Study 2, interviewers were presented with the information as observations of the interviewee completing the taste-testing task and having a brief interview with the researcher about their results. In both studies, the information was presented consecutively, and questions were formulated after each presentation.

1. Background:

The person of interest signed up to participate in this study and they were randomly assigned to the juice taste testing task. Their task was to match apple juice flavours with their corresponding brand in a blind taste test. Scoring $100 \%$ on this task is statistically improbable; however, the person of interest has somehow managed to correctly identify all six juices by matching them to their brand.

The set-up of the study is such that the person of interest could have obtained the correct answers for the task, and achieved a perfect score, if they were left unattended. It so happens that the person of interest was left alone for approximately 3 minutes during the task. At this time, we are not certain what happened in the room while the researcher was away; however, the researcher suspects the participant may have cheated on the task, but she needs more information to prove it.

2. Why we think we cannot trust the person of interest's results: Previous studies have found that being able to distinguish items that are very similar in taste is extremely difficult when there are only two or three choices (think blind taste testing colas). In this study we doubled the number of juices and also employed some tricks to make correct identification nearly impossible. Yet, the person of interest managed to score them all correctly.

3. To motivate the person of interest, a monetary incentive was offered if they got all 6 juices correct (We wanted them to try really hard). The person of interest seemed very excited about this and eager to obtain the gift card. We later learned the person of interest was having financial difficulties. 
4. When the researcher realized the results were anomalous, she conducted an initial interview. The person of interest sounded very nervous. When answering questions about the task and the results, the person of interest frequently stumbled over their words, and took a long time before answering the questions.

5. Also during the initial interview, the person of interest refused to make eye contact with the interviewer, they fidgeted a lot, and then they sat with arms crossed looking very defensive.

\section{Appendix D \\ Test Testing Procedure}

To set up the task, six different apple juice brands were poured into six identical $500 \mathrm{ml}$ plastic bottles with attached paper labels showing the brand name. The containers were uncovered, and the participant was asked to taste each and memorize the brand. For the blind portion of the test, opaque paper covers were slid over each bottle so that the brand name was no longer visible, and the participant turned away while the bottles were shuffled to mix up the order.

The participants were then asked to taste the juice again and identify each brand by taste alone. Each participant made their choice by marking the letter on the covering to the corresponding brand on an answer sheet. During this portion of the task the research assistant left the room under the pretense they needed to check the progress of the interviewer. Meanwhile, the surveillance equipment was recording the participant to verify later if the participant lifted the covers to get a good score or not. A review of all tapes revealed that $100 \%$ of the participants self-elected into an honest condition, as no one cheated on the task. 


\section{Appendix E \\ Dutch Language Police Survey Statements}

Op de onderstaande vragen bestaan geen goede of foute antwoorden. We willen begrijpen hoe u werkelijk denkt over de volgende uitspraken.

Lees de volgende uitspraken en geef aan hoeveel $u$ het eens of oneens bent met elk van hen. Gelieve niet te veel na te denken over uw antwoord. Geef uw eerste reactie door het cijfer te omcirkelen dat overeenkomt met uw overtuigingen. Dank $u$ voor uw tijd en medewerking.

1. Getrainde Agenten kunnen zeer accuraat onderscheid maken tussen waarheid en leugenachtigheid.

2. Impliciete bedreigingen of beloftes tijdens een verhoor kunnen leiden tot waarachtige bekentenissen.

3. Honger en slecht slapen kunnen het beoordelingsvermogen en het vermogen om beslissingen te nemen bij verdachten aantasten.

4. Signalen van nervositeit en spanning zijn goede indicatoren van schuld.

5. Onschuldige verdachten zullen eerder afzien van hun recht op de aanwezigheid van een advocaat bij een verhoor dan schuldige verdachten.

6. Expliciete beloften van een milde veroordeling door rechters kunnen leiden tot waarachtige bekentenissen.

7. Het is een goede gewoonte voor de verhoorder om de verdachte te vertellen wat hij / zij denkt dat er is gebeurd en om bevestiging te zoeken.

8. Personen met een psychologische stoornis zijn gevoeliger voor suggestie tijdens verhoren dan gezonde personen.

9. Een bekentenis moet wel waar zijn als deze accurate details over het misdrijf bevat.

10. Medeleven van de verhoorder kan ertoe leiden dat mensen aannemen dat er mild veroordeeld zal worden, wat er vervolgens toe kan leiden dat deze mensen een valse bekentenis afleggen.

11. Onschuldige mensen leggen nooit vrijwillig een valse bekentenis af. 
12. Adolescenten zijn gevoeliger voor suggestie tijdens verhoren dan volwassenen.

13. Het is beter om ongeloof in het antwoord van een verdachte expliciet te benoemen, om sneller tot de waarheid te komen.

14. Signalen van nervositeit en spanning zijn goede indicatoren van leugenachtigheid.

15. Het is een goede gewoonte om verhoorvragen vooraf voor te bereiden.

16. Het kennen van al de feiten in een zaak zorgt voor een beter interview.

17. Verdachten zouden vroeg in het verhoor geconfronteerd moeten worden met het bewijs dat er tegen hen is.

18. Verhoorders kunnen het verschil zien tussen een valse en een waarachtige bekentenis.

19. Personen met ontwikkelingsproblemen zijn gevoelig voor suggestie tijdens verhoren.

20. Verhoorders zouden de antwoorden van verdachten hardop moeten samenvatten en checken of de samenvatting correct is.

21. Het hebben van een theorie over wie het misdrijf gepleegd heeft en over het motief Is zinvol bij het verhoor.

22. Onschuldige mensen bekennen geen misdrijven.

23. Informatie verzamelen is het primaire doel van een verhoor.

24. Het is beter om ongeloof in het antwoord van een verdachte te communiceren door middel van lichaamstaal, dan om dit expliciet te benoemen.

25 . Het vooraf opstellen van verhoorvragen kan de natuurlijke loop van het interview belemmeren.

26. Een effectieve verhoortactiek is de verdachte laten weten dat jij denkt dat hij/zij schuldig is. 


\section{Appendix F}

\section{Table of Transcription Symbols}

\begin{tabular}{|c|c|c|}
\hline Symbol & Name & Use \\
\hline /text / & Back slash & $\begin{array}{l}\text { Indicates the start and end } \\
\text { points of overlapping speech. }\end{array}$ \\
\hline$=$ & Equal Sign & $\begin{array}{l}\text { Indicates the next utterance } \\
\text { occurs immediately by the } \\
\text { next speaker with no pause. }\end{array}$ \\
\hline $\begin{array}{l}\text { (\# of } \\
\text { seconds) }\end{array}$ & Timed Pause & $\begin{array}{l}\text { A number in parentheses } \\
\text { indicates the time, in seconds, } \\
\text { of a pause in speech. }\end{array}$ \\
\hline$()$. & Micropause & $\begin{array}{l}\text { A brief pause, usually less than } \\
0.2 \text { seconds. }\end{array}$ \\
\hline- & Hyphen & $\begin{array}{l}\text { Indicates an abrupt halt or } \\
\text { interruption in utterance. }\end{array}$ \\
\hline ALL CAPS & $\begin{array}{l}\text { Capitalized } \\
\text { text }\end{array}$ & Indicates shouted speech. \\
\hline underline & $\begin{array}{l}\text { Underlined } \\
\text { text }\end{array}$ & $\begin{array}{l}\text { Indicates the speaker is } \\
\text { emphasising or stressing the } \\
\text { speech. }\end{array}$ \\
\hline$:::$ & Colon(s) & $\begin{array}{l}\text { Indicates prolongation of a } \\
\text { sound }\end{array}$ \\
\hline (hhh) & & Audible exhalation or sigh \\
\hline (text) & Parentheses & $\begin{array}{l}\text { Speech which is unclear or in } \\
\text { doubt in the transcript. }\end{array}$ \\
\hline $\begin{array}{l}\text { ((italic } \\
\text { text )) }\end{array}$ & $\begin{array}{l}\text { Double } \\
\text { Parentheses }\end{array}$ & $\begin{array}{l}\text { Annotation of non-verbal } \\
\text { activity. }\end{array}$ \\
\hline [text] & $\begin{array}{l}\text { Square } \\
\text { brackets }\end{array}$ & $\begin{array}{l}\text { Notes and context outside of } \\
\text { the utterances that are needed } \\
\text { for full comprehension. Also } \\
\text { includes words omitted for } \\
\text { anonymity. }\end{array}$ \\
\hline
\end{tabular}

Note: Most symbols are adapted from Jefferson (1984) 


\section{Appendix G}

\section{Definitions of Question Types}

\begin{tabular}{|c|c|c|}
\hline $\begin{array}{l}\text { Question } \\
\text { Type }\end{array}$ & Definition & Examples \\
\hline Accusatory & $\begin{array}{l}\text { Directly accuses } \\
\text { the interviewee of } \\
\text { wrong doing } \\
\text { Implies that the } \\
\text { interviewee was } \\
\text { involved in wrong } \\
\text { doing } \\
\text { - Asks why the } \\
\text { interviewee } \\
\text { committed a wrong } \\
\text { doing }\end{array}$ & $\begin{array}{l}\text { - I know you } \\
\text { cheated, just tell } \\
\text { me how. } \\
\text { - If you didn't cheat } \\
\text { then how did you } \\
\text { get } 100 \% \\
\text { - Why did you } \\
\text { cheat? }\end{array}$ \\
\hline Other & $\begin{array}{l}\text { - Does not advance } \\
\text { the interview in any } \\
\text { way } \\
\text { - Pleasantries or } \\
\text { small talk } \\
\text { - Well-being check }\end{array}$ & $\begin{array}{l}\text { - Would you be } \\
\text { willing to redo the } \\
\text { test? } \\
\text { - How are you } \\
\text { today? Are you a } \\
\text { student here? } \\
\text { - How are you } \\
\text { feeling? Are you } \\
\text { nervous? }\end{array}$ \\
\hline Neutral & $\begin{array}{l}\text { - Seeks to gather } \\
\text { more information } \\
\text { pertaining to the } \\
\text { case } \\
\text { - Asks for clarifying } \\
\text { details } \\
\text { - Asks for } \\
\text { perspective }\end{array}$ & $\begin{array}{l}\text { - Tell me what you } \\
\text { did when... } \\
\text { - Were you left } \\
\text { alone during the } \\
\text { test? } \\
\text { - Did you find the } \\
\text { test easy or } \\
\text { difficult? }\end{array}$ \\
\hline $\begin{array}{l}\text { Open } \\
\text { Question } \\
\text { (TED) }\end{array}$ & $\begin{array}{l}\text { Allows for the } \\
\text { interviewee to } \\
\text { provide detail and } \\
\text { longer answers } \\
\text { - Contains or implies } \\
\text { to Tell, Explain or } \\
\text { Describe to provide } \\
\text { a complete answer }\end{array}$ & $\begin{array}{l}\text { - Tell me what } \\
\text { happened when } \\
\text { you entered the } \\
\text { room. } \\
\text { - Explain the } \\
\text { process to me. } \\
\text { - Describe the test, } \\
\text { please. }\end{array}$ \\
\hline
\end{tabular}




\begin{tabular}{|c|c|c|}
\hline $\begin{array}{l}\text { Question } \\
\text { Type }\end{array}$ & Definition: & Examples: \\
\hline Probe & $\begin{array}{l}\text { Asking a follow-up } \\
\text { question to fully } \\
\text { understand the } \\
\text { response } \\
\text { Obtaining specific } \\
\text { or more in-depth } \\
\text { information } \\
\text { Who, what, where, } \\
\text { when, why, how } \\
\text { questions }\end{array}$ & $\begin{array}{l}\text { - I don't know } \\
\text { what you mean by } \\
\text { XYZ. Can you } \\
\text { clarify? } \\
\text { - Jason? Who is } \\
\text { that? } \\
\text { - You said she fell. } \\
\text { When she fell, did } \\
\text { she injure any } \\
\text { part of her body? }\end{array}$ \\
\hline Leading & $\begin{array}{l}\text { - Suggests or } \\
\text { encourages the } \\
\text { answer } \\
\text { Respondent is } \\
\text { manipulated to } \\
\text { agree with inserted } \\
\text { qualities or } \\
\text { circumstances that } \\
\text { have not been } \\
\text { previously offered } \\
\text { by the respondent }\end{array}$ & $\begin{array}{l}\text { - Just to be clear, } \\
\text { you were very } \\
\text { drunk, right? } \\
\text { - Are you always } \\
\text { aggressive when } \\
\text { you drink? }\end{array}$ \\
\hline $\begin{array}{l}\text { Appropriate } \\
\text { closed } \\
(\text { AYN })\end{array}$ & $\begin{array}{l}\text { *Context specific - gaining } \\
\text { additional information or } \\
\text { clarifying information } \\
\text { - Answered with a } \\
\text { short response } \\
\text { (one or two words) } \\
\text { - Can be used to } \\
\text { clarify } \\
\text { - } \text { Includes } \\
\text { appropriate use of } \\
\text { echo questions } \\
\text { - Used to obtain } \\
\text { facts quickly }\end{array}$ & $\begin{array}{l}\text { - Were you driving } \\
\text { that day? } \\
\text { - Is Jason your } \\
\text { brother? } \\
\text { - [Person states } \\
\text { XYZ], [Interviewer } \\
\text { responds] XYZ? } \\
\text { (this prompts for } \\
\text { further } \\
\text { information or } \\
\text { clarification) } \\
\text { - Are you } \\
\text { employed? } \\
\text { - Just to be clear, } \\
\text { I heard you say } \\
\text { XYZ, do I [have } \\
\text { that right/ } \\
\text { understand that } \\
\text { correctly]? }\end{array}$ \\
\hline
\end{tabular}




\begin{tabular}{|c|c|c|}
\hline $\begin{array}{l}\text { Question } \\
\text { Type }\end{array}$ & Definition: & Examples: \\
\hline $\begin{array}{l}\text { Inappropria } \\
\text { te closed } \\
\text { (IYN) }\end{array}$ & $\begin{array}{l}\text { *Context specific - used } \\
\text { at the wrong point in the } \\
\text { interview, or excessively } \\
\text { repeating the answer in } \\
\text { question format (echo) as } \\
\text { a means of clarification } \\
\text { - Answered with a } \\
\text { short response } \\
\text { (one or two words) } \\
\text { - Includes } \\
\text { inappropriate use } \\
\text { of echo questions }\end{array}$ & $\begin{array}{l}\text { - Do you know this } \\
\text { man? } \\
\text { - When she fell did } \\
\text { she hit her head? } \\
\text { (when no mention } \\
\text { of a head injury } \\
\text { was made) } \\
\text { - You went to the } \\
\text { store? You went by } \\
\text { car? You bought } \\
\text { bread? You } \\
\text { returned home? }\end{array}$ \\
\hline $\begin{array}{l}\text { Forced } \\
\text { Choice }\end{array}$ & $\begin{array}{l}\text { - Limits responses to } \\
\text { finite choices }\end{array}$ & $\begin{array}{l}\text { - Was the woman } \\
\text { blond or brunette? }\end{array}$ \\
\hline Multiple & $\begin{array}{l}\text { - Many questions } \\
\text { asked at once } \\
\text { - } \quad \text { Interviewers taking } \\
\text { turns asking a } \\
\text { barrage of } \\
\text { questions } \\
\text { - } \quad \text { Rapid fire questions }\end{array}$ & $\begin{array}{l}\text { - When you } \\
\text { arrived, who was } \\
\text { there? What did } \\
\text { you do when you } \\
\text { got there, and how } \\
\text { many people were } \\
\text { already drinking? }\end{array}$ \\
\hline $\begin{array}{l}\text { Opinion/ } \\
\text { Statements }\end{array}$ & $\begin{array}{l}\text { - Posing opinions } \\
\text { - } \text { (naking statements } \\
\text { questions) as } \\
\text { opposed to asking } \\
\text { questions. }\end{array}$ & $\begin{array}{l}\text { - I think you have } \\
\text { more to say and } \\
\text { just don't want to } \\
\text { cooperate. } \\
\text { - Let me tell you } \\
\text { how easily a night } \\
\text { of drinking can go } \\
\text { horribly wrong... }\end{array}$ \\
\hline $\begin{array}{l}\text { Guilt } \\
\text { Presumptiv } \\
\text { e language }\end{array}$ & $\begin{array}{ll}\text { - } & \text { Direct accusations } \\
\text { of guilt or } \\
\text { involvement } \\
\text { - } \quad \text { Insinuations of guilt } \\
\text { or involvement } \\
\text { - } \quad \text { Implied guilt or } \\
\text { involvement }\end{array}$ & $\begin{array}{l}\text { - We know you } \\
\text { killed her, just tell } \\
\text { us why! } \\
\text { - I once } \\
\text { interviewed a cold- } \\
\text { blooded killer who } \\
\text { was just as relaxed } \\
\text { as you are. }\end{array}$ \\
\hline
\end{tabular}




\section{CHAPTER 10}

The Relevance of Identifying Guilt Presumptive Language in Investigative Interviews: Valorisation Addendum 


\section{RELEVANCE}

As mentioned within this thesis, many investigative errors start or are compounded by the events of the investigative interview. Despite decades of research on this topic, police interviewers continue to exhibit behaviour during the interview that can negatively influence the suspect's behaviour and the outcome of the interview. Continued research is needed to ensure that that most important tool in an investigators kit - interviewing skills and questioning techniques - are of the best quality. However, even the best tools in the wrong hands wreak havoc - intentionally or not.

Police interviewers are human beings, and thus, are prone to the same flaws as all humans, even when doing their job. One of the most common human cognitive flaws is to seek out what we expect or what confirms our views. In relation to the investigative interview, this comes in the form of making guilt judgements. Whether explicitly or implicitly stated, guilt-presumptive language undermines the objective of obtaining investigation relevant information (IRI). If a suspect is influenced to cease disclosure of information because the he or she feels accused or prejudged, it can lengthen or stall the investigation. This taxes time and the human resources dedicated to a case. In the worst-case scenario, the interviewer's behaviour may induce a false confession

\subsection{TARGET GROUPS}

The findings contained within this thesis are intended to set a foundation for evidence-based practice in evaluating the investigative interview. It is clear that analysing investigative interviews using traditional methods does not reveal the whole story 
of the interview or the interviewer's skills. Guiltpresumptive language is detrimental to rapportbuilding and information disclosure. This may be due to the suspect's perception of fairness and justice during the process. If it appears the suspect has no voice in the process, and decisions about guilt have been made, there is diminished incentive to cooperate further.

The findings in this thesis may also be beneficial for legal-decision makers such as prosecution lawyers as well as judges. Academics and researchers are often retained to assist judges in determining whether confession evidence can be trusted. Although this studies in this thesis did not specifically examine confessions, it is well established in the literature that a primary source of coerced and false confessions stem from guilt-presumptive language. This factor needs to be presented to the court and given the same credence as physical coercion, as it may produce the same outcomes.

Defence counsel should also be aware of the influence of guilt-presumptive language on their clients - especially in jurisdictions where the presence of counsel during the interview is not a legal right (e.g., Canada), when this right has been waived by the suspect, or in the case of "informal questioning and comments" that can occur outside the interview room (e.g., en route to holding cells, in police transportation, by undercover officers, or noncustodial questioning).

\subsection{INNOVATION}

Examining the language used in the investigative interview for guilt-presumption is the novel contribution of this thesis. Although more work is needed in this area, the findings in this thesis set 
the basis to develop viable techniques to improve interview outcomes. Understanding the detriment of guilt presumption and knowing how to identify this type of language will be a benefit for the training, development of police interviewers. Moreover, examining interviews in this manner will also help researchers explore trends in suspect cooperation, disclosure, rapport-building, and confession evidence.

\subsection{SOCIETAL BENEFITS}

Poorly conducted interviews come at a great cost to society - financial costs, costs to public trust in the criminal justice system, and life changing costs to innocent suspects. Improving the quality of investigative interviews will lessen those costs. 


\section{SUMMARIES, ACKNOWLEDGEMENTS \& CURRICULUM VITAE}




\section{ENGLISH SUMMARY}

The aim of the research conducted for this thesis was to investigate indicators of confirmation bias within the police-suspect investigative interview. Confirmation bias in the investigative interview generally occurs when the interviewer holds a presumption of guilt about the suspect, and then sets out to find evidence of that guilt. The interview then becomes less about information gathering and more about finding support for the suspect's involvement in the crime.

In the present thesis, indicators of confirmation bias were explored through a series of experimental and applied studies. The nonverbal effects of assumed guilt expectation on the behaviour of truth-telling interviewees $(N=52)$ were examined in Study 1 (Chapter 3). The influence of guilt presumption on the interviewer's behaviour was investigated in Study $2(N=107$; Chapter 4$)$ and in Study 3 ( $n=33$; Chapter 5 ). Evidence in the extant literature suggests that pre-existing beliefs are an underlying mechanism of bias. In Study 4 , a sample of police officers ( $N=101$; Chapter 6$)$ were surveyed to examine their beliefs about factors that may influence the investigative interview with suspects. The novel contribution of this research to the discourse on bias and guilt presumption can be found in Studies 5 and 6. In Study 5 (Chapter $7)$, indicators of biased language were identified in a sampling of police-suspect interviews $(N=9)$. In Study 6 (Chapter 8$)$, a sample of police-suspect interviews in a murder case $(N=6)$ were analysed by question type and the utterances used by interviewers. Linguistic tools (e.g., content and pragmatic analysis) were used to demonstrate the richness of information that could be found when the questions and utterances are evaluated within the context of the interview. The amount of information obtained, and suspect cooperation was measured for any effects of language on those variables.

The research findings for the overall thesis suggests that indicators of confirmation bias are detectable through guilt presumptive language. Accusations and insinuations of guilt seem to be the most consistent indicator that an interviewer believes the suspect is guilty and may be attempting to find support for those beliefs. Incidences of bias are subtle; however, the influence on the interview and the suspect's behaviour is clear (denial, defensiveness, and non-cooperation). I argue that the observable nature of biased behaviour may allow for the development of interventions prior to, and during, the investigative interview to reduce biased behaviour in interviewers. 


\section{DUTCH SUMMARY (Samenvatting)}

Het doel van het onderzoek in dit proefschrift was het bestuderen van indicatoren vooringenomenheid tijdens het politieverhoor van verdachten. Vooringenomenheid komt meestal voor in een verhoor wanneer de verhoorder aanneemt dat de verdachte schuldig is en op zoek gaat naar bewijs voor die schuld. Het doel van het verhoor is dan niet langer het verzamelen van informatie, maar het zoeken naar bevestiging dat de verdachte het misdrijf heeft begaan.

In dit proefschrift zijn indicatoren van vooringenomenheid onderzocht in een aantal experimentele en toegepaste studies. In Studie 1 (Hoofdstuk 3) werd het effect onderzocht van non-verbale signalen van de verhoorder die schuld veronderstelt, op het gedrag van waarheidssprekende verdachten $(N=52)$. De invloed van veronderstelde schuld op het gedrag van de verhoorder werd onderzocht in Studie 2 ( $N=107$; Hoofdstuk 4) en in Studie 3 ( $n=33$; Hoofdstuk 5). Uit de literatuur blijkt dat reeds bestaande overtuigingen een onderliggend mechanisme van vooringenomenheid vormen. In Studie 4 ( $N=101$; Hoofdstuk 6$)$ werden politieagenten bevraagd over factoren die volgens hen het verdachtenverhoor zouden kunnen beïnvloeden. De bijdrage van dit onderzoek aan het debat over vooringenomenheid en schuldaanname wordt in studie 5 en 6 beschreven. In Studie 5 (Hoofdstuk 7) werden indicatoren van vooringenomen taalgebruik geïdentificeerd in een selectie van verdachtenverhoren door de politie $(N=9)$. In studie 6 (Hoofdstuk 8 ) werden verdachtenverhoren uit een moordzaak $(N=6)$ geanalyseerd op basis van het type vragen en de uitingen van de verhoorder. Linguïstische methoden (bijvoorbeeld inhoudelijke en pragmatiek analyse) werden gebruikt om aan te tonen dat er een overvloed aan informatie te vinden is als vragen en uitingen binnen de context van het vehoor worden geëvalueerd. Er werd gemeten in hoeverre het taalgebruik een effect had op de hoeveelheid verzamelde informatie en op de medewerking van de verdachte.

De bevindingen van dit proefschrift suggereren dat de indicatoren van confirmation bias te detecteren zijn aan de hand van taalgebruik waaruit een schuld presumptie blijkt. Beschuldigingen en insinuaties van schuld lijken de meest consistente indicatoren te zijn dat een verhoorder gelooft dat de verdachte schuldig is en hiervoor bevestiging aan het zoeken is. Gevallen van vooringenomenheid zijn subtiel, maar hebben een duidelijke invloed op het verhoor en op het gedrag van de verdachte (ontkennen, een defensieve houding aannemen, en niet meewerken). Ik beargumenteer dat de waarneembare aard van vooringenomen gedrag het mogelijk maakt interventies te ontwikkelen die, zowel voor als tijdens het verhoor, het vooringenomen gedrag van de verhoorder kunnen verminderen. 


\section{ACKNOWLEDGEMENTS}

"The most important things in life are the connections you make with others" - Tom Ford

This thesis and PhD achievements would not have been possible if not for the support, guidance, and love of so many people. I already know this is going to be a long one and I'll make no apologies for it. If wealth was measured by the quality of friendships and genuine support, I think that I would be the richest person on the planet.

I would be remiss if I didn't start with the people who believed in me before I even applied to complete a PhD. First and foremost are the fantastic people at the College of Continuing Education (CCE), Dalhousie University. In 2008, at 33 years of age, I decided to finally pursue the university education that eluded me in my late teens and early 20s. The Transition Year Program (TYP) was my gateway to higher learning and opportunity. My deepest thanks to Dr. Isaac Saney, Dr. Melanie Farrimond, and Wanda Ince who have always been my biggest cheerleaders, and who recognised enough potential to award me one of the coveted spots in the program. You three kept me going when I thought I couldn't and supported me during my entire academic career. I miss you folks so much! Thank you!

Many thanks to Dean Andrew Cochrane of the CCE who always made time for me and imparted many wise words in my direction. I truly appreciate your kindness. A big heartfelt thanks to Bonnie BestFleming, Gaye Wishart, and Lorna Little for the opportunity to learn more about the human rights and equity in a university setting, allowed me to 
assist in meaningful contributions at Dalhousie, and for being all around wonderful, caring and supportive friends and co-workers. Special thanks to Dr. Steven Smith, Dean of Science at Saint Mary's University, who took on me on as an undergrad thesis student in desperate need of a supervisor, and then offered me a position as a Masters' student, thus launching my journey into legal psychology. I would not be here if not for you, Steve. I truly appreciate everything you did for me.

I'd also like to thank the team at the Nova Scotia Mental Health Court (MHC) for demonstrating that justice, compassion, and professionalism can coexist to the benefit of persons in conflict with the law, and who also suffer from mental illness. I'd like to specifically thank Chief Judge Pamela Williams for the opportunity to work closely with her team and to contribute to the MHC annual report. It was a valuable and meaningful experience.

A big and special thank you to Prof. dr. Mary Ann Campbell, whom I consider my academic mother in many respects. Mary Ann, working with you on the Mental Health Court project taught me so much about how to conduct quality research. You instilled good research practices in me and trusted me with a large and complex project. This was the opportunity I needed to grow as a researcher in an applied environment. The kindness and professionalism you showed me taught me how to be a good supervisor to students. You supported me and provided sage guidance as I navigated difficult moments in academia. None of these things are lost on me. I channel you often as I continue to navigate academic life. Thank you. 
A big thank you goes out to Katelynn CarterRogers who was my "partner in crime" throughout our Masters' program and the initial part of the PhD. Although our paths eventually diverged, I often fondly remember all the laughs we had and all the shared anger at the perceived injustice in academia (we were right). I'm happy you're finally doing what you love and I'm incredibly proud of the woman you've become. Keep up the great work!

Upon moving across the "pond" to pursue my $\mathrm{PhD}$, I was fortunate to meet some people in the UK who became fast, good, and lasting friends and colleagues. Char Hudson and Liam Satchell - its's been a fun, crazy, interesting, and exciting journey this far. I couldn't ask for better research collaborators and friends. I have no idea how we come out of conferences alive or at least with all our organs in working order. Here's to more good times and world domination - one study at a time.

I cannot forget about all the people and colleagues at the University of Portsmouth who welcomed me at that first Decepticon conference in Cambridge 2015 and to those who made me feel welcome during my time in Portsmouth, especially Gary Dalton and Feni Konotogianni. I'd also like to specifically thank my Portsmouth supervisor Prof. dr. Aldert Vrij. Aldert, I don't know if you even realise how much I enjoyed our weekly meetings. That you took time to check in whenever you could, meant the world to me. It's often the little things that can leave a lasting impact on someone. Thank you.

Thank you to all the instructors and colleagues within the House of Legal Psychology. I've learned a lot from each of you and I appreciate having the opportunity to work with and learn from some of the 
best minds in legal and forensic psychology. I'd also like to give a specific and heartfelt thank you to Prof. dr. Lorraine Hope. Lorraine, your support, guidance, knowledge, information, compassion, and empathy was always available when I needed it. When I was having a particularly difficult time, you noticed with your "eagle eye" and reached out. I want to tell you that your timing was impeccable, and my gratitude knows no bounds. Thank you.

A big thank you for my colleagues and staff at the Maastricht Faculty of Law who are some of the nicest and supportive people I have ever worked with. Prof. André Klip, thank you for always supporting me and my research. I would also like to thank my Promotor and academic father Prof. dr. Peter van Koppen. Peter let's be honest, we were often a thorn in each other's sides. Like most parents, you often had me torn between wanting to earn your approval and disliking you greatly. But like most grown children, whilst we don't always agree with our parents' methods, we know it comes from a good place and I appreciate you. Thank you for giving me the opportunity to conduct my PhD research, for guiding me, for wanting me to be, and do, better. Thank you for asking the hard questions, and for helping me look at things from a different perspective. I wouldn't be here without you. Thank you.

To my co-promotor, line manager, and friend Dr. Robert Horselenberg, in an official capacity, you provided me with opportunities for my research. But you also allowed me to do what I love the most - to teach. By doing that, you set me up for success in the future and I am extremely grateful. However, I mostly want to thank you for being the supportive 
academic big brother I needed. As older siblings often do, you act as a buffer between us 'young ones' and the academic parent - no doubt to the detriment of your own mental health sometimes. It never went unnoticed or unappreciated. Thank you for being a constant source of laughter, fun, and work-life balance by forcing me to take a break occasionally. I'm grateful for our chats, the dinners, the drinks, and the field trips. I'll miss our 'walk and talks'. I loved having meetings up on the old city walls and hearing you talk about the rich history of Maastricht. These things made the rigours of doing a PhD much more bearable. Thank you so very much for everything.

To Chantal Meertens, I don't even know how to begin to thank you for your support as an administrative assistant, but most importantly, your friendship. You did whatever you could to help me and make any tasks easier. Your knowledge, efficiency, and helpfulness always came at precisely the perfect moment. Thank you for being there for the official stuff, as well the laughs, and the tears. I already miss our coffee and lunch dates. I cannot imagine how I would have emerged from this PhD with my sanity intact had it not been for you. I cannot thank you enough. You, my friend, always went above and beyond. Thank you.

To my academic siblings... Tanja van Veldhuizen, thank you for being a source of wisdom, information, insight, and understanding throughout this process. Enide Maegherman (paranymph) and Ale De La Fuente Vilar (paranymph), thank you both for being great friends and helping to forge many lasting memories over the last couple of years. Our self-medication sessions (aka venting and wine) were 
needed and much appreciated. Thank you for checking in with me, emotionally supporting me, and appreciating me. Also, thank you both for helping me organise and arrange my $\mathrm{PhD}$ celebrations and protecting me from any religious zealots during my defence.

One of the hardest things I have ever done is to leave my family behind in Canada while I pursued my academic dreams. I would have never made it through if not for the support and friendship of many people I met in Maastricht. To my fellow Expats: Martha Shiell, Rachel Brown, Kim Jonas, Lisa and Michel Belyk, Ben Schultz, and Irena Boskovic, as well as the Dutch natives Eliza De Sousa Fernandes Perna and Stefan Gruijters - you folks were and continue to be amazing friends. Thank you for welcoming me, embracing me, and for making Maastricht a home away from home.

Finally, my family. First, thank you to my parents to whom I have dedicated this work. I wish my father could have lived to see his eldest child earn a doctorate, but I know he held on as long as he could and that he is proud of me. Thank you, Daddy. To Ken (aka Poppy), thank you for being there for all of us and making our family happier and more loving. To my mother, thank you for instilling the tenacity, stubbornness, thirst for knowledge, and work ethic in me. I wasn't always the easiest child to get along with, so thanks for your patience and being there when I needed to get out of a bind. I know I can count on you when I need to. I love you, Mommy and I hope I've made you proud.

To my children Morghan and Liam Manuel, thank you for being my inspiration. I started this academic journey for you, but I never dreamed that 
realising it would mean I would have to move away from you. However, having such awesome and welladjusted kids set my mind at ease. Although my decision meant massive changes to each of your lives, I never once felt that you didn't understand or support me. I would have never been able to succeed without that knowledge. I love you and I'm extremely proud of you both.

To my husband, Jason Quackenbush... wow, Mister. What a ride it's been. Thank you for understanding my need to do this. Thank you for supporting my decision to move over $5000 \mathrm{~km}$ away from you, mere months after we married. Thank you for providing financial and emotional support throughout this entire journey. Thank you for traveling to Europe when I needed you most. For holding me up when I thought I couldn't possibly stand on my own. For taking care of my father and family when I couldn't be there. For the adventures and laughs on both sides of the pond. Thank you for always believing in me. For being proud of me. Thank you for being my rock, my anchor, and my protector. You've made this endeavour bearable. Here's to the next adventure! I love you. 


\section{DISSEMINATION}

\section{Publications}

Adams-Quackenbush, N. M., Tomas, F., Horselenberg, R., \& Van Koppen, P. J. (2019, in press). Detecting Guiltpresumption in a police-suspect interview: An evaluation of the questions in a Dutch murder case. Journal of Investigative Interviewing Research and Practice.

Adams-Quackenbush, N. M., Horselenberg, R., Hubert, J., Vrij, A., \& Van Koppen, P. (2019, in press). Interview expectancies: Awareness of potential biases influence behaviour in interviewees. Psychiatry, Psychology, and Law. https://doi.org/10.1080/13218719.2018.1485522

Adams-Quackenbush, N. M., Horselenberg, R., \& Van Koppen, P. J. (2018). Where bias begins: a snapshot of police officers' beliefs about factors that influence the investigative interview with suspects. Journal of Police and Criminal Psychology. https://doi.org/10.1007/s11896-018-9301-1

\section{Conference Presentations}

Adams-Quackenbush, N. M., Horselenberg, R., Vrij, A., \& Van Koppen, P. (2018). Detecting bias in police interviews with suspects: A linguistic approach. Abstract accepted to International Investigative Interviewing Research Group (iIIRG) Conference, Porto, Portugal.

Adams-Quackenbush, N. M., Horselenberg, R., Vrij, A., \& Van Koppen, P. (2018). Getting what you ask for: Linguistic indicators of expectancy and bias in interview settings. Abstract accepted to European Association of Psychology and Law (EAPL) Conference, Turku, Finland.

Adams-Quackenbush, N. M., \& Satchell, L. M. (2017). Veracity and deception: Motivation and behaviour. Symposium accepted to European Association of Psychology and Law (EAPL) Conference, Mechelen, Belgium. 


\section{CURRICULUM VITAE}

Nicole Monique Adams-Quackenbush was born on January 15, 1975 in Halifax, Nova Scotia, Canada. Nicole worked for 13 years as a manager within a variety of organisations and sectors (retail, financial, consulting, and training) before making the decision to leave the corporate world and pursue her dreams of a higher education. In 2008, She was accepted into the Transition Year Program at the College of Continuing Education at Dalhousie University. There, through hard work and top marks, she earned entrance to Dalhousie University on a tuition waiver. Nicole enrolled into the Bachelor of Science program where she graduated with honours in Psychology in 2013. During her undergraduate degree, Nicole conducted research on illness behaviours in children with autism and people's ability to comprehend their legal rights upon arrest. During this time, she also was hired by Prof.dr Mary Ann Campbell, director of the Centre for Criminal Justice Studies, University of New Brunswick, to assist in a project that evaluated the efficacy of the Nova Scotia Mental Health Court (2012 - 2014). Upon completing her BSc, Nicole was offered a Graduate Fellowship at Saint Mary's University (SMU) where she studied cognitive load and deception detection under the supervision of $\mathrm{Dr}$ Marc Patry and Dr Steven Smith. In her final year at SMU, Nicole came $1^{\text {st }}$ place at the local 3-Minute Thesis competition, and also won the People's Choice Award. Nicole then went on to represent SMU at the Regional competition in Quebec, Canada where she placed $2^{\text {nd }}$. This secured her a spot in the National competition; although, she did not win. Upon successful completion of the Master of Science 
program (2015), Nicole was offered a position with the House of Legal Psychology in Europe to pursue doctoral studies at Maastricht University (The Netherlands) and the University of Portsmouth (UK).

Aside from her academic achievements, Nicole has also been: a small business consultant (2007), a youth Restorative Justice facilitator (2007 - 2009), a research assistant at the Office of Human Rights, Equity, and Harassment prevention for the President's Office at Dalhousie University (2008 2010), the Ombudsperson at Dalhousie University (2010 - 2012), and student representative in The House of Legal Psychology (2016 - 2017).

Currently, Nicole is working as a Lecturer at the University of Wolverhampton, UK in the department of psychology where she teaches on topics of general, legal, and forensic psychology. Nicole also continues to conduct research in these areas. 
Research has demonstrated that interviewer beliefs about a suspect's guilt can initiate a cycle of confirmation bias. This occurs when the behaviour and responses of the suspect are interpreted by the interviewer as endorsing their beliefs about suspect guilt. Research has also shown that accusatory questions during an investigative interview are indicative of these biased beliefs. Despite these findings, researchers and practitioners rarely evaluate investigative interviews for evidence of guilt-presumptive language. Moreover, when interviews are evaluated, it is mainly on question type, which does not highlight guilt-presumptive language - particularly insinuation and implicit suggestion.

Whilst traditional interview analysis techniques can be valuable for evaluating interviewer performance, they do not tell the whole story. Understanding the detrimental effects of guilt-presumptive language on the investigative interview is valuable for interviewer improvement and development. It is also an effective tool for expert witnesses to make fully informed decisions on the ethical and professional conduct of the interviewer and the validity of confession evidence. 